\title{
Modeling and Simulations for the High Flux Isotope Reactor Cycle 400
}

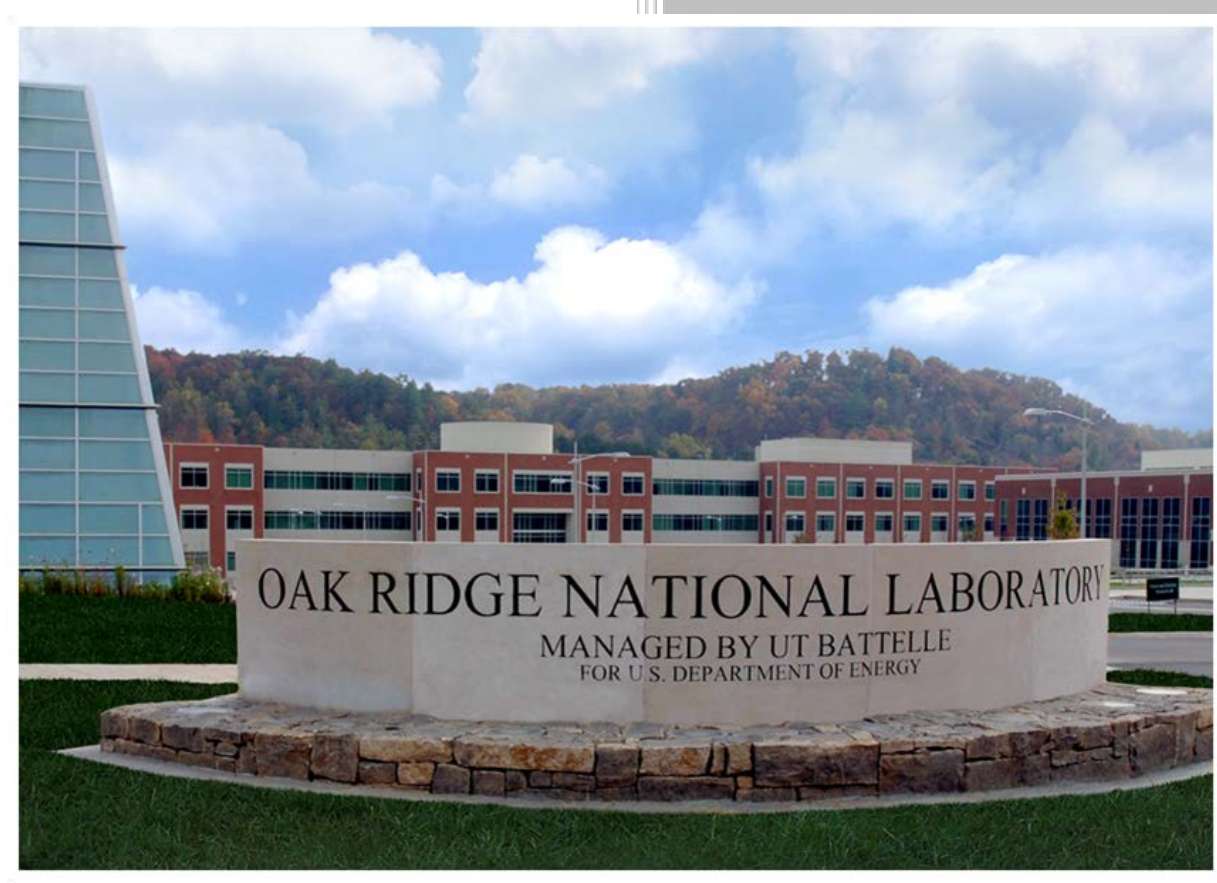

Germina Ilas David Chandler

Brian Ade

Eva Sunny Ben Betzler Dan Pinkston

March 2015

Approved for public release; distribution is unlimited. 


\section{DOCUMENT AVAILABILITY}

Reports produced after January 1, 1996, are generally available free via US Department of Energy (DOE) SciTech Connect.

Website http://www.osti.gov/scitech/

Reports produced before January 1, 1996, may be purchased by members of the public from the following source:

National Technical Information Service

5285 Port Royal Road

Springfield, VA 22161

Telephone 703-605-6000 (1-800-553-6847)

TDD 703-487-4639

Fax 703-605-6900

E-mail info@ntis.gov

Website http://www.ntis.gov/help/ordermethods.aspx

Reports are available to DOE employees, DOE contractors, Energy Technology Data Exchange representatives, and International Nuclear Information System representatives from the following source:

Office of Scientific and Technical Information

PO Box 62

Oak Ridge, TN 37831

Telephone 865-576-8401

Fax 865-576-5728

E-mail reports@osti.gov

Website http://www.osti.gov/contact.html

This report was prepared as an account of work sponsored by an agency of the United States Government. Neither the United States Government nor any agency thereof, nor any of their employees, makes any warranty, express or implied, or assumes any legal liability or responsibility for the accuracy, completeness, or usefulness of any information, apparatus, product, or process disclosed, or represents that its use would not infringe privately owned rights. Reference herein to any specific commercial product, process, or service by trade name, trademark, manufacturer, or otherwise, does not necessarily constitute or imply its endorsement, recommendation, or favoring by the United States Government or any agency thereof. The views and opinions of authors expressed herein do not necessarily state or reflect those of the United States Government or any agency thereof. 
Reactor and Nuclear System Division

Research Reactors Division

\title{
MODELING AND SIMULATIONS FOR THE HIGH FLUX ISOTOPE REACTOR CYCLE 400
}

\author{
Germina Ilas \\ David Chandler \\ Brian Ade \\ Eva Sunny \\ Ben Betzler \\ Dan Pinkston
}

Date Published: March 23, 2015

Prepared by

OAK RIDGE NATIONAL LABORATORY

Oak Ridge, TN 37831-6283

managed by

UT-BATTELLE, LLC

for the

US DEPARTMENT OF ENERGY

under contract DE-AC05-00OR22725 



\section{CONTENTS}

\section{Page}

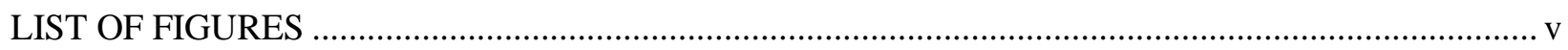

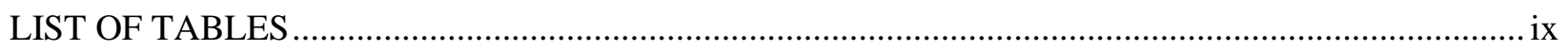

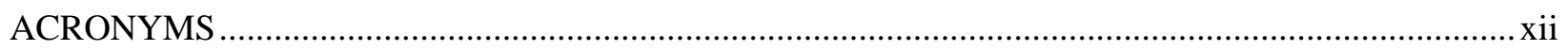

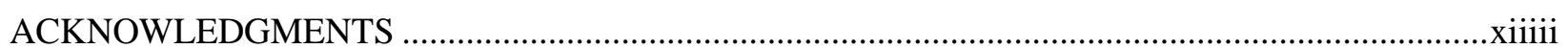

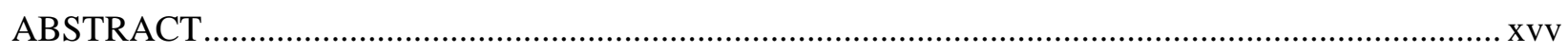

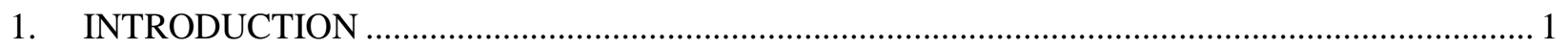

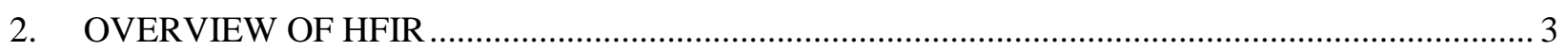

3. A BRIEF HISTORY OF HFIR CORE ANALYSIS MODELS …..................................................... 7

4. COMPUTATIONAL METHODS AND DATA ......................................................................... 9

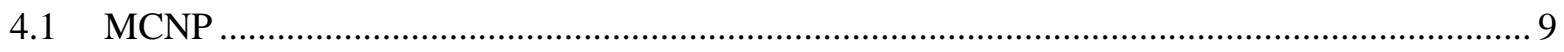

4.2 VESTA

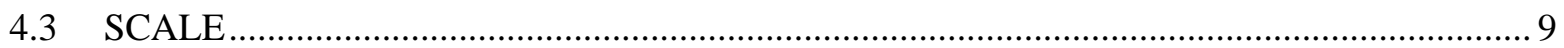

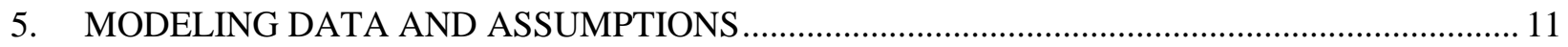

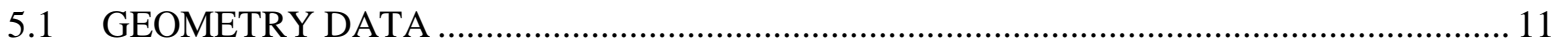

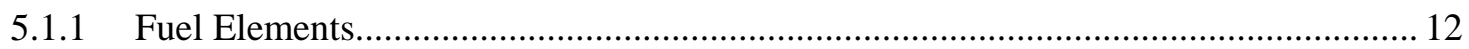

5.1.2 Control Elements .............................................................................................. 14

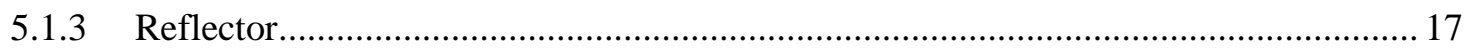

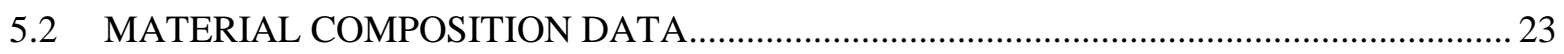

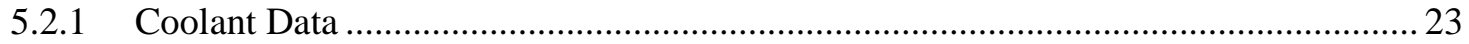

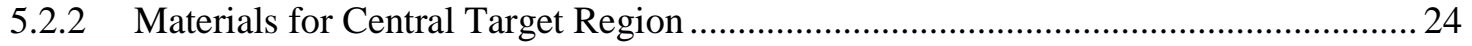

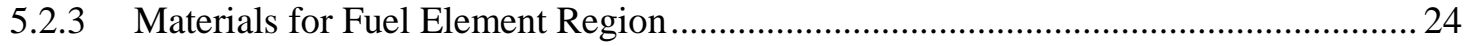

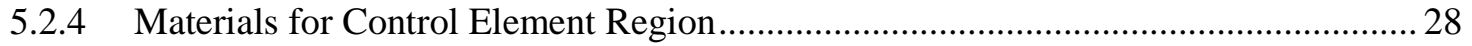

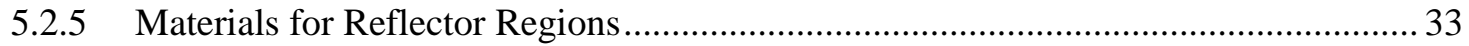

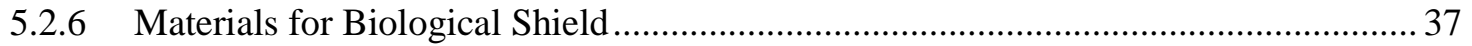

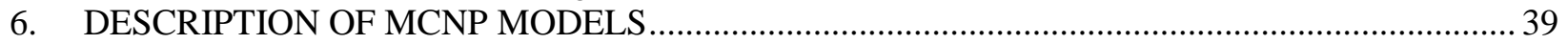

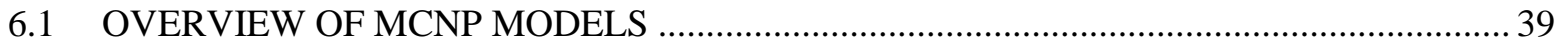

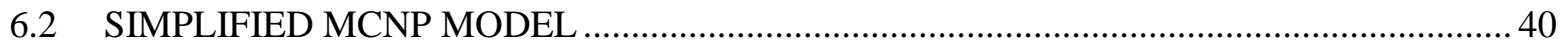

6.2.1 Geometry Data for Homogenized Fuel Plates ......................................................... 41

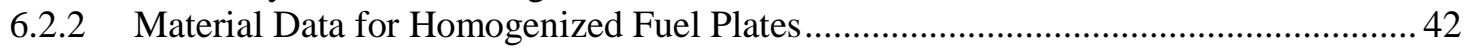

6.2.3 Material Data for Unfueled Regions of Fuel Plates ................................................ 47

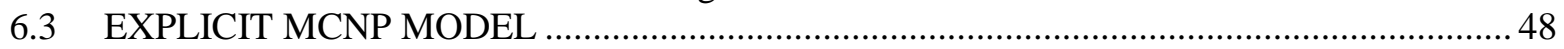

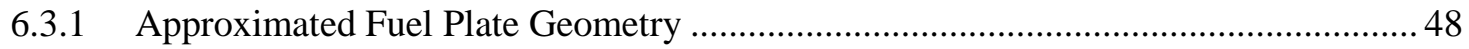

6.3.2 Material Data for Approximated Fuel Plates ............................................................... 50

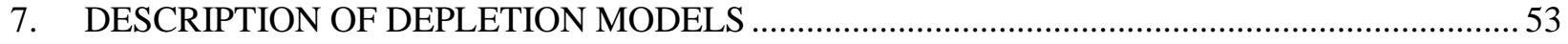

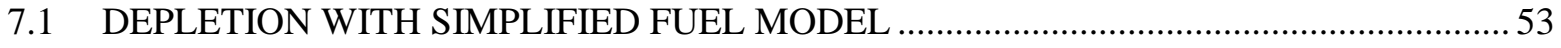

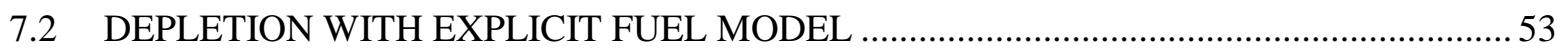

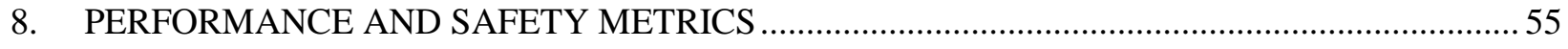

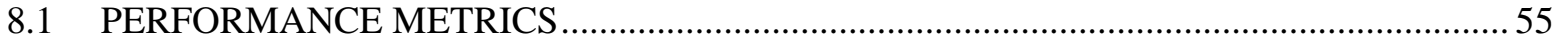




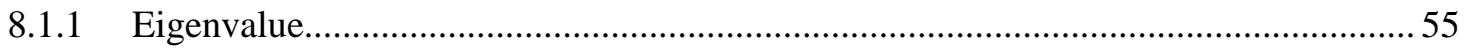

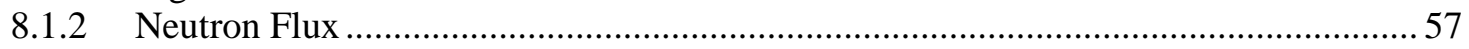

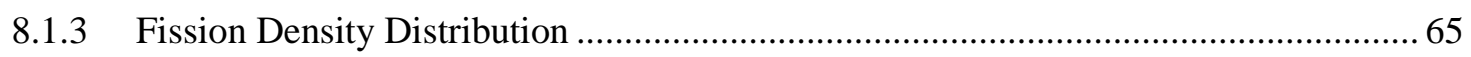

8.1.4 Differential Control Element Worth ................................................................. 72

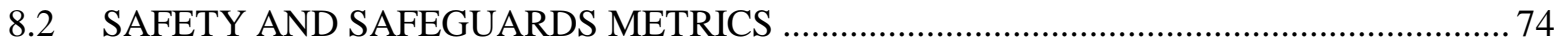

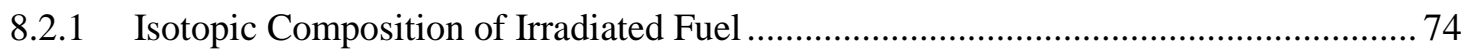

8.2.2 Decay Heat in Irradiated Fuel ................................................................................. 77

8.2.3 Effective Delayed Neutron Fraction and Neutron Lifetime.......................................... 79

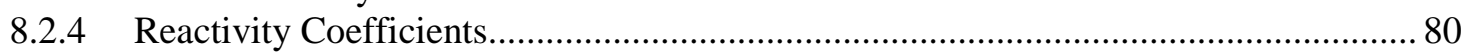

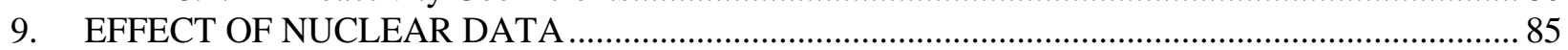

9.1 CROSS-SECTION DATA USED WITH VESTA .............................................................. 85

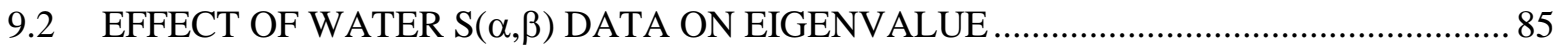

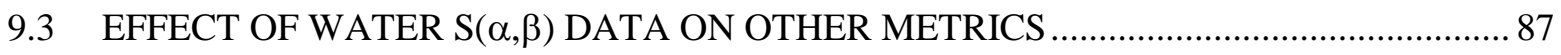

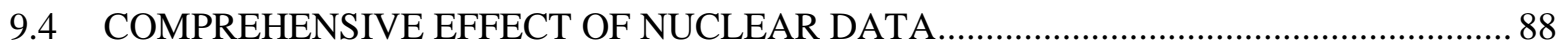

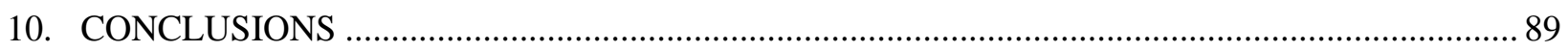

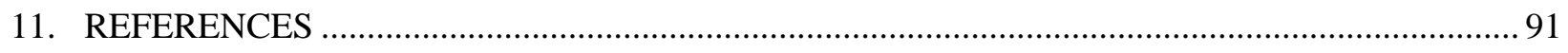

APPENDIX A. MODELING OF CONTROL ELEMENT COMPOSITION ....................................... A-1

APPENDIX B. FLUX DISTRIBUTIONS WITHIN THE HIGH FLUX ISOTOPE REACTOR AT

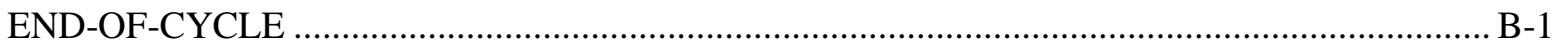

APPENDIX C. FISSION DENSITY DISTRIBUTION DATA AT DAY 13 …...................................... C-1 


\section{LIST OF FIGURES}

Figure

Fig. 1. Illustration of HFIR (cross section at midplane). ............................................................ 3

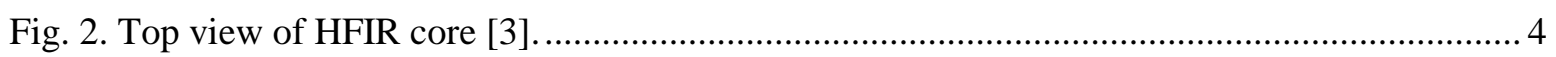

Fig. 3. HFIR inner and outer fuel elements. ......................................................................... 4

Fig. 4. Illustration of fuel plate profiles in HFIR fuel elements................................................... 12

Fig. 5. Flat plate profiles of fuel regions for HFIR fuel elements................................................. 13

Fig. 6. Modeling of the explicit (left), current simplified (middle), and previous [3] simplified (right) fuel elements on the $\mathrm{x}-\mathrm{y}$ plane at the core midplane. .................................................. 13

Fig. 7. Vertical section ( $\mathrm{x}-\mathrm{z}$ plane at $\mathrm{y}=0 \mathrm{~cm}$ ) of the current simplified (left) and previous [3] simplified (right) as-modeled fuel elements............................................................................ 14

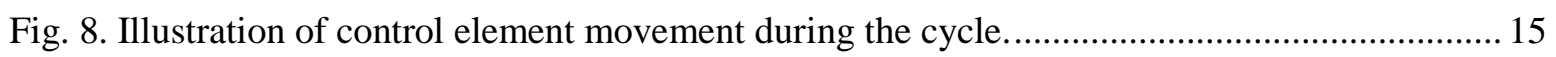

Fig. 9. Illustration of control element movement during Cycle 400.............................................. 16

Fig. 10. Plane ( $\mathrm{x}-\mathrm{y}$ cross section at core midplane) and vertical ( $\mathrm{x}-\mathrm{z}$ cross section) views of the current (left) and previous [3] (right) as-modeled control element regions. ............................ 17

Fig. 11. Cross section of the current (left) and previous [3] (right) representations of the beryllium reflector regions on the core horizontal midplane.

Fig. 12. Illustration of the current (left) and previous [3] (right) as-modeled semipermanent beryllium reflector and a control rod access plug facility.

Fig. 13. Cross section of the current (left) and previous [3] (right) as-modeled PT-1 pneumatic

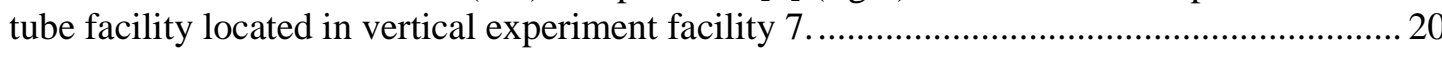

Fig. 14. Cross section of the current (left) and previous [3] (right) representations of the PT-2 pneumatic tube facility located in engineering facility 2 .................................................... 20

Fig. 15. Illustrations of the current (left) and previous [3] (right) representations of the RB-7A

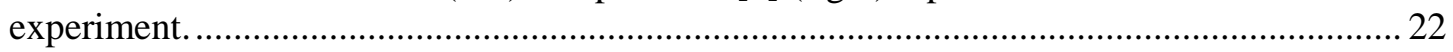

Fig. 16. Extent of the HFIR MCNP model (x-y view at midplane) …........................................... 39

Fig. 17. Illustration of the HFIR MCNP model to the edge of the pressure vessel ( $x-y$ view at

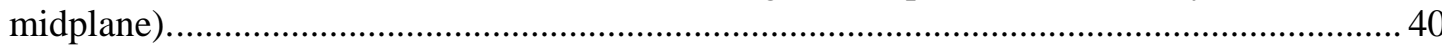

Fig. 18. Modeling of the fuel elements in the simplified MCNP fuel model. ................................. 41

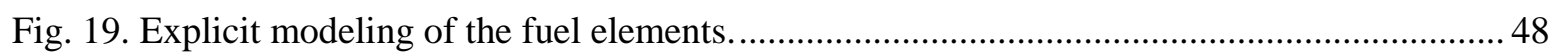

Fig. 20. Approximation of the involute-shaped inner fuel element (top) and outer fuel element

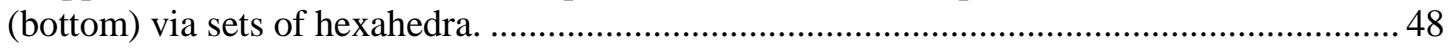

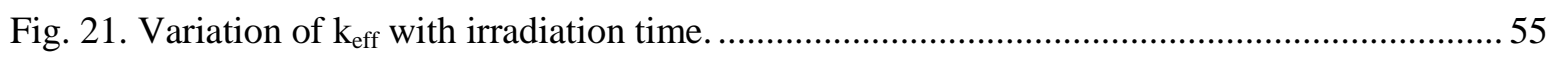

Fig. 22. Effect of depletion step size on $\mathrm{k}_{\mathrm{eff}}$ variation during reactor cycle.................................... 56

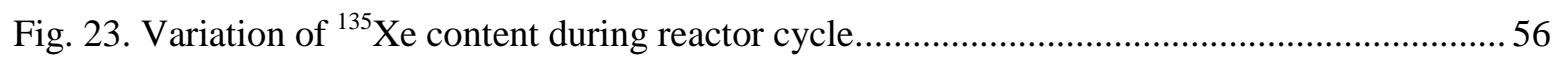

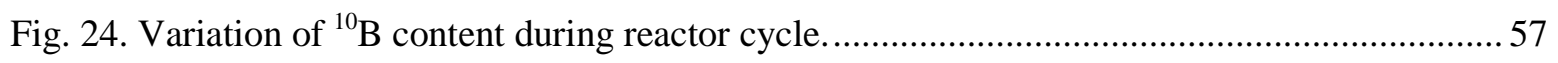

Fig. 25. Radial flux distribution within HFIR at beginning-of-cycle. .......................................... 59 
Fig. 26. R-Z thermal flux distribution within HFIR at beginning-of-cycle................................... 60

Fig. 27. R-Z epithermal flux distribution within HFIR at beginning-of-cycle. ............................... 61

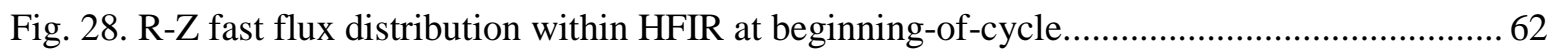

Fig. 29. X-Y thermal flux distribution at the horizontal midplane within HFIR at beginningof-cycle.

Fig. 30. X-Y epithermal flux distribution at the horizontal midplane within the HFIR at beginning-of-cycle.

Fig. 31. X-Y fast flux distribution at the horizontal midplane within HFIR at beginning-ofcycle. 65

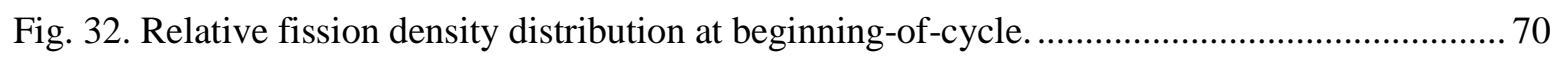

Fig. 33. Relative fission density distribution at end of cycle..................................................... 71

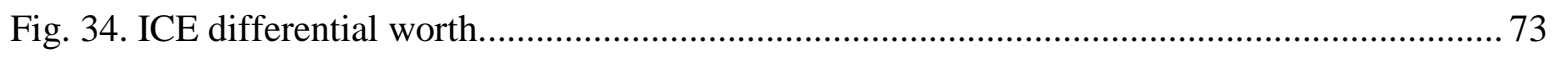

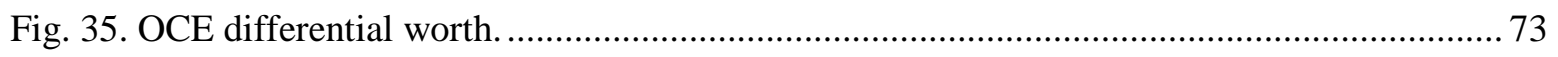

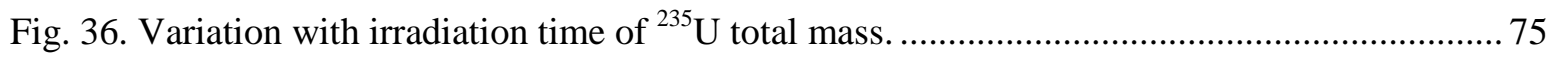

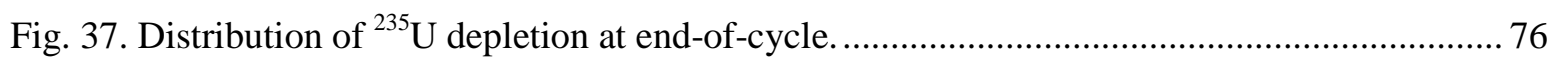

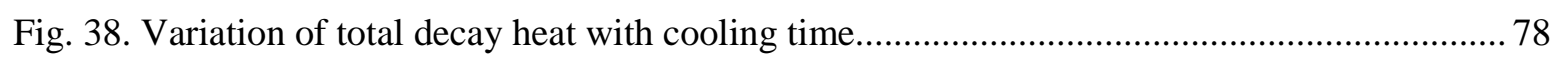

Fig. 39. Variation of $\mathrm{k}_{\text {eff }}$ with reduction of water density in flux trap region at beginning-ofcycle (BOC).

Fig. 40. Variation of $\mathrm{k}_{\mathrm{eff}}$ with reduction of water density in flux trap region at beginning-of-

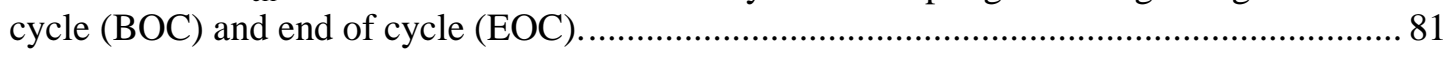

Fig. 41. Effect on $\mathrm{k}_{\text {eff }}$ of $\mathrm{S}(\alpha, \beta)$ data for water (simplified HFIR model)...................................... 86

Fig. 42. Effect on $\mathrm{k}_{\mathrm{eff}}$ of $\mathrm{S}(\alpha, \beta)$ data for water (explicit HFIR model).......................................... 86

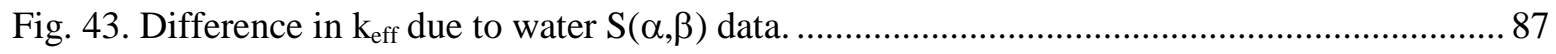

Fig. A.1. Variation of Ta-182 content during inner control element 12 irradiation history............ A-4

Fig. A.3. Comparison measurement-calculation for isotopic content of Eu-151 and Eu-153.......... A-5

Fig. A.4. Comparison measurement-calculation for isotopic content of Eu-152........................... A-5

Fig. A.5. Comparison measurement-calculation for isotopic content of Eu-153........................... A-6

Fig. A.6. Comparison measurement-calculation for isotopic content of Eu-154.......................... A-6

Fig. A.7. Comparison measurement-calculation for isotopic content of Eu-155............................ A-7

Fig. B.1. Radial flux distribution within HFIR at end-of-cycle............................................... B-3

Fig. B.3. R-Z thermal flux distribution within HFIR at end-of-cycle.......................................... B-4

Fig. B.4. R-Z epithermal flux distribution within HFIR at end-of-cycle...................................... B-5

Fig. B.5. R-Z fast flux distribution within HFIR at end-of-cycle. .............................................. B-6

Fig. B.6. X-Y thermal flux distribution at horizontal midplane within HFIR at end-of-cycle........ B-7

Fig. B.7. X-Y epithermal flux distribution at horizontal midplane within HFIR at end-ofcycle. B-8 
Fig. B.8. X-Y fast flux distribution at horizontal midplane within HFIR at end-of-cycle.............. B-9

Fig. C.1. Relative fission density distribution at day 13.......................................................... -5 


\section{LIST OF TABLES}

Table

Page

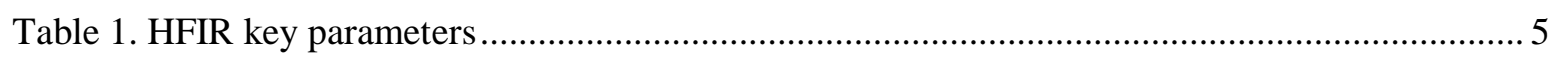

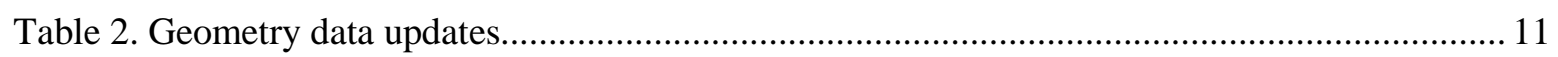

Table 3. Control element position for HFIR Cycle 400.............................................................. 15

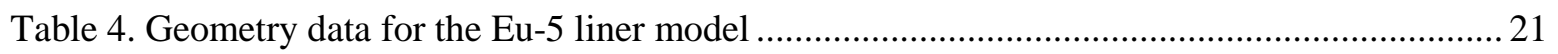

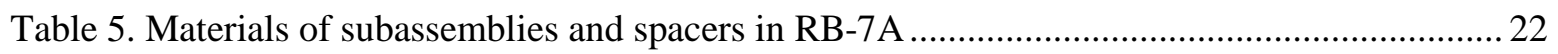

Table 6. Data for inlet, outlet, and in-core water coolant ............................................................. 23

Table 7. Atom density data for inlet, outlet, and in-core water ...................................................... 24

Table 8. Total atom densities updated for cells in central target region .......................................... 24

Table 9. Uranium isotopic ratios for high-enriched uranium fuel .................................................. 25

Table 10. Uranium isotopic composition for high-enriched uranium fuel...................................... 25

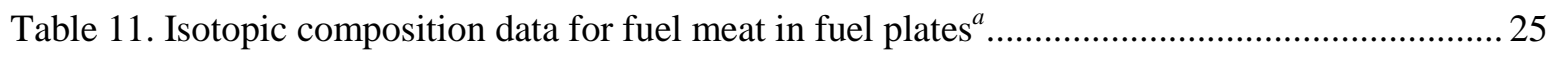

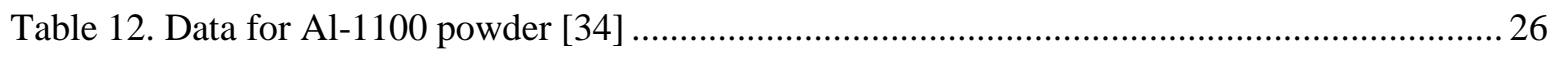

Table 13. Composition for Al-1100 based on test reports ............................................................... 26

Table 14. Atom density data for aluminum-based filler in fuel elements....................................... 27

Table 15. Atom density data for Al-6061 in cladding and side walls of fuel elements .................... 28

Table 16. Material composition data at the beginning of Cycle 400 for inner control element

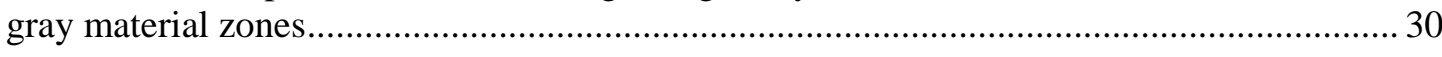

Table 17. Material composition data at the beginning of Cycle 400 for outer control element

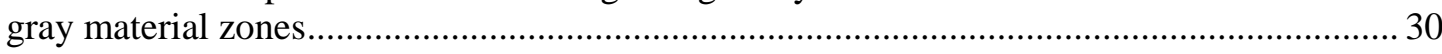

Table 18. Material composition data at the beginning of Cycle 400 for inner control element

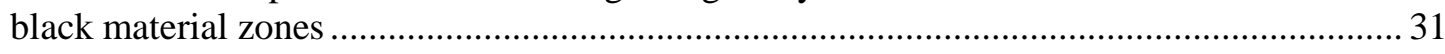

Table 19. Material composition data at the beginning of Cycle 400 for outer control element

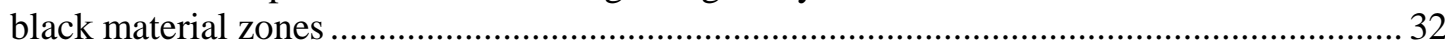

Table 20. Atom density data for white regions of control elements ................................................ 33

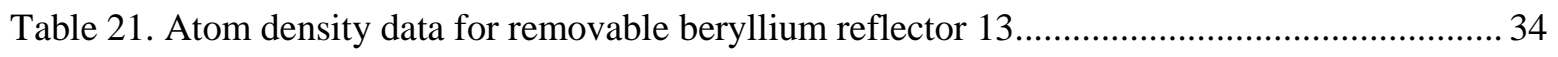

Table 22. Material composition data for permanent beryllium reflector model .............................. 35

Table 23. Atom density data (in at/b-cm) for semipermanent and permanent beryllium

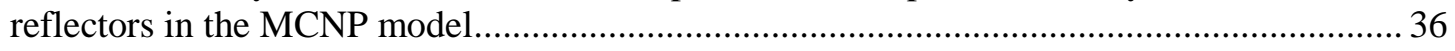

Table 24. Atom densities for material m62 (concrete biological shield) ......................................... 37

Table 25. Radii of the inner fuel element fuel regions in the simplified model .............................. 41

Table 26. Radii of the outer fuel element fuel regions in the simplified model .............................. 42

Table 27. Axial mesh for fuel regions in the HFIR model .......................................................... 42

Table 28. Isotopic composition for homogenized inner fuel element plate radial regions ................ 44 
Table 29. Isotopic composition for homogenized outer fuel element plate radial regions ................ 45

Table 30. Isotopic composition data for fuel element unfueled regions ......................................... 47

Table 31. Radii of the inner fuel element fuel regions in the explicit model................................... 49

Table 32. Radii of the outer fuel element fuel regions in the explicit model.................................. 50

Table 33. Density correction for inner fuel element and outer fuel element materials in the

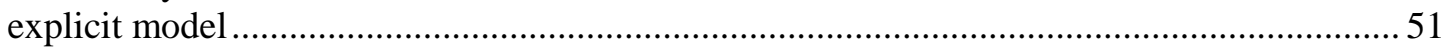

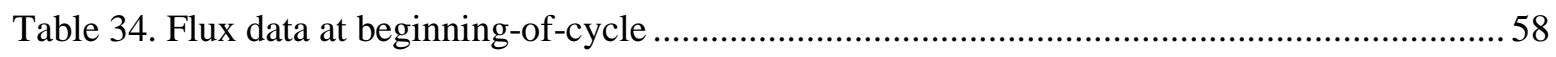

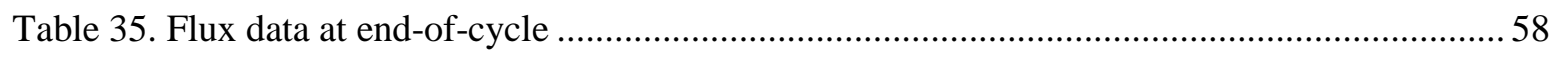

Table 36. Relative fission density at beginning-of-cycle (simplified model).................................. 66

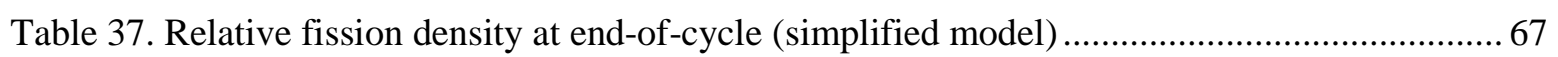

Table 38. Relative fission density at beginning-of-cycle (explicit model) ...................................... 68

Table 39. Relative fission density at end-of-cycle (explicit model) .............................................69 69

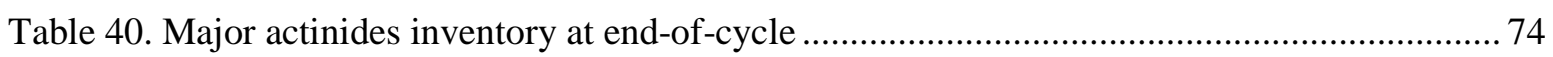

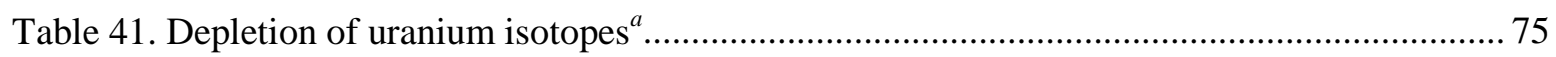

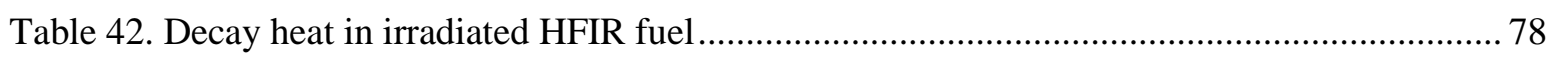

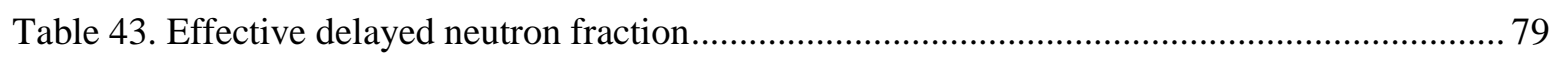

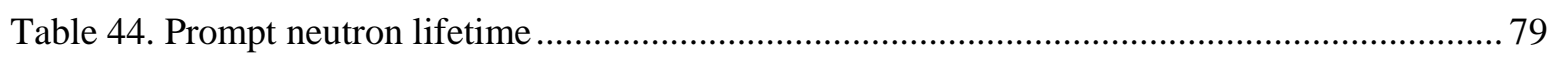

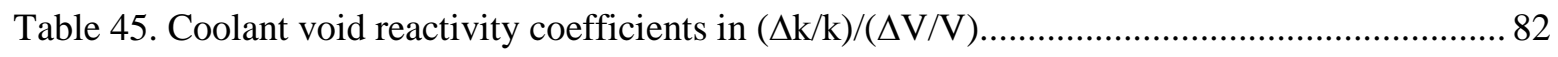

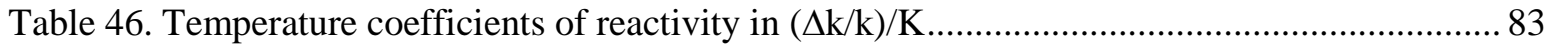

Table 47. Effect of water $S(\alpha, \beta)$ data on major actinides inventory at end-of-cycle (simplified model)

Table A.1. Comparison calculation-measurement for inner control element validation data.......... A-4

Table C.1. Relative fission density at day 13 (simplified model) .................................................... C-3

Table C.2. Relative fission density at day 13 (explicit model) ........................................................ C-4 


\section{ACRONYMS}

2-D two-dimensional

3-D three-dimensional

Al-6061 aluminum alloy type 6061

ANL

Argonne National Laboratory

ANS

American Nuclear Society

ANSI

American National Standards Institute

BOC

$\mathrm{CE}$

beginning-of-cycle

CVR

control element

EF

coolant void reactivity coefficient

EOC

FTT

engineering facility

end-of-cycle

HB

flux trap target

HEU

horizontal beam (tube)

HFIR

high-enriched uranium

HFIRCE

ICE

High Flux Isotope Reactor

IFE

HFIR Critical Experiment (as in HFIRCE-2)

hydraulic tube

inner control element

inner fuel element

LEU low-enriched uranium

$M \& S$

MCNP

modeling and simulation

NIST

OCE

OD

Monte Carlo N-Particle

OFE

National Institute of Standards and Technology

outer control element

outer diameter

outer fuel element

ORNL Oak Ridge National Laboratory

PB

permanent beryllium reflector

PT

pneumatic tube

PTP

peripheral target position

$\mathrm{RB}$

SAR

removable beryllium reflector

SPB

safety analysis report

semipermanent beryllium reflector

TC

temperature coefficient

VXF

vertical experiment facility 



\section{ACKNOWLEDGMENTS}

The authors would like to acknowledge the support for this work provided by the National Nuclear Security Administration, US Department of Energy. Reviews of the manuscript by C. R. Daily and R. J. Ellis at Oak Ridge National Laboratory are appreciated. 



\begin{abstract}
A concerted effort over the past few years has been focused on enhancing the core model for the High Flux Isotope Reactor (HFIR), as part of a comprehensive study for HFIR conversion from high-enriched uranium to low-enriched uranium (LEU) fuel. At this time, the core model used to perform analyses in support of HFIR operation is a Monte Carlo model with the MCNP code for the beginning of Cycle 400, which was documented in detail in a 2005 technical report. An updated HFIR core depletion model that is based on current state-of-the-art methods and nuclear data was needed to serve as reference for the design of an LEU fuel for HFIR.

The recent enhancements in modeling and simulations for HFIR that are discussed in the present report include: (1) revision of the 2005 MCNP model for the beginning of Cycle 400 to improve the modeling data and assumptions as necessary based on appropriate primary reference sources-HFIR drawings and reports; (2) improvement of the fuel region model, including an explicit representation for the involute fuel plate geometry that is specific to HFIR fuel; and (3) revision of the Monte Carlo-based depletion model for HFIR, in use since 2009 but never documented in detail, with the development of a new depletion model for the HFIR explicit fuel plate representation.

The new HFIR models for Cycle 400 are used to determine various metrics of relevance to reactor performance and safety assessments. The calculated metrics are compared, where possible, with measurement data from preconstruction critical experiments at HFIR, data included in the current HFIR safety analysis report, and/or data from previous calculations performed with different methods or codes. The results of the analyses show that the models presented in this report provide a robust and reliable basis for HFIR analyses.
\end{abstract}





\section{INTRODUCTION}

The High Flux Isotope Reactor (HFIR) is a high flux, pressurized, light water cooled and moderated, flux-trap type research reactor operated at the Oak Ridge National Laboratory (ORNL). HFIR is one of the major neutron research facilities at ORNL and supports neutron scattering experiments, materials irradiation research, and isotope production. The reactor [1] is operated with high-enriched uranium (HEU) fuel with a nominal enrichment of $93 \mathrm{wt} \%{ }^{235} \mathrm{U}$. The reactor was designed to operate at $100 \mathrm{MW}$ power. Currently, it is operated at $85 \mathrm{MW}$.

The modeling and simulation (M\&S) of the HFIR core has evolved over the years since design of the reactor started in the early 1960s, taking advantage of developments in computational methods, codes, and nuclear data available at the time, advancing from diffusion-based methods to Monte Carlo neutron transport simulations. Currently the reference model used to perform analyses in support of HFIR operation is a Monte Carlo N-Particle (MCNP) [2] model of HFIR Cycle 400 that was documented in 2005 [3]. This model has been slightly revised [4, 5] to enable Monte Carlo-based depletion simulations for the HFIR core. This revision has served as a basis for extensive HFIR validation studies [6, 7].

During the past few years, a concerted effort has been focused on enhancing the HFIR core model for Cycle 400 as part of a more comprehensive study for designing a HFIR core that would use a lowenriched uranium (LEU) fuel $[8,9,10]$. The first step in the model enhancement effort consisted of revisiting and revising, where appropriate, the modeling data used in the HFIR HEU model [3] to (1) identify the source of the data and associated assumptions used in the MCNP model for Cycle 400 and (2) update these data and assumptions as necessary based on appropriate primary reference sourcesHFIR drawings and reports. The second step in model improvement involved revision of the neutron transport and depletion models for HFIR and documentation of these models. A depletion model for HFIR Cycle 400 has never been documented in detail in a technical report, though different versions of such a model have been used since 2005 for various studies. The third step in the enhancement effort has targeted improvements in fuel region modeling with the goal of implementing an explicit representation for the involute fuel plate geometry that is specific to HFIR fuel.

Different types of models, which differ by the modeling assumptions and approximations used, have resulted from the M\&S improvement effort. These models have been used to perform simulations to determine various metrics of relevance to reactor performance and safety assessments. Presentation of the newly developed models and the results obtained from them, as well as a discussion of their applicability, constitute the main topics of the current report.

A brief overview of the reactor configuration is provided in Section 2, followed by a brief history of the main updates for the HFIR core models in Section 3 and in Section 4 a presentation of the computational methods and data used for the analyses discussed in the present report. Section 5 discusses the modeling data and assumptions, with a focus on those data that have been updated compared to the previous modeling efforts [3]. The steady-state core models and depletion models are described in Sections 6 and 7, respectively. The results of the analyses performed with these models are discussed in Section 8. A sensitivity assessment of the effects of nuclear data is presented in Section 9, followed by concluding remarks in Section 10. Appendixes A to C include more detailed results to complement those presented in Section 8. 



\section{OVERVIEW OF HFIR}

The reactor core consists of a series of concentric annular regions: a central flux trap containing vertical experimental targets; two fuel elements separated by a thin water region; a region containing two control elements (CEs); a beryllium reflector; and a water region to the edge of the pressure vessel, which is located in a pool of water [1]. The configuration is illustrated in Fig. 1, which shows a cross section of the core within the reactor vessel, and in Fig. 2, which shows the top view of the core. Details of the reactor configuration and operation are available in [1].

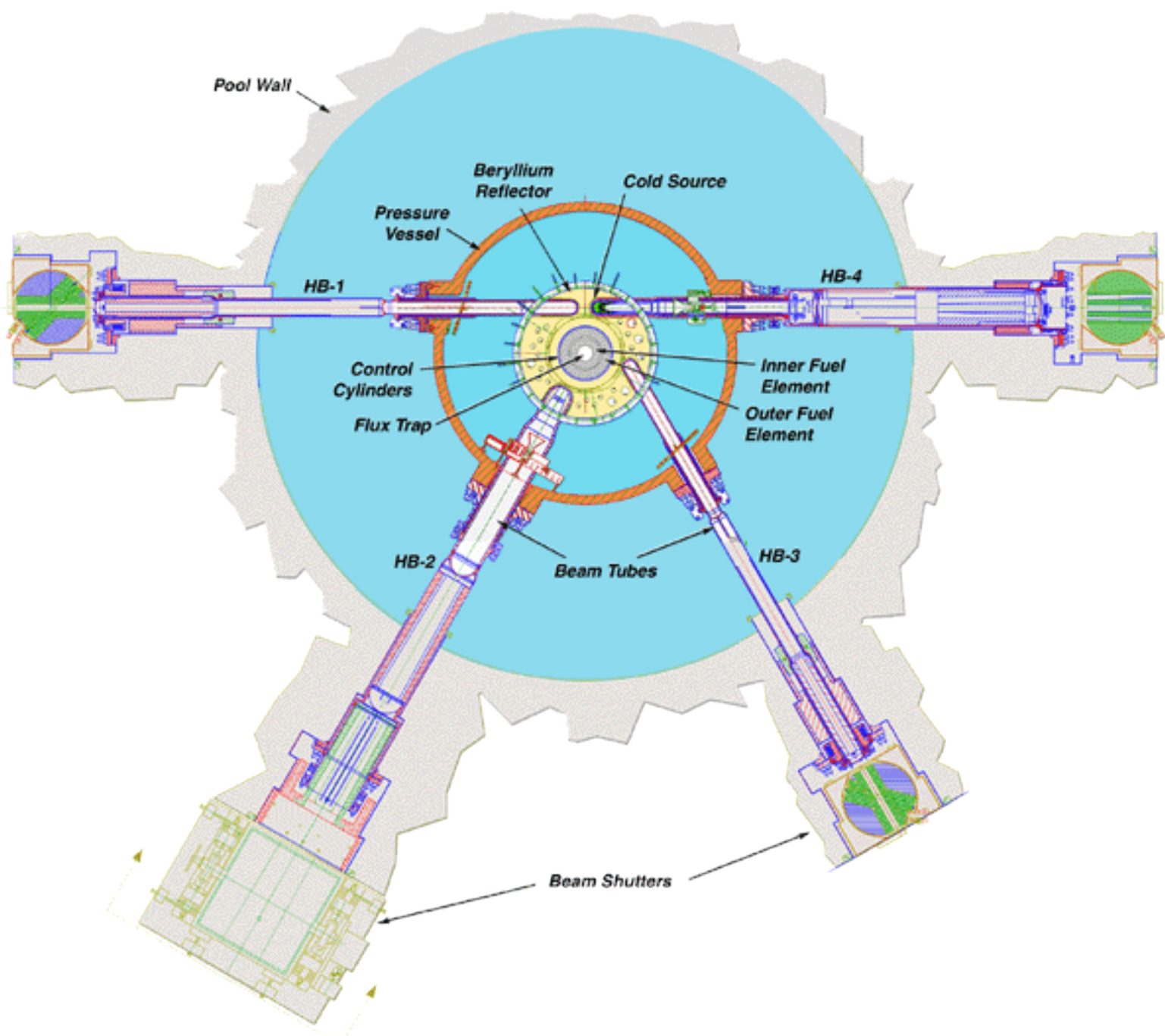

Fig. 1. Illustration of HFIR (cross section at midplane). 


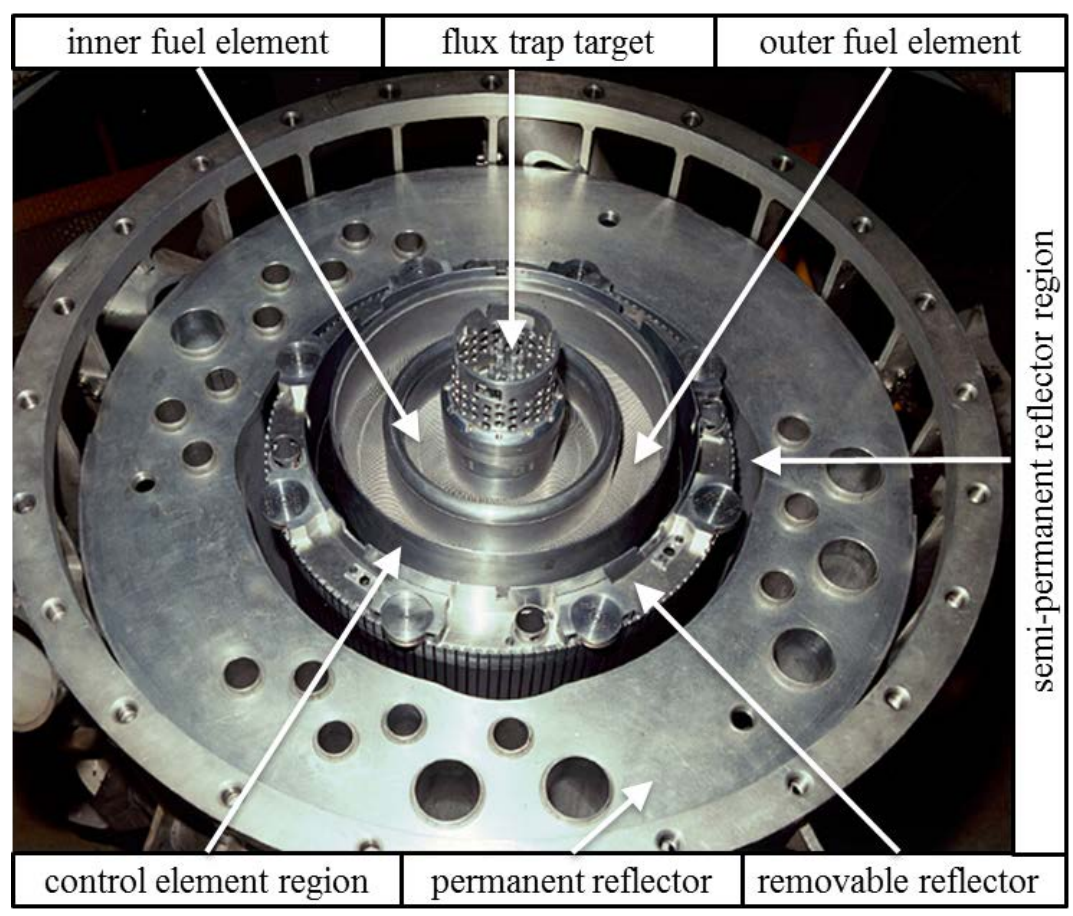

Fig. 2. Top view of HFIR core [3].

The two fuel elements in HFIR are identified as the inner fuel element (IFE) and the outer fuel element (OFE). They are composed of numerous $1.27 \mathrm{~mm}$ thick involute-shaped fuel plates, as illustrated in Fig. 3. The plates are separated by $1.27 \mathrm{~mm}$ thick water-filled cooling channels and are held together by two cylindrical aluminum side walls that are also referred to as side plates. The fuel plates have a sandwich-type design, with a fuel region (also known as fuel meat) and a filler region enclosed in an aluminum-based clad. The fuel region contains a mixture of aluminum powder and uranium oxide $\left(\mathrm{U}_{3} \mathrm{O}_{8}\right)$ with $93 \mathrm{wt} \%{ }^{235} \mathrm{U}$ nominal enrichment and is characterized by a variable thickness along the width of the fuel plate (radial contouring) and a uniform thickness along the length of the fuel plate for a given radius. The aluminum-based filler region is added as the complement of the contoured fuel region to make up, in a flat plate (i.e., before bending it into an involute shape) reference system, a rectangular parallelepiped that can be encased in cladding. The IFE filler region contains a burnable poison in the form of $\mathrm{B}_{4} \mathrm{C}$, which is dispersed in the aluminium-based filler material. The poison content varies across the width of the plate, helping to flatten the radial power profile. The key parameters for the core are presented in Table 1.

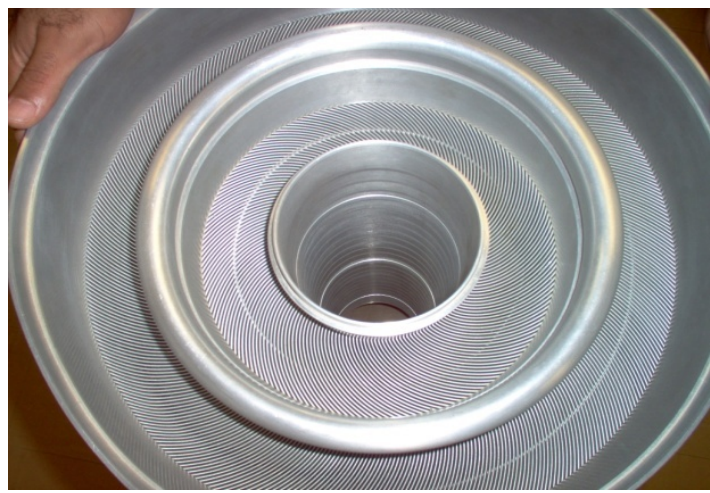

Fig. 3. HFIR inner and outer fuel elements [9]. 
Table 1. HFIR key parameters

\begin{tabular}{|c|c|c|}
\hline \multicolumn{3}{|l|}{ Reactor } \\
\hline Operating power (MW) & \multicolumn{2}{|c|}{85} \\
\hline Cycle length (days) & \multicolumn{2}{|c|}{$24-26$} \\
\hline Number of fuel elements & \multicolumn{2}{|c|}{2} \\
\hline \multicolumn{3}{|l|}{ Fuel } \\
\hline Type & \multicolumn{2}{|c|}{$\mathrm{U}_{3} \mathrm{O}_{8}-\mathrm{Al}$} \\
\hline Enrichment, nominal (wt $\%{ }^{235} \mathrm{U}$ ) & \multicolumn{2}{|c|}{93} \\
\hline Total load ${ }^{235} \mathrm{U}(\mathrm{kg})$ & \multicolumn{2}{|c|}{9.4} \\
\hline Total load uranium (kg) & \multicolumn{2}{|c|}{10.1} \\
\hline Fuel Elements & Inner Fuel Element & Outer Fuel Element \\
\hline Load of ${ }^{235} \mathrm{U}(\mathrm{kg})$ & 2.6 & 6.8 \\
\hline Number of fuel plates & 171 & 369 \\
\hline Fuel plate width (cm) & 8.1 & 7.3 \\
\hline Fuel plate thickness (cm) & 0.127 & 0.127 \\
\hline Coolant channel between plates (cm) & 0.127 & 0.127 \\
\hline Fuel plate clad thickness $(\mathrm{cm})$ & 0.0254 & 0.0254 \\
\hline
\end{tabular}

The flux trap target (FTT) assembly holder sits inside the IFE and forms the center of the reactor core. This region is referred to as the "flux trap target region." Thirty-one interior and six peripheral target positions (PTPs) are provided in the flux trap for materials irradiation and isotope production experiments. Aluminum target rods containing irradiation capsules occupy the flux trap positions. The PTPs, which are located at the outer radial edge of the flux trap, are best suited for materials irradiation experiments, which in general require high fast neutron fluxes. The FTT peak thermal neutron flux of $\sim 2.3 \times 10^{15}$ neutrons $/ \mathrm{cm}^{2}$-s, which occurs at the center of this region, is advantageous to isotope production experiments (i.e., ${ }^{252} \mathrm{Cf},{ }^{63} \mathrm{Ni},{ }^{75} \mathrm{Se},{ }^{188} \mathrm{Re}$ ). A hydraulic tube (HT) facility located just off the reactor core centerline, in a very high thermal flux region, allows for the insertion and removal of irradiation capsules during reactor operation.

The CE region is an annular region between the OFE and the beryllium reflector and contains two thin, poison-bearing, CEs. The CEs are driven in opposite directions of each other during the reactor cycle to compensate for the reactivity loss due to fission product generation and fuel consumption during irradiation. Each CE is composed of three longitudinal sections, each with different neutron absorption properties: $\mathrm{Al}$ (transparent to neutrons), Ta-Al (moderate neutron absorber), and $\mathrm{Eu}_{2} \mathrm{O}_{3}-\mathrm{Al}$ (strong neutron absorber). The Ta- $\mathrm{Al}$ and $\mathrm{Eu}_{2} \mathrm{O}_{3}-\mathrm{Al}$ regions are often referred to as the gray and black regions, respectively, based on their neutron absorption characteristics. The inner CE (ICE), which is withdrawn in the downward direction during the cycle, is a cylinder composed of four control plates welded together. The ICE is used for shimming and regulation purposes. The outer CE (OCE), which is withdrawn in the upward direction during the cycle, consists of four separate control plates, each having an independent drive and safety release mechanism. The OCE is used for safety and shim purposes. During reactor operation, the ICE and OCE are vertically withdrawn symmetrically with respect to the core midplane to drive the poison sections out of the core and to maintain a symmetric power density distribution in the axial direction.

A large concentric ring of beryllium reflector $\sim 1 \mathrm{ft}$ thick surrounds the CE region. The beryllium reflector is subdivided into three radial regions that are named based on the frequency they are replaced due to neutron exposure: the removable beryllium reflector $(\mathrm{RB})$, the semipermanent beryllium reflector (SPB), and the permanent beryllium reflector (PB). Eight large and four small RB experiment facilities are located in the RB. Four control rod access plug facilities, each containing two small irradiation facilities, are contained in the SPB. The PB is penetrated by 22 vertical experiment facilities (VXFs), four 
horizontal beam (HB) tubes transporting neutrons to cold and thermal neutron scattering instruments, and two slant engineering facilities (EFs). Two pneumatic tube (PT) facilities, designated PT-1 and PT-2, are located in VXF-7 and EF-2, respectively, and are used for neutron activation analysis activities.

The beryllium reflector is surrounded radially by a light water reflector of effectively infinite

thickness. The reactor core is also reflected in the axial directions by light water. A stainless steel pressure vessel with an approximately $8 \mathrm{ft}$ inner diameter contains the reactor core and water reflector. 


\section{A BRIEF HISTORY OF HFIR CORE ANALYSIS MODELS}

Although a detailed documentation of how the models used for HFIR core analyses have evolved over the years would make for a very interesting read, given that the modeling effort has spanned more than half a century and covered remarkable advances in computational methods and nuclear data during that time, that is not the purpose of the summary presented in this section. Rather, a timeline of the evolution in HFIR modeling is sketched to point out the types of methods that were used while focusing on developments in the past decades.

HFIR reached its first critical state on August 25, 1965, and has operated at full power since 1966. The core studies that were conducted during the early phases of HFIR design in the early 1960s through the 1970s were mostly based on multigroup, one-dimensional neutron diffusion codes, some of them featuring additional depletion capabilities [1], and tailored neutron cross-section data. These depletion capabilities might seem rudimentary compared to the capabilities available today, as they included only a small number of transmutation chains [1] for: two actinides $\left({ }^{235} \mathrm{U}\right.$ and $\left.{ }^{238} \mathrm{U}\right)$, four fission products, and one burnable poison $\left({ }^{10} \mathrm{~B}\right)$. The limitations existing at the time in computational capabilities and resources to support HFIR M\&S were heavily complemented by an extensive HFIR experimental program [1].

In the 1980s and 1990s, two-dimensional (2-D) models of the core (in R-Z geometry) were developed using the diffusion theory-based code system with depletion capabilities BOLD-VENTURE [11]. Various approaches were devised at the time to develop adequate cross-section data libraries for use with the BOLD-VENTURE model of HFIR [12, 13]. Another HFIR model, developed and used in the 1990s, was based on a 2-D representation of the core and used the DORT discrete ordinates neutron transport code [14].

In the mid-1990s, a steady effort was focused on developing three-dimensional (3-D) models of HFIR for Monte Carlo neutron transport simulations with the MCNP [2] code to support the design of the HFIR cold source. As stated in [15], the development of an MCNP model for HFIR was initiated in 1995 by L. A. Smith and J. C. Gehin; more geometry details were added later during that year by J. C. Gehin and J. A. Bucholz to support the HFIR cold source design. The first illustration of an MCNP HFIR model was shown in the report documenting the preconceptual design of the HFIR cold source [16]. Important additions were made later to the model by D. E. Peplow to include details for the beam tubes and cold source [17].

The MCNP model was significantly revised and thoroughly documented in 2005 by N. Xoubi and R. T. Primm [3]. This revised model was developed to provide a detailed and accurate 3-D representation of the HFIR configuration at the beginning-of-cycle (BOC) for HFIR Cycle 400, which operated between April 27 and May 21, 2004. The 2005 MCNP model was slightly revised in 2009 to refine the spatial mesh and the modeling of the HFIR CEs for use in depletion simulations of the core. A SCALE [18] model for HFIR Cycle 400, which is equivalent to the MCNP model for this same reactor cycle, was developed in 2011 by D. Ilas [19].

Before 2008, depletion analyses for the HFIR core were performed using BOLD-VENTURE models [13]. Later on, depletion models [20, 21, 9] were developed using the Monte Carlo-based depletion codes MONTEBURNS [22], ALEPH [23, 24], and VESTA [25], which directly use the MCNP model for Cycle 400. 



\section{COMPUTATIONAL METHODS AND DATA}

The models and analyses discussed in this report rely on three modeling and simulation tools: the Monte Carlo transport code MCNP5 [2], the Monte Carlo-based depletion tool VESTA [25], and the SCALE nuclear analysis code system [18]. Brief descriptions of the codes used and the associated nuclear data are provided in this section.

\subsection{MCNP}

MCNP is a general-purpose Monte Carlo code developed at Los Alamos National Laboratory that can be used to simulate neutron, photon, electron, or coupled neutron/photon/electron transport, including the capability to calculate eigenvalues for critical systems in 3-D arbitrary geometry configurations. Its capabilities to model complex geometries and to use pointwise cross-section data for the neutron transport treatment make the code a desirable tool for analysis of highly heterogeneous nuclear reactor systems such as HFIR. For analyses discussed here, versions 1.5.1 and 1.6.0 of MCNP5 have been used, with cross-section data based on ENDF/B-VII.0 [26] evaluations. Version 1.5.1 was used with VESTA, and version 1.60 was used for all other analyses.

\subsection{VESTA}

VESTA is a Monte Carlo-based depletion tool developed at Institut de Radioprotection et de Sûreté Nucléaire-Institute for Radiological Protection and Nuclear Safety-in France. Version 2.0.2 of VESTA was used for simulations discussed in the current report. VESTA simulates fuel depletion by iteratively coupling a neutron transport solver with a point depletion and decay solver. The version of the code used here, version 2.0.2, couples MCNP5 with the point depletion code ORIGEN 2.2 [27].

At each depletion step, the transport flux solution from MCNP is used to generate the cross-section data for the ORIGEN 2.2 depletion calculation; the isotopic composition data resulting from ORIGEN 2.2 calculations are used in the subsequent MCNP transport calculation to obtain cross sections for the next depletion step, and so forth in an iterative manner until the desired irradiation history is complete. The fission source file containing the converged spatial distribution of fission points from the previous transport step is used as the initial source distribution for the subsequent transport calculation within the VESTA simulation. The one-group cross sections required by ORIGEN 2.2 are obtained by weighting pre-generated pointwise cross-section data with MCNP-calculated very fine group flux data, typically in a 43,000-group structure. These pointwise cross-section data are consistent with the cross-section data set used in the MCNP transport calculation as both sets are precomputed based on the same ENDF/B data files.

Compared to other Monte Carlo-based depletion simulation tools, VESTA has the advantage of providing modeling capabilities essential for HFIR analyses such as the explicit simulation of CE movement during the reactor cycle and the depletion of nonfissile materials, which in the case of HFIR makes it possible to account for the irradiation of the CEs, beryllium reflector, or nonfissile targets during the reactor cycle.

For analyses discussed in this report, the cross-section data used with the MCNP neutron transport solver and the ORIGEN 2.2 depletion solver in VESTA are based on ENDF/B-VII.0 data. All cross sections are considered at $300 \mathrm{~K}$ temperature, with the water thermal scattering data, as available from the MCNP5 release, at 293.6 K. The fission yield data and the nuclear decay data used with ORIGEN 2.2 are based on ENDF/B-VII.1 [28] evaluations.

\subsection{SCALE}

SCALE is a modular nuclear analysis code system developed at ORNL that uses automated sequences to provide cross-section processing, reactor lattice physics, criticality safety, radiation 
shielding, and spent fuel characterization analysis capabilities. Version 6.1.3 of SCALE has been used to perform source term calculations in HFIR analyses for this report. 


\section{MODELING DATA AND ASSUMPTIONS}

\subsection{GEOMETRY DATA}

The geometry data in the previously documented Cycle 400 MCNP model [3] were revisited to compare the values used in the model with corresponding data from HFIR primary references (drawings and reports). For some of the geometry data that were updated, in particular radii for cylindrical regions, Table 2 lists the values that have been updated along with the HFIR drawings that are the basis for the update. Other geometry updates not included in Table 2, and the bases for the approximations used are discussed further in this section.

Table 2. Geometry data updates

\begin{tabular}{|c|c|c|c|c|c|}
\hline & \multirow[b]{2}{*}{ Parameter $^{a}$} & \multirow{2}{*}{$\begin{array}{c}\text { Reference } \\
\text { (HFIR drawing number) }\end{array}$} & \multicolumn{2}{|c|}{ Parameter value $^{b}$} & \multirow{2}{*}{$\begin{array}{c}\text { Radius }^{c} \\
\text { (cm) }\end{array}$} \\
\hline & & & $\begin{array}{l}\text { Nominal } \\
\text { (in.) }\end{array}$ & $\begin{array}{l}\text { (\%) } \\
\text { (in.) }\end{array}$ & \\
\hline 1 & ID of IFE inner side plate & E-42118 rev $R$ & 5.0690 & 0.005 & 6.43763 \\
\hline 2 & OD of IFE inner side plate & E-42112 rev H & 5.4243 & 0.001 & 6.88886 \\
\hline 3 & ID of IFE outer side plate & E-42117 rev H & 10.0895 & 0.0025 & 12.81367 \\
\hline 4 & OD of IFE outer side plate & E-42118 rev R & 10.5800 & 0.005 & 13.43660 \\
\hline 5 & ID of OFE inner side plate & E-42126 rev N & 11.2350 & 0.005 & 14.26845 \\
\hline 6 & OD of OFE inner side plate & E-42120 rev H & 11.7316 & 0.001 & 14.89913 \\
\hline 7 & ID of OFE outer side plate & E-42125 rev J & 16.6428 & 0.001 & 21.13636 \\
\hline 8 & OD of OFE outer side plate & E-42126 rev N & 17.1390 & 0.005 & 21.76653 \\
\hline \multirow[t]{3}{*}{9} & ID of aluminum liner & M-11506-OH-200 rev 6 & $18.867^{\mathrm{d}}$ & & 23.96109 \\
\hline & (at inner RB) & M-11506-OH-208 rev 6 & & & \\
\hline & & M-11506-OH-213 rev 2 & & & \\
\hline \multirow[t]{3}{*}{10} & OD of aluminum liner & M-11506-OH-200 rev 6 & 18.993 & 0.005 & 24.12111 \\
\hline & (at inner RB) & M-11506-OH-208 rev 6 & & & \\
\hline & & M-11506-OH-213 rev 2 & & & \\
\hline 11 & OD of RB inner cylinder & M-11506-OH-208E rev 6 & 19.776 & 0.002 & 25.11552 \\
\hline \multirow[t]{2}{*}{$12^{e}$} & ID of RB middle cylinder & M-11506-OH-214E rev 7 & 19.780 & 0.002 & 25.17601 \\
\hline & (116 grooves along ID) & M-11506-OH-200 rev 6 & & & \\
\hline 13 & OD of RB middle cylinder & M-11506-OH-214E rev 7 & 21.512 & 0.002 & 27.32024 \\
\hline \multirow[t]{2}{*}{$14^{e}$} & ID of RB outer cylinder & M-11506-OH-214E rev 7 & 21.516 & 0.002 & 27.37100 \\
\hline & (104 grooves along ID) & M-11506-OH-200 rev 6 & & & \\
\hline \multirow[t]{2}{*}{$15^{e}$} & OD of RB outer cylinder & M-11506-OH-214E rev 7 & 23.754 & 0.002 & 30.11976 \\
\hline & (120 grooves along OD) & M-11506-OH-200 rev 6 & & & \\
\hline 16 & ID of SPB segments & E-42323 rev L & 23.884 & 0.004 & 30.33268 \\
\hline $17^{f}$ & $\begin{array}{l}\text { OD of SPB segments } \\
\text { ( } 56 \text { grooves along OD) }\end{array}$ & E-42323 rev L & 26.250 & 0.002 & 33.30767 \\
\hline 18 & ID of PTP tube in flux trap ${ }^{g}$ & M-11443-0H-001-E rev 6 & 0.516 & 0.007 & 0.65532 \\
\hline 19 & ID of HT in flux trap & M-11506-OH-517-E rev 4 & 0.560 & 0.005 & 0.71120 \\
\hline 20 & OD of HT in flux trap & M-11506-OH-517-E rev 4 & 0.657 & 0.001 & 0.83439 \\
\hline
\end{tabular}

${ }^{a}$ ID = inner diameter; OD = outer diameter; IFE = inner fuel element; OFE = outer fuel element; RB = removable beryllium reflector; SPB = semipermanent beryllium reflector; PTP = peripheral target position; HT = hydraulic tube.

${ }^{b}$ Value for diameter as given in primary reference (drawing).

${ }^{c}$ Radii values, in centimeters, are used in the MCNP model.

${ }^{d}$ The ID was calculated as (OD - 2t), where $t$ is the liner thickness. The reported nominal value and uncertainty for $t$ are 0.063 in. and 0.002 in. Based on uncertainties for OD and t, the uncertainty for ID is derived as 0.005745 in.

${ }^{e}$ Reference and as-modeled diameters differ. The as-modeled cylinders account for flow grooves, each with $0.075474 \mathrm{~cm}^{2}$ area.

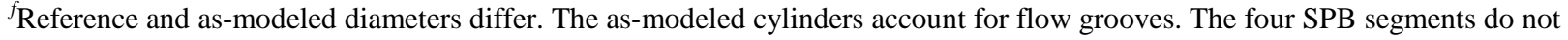
complete a circle. Each of these segments has a $90^{\circ}$ sector angle with its origin at 4.2426 in. from core centerline.

${ }^{g}$ The PTP tube OD and wall thickness are $0.70 \pm 0.005 \mathrm{in}$. and $0.092 \pm 0.005 \mathrm{in}$. in the drawings. The ID was calculated as the difference between the OD and two times the thickness. 


\subsubsection{Fuel Elements}

There are 171 fuel plates in the IFE and 369 in the OFE, with involute shapes [1]. Each fuel plate includes a fuel region and a filler region encased in cladding, as illustrated in Fig. 4. The plates within a fuel element are held together by two side plates. All fuel plates have an axial length of $24 \mathrm{in} .(60.96 \mathrm{~cm})$, with the active fuel region in the plate spanning $20 \mathrm{in} .(50.8 \mathrm{~cm})$ of this length [1]. The thickness of the fuel region varies smoothly along the width of the fuel plate. The profiles of the fuel regions in a flat plate (i.e., plate before forming into an involute shape) are illustrated in Fig. 5 for the IFE and OFE. The fuel contouring data for the IFE and OFE were taken from ORNL drawings DWG D42114 and DWG D42122, respectively, and are illustrated in Fig. 5. The locations of the start and end coordinates of the fuel region for a flat plate contour for the IFE and OFE plate are taken as the average of the maximum and minimum outline values as specified in these drawings. This results in start and end locations along the flat fuel plate of $0.092 \mathrm{in} .(0.23368 \mathrm{~cm})$ and $3.159 \mathrm{in}$. $(8.02386 \mathrm{~cm})$ from the origin of the involute for the IFE plate and $0.084 \mathrm{in} .(0.21336 \mathrm{~cm})$ and $2.846 \mathrm{in} .(7.22884 \mathrm{~cm})$ for the OFE plate. The corresponding volumes of the fuel regions, calculated based on fuel contouring data provided in drawings DWG D42114 and DWG D42122, are $20.98888 \mathrm{~cm}^{3}$ and $18.69084 \mathrm{~cm}^{3}$, respectively, for the IFE and OFE plates.

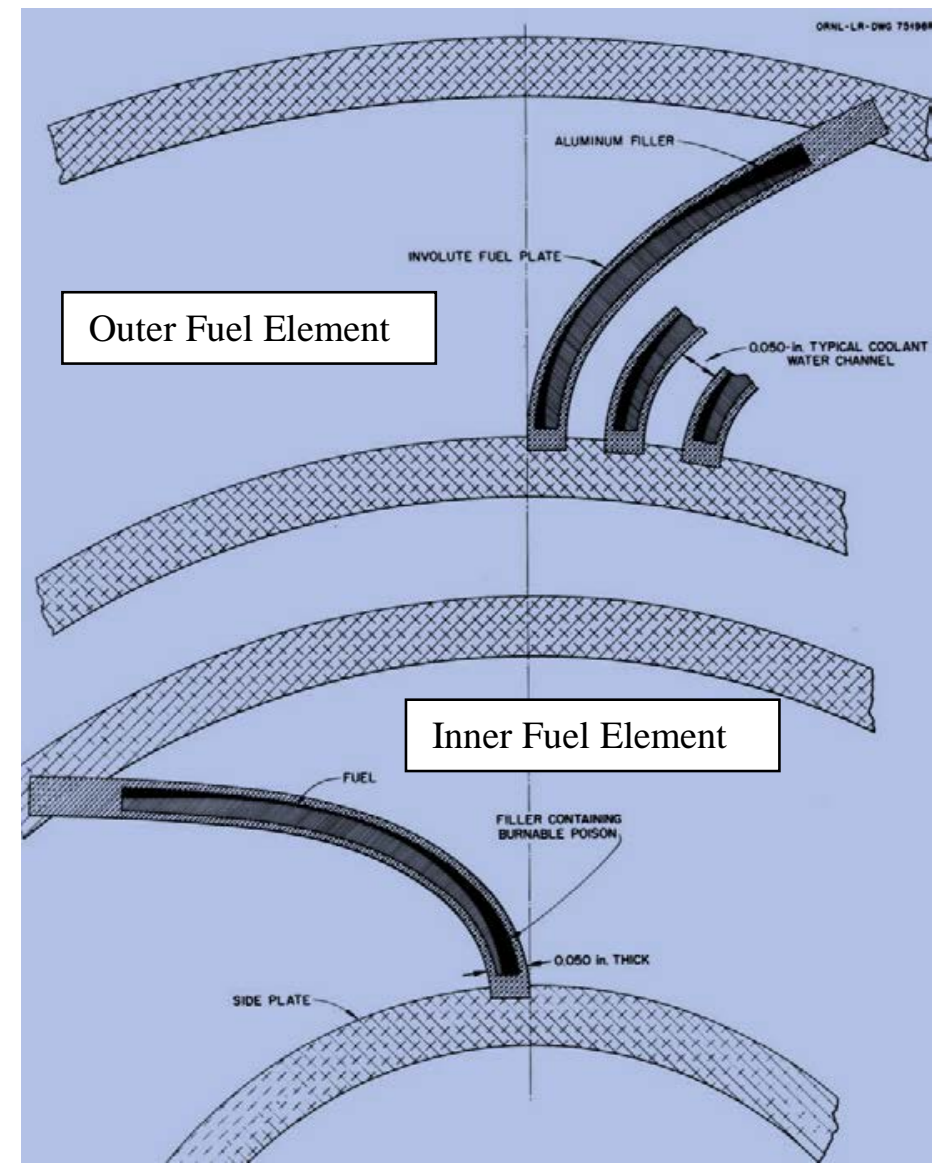

Fig. 4. Illustration of fuel plate profiles in HFIR fuel elements. 

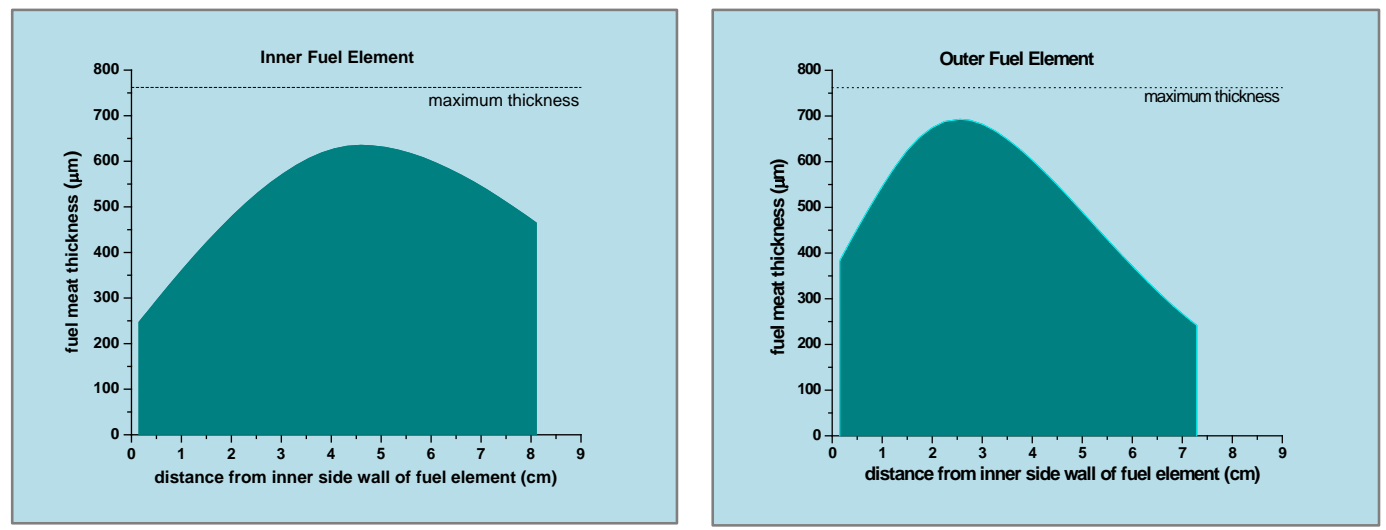

Fig. 5. Flat plate profiles of fuel regions for HFIR fuel elements.

The modeling data for the IFE outer top adapter and OFE inner top adapter were updated for consistency with HFIR drawings, using drawings E-42118, E-42126, and E-49451 for the IFE assembly, the OFE assembly, and the adapter ring, respectively. The top of the water gap between the two fuel elements, which previously [3] was modeled as terminating at the axial top of the active fuel zone ( $25.4 \mathrm{~cm}$ with respect to the core midplane), was extended to $31.80842 \mathrm{~cm}$ with respect to the core midplane. In addition, the axial plane defining the top adapter length was reduced from $41.91 \mathrm{~cm}$ as used previously [3] to $39.6875 \mathrm{~cm}$ with respect to the core midplane. As shown in the drawings mentioned above and in the reactor assembly vertical section drawing, M-11506-OH-501, there are no bottom adapters connecting the two fuel elements; the water coolant flowing through the gap between the fuel elements exits this gap at the terminus of the side plates. Therefore, the modeled IFE outer and OFE inner bottom adapters [3] were removed and were replaced with water coolant in the current model.

The as-modeled fuel elements are illustrated in Figs. 6 and 7. Figure 6 shows $x-y$ cross sections of the fuel elements modeled using the explicit and simplified methods discussed in detail in Section 6. Figure 7 provides elevation view, side-by-side, illustrations of the current and previous [3] simplified models.
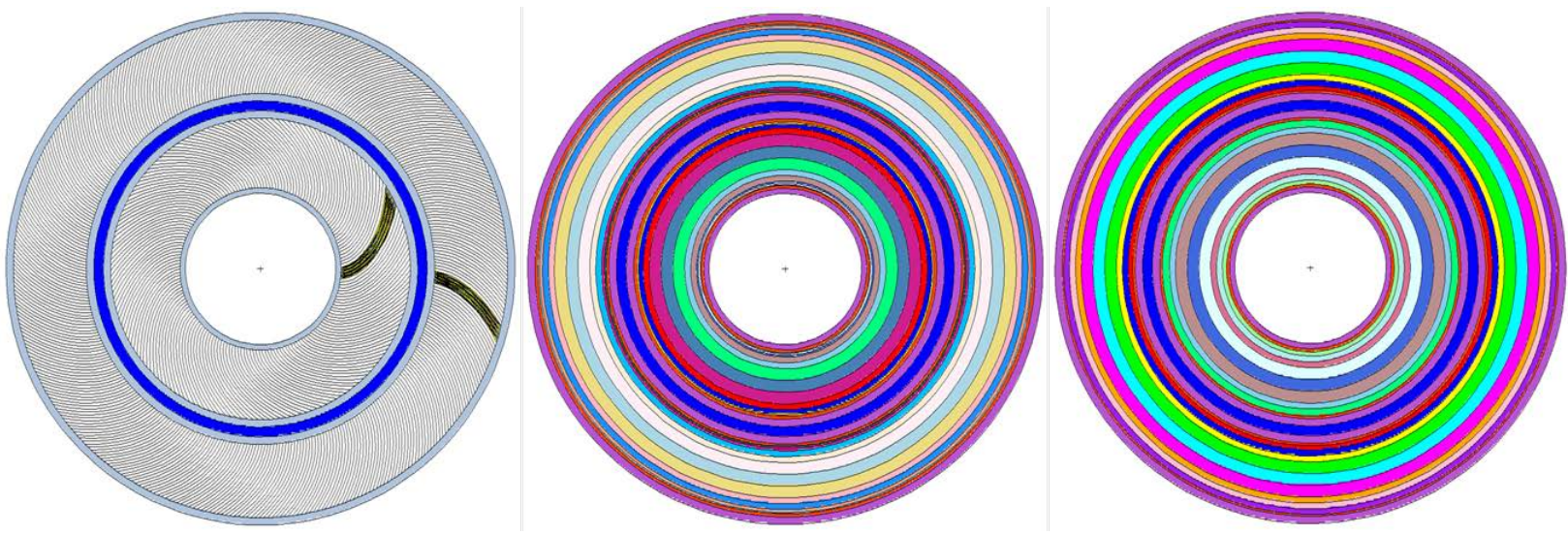

Fig. 6. Modeling of the explicit (left), current simplified (middle), and previous [3] simplified (right) fuel elements on the $x-y$ plane at the core midplane. 

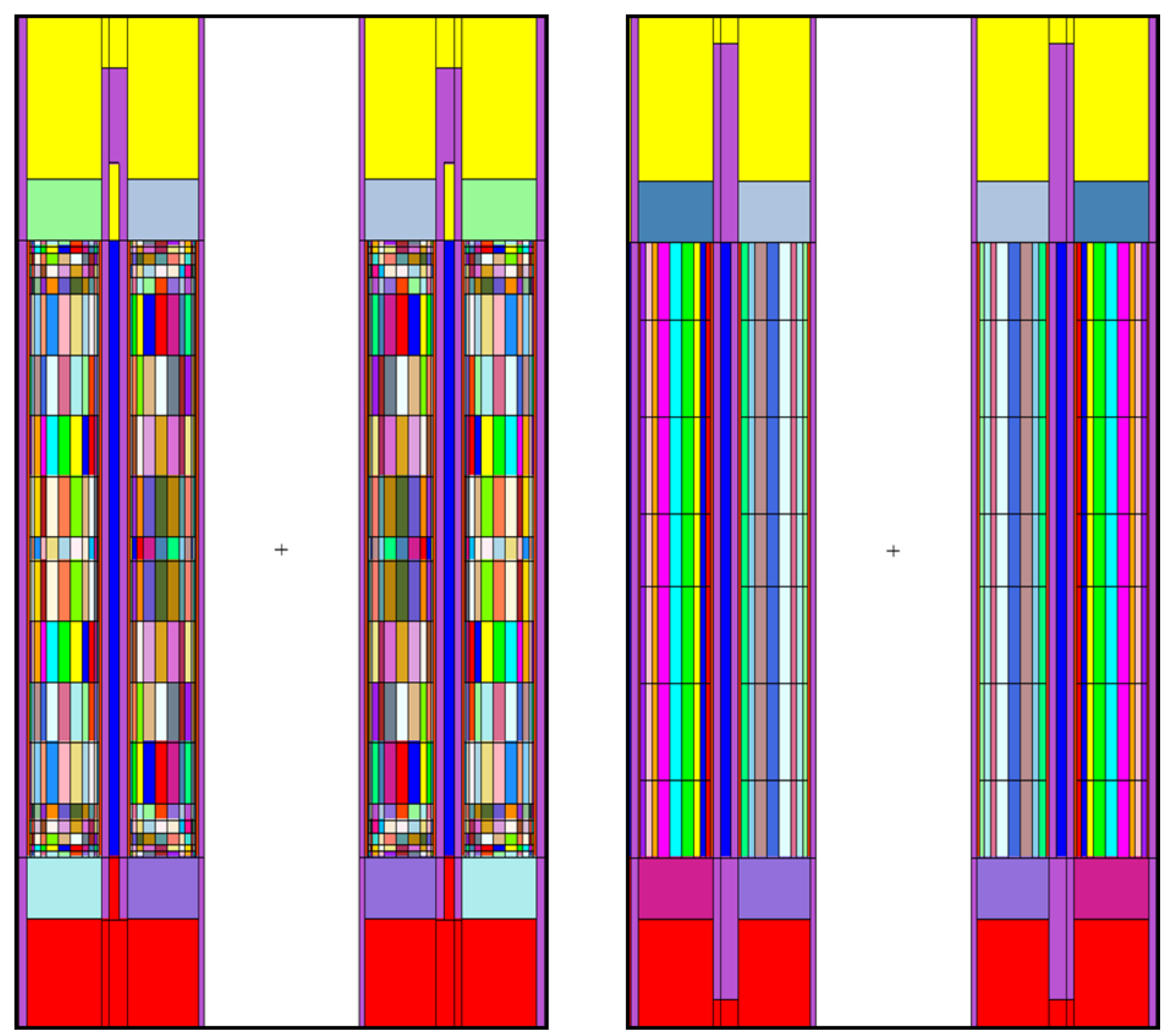

Fig. 7. Vertical section ( $x-z$ plane at $y=0 \mathrm{~cm})$ of the current simplified (left) and previous [3] simplified (right) as-modeled fuel elements.

\subsubsection{Control Elements}

As discussed in Section 2, the two CEs move vertically in opposite directions with respect to the core midplane during the cycle to maintain critical conditions - the ICE moves downward and the OCE moves upward to drive the neutron absorbing sections of the CEs out of the core to increase reactivity. This movement is illustrated in Fig. 8. The movement of the CEs during the cycle is simulated by using surface transformation cards in the MCNP model to set the appropriate axial positions for the desired time during the reactor cycle. The positions corresponding to the current Cycle 400 model are presented in Table 3. The values listed for the transformation (i.e., translation) cards are the measured positions as recorded by the reactor operators for Cycle 400 . These values are expressed with respect to the shutdown position - the state at which the upper edge of the ICE black region is located at the upper edge of the unfueled core region (30.48 cm with respect to core midplane) and the lower edge of the OCE black region is located at the lower edge of the unfueled core region $(-30.48 \mathrm{~cm}$ with respect to core midplane).

Table 3 also shows the actual position of the upper edge of the ICE gray region relative to the core horizontal midplane. The values used in the transformation cards for the ICE and OCE in the depletion model for Cycle 400 have the same absolute value but have different signs (the ICE is withdrawn in the downward direction and the OCE is withdrawn symmetrically and upward with respect to the core horizontal midplane). The transformation cards are applied to the surfaces defining the CEs to obtain the actual position during the irradiation cycle relative to the core horizontal midplane. The relative locations and movements of the two CEs as a function of irradiation time are illustrated in Fig. 9. 


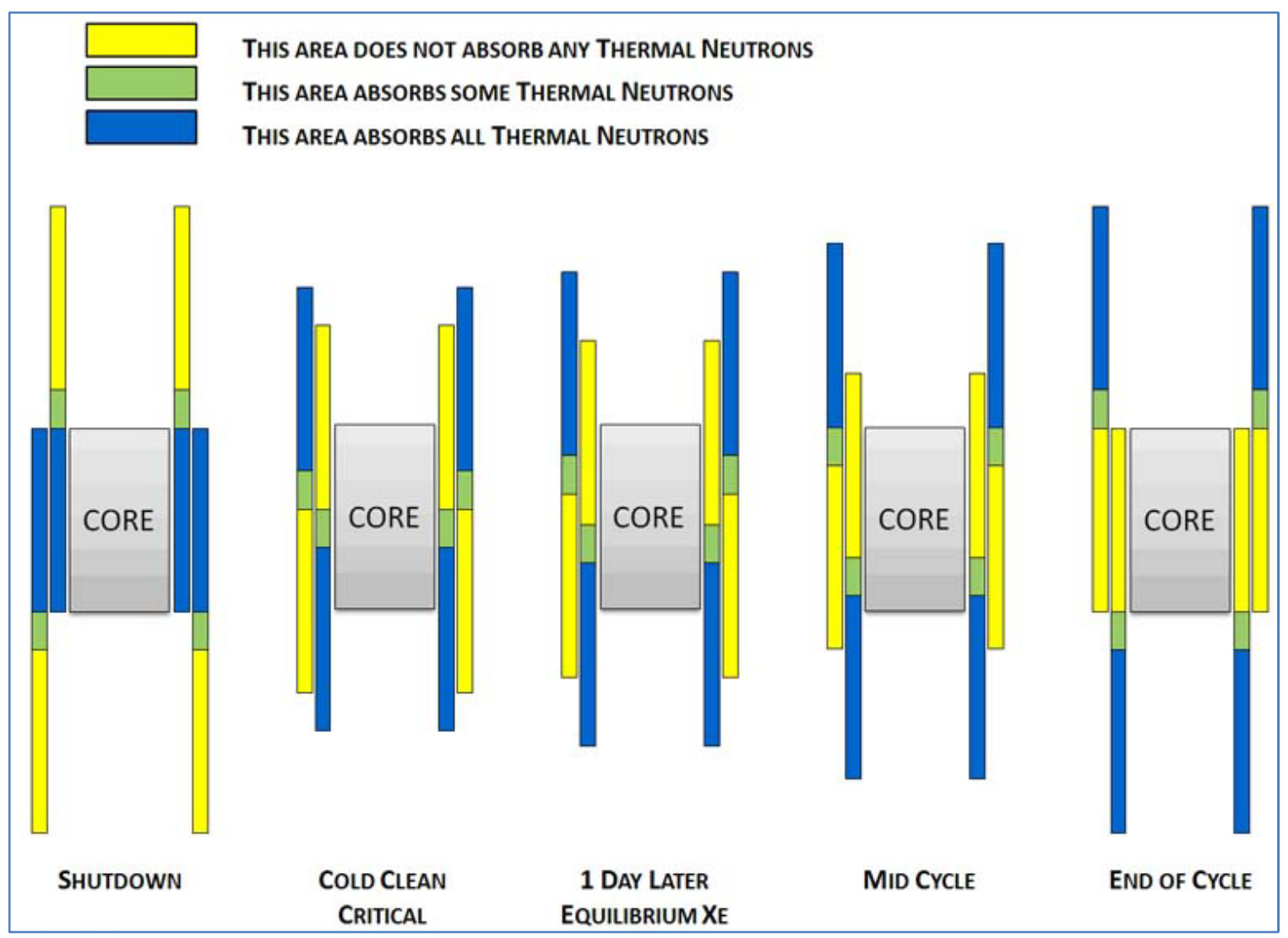

Fig. 8. Illustration of control element movement during the cycle.

Table 3. Control element position for HFIR Cycle 400

\begin{tabular}{|c|c|c|}
\hline $\begin{array}{l}\text { Time } \\
\text { (days) }\end{array}$ & $\begin{array}{l}\text { Transformation card } \\
\text { axial translation } \\
\text { (cm) }\end{array}$ & $\begin{array}{l}\text { Actual axial location } \\
\text { of upper edge of ICE } \\
\text { gray region }{ }^{a} \\
(\mathrm{~cm})\end{array}$ \\
\hline 0 & 45.72 & -2.54 \\
\hline 1 & 50.93 & -7.75 \\
\hline 2 & 52.27 & -9.09 \\
\hline 3 & 52.58 & -9.40 \\
\hline 4 & 52.73 & -9.55 \\
\hline 5 & 52.81 & -9.63 \\
\hline 6 & 52.93 & -9.75 \\
\hline 7 & 53.09 & -9.91 \\
\hline 8 & 53.26 & -10.08 \\
\hline 9 & 53.47 & -10.29 \\
\hline 10 & 53.77 & -10.59 \\
\hline 11 & 54.05 & -10.87 \\
\hline 12 & 54.46 & -11.28 \\
\hline 13 & 54.89 & -11.71 \\
\hline 14 & 55.32 & -12.14 \\
\hline 15 & 55.93 & -12.75 \\
\hline 16 & 56.57 & -13.39 \\
\hline 17 & 57.25 & -14.07 \\
\hline
\end{tabular}


Table 3 (continued)

\begin{tabular}{ccc}
\hline $\begin{array}{c}\text { Time } \\
\text { (days) }\end{array}$ & $\begin{array}{c}\text { Transformation card } \\
\text { axial translation } \\
\text { (cm) }\end{array}$ & $\begin{array}{c}\text { Actual axial location } \\
\text { of upper edge of ICE } \\
\text { gray region }\end{array}$ \\
\hline (cm) \\
\hline 18 & 58.04 & -14.86 \\
19 & 58.90 & -15.72 \\
20 & 59.92 & -16.74 \\
21 & 61.15 & -17.97 \\
22 & 62.38 & -19.20 \\
23 & 63.98 & -20.80 \\
24 & 65.79 & -22.61 \\
24.67 & 68.22 & -25.04 \\
\hline
\end{tabular}

${ }^{a}$ With respect to core midplane at $\mathrm{z}=0 \mathrm{~cm}$.

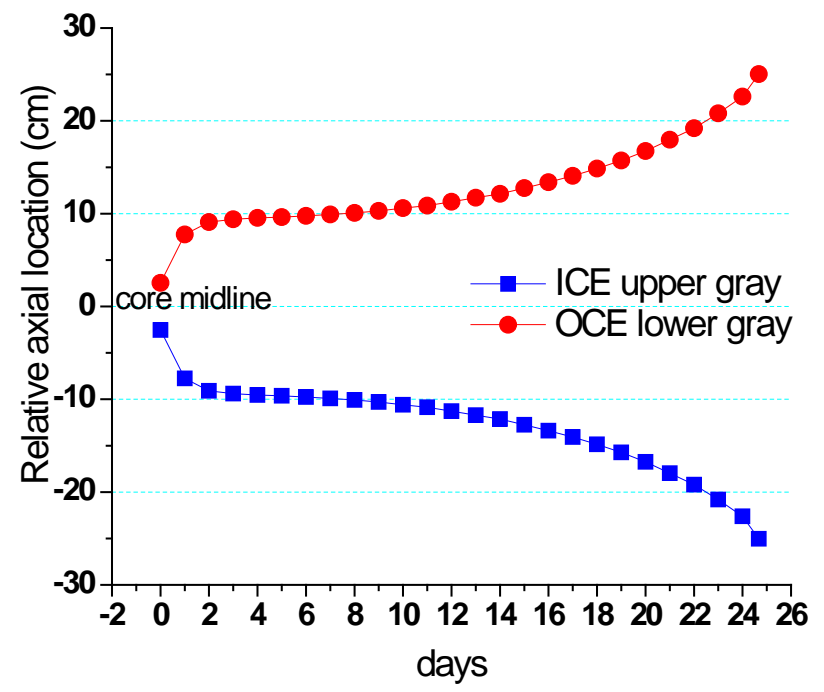

Fig. 9. Illustration of control element

movement during Cycle 400. (ICE = inner control element; OCE = outer control element.)

The model for the OCE, which is made of four separate safety plates, was updated for better consistency with the HFIR drawings. According to drawing E-49820 rev Y, the origin of each safety plate quadrant is offset $0.041 \mathrm{in}$. from the core vertical centerline. The inner and outer radii of the safety plates are $9.05 \mathrm{in} .(22.987 \mathrm{~cm})$ and $9.30 \mathrm{in} .(23.622 \mathrm{~cm})$, respectively, and the thickness of the inner and outer aluminum clad is $1 / 32$ in. $(0.079375 \mathrm{~cm})$. The safety plate geometry was modified to include the $0.041 \mathrm{in}$. $(0.10414 \mathrm{~cm})$ offset; with a sector angle of 8349'; the gap distances between the inner and outer radii edges of neighboring safety plates are 1.03418 in. $(2.626817 \mathrm{~cm})$ and $1.06115 \mathrm{in} .(2.695321 \mathrm{~cm})$, respectively. An average gap of $1.04767 \mathrm{in} .(2.661082 \mathrm{~cm})$ between safety plates is modeled to preserve the volume of the $\mathrm{CE}$ active (i.e., neutron-absorbing) regions, each with thickness of 0.1875 in. $(0.47625 \mathrm{~cm})$. The as-modeled volumes of the 0.1875 in. thick safety plate gray and black regions, including all pressure equalization flow holes are $824.79543 \mathrm{~cm}^{3}$ and $3629.09987 \mathrm{~cm}^{3}$, respectively.

The angle of rotation defined in the model (tr card tr51) to position the control cylinder and safety plates was changed from $20.6099^{\circ}$ to $21.0000^{\circ}$. A 21-degree rotation is based off the lower head drawing, 
E-42269; the fuel grid support pedestal drawing, E-42350; the inner control cylinder assembly drawing, E-49822; and the inner control cylinder details drawing, E-49824.

Translation cards were included in the MCNP model to enable independent movement of each of the OCE quadrants if desired by the user.

Each of the two gray regions, one in the ICE and one in the OCE, were modeled as having 5 axial layers of 1 in. $(2.54 \mathrm{~cm})$ each, each with a different material composition at BOC-400. The total height of the gray region is 5 in. $(12.7 \mathrm{~cm})$. Each of the two black regions, which have a 22 in. $(55.88 \mathrm{~cm})$ axial dimension, was modeled as having five axial zones, each 4.4 in. $(11.176 \mathrm{~cm})$ long, each with a different material composition at BOC-400, and the material compositions defined for these regions corresponded to fresh, unirradiated compositions. Each of the gray and black regions were previously [3] modeled as having only 1 axial layer each. Figure 10 illustrates the differences between the current and previous [3] as-modeled CE regions.

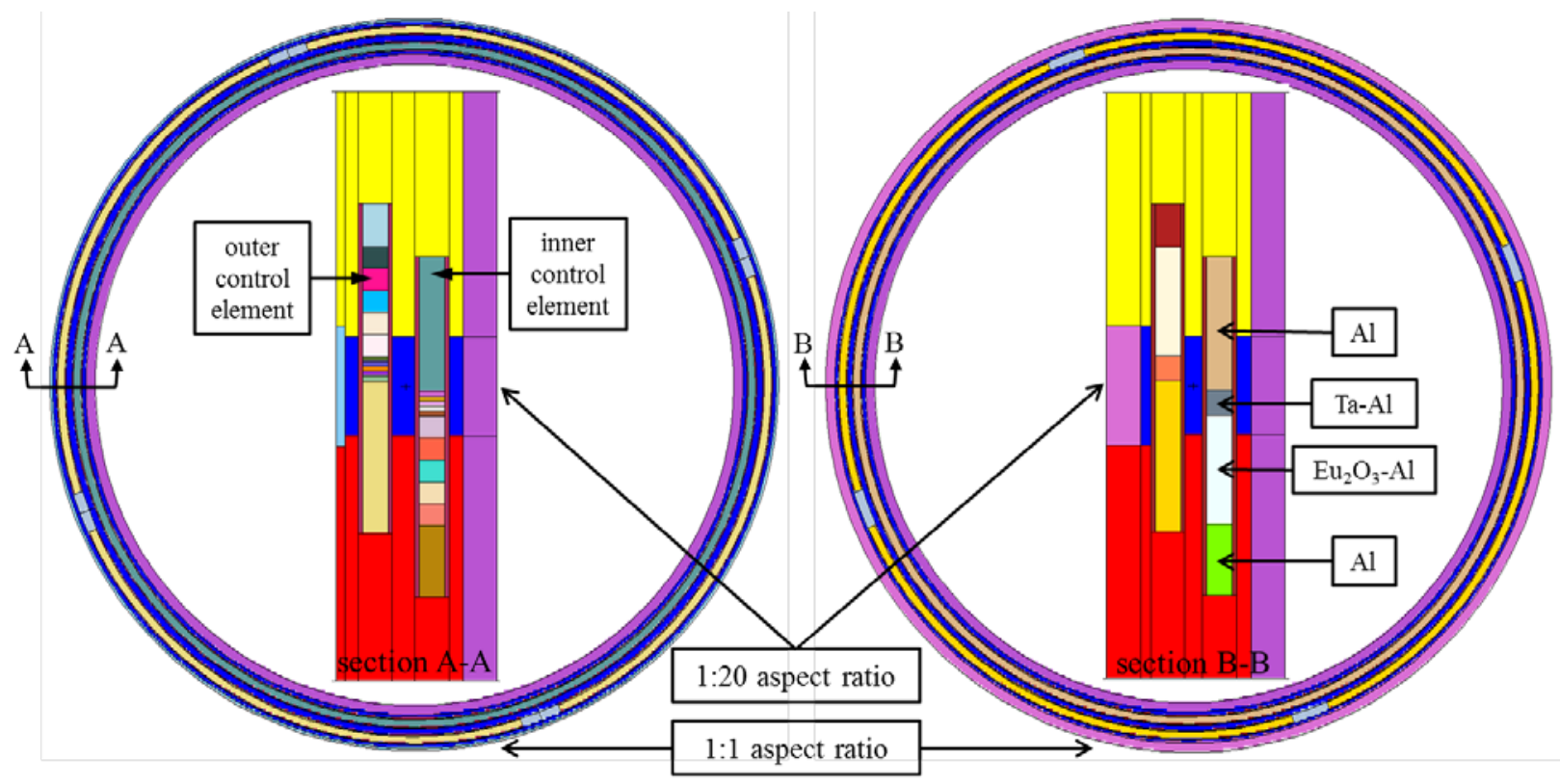

Fig. 10. Plane ( $x$-y cross section at core midplane) and vertical ( $x-z$ cross section) views of the current (left) and previous [3] (right) as-modeled control element regions.

\subsubsection{Reflector}

The model of the beryllium reflector, including the three reflector regions and the experiment facilities within them, was updated to better reflect up-to-date references and drawings. This section documents the enhancements made in the beryllium reflector region. Illustrations of the current and previous [3] as-modeled reflector regions are provided in Fig. 11 and are discussed in detail in the following subsections. 


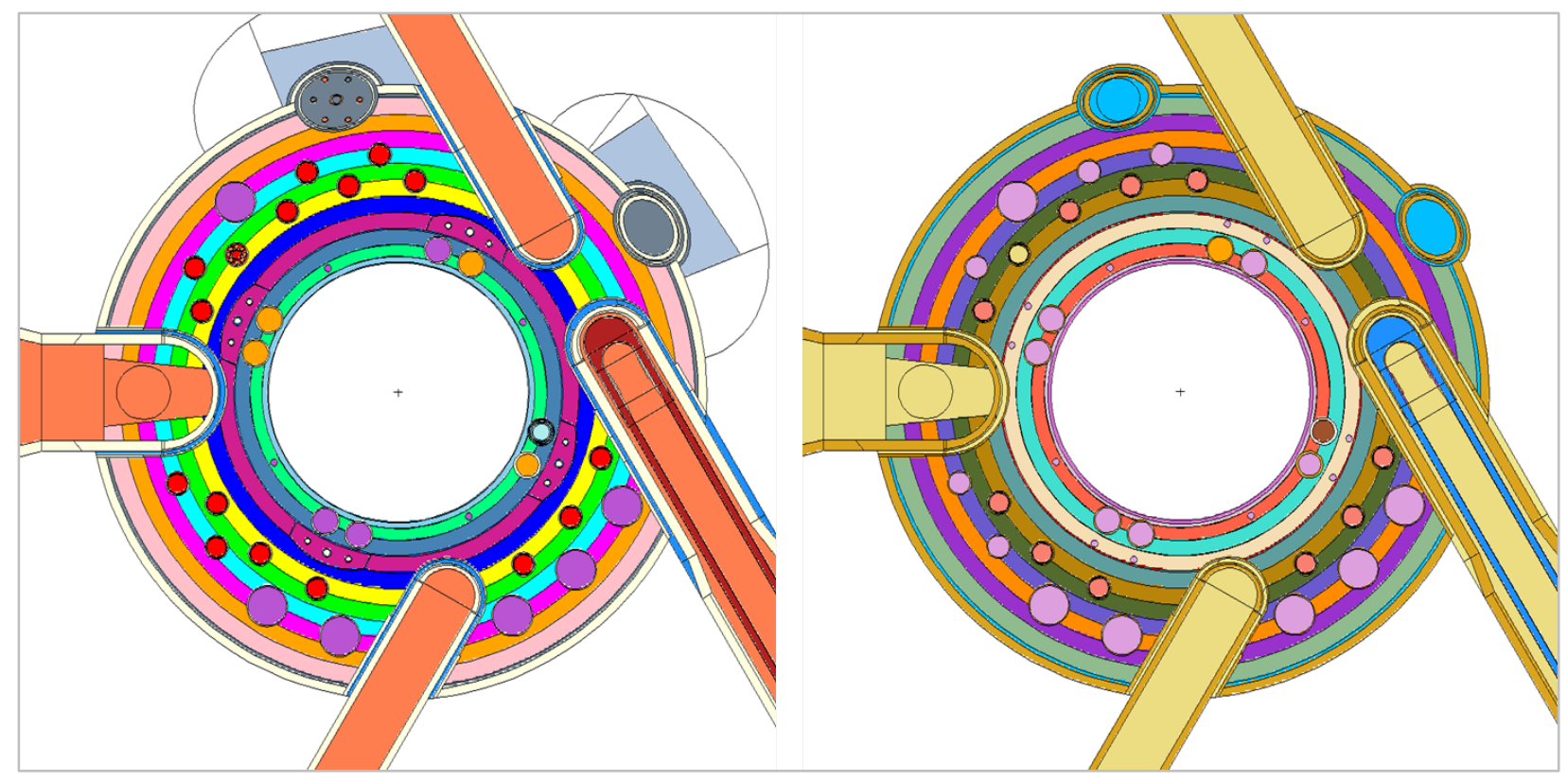

Fig. 11. Cross section of the current (left) and previous [3] (right) representations of the beryllium reflector regions on the core horizontal midplane.

\subsubsection{Semipermanent reflector and control rod access plug assemblies}

The four SPB quadrants and the four control rod access plug assemblies were explicitly modeled. Before this revision, the SPB and control rod access plug assemblies were modeled as a single cylinder of beryllium, with eight beryllium targets located directly behind the eight large RB facilities.

According to drawings E-42024 and E-42323, the inner and outer radii of the SPB are 11.942 in. $(30.33268 \mathrm{~cm})$ and $13.125 \mathrm{in}$. (33.3375 cm), respectively. The outer radius of the SPB is modeled as $33.307665 \mathrm{~cm}$ to take into account the water located in the 56 flow grooves, with 14 grooves in each quadrant. Each flow groove has a cross-sectional area of $0.075474 \mathrm{~cm}^{2}$. The SPB quadrants are separated by gaps with a 6 in. $(15.24 \mathrm{~cm})$ width. The control rod access plug assemblies are $5.875 \mathrm{in} .(14.9225 \mathrm{~cm})$ wide, thus leaving a small water gap of $1 / 16$ in. $(0.15875 \mathrm{~cm})$ between the components. The outer radii of the control rod access plug assemblies and of the water gaps separating them from the PB are 5.669 in. $(14.39926 \mathrm{~cm})$ and $5.731 \mathrm{in}$. $(14.55674 \mathrm{~cm})$, respectively, with their origin located at $7.893 \mathrm{in}$. $(20.04822 \mathrm{~cm})$ from the core vertical centerline.

The control rod access plug facilities are typically loaded with dummy aluminum targets. According to the HFIR Experiment Tracking System, these plug facilities were loaded with dummy aluminum targets (drawing D-49187) during Cycle 400; therefore, the beryllium targets included in the previous core model [3] were replaced with dummy aluminum targets. An aluminum tie rod with an outer diameter (OD) of 0.500 in. $(1.27 \mathrm{~cm}$ ), per drawing E-42380, was added to each of the four control rod access plug assemblies. The two control rod access plug facilities within each assembly were positioned, per drawing D-42322, at $\pm 15^{\circ}$ with respect to the tie rod, on a circle with radius of $6.25 \mathrm{in}$. $(15.876 \mathrm{~cm})$. Differences between the current and previous [3] as-modeled SPBs and control rod access plug facilities are illustrated in Fig. 12. 

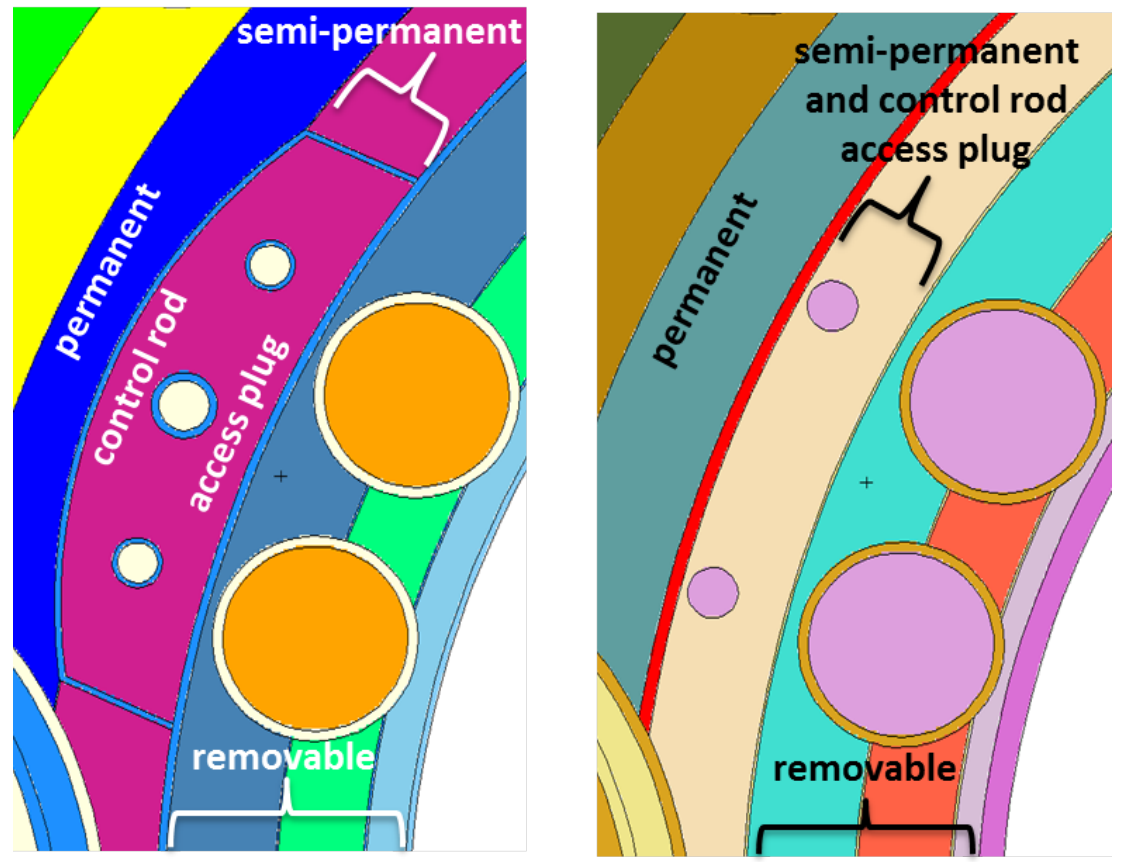

Fig. 12. Illustration of the current (left) and previous [3] (right) as-modeled semipermanent beryllium reflector and a control rod access plug facility.

\subsubsection{Pneumatic tube facilities in VXF-7 and EF-2}

More details were added to the two pneumatic facilities in locations VXF-7 and EF-2 for improved characterization of the fluxes, dose rates, and heating rates within these facilities. Before this revision, the supply, exhaust, and flight tubes within VXF-7 and EF-2 were modeled as one steel tube filled with air.

The PT-1 facility in VXF-7 consists of four supply and four exhaust stainless steel tubes (drawing M-20977-EM-130-E) located on a bolt circle with an OD (drawing M-20977-EN-121-D) of 1.159 in. $(2.94386 \mathrm{~cm})$. According to drawing M-20977-EM-130-E, the ODs and wall thicknesses of these tubes are $0.375 \mathrm{in} .(0.9525 \mathrm{~cm})$ and $0.035 \mathrm{in} .(0.0889 \mathrm{~cm})$, respectively. A centrally positioned flight tube made of stainless steel has an OD and wall thickness of 0.75 in. $(1.905 \mathrm{~cm})$ and 0.065 in. $(0.1651 \mathrm{~cm})$, respectively. Air is modeled inside, and water is modeled outside of the flight tubes. A small dummy rabbit is modeled at the centerline, for tallying purposes, and contains water with a density of $0.5 \mathrm{~g} / \mathrm{cm}^{3}$. Figure 13 illustrates the differences between the current and previous [3] as-modeled PT-1 facility located in VXF-7.

The model for the PT-2 facility in EF-2 was modified to include the flight, exhaust, and supply stainless steel tubes within the EF slant tube according to geometry data in drawing X3E209770207. The tubes located in the $4 \mathrm{in}$. OD slant tube, extending downward at an angle of about $41^{\circ}$ from the vertical centerline, were modeled to extend the height of the beryllium reflector $(30.48 \mathrm{~cm}$ with respect to the core midplane). One of the air tubes was assumed to face the reactor core. The centrally located, air-filled flight tube has an OD and wall thickness of $0.75 \mathrm{in}$. (1.905) and $0.065 \mathrm{in}$. $(0.1651 \mathrm{~cm})$, respectively. The other three air-filled supply tubes, the air-filled exhaust tube, and the two water-filled discharge tubes all have ODs and wall thicknesses of $0.375 \mathrm{in} .(0.9525 \mathrm{~cm})$ and $0.035 \mathrm{in} .(0.0889 \mathrm{~cm})$, respectively. The six tubes surrounding the centrally located, air-filled flight tube are equally spaced on a bolt circle with an OD of 3.375 in. $(8.5725 \mathrm{~cm})$. A small dummy rabbit is modeled at the centerline for tallying purposes and contains water with a density of $0.5 \mathrm{~g} / \mathrm{cm} 3$. The modeling differences between the current and previous [3] representations of the PT-2 facility can be observed in Fig. 14. 

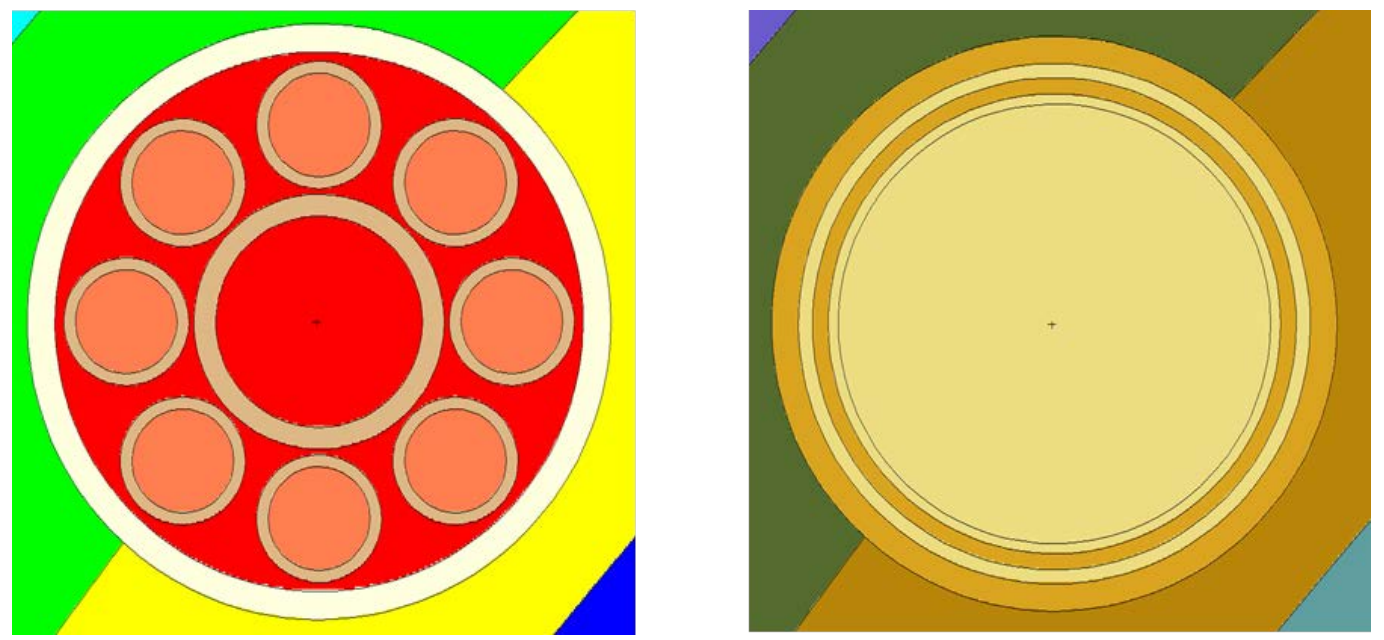

Fig. 13. Cross section of the current (left) and previous [3] (right) as-modeled PT-1 pneumatic tube facility located in vertical experiment facility 7.
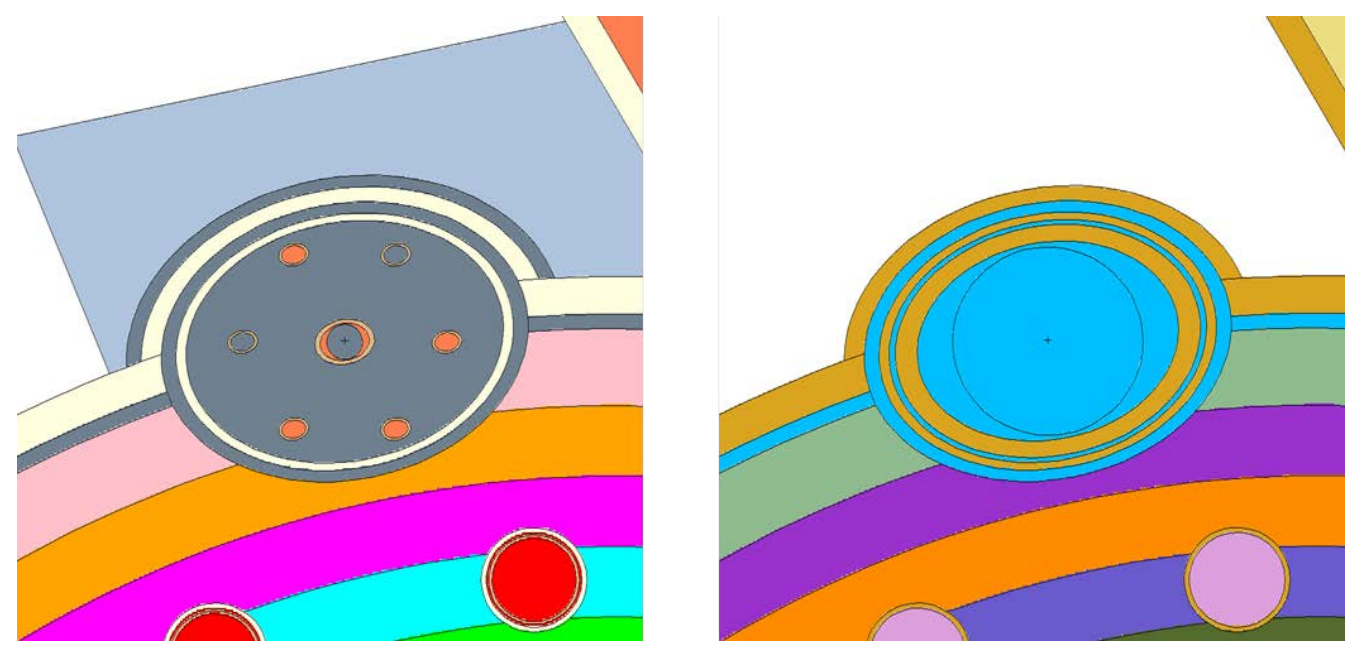

Fig. 14. Cross section of the current (left) and previous [3] (right) representations of the PT-2 pneumatic tube facility located in engineering facility 2 . Beryllium blister pack surrounds the engineering facility in the updated representation.

\subsubsection{Reflector blister packs}

Drawings E-49787 and E-49788 were used to model the beryllium reflector blister packs that surround the engineering slant facilities EF-1 and EF-2. The EF-1 blister assembly was modeled between aluminum cage ribs 9 and 11, and the EF-2 blister assembly was modeled between ribs 7 and 24 . The blister assemblies were modeled with ODs of $5.5 \mathrm{in}$. $(13.97 \mathrm{~cm})$, depths of $4.5 \mathrm{in}$. $(11.43 \mathrm{~cm})$, and widths of 9.0 in $(22.86 \mathrm{~cm})$. These were added to the model to better characterize the neutron flux in the PT-2 facility. The as-modeled beryllium blister packs surrounding the EF tubes are illustrated in Figs. 11 and 14. 


\subsubsection{Removable Beryllium Experiment RB-7A}

The models of the target and liner at the experiment location in RB-7A were revised to include more details. The model of the experiment liner was updated based on HFIR drawings M-11506-OH-222-E and M-11506-OH-223-E. The $\mathrm{Eu}_{2} \mathrm{O}_{3}$ stacked rings enclosed between two stainless steel tubes were explicitly modeled rather than homogenizing the steel tubes and rings as in the previous model [3]. The $\mathrm{Eu}_{2} \mathrm{O}_{3}$ liner section located in RB-7A is 18.75 in. $(47.63 \mathrm{~cm})$ long; $9.50 \mathrm{in.}(24.13 \mathrm{~cm})$ of the liner is located below the core horizontal midplane. Small helium gas gaps are located between the steel tubes and the $\mathrm{Eu}_{2} \mathrm{O}_{3}$ section. The radii used to model the components of the so-called Eu-5 liner are listed in Table 4. A $\mathrm{Eu}_{2} \mathrm{O}_{3}$ density of $7.60 \mathrm{~g} / \mathrm{cm}^{3}$ was used, as specified in drawing EABD-HFIR-2004-001. The data for the europium isotopic composition were taken from [29].

Table 4. Geometry data for the Eu-5 liner model

\begin{tabular}{lcc}
\hline \multicolumn{1}{c}{ Region } & Diameter(in.) & Radius (cm) \\
\hline SST inner tube inner diameter (ID) & 1.6625 & 2.11138 \\
SST inner tube outer diameter (OD) & 1.7530 & 2.22631 \\
$\mathrm{Eu}_{2} \mathrm{O}_{3}$ ID & 1.7560 & 2.23012 \\
$\mathrm{Eu}_{2} \mathrm{O}_{3}$ OD & 1.9000 & 2.41300 \\
SST outer tube ID & 1.9030 & 2.41681 \\
SST outer tube OD & 1.9920 & 2.52984 \\
\hline
\end{tabular}

Data in drawings X3E020977A390-419 and EABD-HFIR-2004-001 were used to model the RB-17J experiment located in RB-7A in more detail. The water gap, 316 stainless steel housing tube, gas gap, and 316 stainless steel secondary containment housing were modeled explicitly within the Eu-5 liner. The two $\mathrm{Eu}_{2} \mathrm{O}_{3}-\mathrm{Al}$ shields inside the secondary containment were modeled as a material (m37 in the MCNP model) composed of $30 \% \mathrm{Eu}_{2} \mathrm{O}_{3}$ and $70 \%$ aluminum alloy type 6061 (Al-6061), by volume, as specified in drawing EABD-HFIR-2004-001. Each of these two shields has a thickness of $0.5 \mathrm{in} .(1.27 \mathrm{~cm})$. The axial location of one shield is between 8.75 and $9.25 \mathrm{in}$. (22.225 and $23.495 \mathrm{~cm}$ ) with respect to the core horizontal midplane; for the other shield, the axial location is between -8.328 and $-8.828 \mathrm{in}$. $(-22.42312$ and $-21.15312 \mathrm{~cm}$ ) relative to the core horizontal midplane.

The subassemblies and spacers located between the $\mathrm{Eu}_{2} \mathrm{O}_{3}-\mathrm{Al}$ shields and within the 316 stainless steel secondary containment housing were modeled as one homogenized material (m39 in the MCNP model) with the compositions listed in Table 5. The volume fractions listed in this table are based on the total volume of the occupied region, elemental masses listed in drawing EABD-HFIR-2004-001, and volume calculations associated with drawings X3E020977A390-419. One material (m45 in the MCNP model) was used to fill the region above the top shield and within the secondary containment housing. This material was assumed to be $15 \% 316$ stainless steel and $85 \%$ helium gas, by volume, based on drawings X3E020977A401 and X3E020977A404. The region below the bottom of the $\mathrm{Eu}_{2} \mathrm{O}_{3}-\mathrm{Al}$ shield was modeled as one material composed of $25 \% 316$ stainless steel and $75 \% \mathrm{Al}-6061$ by volume. Under this latter region, there is water exiting the removable reflector. The stainless steel composition is based on data from [30] and the isotopic compositions of the elements involved are based on data from [29]. Illustrations of the current and previous [3] as-modeled experiments in the RB-7A experiment facility are provided in Fig. 15. 
Table 5. Materials of subassemblies and spacers in RB-7A

\begin{tabular}{lc}
\hline Material & Volume fraction \\
\hline $\mathrm{Al}-6061$ & 0.02551 \\
$\mathrm{TZM}^{a}$ & 0.15080 \\
\hline $\mathrm{SS}-304$ & 0.06274 \\
$\mathrm{~V}$ & 0.18054 \\
Alumina & 0.00652 \\
\hline $\mathrm{Li}$ & 0.31701 \\
gas (void) & 0.17579 \\
\hline${ }^{a}$ Ti-Zr-Mo alloy (99 wt\% Mo) &
\end{tabular}

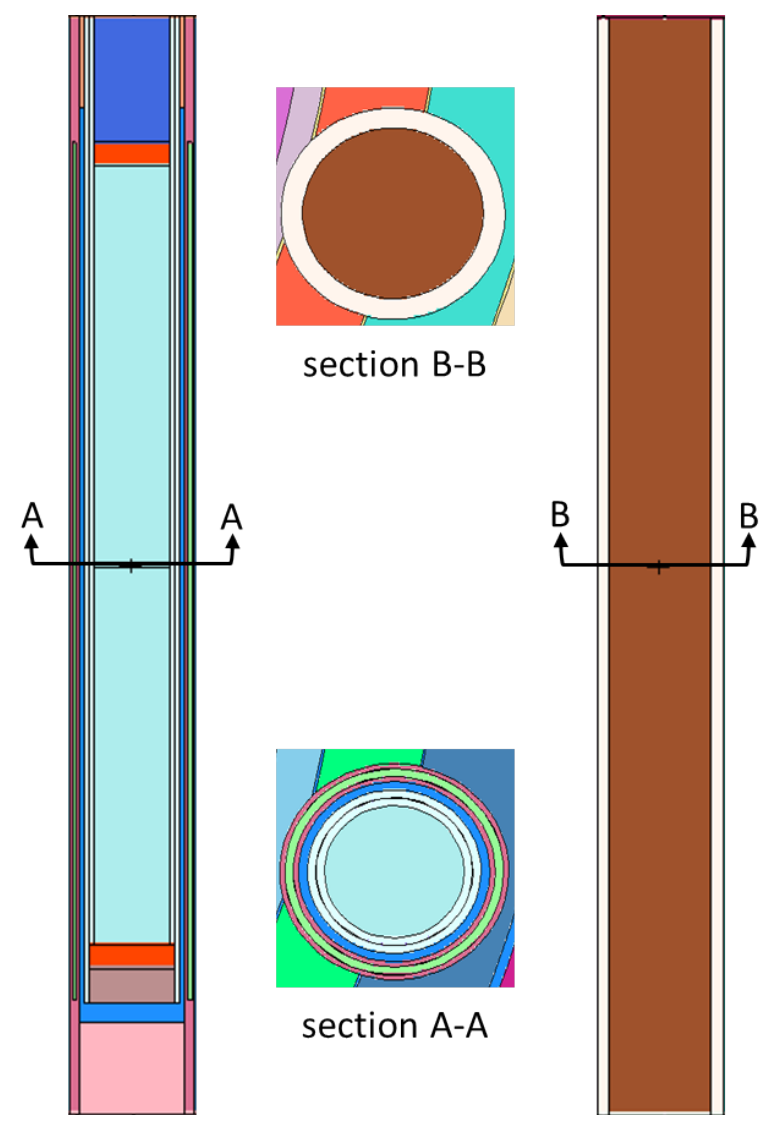

Fig. 15. Illustrations of the current (left) and previous [3] (right) representations of the RB-7A experiment.

\subsubsection{Outer small vertical experiment facilities}

The outer small VXFs were modeled previously [3] as containing beryllium plugs. However, during Cycle 400 and other typical cycles when these facilities are not being used, these outer VXFs actually contain a steel liner and are filled with water. Therefore, the models for the regions within the outer small VXF aluminum liners were modified to include a steel liner and water coolant similar to the model used for the inner small VXFs. 


\subsection{MATERIAL COMPOSITION DATA}

\subsubsection{Coolant Data}

The material composition data for the coolant in the MCNP model were updated for better consistency with the coolant information provided in the HFIR Safety Analysis Report (SAR) [31]. The HFIR SAR specifies the following.

- " "The coolant enters the pressure vessel at nominal conditions of 468 psig and $120^{\circ} \mathrm{F} . "$

- "Nominal operating temperature range is currently $120^{\circ} \mathrm{F}$ inlet and $156^{\circ} \mathrm{F}$ outlet."

- "During normal operation, the nominal core pressure drop is approximately 100 psi."

Note the difference between psi and psig units for pressure; if the pressure is expressed in psig units, the value in psi units is obtained by adding 14.7 to that pressure value. Pressure, temperature, and density data consistent with the above-mentioned coolant data are given in Table 6. The in-core temperature and pressure are calculated as the average of the inlet and outlet temperature and pressure values. The water density corresponding to the specified coolant condition (temperature and pressure) was obtained using the National Institute of Standards and Technology (NIST) calculator for thermophysical properties of fluids [32].

Table 6. Data for inlet, outlet, and in-core water coolant

\begin{tabular}{llll}
\hline \multicolumn{1}{c}{$\begin{array}{c}\text { Material identifier } \\
\text { in model }\end{array}$} & \multicolumn{1}{c}{$\mathbf{~ m 1}$} & \multicolumn{1}{c}{$\mathbf{~ m 2}$} & \multicolumn{1}{c}{$\mathbf{~ m 3}$} \\
\hline Water region & outlet & in-core & inlet \\
Pressure (psi) & 382.7 & 432.7 & 482.7 \\
Temperature (F) & 156 & 138 & 120 \\
Density $\left(\mathrm{g} / \mathrm{cm}^{3}\right)$ & 0.97951 & 0.98502 & 0.98994 \\
\hline
\end{tabular}

Composition data for the coolant material identified as $\mathrm{m} 4$ in the model are the same as for material $\mathrm{m} 1$ (i.e., outlet water). Composition data for materials $\mathrm{m} 5$ and $\mathrm{m} 9$ in the model are the same as for material $\mathrm{m} 2$ (i.e., in-core water). Composition data for materials $\mathrm{m} 6$ and $\mathrm{m} 7$ in the model are the same as for material $\mathrm{m} 3$ (i.e., inlet water). Composition data for the pool water (material $\mathrm{m} 8$ in the model) were updated to correspond to a density of $1.000 \mathrm{~g} / \mathrm{cm}^{3}$.

The number densities for hydrogen $(\mathrm{H})$ and oxygen $(\mathrm{O}), n_{\mathrm{H}}$ and $n_{\mathrm{O}}$, for water at density $\rho_{\mathrm{H}_{2} \mathrm{O}}$ were calculated, in atoms/b-cm units, as

$$
n_{O}=10^{-24} \rho_{H_{2} O} \frac{N_{A}}{M_{H_{2} O} O} \quad n_{H}=2 n_{O}
$$

In Eq. 1, $M_{\mathrm{H}_{2} \mathrm{O}}=2 M_{H}+M_{O}$ is the water atomic mass, $M_{H}$ and $M_{O}$ are the atomic masses for $\mathrm{H}$ and $\mathrm{O}$, and $\mathrm{N}_{\mathrm{A}}$ is the Avogadro's number. The atomic masses for $\mathrm{H}$ (1.00794 amu) and O (15.9994 amu) were taken from the NIST WebBook [29]. A value of $6.02214 \times 10^{23} \mathrm{~mol}^{-1}$ was used for $\mathrm{N}_{\mathrm{A}}$. Cross-section data for ${ }^{1} \mathrm{H}$ and ${ }^{16} \mathrm{O}$ were applied in the model to the $\mathrm{H}$ and $\mathrm{O}$ contents in water, calculated as mentioned above, as well as in all materials in the configuration that have water as a component. The revised coolant data for coolant materials $\mathrm{m} 1$ to $\mathrm{m} 9$ in the model are presented in Table 7. 
Table 7. Atom density data for inlet, outlet, and in-core water

\begin{tabular}{lcccc}
\hline \multicolumn{1}{c}{ Material } & Material identification numbers & H (at/b-cm) & O (at/b-cm) & Total $(\mathbf{a t} / \mathbf{b}-\mathbf{c m})$ \\
\hline Inlet water & $\mathrm{m} 3, \mathrm{~m} 6, \mathrm{~m} 7$ & $6.61833 \mathrm{E}-02$ & $3.30917 \mathrm{E}-02$ & $9.92750 \mathrm{E}-02$ \\
In-core water & $\mathrm{m} 2, \mathrm{~m} 5, \mathrm{~m} 9$ & $6.58544 \mathrm{E}-02$ & $3.29272 \mathrm{E}-02$ & $9.87816 \mathrm{E}-02$ \\
Outlet water & $\mathrm{m} 1, \mathrm{~m} 4$ & $6.54860 \mathrm{E}-02$ & $3.27430 \mathrm{E}-02$ & $9.82291 \mathrm{E}-02$ \\
Pool water & $\mathrm{m} 8$ & $6.68559 \mathrm{E}-02$ & $3.34280 \mathrm{E}-02$ & $1.00284 \mathrm{E}-01$ \\
\hline
\end{tabular}

\subsubsection{Materials for Central Target Region}

The total number densities on the cell cards in the previous model [3] were updated, where necessary, to be consistent with the total number density derived from the material data cards. The updated values are listed in Table 8. This concerns data for shrouded targets-material m512 and PTP experimentsmaterials m711, m722, m723, m726, m732, m733, m736, m742, m743, m746, m751, m752, m753, $\mathrm{m} 756$, m766, and m767.

Table 8. Total atom densities updated for cells in central target region

\begin{tabular}{lc}
\hline Material identifier & $\begin{array}{c}\text { Total atom density } \\
\text { (at/b-cm) }\end{array}$ \\
\hline m723, m726, m733, m736, m743, m746, & $6.03240 \mathrm{E}-02$ \\
m751, m756, m766 & \\
m722 & $5.48665 \mathrm{E}-02$ \\
m732 & $5.43818 \mathrm{E}-02$ \\
$\mathrm{~m} 742$ & $5.42013 \mathrm{E}-02$ \\
$\mathrm{~m} 752$ & $5.45761 \mathrm{E}-02$ \\
$\mathrm{~m} 753$ & $4.74971 \mathrm{E}-02$ \\
$\mathrm{~m} 767$ & $4.74971 \mathrm{E}-02$ \\
\hline
\end{tabular}

Target material for the shrouded aluminum target (material m512) has a total number density of $6.03240 \times 10^{-2} \mathrm{at} / \mathrm{b}-\mathrm{cm}$, based on the material cards section in the input. However, the number density used for the cell cards in which this material is used is set to $4.82102 \times 10^{-2} \mathrm{at} / \mathrm{b}-\mathrm{cm}$, which corresponds to $80 \%$ of the density inferred based on the material cards. According to internal communications, this accounts for the actual composition of the target at the time of Cycle 400, when the shrouded aluminum rods were made by taking hollow rods and filling them with aluminum slugs that had only $80 \%$ of the nominal aluminum density. The number density for m512 on all cell cards where this material is used was kept at the value of $4.82102 \times 10^{-2}$ at/b-cm as used in the previous model [3].

The coolant material within the HT was changed from air to water; the in-core water composition in Table 7 was used for the update. The cards in the model for materials m511, m512, m530, m711, m723, m726, m733, m736, m743, m746, m751, m756, and m766 are all using "al27.12t" (data at 293.6 K) for the thermal scattering treatment.

\subsubsection{Materials for Fuel Element Region}

\subsubsection{Material data for fuel in fuel plates}

\section{Uranium isotopic composition}

According to [3], the enriched uranium material shall contain between 92 and $94 \mathrm{wt} \%{ }^{235} \mathrm{U}$ in total uranium, with a nominal enrichment of $93 \mathrm{wt} \%$. The fuel plate loading reports from Cycle 400 onward indicate an average enrichment of $\sim 93.2 \mathrm{wt} \%{ }^{235} \mathrm{U}$ in total uranium; therefore, a reference fuel 
enrichment of 93.2 wt $\%{ }^{235} U$ is used in the revised model for Cycle 400 . The ${ }^{234} U$ and ${ }^{236} U$ contents were selected based on data included in Table A.6 of [1] and data for a $\mathrm{U}_{3} \mathrm{O}_{8}$ typical certification report [33], which are listed in Table 9.

Table 9. Uranium isotopic ratios for high-enriched uranium fuel

\begin{tabular}{cccc}
\hline Isotopic ratio & Based on [1] & Based on [33] & Selected for modeling \\
\hline${ }^{234} \mathrm{U} /{ }^{235} \mathrm{U}$ & 0.0107 & 0.0110 & 0.011 \\
${ }^{236} \mathrm{U} /{ }^{235} \mathrm{U}$ & 0.0043 & 0.0041 & 0.004 \\
\hline
\end{tabular}

The calculated reference isotopic composition for uranium is presented in Table 10. Data in this table were obtained using the reference enrichment of $93.2 \mathrm{wt} \%{ }^{235} \mathrm{U}$ and the isotopic ratios shown in Table 9. The ${ }^{238} \mathrm{U}$ content was calculated as the difference between $100 \%$ and the sum of the isotopic contents in weight percents for ${ }^{234} \mathrm{U},{ }^{235} \mathrm{U}$, and ${ }^{236} \mathrm{U}$.

Table 10. Uranium isotopic composition for high-enriched uranium fuel

\begin{tabular}{cc}
\hline Isotope & $\begin{array}{c}\text { Isotopic content } \\
\text { (wt \% of total uranium) }\end{array}$ \\
\hline${ }^{234} \mathrm{U}$ & 1.025 \\
${ }^{235} \mathrm{U}$ & 93.200 \\
${ }^{236} \mathrm{U}$ & 0.373 \\
${ }^{238} \mathrm{U}$ & 5.402 \\
\hline
\end{tabular}

\section{Fuel composition}

The fuel is a $\mathrm{U}_{3} \mathrm{O}_{8}-\mathrm{Al}$ dispersion [34]. The densities of $\mathrm{U}_{3} \mathrm{O}_{8}$ and aluminum in this dispersion are $8.22 \mathrm{~g} / \mathrm{cm}^{3}$ and $2.7 \mathrm{~g} / \mathrm{cm}^{3}$, respectively [33]. The nominal value for the void fraction in the fuel meat is $3 \%$ [35]. The total nominal amount of ${ }^{235} \mathrm{U}$ in a fuel plate is $15.18 \mathrm{~g}$ for the IFE and $18.44 \mathrm{~g}$ for the OFE [34]. The actual ${ }^{235} \mathrm{U}$ load per plate for fuel loaded in Cycle 400, extracted from material certification reports, is $15.25 \mathrm{~g}$ and $18.52 \mathrm{~g}$ for the IFE and OFE, respectively. These latter values, which are consistent with the nominal values within uncertainty, were used for the revised model of Cycle 400.

Based on the composition data and the fuel contouring data (see Section 5.1.1), the volume fractions of $\mathrm{U}_{3} \mathrm{O}_{8}$ and aluminum in the fuel meat are 0.11204 and 0.85796 for the IFE plate, and 0.15280 and 0.81720 for the OFE plate. The isotopic compositions for the fuel meat in the IFE and OFE are shown in Table 11; they were calculated based on the material data for the fuel meat components and the corresponding volume fractions.

Table 11. Isotopic composition data for fuel meat in fuel plates ${ }^{a}$

\begin{tabular}{|c|c|c|c|c|}
\hline Isotope & $\begin{array}{c}\text { Density } \\
\text { in IFE fuel meat } \\
\left(\mathrm{g} / \mathrm{cm}^{3}\right)\end{array}$ & $\begin{array}{l}\text { Atom density } \\
\text { in IFE fuel meat } \\
(\mathbf{a t} / \mathbf{b}-\mathbf{c m})\end{array}$ & $\begin{array}{c}\text { Density } \\
\text { in OFE fuel meat } \\
\left(\mathrm{g} / \mathrm{cm}^{3}\right)\end{array}$ & $\begin{array}{c}\text { Atom density } \\
\text { in OFE fuel meat } \\
\text { (at/b-cm) }\end{array}$ \\
\hline U-234 & 7.99233E-03 & 2.05652E-05 & $1.08995 \mathrm{E}-02$ & 2.80455E-05 \\
\hline U-235 & 7.26575E-01 & $1.86158 \mathrm{E}-03$ & $9.90859 \mathrm{E}-01$ & 2.53872E-03 \\
\hline U-236 & $2.90630 \mathrm{E}-03$ & 7.41473E-06 & 3.96344E-03 & $1.01118 \mathrm{E}-05$ \\
\hline $\mathrm{U}-238$ & 4.21133E-02 & 1.06537E-04 & $5.74316 \mathrm{E}-02$ & $1.45289 \mathrm{E}-04$ \\
\hline O-16 & $1.41416 \mathrm{E}-01$ & 5.32289E-03 & $1.92855 \mathrm{E}-01$ & 7.25903E-03 \\
\hline $\mathrm{Al}-27$ & $2.31648 \mathrm{E}+00$ & 5.17027E-02 & $2.20644 \mathrm{E}+00$ & 4.92467E-02 \\
\hline Total & $3.23748 \mathrm{E}+00$ & 5.90217E-02 & $3.46245 \mathrm{E}+00$ & 5.92279E-02 \\
\hline
\end{tabular}

${ }^{a} \mathrm{IFE}=$ inner fuel element, OFE = outer fuel element. 


\subsubsection{Material data for filler in fuel plates}

The material used for the filler of the fuel plates is aluminum powder 101. The specifications provided in [34] for this material are listed in Table 12.

Table 12. Data for Al-1100 powder [34]

\begin{tabular}{cc}
\hline Element & Weight \% \\
\hline $\mathrm{B}$ & 0.001 maximum \\
$\mathrm{Cd}$ & 0.002 maximum \\
$\mathrm{Li}$ & 0.008 maximum \\
$\mathrm{Zn}$ & 0.100 maximum \\
$\mathrm{Cu}$ & 0.200 maximum \\
$\mathrm{Si}$ and $\mathrm{Fe}$ & 0.250 maximum \\
$\mathrm{Al}_{2} \mathrm{O}_{3}$ & 0.700 maximum \\
$\mathrm{Al}$ (metallic) & remainder to $100 \%$ \\
\hline
\end{tabular}

An estimate of the Al-1100 composition was made based on data in four material test reports that include actual compositions for aluminum powder in lots C077118 [36], C026004 [37], C070078 [38], and C052014 [39]. The estimated isotopic composition is listed in Table 13.

Table 13. Composition for Al-1100 based on test reports

\begin{tabular}{cc}
\hline Element & Weight \% \\
\hline $\mathrm{Fe}$ & 0.1355 \\
$\mathrm{Si}$ & 0.0428 \\
$\mathrm{O}$ & 0.0235 \\
$\mathrm{Zn}$ & 0.0062 \\
$\mathrm{Cu}$ & 0.0025 \\
$\mathrm{~B}$ & 0.0019 \\
$\mathrm{Cd}$ & 0.0004 \\
$\mathrm{Li}$ & 0.0002 \\
$\mathrm{Al}$ & 99.7870 \\
\hline
\end{tabular}

A density of $2.7 \mathrm{~g} / \mathrm{cm}^{3}$ is used for the filler material. The IFE filler includes a small amount of $\mathrm{B}_{4} \mathrm{C}$; the OFE filler does not contain $\mathrm{B}_{4} \mathrm{C}$ [34]. The nominal amount of ${ }^{10} \mathrm{~B}$ per IFE fuel plate is $0.0164 \mathrm{~g} \pm 0.0016 \mathrm{~g}$ [34] for ${ }^{10} \mathrm{~B}$ load per core of $2.8 \mathrm{~g}$ [34]. Actual loading data from the fuel element certification packages for fuel elements used in HFIR cycles 370-433 indicate an average (over all of these cycles) core load value of $2.709 \mathrm{~g}{ }^{10} \mathrm{~B}$. This average value was used in the revised model for Cycle 400. The value corresponds to a ${ }^{10} \mathrm{~B}$ load per plate of $0.0158 \mathrm{~g}$, which is consistent (within uncertainty) with the nominal value of $0.0164 \mathrm{~g}$. The average isotopic content of ${ }^{10} \mathrm{~B}$ in boron is $18.5 \mathrm{wt} \%$ [40]. A density of $2.47 \mathrm{~g} / \mathrm{cm}^{3}$ [34] is used for $\mathrm{B}_{4} \mathrm{C}$. The number density data calculated for the IFE and OFE fillers are listed in Table 14. 
Table 14. Atom density data for aluminum-based filler in fuel elements

\begin{tabular}{|c|c|c|c|c|c|c|}
\hline Element & Nuclide & $\begin{array}{l}\text { Nuclide mole } \\
\text { fraction }^{a}\end{array}$ & $\begin{array}{c}\text { Nuclide } \\
\text { identifier in } \\
\text { MCNP model }\end{array}$ & $\begin{array}{c}\text { Nuclide } \\
\text { mass } \\
\text { (amu) }\end{array}$ & $\begin{array}{l}\text { Atom density } \\
\text { in IFE } \\
\text { (at } / \mathbf{b}-\mathbf{c m})\end{array}$ & $\begin{array}{c}\text { Atom density } \\
\text { in OFE } \\
\text { (at/b-cm) }\end{array}$ \\
\hline $\mathrm{Al}$ & $\mathrm{Al}-27$ & 1.0000 & 13027 & 26.98154 & 5.98697E-02 & $6.01342 \mathrm{E}-02$ \\
\hline \multirow[t]{2}{*}{ B } & B-10 & 0.1997 & 5010 & 10.01294 & 1.03943E-04 & 5.70793E-07 \\
\hline & B-11 & 0.8003 & 5011 & 11.00931 & 4.16468E-04 & $2.28700 \mathrm{E}-06$ \\
\hline C & C-12 & 1.0000 & 6012 & 12.0107 & 1.29926E-04 & 0 \\
\hline $\mathrm{O}$ & O-16 & 1.0000 & 8016 & 15.9994 & 2.37671E-05 & 2.38824E-05 \\
\hline \multirow[t]{4}{*}{$\mathrm{Fe}$} & $\mathrm{Fe}-54$ & 0.05845 & 26054 & 53.93961 & 2.29483E-06 & 2.30597E-06 \\
\hline & Fe-56 & 0.91754 & 26056 & 55.93494 & 3.60239E-05 & 3.61987E-05 \\
\hline & Fe-57 & 0.02119 & 26057 & 56.93539 & 8.31948E-07 & 8.35987E-07 \\
\hline & $\mathrm{Fe}-58$ & 0.00282 & 26058 & 57.93328 & 1.10717E-07 & $1.11255 \mathrm{E}-07$ \\
\hline \multirow[t]{3}{*}{ Si } & Si-28 & 0.92223 & 14028 & 27.97693 & $2.27411 \mathrm{E}-05$ & $2.28515 \mathrm{E}-05$ \\
\hline & $\mathrm{Si}-29$ & 0.04685 & 14029 & 28.97649 & 1.15527E-06 & $1.16088 \mathrm{E}-06$ \\
\hline & Si-30 & 0.03092 & 14030 & 29.97377 & 7.62452E-07 & 7.66153E-07 \\
\hline \multirow[t]{2}{*}{$\mathrm{Cu}$} & Cu-63 & 0.6915 & 29063 & 62.92960 & $1.53191 \mathrm{E}-06$ & $1.53935 \mathrm{E}-06$ \\
\hline & $\mathrm{Cu}-65$ & 0.3085 & 29065 & 64.92779 & 6.83435E-07 & 6.86753E-07 \\
\hline \multirow[t]{8}{*}{ Cd } & Cd-106 & 0.0125 & 48106 & 105.9065 & 7.19731E-10 & 7.23225E-10 \\
\hline & Cd-108 & 0.0089 & 48108 & 107.9042 & $5.12449 \mathrm{E}-10$ & 5.14936E-10 \\
\hline & Cd-110 & 0.1249 & 48110 & 109.903 & 7.19156E-09 & 7.22647E-09 \\
\hline & Cd-111 & 0.1280 & 48111 & 110.9042 & 7.37005E-09 & 7.40583E-09 \\
\hline & Cd-112 & 0.2413 & 48112 & 111.9028 & 1.38937E-08 & $1.39611 \mathrm{E}-08$ \\
\hline & Cd-113 & 0.1222 & 48113 & 112.9044 & 7.03609E-09 & 7.07025E-09 \\
\hline & Cd-114 & 0.2873 & 48114 & 113.9034 & 1.65423E-08 & $1.66226 \mathrm{E}-08$ \\
\hline & Cd-116 & 0.0749 & 48116 & 115.9048 & 4.31263E-09 & 4.33357E-09 \\
\hline \multirow[t]{2}{*}{$\mathrm{Li}$} & Li-6 & 0.0759 & 3006 & 6.015123 & 3.53933E-08 & 3.55651E-08 \\
\hline & $\mathrm{Li}-7$ & 0.9241 & 3007 & 7.016005 & 4.30922E-07 & 4.33014E-07 \\
\hline Total & & & & & $6.06104 \mathrm{E}-02$ & $6.02280 \mathrm{E}-02$ \\
\hline
\end{tabular}

${ }^{a}$ As provided in [28], except for B, C, and O; isotope fractions for B are inferred based on weight fractions available from [40] $\left(0.185\right.$ wt $\%{ }^{10} \mathrm{~B}$ and 0.815 wt $\left.\%{ }^{11} \mathrm{~B}\right)$; the total number of $\mathrm{C}$ and $\mathrm{O}$ atoms are calculated using the atomic mass numbers for these elements, but in the MCNP models cross section of ${ }^{12} \mathrm{C}$ and ${ }^{16} \mathrm{O}$ are applied to them.

${ }^{b} \mathrm{IFE}=$ inner fuel element, $\mathrm{OFE}=$ outer fuel element.

\subsubsection{Material data for side plates and cladding of fuel plates}

The materials used for the side plates and cladding of the fuel plates are aluminum alloy 6061-T6511 and aluminum alloy 6061-O [34], with specifications provided by standards ASTM B241-12 [41] and ASTM B209-10 [42]. Minimum and maximum contents in weight percents are provided in these standards for $\mathrm{Mg}, \mathrm{Al}, \mathrm{Si}, \mathrm{Ti}, \mathrm{Cr}, \mathrm{Mn}, \mathrm{Fe}, \mathrm{Cu}$, and $\mathrm{Zn}$, with $\mathrm{Al}$ the main component. The chemical compositions listed in [41] and [42] are identical. The calculated isotopic composition data used in the revised model are given in Table 15. The isotopic mass and isotopic abundance data that were used to convert the elemental compositions from weight percents to at/b-cm are also included in this table. A density of $2.7 \mathrm{~g} / \mathrm{cm}^{3}$ was used for Al-6061. The amount of each of the elemental impurities was calculated as the average of the minimum and maximum specifications [41]. The Al content was calculated as a complement to $100 \%$ of the sum of all the other components. All materials in the HFIR model that include Al-6061 were updated for consistency with the data in Table 15. 
The material cards in the MCNP model for materials 20, 21, 22, 25, and 26 all use "al27.12t" for the thermal scattering treatment.

Table 15. Atom density data for Al-6061 in cladding and side walls of fuel elements

\begin{tabular}{|c|c|c|c|c|c|c|}
\hline Element & Weight $\%^{a}$ & Nuclide & $\begin{array}{l}\text { Nuclide mole } \\
\text { fraction }^{b}\end{array}$ & $\begin{array}{l}\text { Nuclide mass }{ }^{c} \\
\text { (amu) }\end{array}$ & $\begin{array}{l}\text { Nuclide identifier } \\
\text { in MCNP model }\end{array}$ & $\begin{array}{l}\text { Atom density } \\
\text { (at/b-cm) }\end{array}$ \\
\hline \multirow[t]{3}{*}{$\mathrm{Mg}$} & 1.0000 & Mg-24 & 0.7899 & 23.98504 & 12024 & 5.28433E-04 \\
\hline & & Mg-25 & 0.1000 & 24.98584 & 12025 & 6.68988E-05 \\
\hline & & Mg-26 & 0.1101 & 25.98259 & 12026 & 7.36555E-05 \\
\hline $\mathrm{Al}$ & 97.3050 & $\mathrm{Al}-27$ & 1.0000 & 26.98154 & 13027 & 5.86385E-02 \\
\hline \multirow[t]{3}{*}{$\mathrm{Si}$} & 0.6000 & Si-28 & 0.92223 & 27.97693 & 14028 & 3.20349E-04 \\
\hline & & $\mathrm{Si}-29$ & 0.04685 & 28.97649 & 14029 & $1.62740 \mathrm{E}-05$ \\
\hline & & Si-30 & 0.03092 & 29.97377 & 14030 & $1.07405 \mathrm{E}-05$ \\
\hline \multirow[t]{5}{*}{$\mathrm{Ti}$} & 0.0750 & Ti-46 & 0.0825 & 45.95263 & 22046 & 2.10182E-06 \\
\hline & & Ti-47 & 0.0744 & 46.95176 & 22047 & $1.89546 \mathrm{E}-06$ \\
\hline & & Ti-48 & 0.7372 & 47.94795 & 22048 & $1.87814 \mathrm{E}-05$ \\
\hline & & Ti-49 & 0.0541 & 48.94787 & 22049 & $1.37829 \mathrm{E}-06$ \\
\hline & & Ti-50 & 0.0518 & 49.94479 & 22050 & $1.31969 \mathrm{E}-06$ \\
\hline \multirow[t]{4}{*}{$\mathrm{Cr}$} & 0.1950 & Cr-50 & 0.0435 & 49.94604 & 24050 & 2.64953E-06 \\
\hline & & Cr-52 & 0.8379 & 51.94051 & 24052 & 5.10935E-05 \\
\hline & & Cr-53 & 0.0950 & 52.94065 & 24053 & 5.79359E-06 \\
\hline & & Cr-54 & 0.0237 & 53.93888 & 24054 & $1.44215 \mathrm{E}-06$ \\
\hline $\mathrm{Mn}$ & 0.0750 & Mn-55 & 1.0000 & 54.93805 & 25055 & 2.21974E-05 \\
\hline \multirow[t]{4}{*}{$\mathrm{Fe}$} & 0.3500 & $\mathrm{Fe}-54$ & 0.05845 & 53.93961 & 26054 & 5.95637E-06 \\
\hline & & $\mathrm{Fe}-56$ & 0.91754 & 55.93494 & 26056 & 9.35023E-05 \\
\hline & & Fe-57 & 0.02119 & 56.93539 & 26057 & 2.15938E-06 \\
\hline & & Fe-58 & 0.00282 & 57.93328 & 26058 & 2.87373E-07 \\
\hline \multirow[t]{2}{*}{$\mathrm{Cu}^{d}$} & 0.4000 & $\mathrm{Cu}-63$ & 0.6915 & 62.92960 & 29063 & 7.07748E-05 \\
\hline & & $\mathrm{Cu}-65$ & 0.3085 & 64.92779 & 29065 & 3.15749E-05 \\
\hline Total & 100.000 & & & & & $5.99678 \mathrm{E}-02$ \\
\hline
\end{tabular}

${ }^{a}$ Based on data in ASTM B241-12 [41].

${ }^{b}$ As provided in [29].

${ }^{c}$ As provided in [29].

${ }^{d}$ Based on ASTM B241-12, average contents for $\mathrm{Cu}$ and $\mathrm{Zn}$ are $0.275 \%$ and $0.125 \%$, respectively. As there are no isotopic cross sections for all $\mathrm{Zn}$ isotopes in the cross-section libraries used for depletion simulations, $\mathrm{Cu}$ and $\mathrm{Zn}$ are represented as $\mathrm{Cu}$ in the model.

\subsubsection{Materials for Control Element Region}

Materials for black and gray zones of the CE regions were updated using the same method described in [5] and [9]. Though the method is the same as previously used, more up-to-date versions of the codes involved $[18,25]$ were used. In addition, all nuclear data used with these codes are based on ENDF/B-VII.0. Twenty materials $(2 \times 2 \times 5)$ are used in the gray and black regions of the CEs compared to only four in the previous model [9]. The updated composition data for these materials are listed in Tables 16-19. Only the nuclides with contents larger than $10^{-10}$ at/b-cm in each of the CE regions (gray or black) are included in these tables. More details about the calculation of the composition for the CEs present in HFIR at BOC-400 are discussed in Appendix A of this report. 
Composition data for the CE cladding material (m21), as well as for other components not present in the fuel element region or central target region that include Al-6061 (see Table 15), are based on specifications in ASTM B241 [41]. Material data for the white regions in the CEs have been updated for consistency with the data used for Al-6061 (Table 15) and water (Tables 6 and 7). Materials in the upper and lower white regions of the ICE are identified as m402 and m403. Materials in the upper and lower white regions of the OCE are identified as $\mathrm{m} 412$ and m413. Material m402, located adjacent to the ICE gray region, and material $\mathrm{m} 413$, located adjacent to the OCE gray region, reside in-core (active region) for most of the time during a typical cycle. Material m403, located adjacent to the ICE black region, and material m412, located adjacent to the OCE black region, reside below and above the active region of the core, respectively, for most of the time during a typical cycle. Composition data for the white regions as used in the MCNP models are listed in Table 20. 
Table 16. Material composition data at the beginning of Cycle 400 for inner control element gray material zones

\begin{tabular}{|c|c|c|c|c|c|c|c|c|c|c|c|c|c|c|}
\hline \multicolumn{3}{|c|}{$\mathrm{m} 4001$} & \multicolumn{3}{|c|}{$\mathrm{m} 4002$} & \multicolumn{3}{|c|}{$\mathrm{m} 4003$} & \multicolumn{3}{|c|}{ m4004 } & \multicolumn{3}{|c|}{ m4005 } \\
\hline Nuclide & $\begin{array}{l}\text { Iden- } \\
\text { tifier }\end{array}$ & at/b-cm & Nuclide & $\begin{array}{l}\text { Iden- } \\
\text { tifier }\end{array}$ & at/b-cm & Nuclide & $\begin{array}{l}\text { Iden- } \\
\text { tifier }\end{array}$ & at/b-cm & Nuclide & $\begin{array}{l}\text { Iden- } \\
\text { tifier }\end{array}$ & at/b-cm & Nuclide & $\begin{array}{l}\text { Iden- } \\
\text { tifier }\end{array}$ & at/b-cm \\
\hline $\mathrm{Al}-27$ & 13027 & 3.36771E-02 & $\mathrm{Al}-27$ & 13027 & 3.36771E-02 & $\mathrm{Al}-27$ & 13027 & 3.36771E-02 & $\mathrm{Al}-27$ & 13027 & 3.36771E-02 & $\mathrm{Al}-27$ & 13027 & 3.36771E-02 \\
\hline O-16 & 8016 & 1.38896E-03 & O-16 & 8016 & 1.38896E-03 & O-16 & 8016 & 1.38896E-03 & O-16 & 8016 & 1.38896E-03 & O-16 & 8016 & 1.38896E-03 \\
\hline $\mathrm{H}-1$ & 1001 & 2.77791E-03 & H-1 & 1001 & 2.77791E-03 & $\mathrm{H}-1$ & 1001 & 2.77791E-03 & $\mathrm{H}-1$ & 1001 & 2.77791E-03 & $\mathrm{H}-1$ & 1001 & 2.77791E-03 \\
\hline Та-181 & 73181 & $1.12700 \mathrm{E}-02$ & Та-181 & 73181 & $1.28200 \mathrm{E}-02$ & Та-181 & 73181 & $1.37900 \mathrm{E}-02$ & Та-181 & 73181 & $1.47100 \mathrm{E}-02$ & Тa-181 & 73181 & $1.58200 \mathrm{E}-02$ \\
\hline Та-182 & 73182 & $2.62100 \mathrm{E}-05$ & Та-182 & 73182 & $3.20200 \mathrm{E}-05$ & Та-182 & 73182 & $3.48500 \mathrm{E}-05$ & Та-182 & 73182 & 3.70900E-05 & Тa-182 & 73182 & 4.06800E-05 \\
\hline Hf-179 & 72179 & $3.85100 \mathrm{E}-10$ & Hf-179 & 72179 & $4.21000 \mathrm{E}-10$ & Hf-179 & 72179 & $4.17400 \mathrm{E}-10$ & Hf-179 & 72179 & $4.86000 \mathrm{E}-10$ & Hf-179 & 72179 & $4.80700 \mathrm{E}-10$ \\
\hline Hf-180 & 72180 & 7.66200E-07 & Hf-180 & 72180 & $7.27000 \mathrm{E}-07$ & Hf-180 & 72180 & $6.58500 \mathrm{E}-07$ & Hf-180 & 72180 & $5.79600 \mathrm{E}-07$ & Hf-180 & 72180 & 4.93400E-07 \\
\hline W-182 & 74182 & $2.31700 \mathrm{E}-04$ & W-182 & 74182 & $2.80500 \mathrm{E}-04$ & W-182 & 74182 & $2.98500 \mathrm{E}-04$ & W-182 & 74182 & $3.09800 \mathrm{E}-04$ & W-182 & 74182 & 3.31500E-04 \\
\hline W-183 & 74183 & 7.60300E-03 & W-183 & 74183 & $6.58000 \mathrm{E}-03$ & W-183 & 74183 & 5.89500E-03 & W-183 & 74183 & $5.20400 \mathrm{E}-03$ & W-183 & 74183 & 4.29800E-03 \\
\hline W-184 & 74184 & $1.60500 \mathrm{E}-03$ & W-184 & 74184 & $1.07900 \mathrm{E}-03$ & W-184 & 74184 & $8.12500 \mathrm{E}-04$ & W-184 & 74184 & $5.93900 \mathrm{E}-04$ & W-184 & 74184 & 3.83700E-04 \\
\hline W-186 & 74186 & $1.55900 \mathrm{E}-06$ & W-186 & 74186 & $7.84000 \mathrm{E}-07$ & W-186 & 74186 & 4.68200E-07 & W-186 & 74186 & $2.61600 \mathrm{E}-07$ & W-186 & 74186 & $1.16400 \mathrm{E}-07$ \\
\hline Re-185 & 75185 & $1.15600 \mathrm{E}-05$ & Re-185 & 75185 & 7.00200E-06 & Re-185 & 75185 & $4.89800 \mathrm{E}-06$ & Re-185 & 75185 & $3.26000 \mathrm{E}-06$ & Re-185 & 75185 & $1.84900 \mathrm{E}-06$ \\
\hline \multirow[t]{2}{*}{ Re-187 } & 75187 & $8.84700 \mathrm{E}-07$ & Re-187 & 75187 & 3.82200E-07 & Re-187 & 75187 & $1.98500 \mathrm{E}-07$ & Re-187 & 75187 & $9.44200 \mathrm{E}-08$ & Re-187 & 75187 & 3.36100E-08 \\
\hline & Total & 5.85947E-02 & & Total & 5.86444E-02 & & Total & 5.86811E-02 & & Total & 5.87030E-02 & & Total & 5.87204e-E2 \\
\hline
\end{tabular}

Table 17. Material composition data at the beginning of Cycle 400 for outer control element gray material zones

\begin{tabular}{|c|c|c|c|c|c|c|c|c|c|c|c|c|c|c|}
\hline \multicolumn{3}{|c|}{ m4111 } & \multicolumn{3}{|c|}{ m4112 } & \multicolumn{3}{|c|}{$\mathrm{m} 4113$} & \multicolumn{3}{|c|}{ m4114 } & \multicolumn{3}{|c|}{ m4115 } \\
\hline Nuclide & $\begin{array}{l}\text { Iden- } \\
\text { tifier }\end{array}$ & at/b-cm & Nuclide & $\begin{array}{l}\text { Iden- } \\
\text { tifier }\end{array}$ & at/b-cm & Nuclide & $\begin{array}{l}\text { Iden- } \\
\text { tifier }\end{array}$ & at/b-cm & Nuclide & $\begin{array}{l}\text { Iden- } \\
\text { tifier }\end{array}$ & at/b-cm & Nuclide & $\begin{array}{l}\text { Iden- } \\
\text { tifier }\end{array}$ & at $/ \mathbf{b}-\mathbf{c m}$ \\
\hline $\mathrm{Al}-27$ & 13027 & 3.23123E-02 & $\mathrm{Al}-27$ & 13027 & 3.23123E-02 & $\mathrm{Al}-27$ & 13027 & 3.23123E-02 & $\mathrm{Al}-27$ & 13027 & 3.23123E-02 & $\mathrm{Al}-27$ & 13027 & $3.23123 \mathrm{E}-02$ \\
\hline O-16 & 8016 & 1.38360E-03 & O-16 & 8016 & 1.38360E-03 & O-16 & 8016 & 1.38360E-03 & O-16 & 8016 & 1.38360E-03 & O-16 & 8016 & $1.38360 \mathrm{E}-03$ \\
\hline $\mathrm{H}-1$ & 1001 & 2.76720E-03 & H-1 & 1001 & 2.76720E-03 & H-1 & 1001 & 2.76720E-03 & H-1 & 1001 & 2.76720E-03 & H-1 & 1001 & $2.76720 \mathrm{E}-03$ \\
\hline Та-181 & 73181 & 1.89400E-02 & Та-181 & 73181 & $1.86600 \mathrm{E}-02$ & Ta-181 & 73181 & $1.84100 \mathrm{E}-02$ & Та-181 & 73181 & $1.81400 \mathrm{E}-02$ & Тa-181 & 73181 & $1.76300 \mathrm{E}-02$ \\
\hline Тa-182 & 73182 & $1.27700 \mathrm{E}-05$ & Тa-182 & 73182 & $1.28500 \mathrm{E}-05$ & Ta-182 & 73182 & $1.32100 \mathrm{E}-05$ & Ta-182 & 73182 & 1.32300E-05 & Та-182 & 73182 & $1.20400 \mathrm{E}-05$ \\
\hline Hf-179 & 72179 & $1.07300 \mathrm{E}-10$ & Hf-179 & 72179 & $1.17300 \mathrm{E}-10$ & Hf-179 & 72179 & $1.31500 \mathrm{E}-10$ & Hf-179 & 72179 & $1.42400 \mathrm{E}-10$ & Hf-179 & 72179 & $1.44100 \mathrm{E}-10$ \\
\hline Hf-180 & 72180 & $1.05200 \mathrm{E}-07$ & Hf- 180 & 72180 & $1.26300 \mathrm{E}-07$ & Hf- 180 & 72180 & $1.48900 \mathrm{E}-07$ & Hf- 180 & 72180 & $1.68700 \mathrm{E}-07$ & Hf- 180 & 72180 & $1.87300 \mathrm{E}-07$ \\
\hline W-182 & 74182 & 1.35300E-04 & W-182 & 74182 & 1.36300E-04 & W-182 & 74182 & $1.39300 \mathrm{E}-04$ & W-182 & 74182 & $1.38500 \mathrm{E}-04$ & W-182 & 74182 & $1.25800 \mathrm{E}-04$ \\
\hline W-183 & 74183 & $9.48000 \mathrm{E}-04$ & W-183 & 74183 & $1.21200 \mathrm{E}-03$ & W-183 & 74183 & $1.43600 \mathrm{E}-03$ & W-183 & 74183 & $1.68300 \mathrm{E}-03$ & W-183 & 74183 & $2.15800 \mathrm{E}-03$ \\
\hline W-184 & 74184 & $2.23500 \mathrm{E}-05$ & W-184 & 74184 & 3.62800E-05 & W-184 & 74184 & $5.14100 \mathrm{E}-05$ & W-184 & 74184 & 7.08400E-05 & W-184 & 74184 & $1.14300 \mathrm{E}-04$ \\
\hline W-186 & 74186 & $5.16200 \mathrm{E}-10$ & W-186 & 74186 & 1.33000E-09 & W-186 & 74186 & 2.65500E-09 & W-186 & 74186 & 4.95900E-09 & W-186 & 74186 & $1.16900 \mathrm{E}-08$ \\
\hline Re-185 & 75185 & 4.35300E-08 & Re-185 & 75185 & 8.79600E-08 & Re-185 & 75185 & $1.47000 \mathrm{E}-07$ & Re-185 & 75185 & 2.34800E-07 & Re-185 & 75185 & $4.58300 \mathrm{E}-07$ \\
\hline \multirow[t]{2}{*}{ Re-187 } & 75187 & 4.15800E-11 & Re-187 & 75187 & $1.35700 \mathrm{E}-10$ & Re-187 & 75187 & $3.19900 \mathrm{E}-10$ & Re-187 & 75187 & $6.93500 \mathrm{E}-10$ & Re-187 & 75187 & $1.96000 \mathrm{E}-09$ \\
\hline & Total & 5.65217E-02 & & Total & 5.65207E-02 & & Total & 5.65133E-02 & & Total & 5.65133E-02 & & Total & 5.65039E-02 \\
\hline
\end{tabular}


Table 18. Material composition data at the beginning of Cycle 400 for inner control element black material zones

\begin{tabular}{|c|c|c|c|c|c|c|c|c|c|c|c|c|c|c|}
\hline \multicolumn{3}{|c|}{ m4011 } & \multicolumn{3}{|c|}{ m4012 } & \multicolumn{3}{|c|}{$\mathrm{m} 4013$} & \multicolumn{3}{|c|}{ m4014 } & \multicolumn{3}{|c|}{ m4015 } \\
\hline Nuclide & $\begin{array}{l}\text { Iden- } \\
\text { tifier }\end{array}$ & at/b-cm & Nuclide & $\begin{array}{l}\text { Iden- } \\
\text { tifier }\end{array}$ & at/b-cm & Nuclide & $\begin{array}{l}\text { Iden- } \\
\text { tifier }\end{array}$ & at/b-cm & Nuclide & $\begin{array}{l}\text { Iden- } \\
\text { tifier }\end{array}$ & at/b-cm & Nuclide & $\begin{array}{l}\text { Iden- } \\
\text { tifier }\end{array}$ & at/b-cm \\
\hline $\mathrm{Al}-27$ & 13027 & 3.94063E-02 & $\mathrm{Al}-27$ & 13027 & 3.94063E-02 & $\mathrm{Al}-27$ & 13027 & 3.94063E-02 & $\mathrm{Al}-27$ & 13027 & 3.94063E-02 & $\mathrm{Al}-27$ & 13027 & 3.94063E-02 \\
\hline O-16 & 8016 & $1.31180 \mathrm{E}-02$ & O-16 & 8016 & $1.31180 \mathrm{E}-02$ & O-16 & 8016 & $1.31180 \mathrm{E}-02$ & O-16 & 8016 & 1.31180E-02 & O-16 & 8016 & $1.31180 \mathrm{E}-02$ \\
\hline Eu-151 & 63151 & 7.43300E-04 & Eu-151 & 63151 & 3.01200E-03 & Eu-151 & 63151 & 4.05100E-03 & Eu-151 & 63151 & 4.18600E-03 & Eu-151 & 63151 & 4.20400E-03 \\
\hline Eu-152 & 63152 & 6.50100E-04 & Eu-152 & 63152 & 5.71600E-04 & Eu-152 & 63152 & $9.07200 \mathrm{E}-05$ & Eu-152 & 63152 & 1.28200E-05 & Eu-152 & 63152 & 2.21300E-06 \\
\hline Eu-153 & 63153 & 4.84800E-03 & Eu-153 & 63153 & 4.49700E-03 & Eu-153 & 63153 & 4.51600E-03 & Eu-153 & 63153 & 4.53100E-03 & Eu-153 & 63153 & 4.53400E-03 \\
\hline Eu-154 & 63154 & $7.61500 \mathrm{E}-04$ & Eu-154 & 63154 & $1.44700 \mathrm{E}-04$ & Eu-154 & 63154 & $1.65700 \mathrm{E}-05$ & Eu-154 & 63154 & $2.28400 \mathrm{E}-06$ & Eu-154 & 63154 & 4.01000E-07 \\
\hline Eu-155 & 63155 & $1.70000 \mathrm{E}-04$ & Eu-155 & 63155 & 8.66800E-06 & Eu-155 & 63155 & $1.19700 \mathrm{E}-07$ & Eu-155 & 63155 & 2.27900E-09 & Gd-152 & 64152 & $1.01300 \mathrm{E}-06$ \\
\hline Eu-156 & 63156 & $1.33400 \mathrm{E}-06$ & Eu-156 & 63156 & $1.20000 \mathrm{E}-08$ & Gd-152 & 64152 & 4.23600E-05 & Gd-152 & 64152 & $5.88500 \mathrm{E}-06$ & Gd-154 & 64154 & 7.20000E-08 \\
\hline Gd-152 & 64152 & 7.70100E-04 & Gd-152 & 64152 & 3.12800E-04 & Gd-153 & 64153 & 3.61300E-08 & Gd-153 & 64153 & 7.04900E-10 & Sm-152 & 62152 & 5.28300E-07 \\
\hline Gd-153 & 64153 & $2.70400 \mathrm{E}-05$ & Gd-153 & 64153 & $2.29100 \mathrm{E}-06$ & Gd-154 & 64154 & $2.98100 \mathrm{E}-06$ & Gd-154 & 64154 & 4.10000E-07 & & Total & 6.12665e-02 \\
\hline Gd-154 & 64154 & $1.79600 \mathrm{E}-04$ & Gd-154 & 64154 & $2.70000 \mathrm{E}-05$ & Gd-155 & 64155 & $2.54700 \mathrm{E}-08$ & Gd-155 & 64155 & $5.04100 \mathrm{E}-10$ & & & \\
\hline Gd-155 & 64155 & $1.55200 \mathrm{E}-05$ & Gd-155 & 64155 & $1.39800 \mathrm{E}-06$ & Gd-156 & 64156 & 2.91600E-09 & Sm-152 & 62152 & 3.06700E-06 & & & \\
\hline Gd-156 & 64156 & $1.95000 \mathrm{E}-04$ & Gd-156 & 64156 & $1.77500 \mathrm{E}-06$ & Sm-150 & 62150 & $2.06200 \mathrm{E}-10$ & & Total & 6.12657e-02 & & & \\
\hline Gd-157 & 64157 & 4.45500E-07 & Gd-157 & 64157 & 1.53900E-09 & Sm-152 & 62152 & $2.20300 \mathrm{E}-05$ & & & & & & \\
\hline Gd-158 & 64158 & 3.59000E-06 & Gd-158 & 64158 & $2.56600 \mathrm{E}-09$ & Sm-154 & 62154 & $5.40800 \mathrm{E}-10$ & & & & & & \\
\hline Sm-148 & 62148 & $2.08100 \mathrm{E}-10$ & Sm-149 & 62149 & $1.59300 \mathrm{E}-10$ & & Total & $6.12661 \mathrm{e}-02$ & & & & & & \\
\hline Sm-149 & 62149 & $8.08200 \mathrm{E}-10$ & Sm-150 & 62150 & $9.97200 \mathrm{E}-10$ & & & & & & & & & \\
\hline Sm-150 & 62150 & $1.05000 \mathrm{E}-08$ & Sm-151 & 62151 & $2.23900 \mathrm{E}-10$ & & & & & & & & & \\
\hline Sm-151 & 62151 & $1.55600 \mathrm{E}-09$ & Sm-152 & 62152 & $1.60200 \mathrm{E}-04$ & & & & & & & & & \\
\hline Sm-152 & 62152 & $3.54500 \mathrm{E}-04$ & Sm-154 & 62154 & 7.67900E-09 & & & & & & & & & \\
\hline \multirow[t]{2}{*}{ Sm-154 } & 62154 & 4.18600E-07 & & Total & 6.12637e-02 & & & & & & & & & \\
\hline & Total & 6.12447E-02 & & & & & & & & & & & & \\
\hline
\end{tabular}


Table 19. Material composition data at the beginning of Cycle 400 for outer control element black material zones

\begin{tabular}{|c|c|c|c|c|c|c|c|c|c|c|c|c|c|c|}
\hline \multicolumn{3}{|c|}{ m4101 } & \multicolumn{3}{|c|}{ m4102 } & \multicolumn{3}{|c|}{ m4103 } & \multicolumn{3}{|c|}{ m4104 } & \multicolumn{3}{|c|}{ m4105 } \\
\hline Nuclide & $\begin{array}{l}\text { Iden- } \\
\text { tifier }\end{array}$ & at/b-cm & Nuclide & $\begin{array}{l}\text { Iden- } \\
\text { tifier }\end{array}$ & at/b-cm & Nuclide & $\begin{array}{l}\text { Iden- } \\
\text { tifier }\end{array}$ & $\mathbf{a t} / \mathbf{b}-\mathbf{c m}$ & Nuclide & $\begin{array}{l}\text { Iden- } \\
\text { tifier }\end{array}$ & at $/ \mathbf{b}-\mathbf{c m}$ & Nuclide & $\begin{array}{l}\text { Iden- } \\
\text { tifier }\end{array}$ & $\mathbf{a t} / \mathbf{b}-\mathbf{c m}$ \\
\hline $\mathrm{Al}-27$ & 13027 & 3.78541E-02 & $\mathrm{Al}-27$ & 13027 & 3.78541E-02 & $\mathrm{Al}-27$ & 13027 & 3.78541E-02 & $\mathrm{Al}-27$ & 13027 & 3.78541E-02 & $\mathrm{Al}-27$ & 13027 & $3.78541 \mathrm{E}-02$ \\
\hline O-16 & 8016 & 1.26013E-02 & $0-16$ & 8016 & 1.26013E-02 & O-16 & 8016 & 1.26013E-02 & O-16 & 8016 & 1.26013E-02 & O-16 & 8016 & 1.26013E-02 \\
\hline Eu-151 & 63151 & 4.04200E-03 & Eu-151 & 1001 & 4.03700E-03 & Eu-151 & 1001 & 3.99800E-03 & Eu-151 & 1001 & 3.69800E-03 & Eu-151 & 1001 & $2.62400 \mathrm{E}-03$ \\
\hline Eu-152 & 63152 & 5.70200E-07 & Eu-152 & 73181 & 3.47400E-06 & Eu-152 & 73181 & 2.73300E-05 & Eu-152 & 73181 & 2.01400E-04 & Eu-152 & 73181 & $6.64800 \mathrm{E}-04$ \\
\hline Eu-153 & 63153 & 4.35500E-03 & Eu-153 & 73182 & 4.35400E-03 & Eu-153 & 73182 & 4.35000E-03 & Eu-153 & 73182 & 4.31800E-03 & Eu-153 & 73182 & 4.27700E-03 \\
\hline Eu-154 & 63154 & $1.10600 \mathrm{E}-07$ & Eu-154 & 72179 & $6.82300 \mathrm{E}-07$ & Eu-154 & 72179 & 5.19100E-06 & Eu-154 & 72179 & $4.50500 \mathrm{E}-05$ & Eu-154 & 72179 & $2.66100 \mathrm{E}-04$ \\
\hline Gd-152 & 64152 & $2.40400 \mathrm{E}-07$ & Eu-155 & 72180 & $2.04200 \mathrm{E}-10$ & Eu-155 & 72180 & $1.22200 \mathrm{E}-08$ & Eu-155 & 72180 & 8.77200E-07 & Eu-155 & 72180 & $2.49400 \mathrm{E}-05$ \\
\hline Gd-154 & 64154 & $1.02100 \mathrm{E}-08$ & Gd-152 & 74183 & $1.46600 \mathrm{E}-06$ & Gd-152 & 74183 & $1.15900 \mathrm{E}-05$ & Gd-152 & 74183 & 8.88600E-05 & Gd-152 & 74183 & 3.47200E-04 \\
\hline \multirow[t]{12}{*}{ Sm-152 } & 62152 & $1.09300 \mathrm{E}-07$ & Gd-154 & 74186 & 6.31100E-08 & Gd-153 & 74184 & $3.26200 \mathrm{E}-09$ & Gd-153 & 74184 & $2.06600 \mathrm{E}-07$ & Gd-153 & 74184 & 4.18300E-06 \\
\hline & Total & 5.88534E-02 & Sm-152 & 62152 & $6.66400 \mathrm{E}-07$ & Gd-154 & 74186 & $4.80600 \mathrm{E}-07$ & Gd-154 & 74186 & 4.20200E-06 & Gd-154 & 74186 & $2.65400 \mathrm{E}-05$ \\
\hline & & & & Total & 5.88527e-02 & Gd-155 & 75185 & $1.79600 \mathrm{E}-09$ & Gd-155 & 75185 & $1.25400 \mathrm{E}-07$ & Gd-155 & 75185 & $3.28200 \mathrm{E}-06$ \\
\hline & & & & & & Sm-152 & 62152 & 5.26400E-06 & Gd-156 & 75186 & $3.76700 \mathrm{E}-08$ & Gd-156 & 75186 & $6.11000 \mathrm{E}-06$ \\
\hline & & & & & & & Total & $5.88532 \mathrm{e}-02$ & Sm-152 & 62152 & 4.00000E-05 & Gd-157 & 75187 & $1.95200 \mathrm{E}-08$ \\
\hline & & & & & & & & & Sm-154 & 62154 & 1.12300E-09 & Gd-158 & 75188 & 4.01800E-08 \\
\hline & & & & & & & & & & Total & $5.88476 \mathrm{e}-02$ & Sm-149 & 62149 & 3.12400E-10 \\
\hline & & & & & & & & & & & & Sm-150 & 62150 & $1.29800 \mathrm{E}-09$ \\
\hline & & & & & & & & & & & & Sm-151 & 62151 & $2.21000 \mathrm{E}-10$ \\
\hline & & & & & & & & & & & & Sm-152 & 62152 & $1.48000 \mathrm{E}-04$ \\
\hline & & & & & & & & & & & & Sm-154 & 62154 & $6.52700 \mathrm{E}-08$ \\
\hline & & & & & & & & & & & & & Total & $5.88476 \mathrm{e}-02$ \\
\hline
\end{tabular}


Table 20. Atom density data for white regions of control elements

\begin{tabular}{|c|c|c|c|c|}
\hline Nuclide & $\begin{array}{c}\mathrm{m} 402 \\
\text { (at/b-cm) }\end{array}$ & $\begin{array}{c}\mathrm{m} 403 \\
\text { (at/b-cm) }\end{array}$ & $\begin{array}{c}\mathrm{m} 412 \\
\text { (at/b-cm) }\end{array}$ & $\begin{array}{c}\mathrm{m} 413 \\
\text { (at/b-cm) }\end{array}$ \\
\hline Mg-24 & 5.03512E-04 & 5.08497E-04 & 5.08497E-04 & $5.03512 \mathrm{E}-04$ \\
\hline Mg-25 & 6.37438E-05 & 6.43749E-05 & 6.43749E-05 & 6.37438E-05 \\
\hline Mg-26 & 7.01819E-05 & 7.08768E-05 & 7.08768E-05 & 7.01819E-05 \\
\hline $\mathrm{Al}-27$ & 5.58731E-02 & 5.64263E-02 & 5.64263E-02 & 5.58731E-02 \\
\hline $\mathrm{Si}-28$ & 3.05241E-04 & 3.08263E-04 & 3.08263E-04 & 3.05241E-04 \\
\hline $\mathrm{Si}-29$ & $1.55065 \mathrm{E}-05$ & $1.56600 \mathrm{E}-05$ & $1.56600 \mathrm{E}-05$ & $1.55065 \mathrm{E}-05$ \\
\hline Si-30 & $1.02339 \mathrm{E}-05$ & 1.03353E-05 & 1.03353E-05 & $1.02339 \mathrm{E}-05$ \\
\hline Ti-46 & $2.00270 \mathrm{E}-06$ & 2.02253E-06 & 2.02253E-06 & 2.00270E-06 \\
\hline Ti-47 & 1.80607E-06 & 1.82395E-06 & 1.82395E-06 & 1.80607E-06 \\
\hline Ti-48 & $1.78956 \mathrm{E}-05$ & $1.80728 \mathrm{E}-05$ & $1.80728 \mathrm{E}-05$ & 1.78956E-05 \\
\hline Ti-49 & $1.31329 \mathrm{E}-06$ & $1.32629 \mathrm{E}-06$ & $1.32629 \mathrm{E}-06$ & 1.31329E-06 \\
\hline Ti-50 & $1.25745 \mathrm{E}-06$ & $1.26990 \mathrm{E}-06$ & $1.26990 \mathrm{E}-06$ & $1.25745 \mathrm{E}-06$ \\
\hline Cr-50 & 2.52457E-06 & 2.54957E-06 & 2.54957E-06 & 2.52457E-06 \\
\hline Cr-52 & 4.86839E-05 & 4.91659E-05 & 4.91659E-05 & 4.86839E-05 \\
\hline Cr-53 & 5.52036E-06 & 5.57502E-06 & 5.57502E-06 & 5.52036E-06 \\
\hline Cr-54 & 1.37413E-06 & $1.38774 \mathrm{E}-06$ & 1.38774E-06 & 1.37413E-06 \\
\hline Mn-55 & 2.11506E-05 & $2.13600 \mathrm{E}-05$ & $2.13600 \mathrm{E}-05$ & 2.11506E-05 \\
\hline $\mathrm{Fe}-54$ & 5.67547E-06 & 5.73166E-06 & 5.73166E-06 & 5.67547E-06 \\
\hline Fe-56 & 8.90927E-05 & 8.99748E-05 & 8.99748E-05 & 8.90927E-05 \\
\hline Fe-57 & 2.05754E-06 & 2.07791E-06 & 2.07791E-06 & 2.05754E-06 \\
\hline Fe-58 & $2.73821 \mathrm{E}-07$ & 2.76532E-07 & 2.76532E-07 & $2.73821 \mathrm{E}-07$ \\
\hline $\mathrm{Cu}-63$ & $6.74370 \mathrm{E}-05$ & 6.81047E-05 & 6.81047E-05 & $6.74370 \mathrm{E}-05$ \\
\hline $\mathrm{Cu}-65$ & 3.00858E-05 & 3.03836E-05 & 3.03836E-05 & 3.00858E-05 \\
\hline $\mathrm{H}-1$ & 3.10571E-03 & $2.47056 \mathrm{E}-03$ & 2.49687E-03 & 3.10571E-03 \\
\hline O-16 & $1.55285 \mathrm{E}-03$ & $1.23528 \mathrm{E}-03$ & $1.24843 \mathrm{E}-03$ & 1.55285E-03 \\
\hline Total & 6.17983E-02 & 6.14113E-02 & 6.14507E-02 & 6.17983E-02 \\
\hline
\end{tabular}

\subsubsection{Materials for Reflector Regions}

Material composition data for the RB were updated for consistency with the composition of the beryllium material as obtained from material test reports. Materials used for regions in the RB are identified as $\mathrm{m} 101, \mathrm{~m} 102$, and $\mathrm{m} 103$. The RB was fresh at BOC-400 and was identified as RB 13 . The fabrication file HFIR-ME-FF-254 indicates that the raw material for this reflector was taken from two different purchase orders. Most of the beryllium material for RB 13 comes from the first of these two purchase orders, which indicates that the material was specified per HFIR-JS-32 [42]. The certified material test reports from OP-RO-JN-5-1-76 [44], which makes up the vast majority of RB 13, are available. The remaining beryllium material for RB 13, which comes from the second purchase order, was purchased under RRD-MS-32, rev.0 [45] on the same purchase requisition as the raw material for PB 4, which was present in the reactor during Cycle 400.

The material composition used for the RB in the revised model, listed in Table 21, was determined based on the specifications in test reports from OP-RO-JN-5-1-76 [44]. The density used was $1.851 \mathrm{~g} / \mathrm{cm}^{3}$ [44]. The total for the material components as available was slightly larger than $100 \%$. 
However, the data were used as provided, with no adjustment, as it would constitute a conservative estimation.

Table 21. Atom density data for removable beryllium reflector 13

\begin{tabular}{|c|c|c|c|c|c|}
\hline Element & Weight \% & Isotope & Isotope mole fraction ${ }^{a}$ & $\begin{array}{l}\text { Isotope identifier in } \\
\text { MCNP model }\end{array}$ & $\begin{array}{l}\text { Atom density } \\
\text { (at/b-cm) }\end{array}$ \\
\hline $\mathrm{Be}$ & 98.99 & Be-9 & 1.0000 & 4009 & $1.22439 \mathrm{E}-01$ \\
\hline $\mathrm{O}$ & 1.22 & O-16 & 1.0000 & 8016 & 8.49989E-04 \\
\hline \multirow[t]{4}{*}{$\mathrm{Fe}$} & 0.159 & $\mathrm{Fe}-54$ & 0.0585 & 26054 & $1.85504 \mathrm{E}-06$ \\
\hline & & $\mathrm{Fe}-56$ & 0.9175 & 26056 & 2.91202E-05 \\
\hline & & Fe-57 & 0.0212 & 26057 & 6.72512E-07 \\
\hline & & Fe-58 & 0.0028 & 26058 & 8.94990E-08 \\
\hline $\mathrm{C}$ & 0.091 & $\mathrm{C}-12$ & 1.0000 & 6012 & $8.44560 \mathrm{E}-05$ \\
\hline \multirow[t]{3}{*}{$\mathrm{Si}$} & 0.0423 & $\mathrm{Si}-28$ & 0.9222 & 14028 & $1.54830 \mathrm{E}-05$ \\
\hline & & $\mathrm{Si}-29$ & 0.0469 & 14029 & 7.86548E-07 \\
\hline & & Si-30 & 0.0309 & 14030 & 5.19105E-07 \\
\hline $\mathrm{Al}$ & 0.0346 & $\mathrm{Al}-27$ & 1.0000 & 13027 & $1.42944 \mathrm{E}-05$ \\
\hline \multirow[t]{5}{*}{$\mathrm{Ni}$} & 0.026 & $\mathrm{Ni}-58$ & 0.6808 & 28058 & 3.36157E-06 \\
\hline & & $\mathrm{Ni}-60$ & 0.2622 & 28060 & $1.29487 \mathrm{E}-06$ \\
\hline & & $\mathrm{Ni}-61$ & 0.0114 & 28061 & $5.62871 \mathrm{E}-08$ \\
\hline & & $\mathrm{Ni}-62$ & 0.0363 & 28062 & 1.79468E-07 \\
\hline & & $\mathrm{Ni}-64$ & 0.0093 & 28064 & 4.57054E-08 \\
\hline \multirow[t]{2}{*}{$\mathrm{N}$} & 0.024 & $\mathrm{~N}-14$ & 0.9964 & 7014 & $1.90304 \mathrm{E}-05$ \\
\hline & & $\mathrm{N}-15$ & 0.0036 & 7015 & 6.95239E-08 \\
\hline \multirow[t]{2}{*}{$\mathrm{Br}$} & 0.0127 & $\mathrm{Br}-79$ & 0.5069 & 35079 & 8.98085E-07 \\
\hline & & $\mathrm{Br}-81$ & 0.4931 & 35081 & 8.73635E-07 \\
\hline \multirow[t]{5}{*}{$\mathrm{Ti}$} & 0.0091 & Ti-46 & 0.0825 & 22046 & $1.74831 \mathrm{E}-07$ \\
\hline & & Ti-47 & 0.0744 & 22047 & 1.57666E-07 \\
\hline & & Ti-48 & 0.7372 & 22048 & $1.56225 \mathrm{E}-06$ \\
\hline & & Ti-49 & 0.0541 & 22049 & $1.14647 \mathrm{E}-07$ \\
\hline & & Ti-50 & 0.0518 & 22050 & 1.09773E-07 \\
\hline \multirow[t]{4}{*}{$\mathrm{Cr}$} & 0.009 & Cr-50 & 0.0435 & 24050 & 8.38337E-08 \\
\hline & & Cr-52 & 0.8379 & 24052 & 1.61665E-06 \\
\hline & & Cr-53 & 0.0950 & 24053 & $1.83315 \mathrm{E}-07$ \\
\hline & & Cr-54 & 0.0237 & 24054 & 4.56310E-08 \\
\hline \multirow[t]{2}{*}{$\mathrm{Cu}$} & 0.008 & $\mathrm{Cu}-63$ & 0.6915 & 29063 & $9.70401 \mathrm{E}-07$ \\
\hline & & $\mathrm{Cu}-65$ & 0.3085 & 29065 & 4.32926E-07 \\
\hline $\mathrm{Mn}$ & 0.0065 & Mn-55 & 1.0000 & 25055 & 1.31886E-06 \\
\hline \multirow[t]{3}{*}{$\mathrm{Mg}$} & 0.0061 & Mg-24 & 0.7899 & 12024 & 2.20985E-06 \\
\hline & & Mg-25 & 0.1000 & 12025 & 2.79763E-07 \\
\hline & & Mg-26 & 0.1101 & 12026 & 3.08019E-07 \\
\hline \multirow[t]{3}{*}{$\mathrm{U}$} & 0.0053 & U-234 & 0.0001 & 92234 & $1.34029 \mathrm{E}-11$ \\
\hline & & U-235 & 0.0072 & 92235 & $1.78804 \mathrm{E}-09$ \\
\hline & & U-238 & 0.9927 & 92238 & $2.46400 \mathrm{E}-07$ \\
\hline
\end{tabular}


Table 21, (continued)

\begin{tabular}{cccccc}
\hline Element & Weight $\%$ & Isotope & Isotope mole fraction $^{a}$ & $\begin{array}{c}\text { Isotope identifier in } \\
\text { MCNP model }\end{array}$ & $\begin{array}{c}\text { Atom density } \\
\text { (at/b-cm) }\end{array}$ \\
\hline H & 0.0042 & H-1 & 1.0000 & 1001 & $4.64485 \mathrm{E}-05$ \\
F & 0.004 & F-19 & 1.0000 & 9019 & $2.34693 \mathrm{E}-06$ \\
Co & 0.0004 & Co-59 & 1.0000 & 27059 & $7.56584 \mathrm{E}-08$ \\
B & 0.0003 & B-10 & 0.1990 & 5010 & $6.15552 \mathrm{E}-08$ \\
& & B-11 & 0.8010 & 5011 & $2.47767 \mathrm{E}-07$ \\
Sc & 0.00012 & Sc-45 & 1.0000 & 21045 & $2.97544 \mathrm{E}-08$ \\
Li & 0.00005 & Li-6 & 0.0759 & 3006 & $6.09547 \mathrm{E}-09$ \\
& & Li-7 & 0.9241 & 3007 & $7.42138 \mathrm{E}-08$ \\
Total & 100.653 & & & & $\mathbf{1 . 2 3 5 2 1 E - 0 1}$ \\
\hline
\end{tabular}

${ }^{a}$ As provided in [29].

During Cycle 400, PB 4 was in-service. For PB 4, the fabrication file HFIR-ME-FF-313 indicates that the raw material was purchased under RRD-MS-32, rev.0 [45]. The actual certified material test report for the raw beryllium material for this reflector was identified [46]. The corresponding material composition data are listed in Table 22; the component weight percents do not total $100 \%$, but $99.71 \%$.

Table 22. Material composition data for permanent beryllium reflector model

\begin{tabular}{cr}
\hline Element & Weight \% \\
\hline $\mathrm{Be}$ & 99.11 \\
$\mathrm{O}$ & 0.58 \\
$\mathrm{C}$ & 0.11 \\
$\mathrm{Mg}$ & 0.03 \\
$\mathrm{Al}$ & 0.04 \\
$\mathrm{Si}$ & 0.03 \\
$\mathrm{Fe}$ & 0.10 \\
Total & 100.00 \\
\hline
\end{tabular}

The material composition data for the semipermanent and permanent reflectors were updated based on available data [31, 46] to include $98 \mathrm{vol} \%$ beryllium and 2 vol \% water [31]. It was assumed that the density of the water is $0.98840 \mathrm{~g} / \mathrm{cm}^{3}$ and corresponds to a temperature and pressure of $126^{\circ} \mathrm{F}$ and $478.2 \mathrm{psi}$ [47]. The trace quantities of ${ }^{3} \mathrm{He}$ and ${ }^{6} \mathrm{Li}$ in beryllium were updated from the values used in the previous model [3] to specific values estimated as existing in the reflector at the beginning of Cycle 400. These values were estimated based on a new method described in [48]. The updated values for the SPB and PB material are listed in Table 23. 
Table 23. Atom density data (in at/b-cm) for semipermanent and permanent beryllium reflectors in the MCNP model

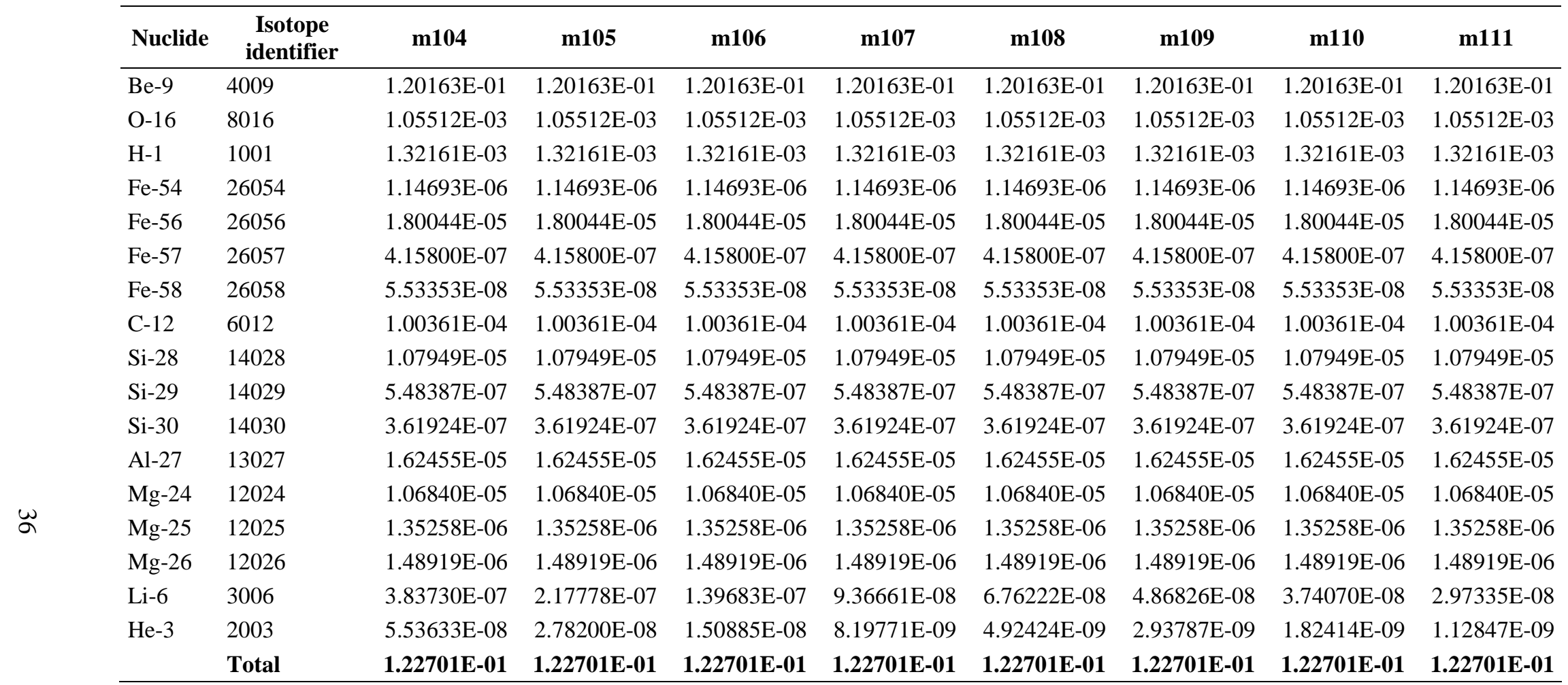




\subsubsection{Materials for Biological Shield}

The biological shield consists of both barite and ordinary concrete (HFIR drawing 1546-01-M-5022). The volume fractions of ordinary and barite concrete in the shield are considered to be 0.75 and 0.25 , respectively. According to specifications in [49] and [50], the minimum densities for the ordinary and barite concrete for HFIR are 140 and $210 \mathrm{lb} / \mathrm{ft}^{3}$, respectively, which correspond to 2.24 and $3.36 \mathrm{~g} / \mathrm{cm}^{3}$, respectively. Material composition data for the two types of concrete used in the model were taken from American Nuclear Society standard 6.4 [51]. The material densities for the two types of concrete, ordinary and barite, are 2.35 and $3.35 \mathrm{~g} / \mathrm{cm}^{3}$, which are reasonably consistent with the minimum densities in [49] and [50]. The resulting density for the concrete shielding used in the model is $2.60 \mathrm{~g} / \mathrm{cm}^{3}$. The material identifier for the biological shield is m62. The composition data for this material are listed in Table 24.

Table 24. Atom densities for material m62 (concrete biological shield)

\begin{tabular}{cccccc}
\hline Element & $\begin{array}{c}\text { Density } \\
\text { (g/cc) }\end{array}$ & Isotope & $\begin{array}{c}\text { Isotope mole } \\
\text { fraction }\end{array}$ & $\begin{array}{c}\text { Isotope } \\
\text { identifier in } \\
\text { MCNP model }\end{array}$ & $\begin{array}{c}\text { Atom density } \\
\text { (at/b-cm) }\end{array}$ \\
\hline $\mathrm{H}$ & 0.013 & $\mathrm{Be}-9$ & 1.0000 & 1001 & $8.51983 \mathrm{E}-04$ \\
$\mathrm{O}$ & 1.139 & $\mathrm{O}-16$ & 1.0000 & 8016 & $4.28717 \mathrm{E}-02$ \\
$\mathrm{Si}$ & 0.565 & $\mathrm{Si}-28$ & 0.9222 & 14028 & $1.11776 \mathrm{E}-02$ \\
& & $\mathrm{Si}-29$ & 0.0469 & 14029 & $5.67831 \mathrm{E}-04$ \\
& & $\mathrm{Si}-30$ & 0.0309 & 14030 & $3.74756 \mathrm{E}-04$ \\
$\mathrm{Ca}$ & 0.188 & $\mathrm{Ca}-40$ & 0.9694 & 20040 & $2.73120 \mathrm{E}-03$ \\
& & $\mathrm{Ca}-42$ & 0.0065 & 20042 & $1.82285 \mathrm{E}-05$ \\
& & $\mathrm{Ca}-43$ & 0.0014 & 20043 & $3.80347 \mathrm{E}-06$ \\
& & $\mathrm{Ca}-44$ & 0.0209 & 20044 & $5.87706 \mathrm{E}-05$ \\
& & $\mathrm{Ca}-46$ & 0.0000 & 20046 & $1.12695 \mathrm{E}-07$ \\
& & $\mathrm{Ca}-48$ & 0.0019 & 20048 & $5.26851 \mathrm{E}-06$ \\
$\mathrm{Na}$ & 0.030 & $\mathrm{Na}-23$ & 1.0000 & 11023 & $7.85846 \mathrm{E}-04$ \\
$\mathrm{Mg}$ & 0.006 & $\mathrm{Mg}-24$ & 0.7899 & 12024 & $1.07644 \mathrm{E}-04$ \\
& & $\mathrm{Mg}-25$ & 0.1000 & 12025 & $1.36275 \mathrm{E}-05$ \\
& & $\mathrm{Mg}-26$ & 0.1101 & 12026 & $1.50039 \mathrm{E}-05$ \\
$\mathrm{Al}$ & 0.084 & $\mathrm{Al}-27$ & 1.0000 & 13027 & $1.86926 \mathrm{E}-03$ \\
$\mathrm{~S}$ & 0.093 & $\mathrm{~S}-32$ & 0.9499 & 16032 & $1.65022 \mathrm{E}-03$ \\
& & $\mathrm{~S}-33$ & 0.0075 & 16033 & $1.30294 \mathrm{E}-05$ \\
& & $\mathrm{~S}-34$ & 0.0425 & 16034 & $7.38335 \mathrm{E}-05$ \\
& & $\mathrm{~S}-36$ & 0.0001 & 16036 & $1.73726 \mathrm{E}-07$ \\
$\mathrm{~K}$ & 0.034 & $\mathrm{~K}-39$ & 0.9326 & 19039 & $4.84790 \mathrm{E}-04$ \\
& & $\mathrm{~K}-40$ & 0.0001 & 19040 & $6.08209 \mathrm{E}-08$ \\
& & $\mathrm{~K}-41$ & 0.0673 & 19041 & $3.49860 \mathrm{E}-05$ \\
\hline
\end{tabular}


Table 24. (continued)

\begin{tabular}{cccccc}
\hline Element & $\begin{array}{c}\text { Density } \\
\text { (g/cc) }\end{array}$ & Isotope & $\begin{array}{c}\text { Isotope mole } \\
\text { fraction }\end{array}$ & $\begin{array}{c}\text { Isotope } \\
\text { identifier in } \\
\text { MCNP model }\end{array}$ & $\begin{array}{c}\text { Atom density } \\
\text { (at/b-cm) }\end{array}$ \\
\hline $\mathrm{Fe}$ & 0.062 & $\mathrm{Fe}-54$ & 0.0585 & 26054 & $3.87637 \mathrm{E}-05$ \\
& & $\mathrm{Fe}-56$ & 0.9175 & 26056 & $6.08507 \mathrm{E}-04$ \\
& & $\mathrm{Fe}-57$ & 0.0212 & 26057 & $1.40531 \mathrm{E}-05$ \\
& & $\mathrm{Fe}-58$ & 0.0028 & 26058 & $1.87021 \mathrm{E}-06$ \\
$\mathrm{Ba}$ & 0.388 & $\mathrm{Ba}-130$ & 0.0011 & 56130 & $1.80241 \mathrm{E}-06$ \\
& & $\mathrm{Ba}-132$ & 0.0010 & 56132 & $1.71739 \mathrm{E}-06$ \\
& & $\mathrm{Ba}-134$ & 0.0242 & 56134 & $4.10983 \mathrm{E}-05$ \\
& & $\mathrm{Ba}-135$ & 0.0659 & 56135 & $1.12089 \mathrm{E}-04$ \\
& & $\mathrm{Ba}-136$ & 0.0785 & 56136 & $1.33548 \mathrm{E}-04$ \\
& & $\mathrm{Ba}-137$ & 0.1123 & 56137 & $1.90987 \mathrm{E}-04$ \\
& & $\mathrm{Ba}-138$ & 0.7170 & 56138 & $1.21914 \mathrm{E}-03$ \\
Total & $\mathbf{2 . 6 0}$ & & & & $\mathbf{6 . 6 0 7 3 3 E - 0 2}$ \\
\hline
\end{tabular}




\section{DESCRIPTION OF MCNP MODELS}

\subsection{OVERVIEW OF MCNP MODELS}

Each of the two MCNP models presented in this report is a 3-D representation of the reactor. The only difference between the models is the approach used for modeling the fuel elements; with the exception of the fuel elements model, all other aspects of the models are the same. Each model explicitly represents the experiment locations in the central target region and the beryllium reflectors and includes out-of-core components such as irradiation facilities, HB tubes, EF tubes, and the reactor shielding and biological protection. The model extends to an outer radius of $7.2 \mathrm{~m}$ and a total height of $3.0 \mathrm{~m}$. Starting from the reactor centerline, it includes the following main concentric, annular regions: flux trap target region, fuel region, control region, RB region, SPB region, and PB region. The radial layout of the model is illustrated in Figs. 16 and 17, which present a cross section at the core midplane, with various regions and materials shown in different colors. Figure 16 illustrates the extent of the model, whereas Fig. 17 provides a zoomed in cross section of the model out to the edge of the pressure vessel.

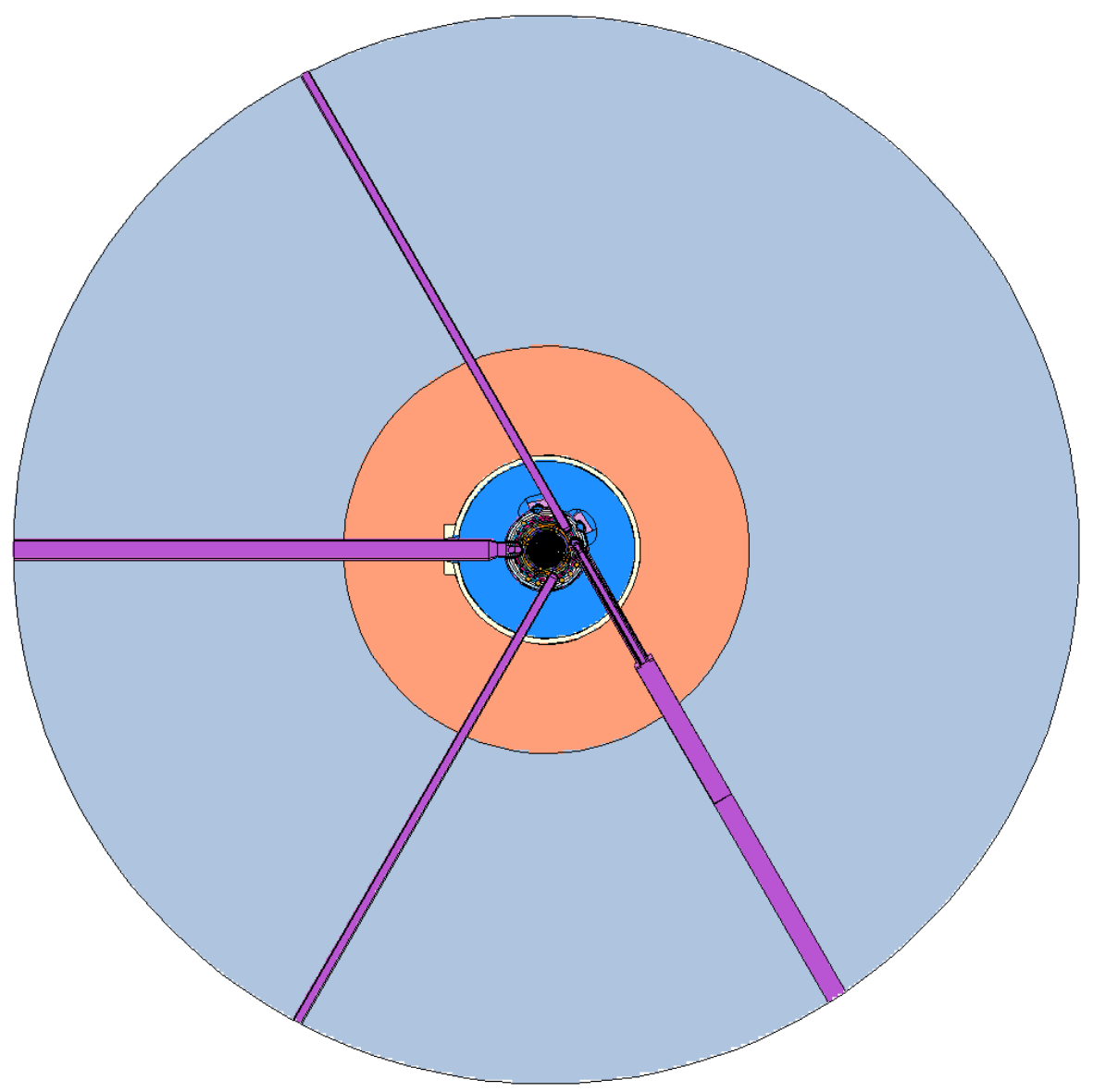

Fig. 16. Extent of the HFIR MCNP model ( $x-y$ view at midplane). 


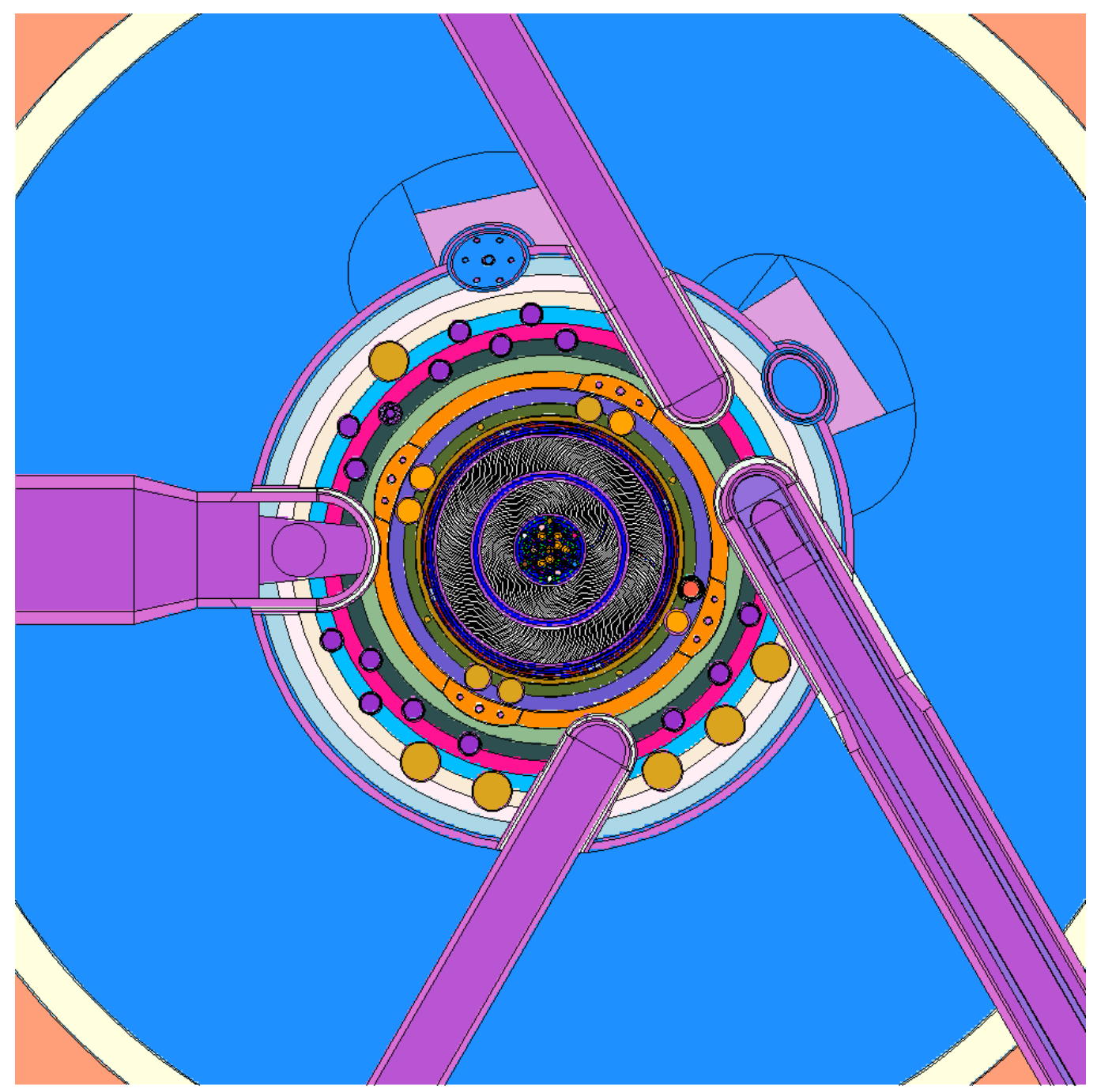

Fig. 17. Illustration of the HFIR MCNP model to the edge of the pressure vessel ( $x-y$ view at midplane).

\subsection{SIMPLIFIED MCNP MODEL}

In the simplified model, the fuel elements are modeled by homogenizing the fuel meat, filler, and cladding of the fuel plates and the water coolant between the fuel plates. This method of homogenizing the fuel plates and coolant channels was considered adequate because (1) the plates and channels are very thin and (2) only a small quantity of ${ }^{238} \mathrm{U}$ is present in the HEU fuel, so the self-shielding associated with this nuclide would be less significant than for an LEU fuel. Validation studies performed for HFIR have verified the adequacy of this assumption $[6,7,9]$. To approximate the variation of the ${ }^{235} \mathrm{U}$ content in the radial direction of the fuel plate (i.e., radial fuel contouring), a number of radial regions with different ${ }^{235} \mathrm{U}$ concentrations are defined in the IFE and OFE, as illustrated in Fig. 18. This simplified approach for representation of the fuel elements is similar to the one previously used [3]. 

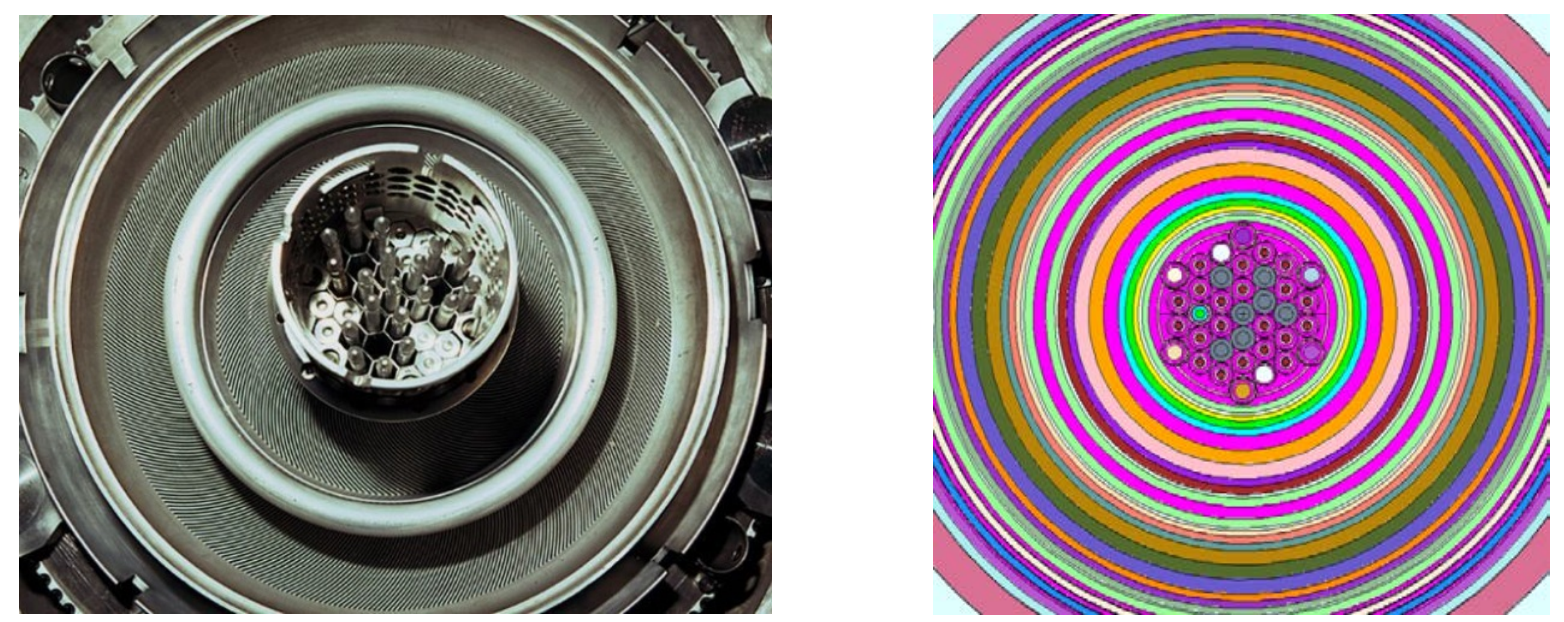

Fig. 18. Modeling of the fuel elements in the simplified MCNP fuel model. Top view of fuel elements (left) and $x-y$ view of the MCNP model at core midplane (right).

\subsubsection{Geometry Data for Homogenized Fuel Plates}

The geometry data for the innermost and outermost radii of the fuel region in each of the two fuel elements were updated for consistency with the actual fuel contouring data, as discussed in Section 5.1.1 of this report. The numbers of radial regions in the revised model were changed with respect to the previous model [3] to accommodate the updates of the innermost and outermost radii and to refine the radial mesh, especially toward the radial edges of the fuel elements where large flux gradients are expected. There are 11 radial regions each in the IFE and OFE, compared to 8 and 9, respectively, in the 2005 model [3], as illustrated in Fig. 6. The radii for the radial regions in the IFE and OFE are listed in Tables 25 and 26. The number of axial regions has been increased from 7 in the previous model to 19 in the current, revised model (Table 27). The axial mesh has been refined for locations close to the axial ends of the active fuel active region to accurately capture the axial peaking where larger flux gradients are expected (see Fig. 7).

Table 25. Radii of the inner fuel element fuel regions in the simplified model

\begin{tabular}{cccc}
\hline Region & $\mathbf{R}_{\mathbf{i}}(\mathbf{c m})^{\boldsymbol{a}}$ & $\mathbf{R}_{\mathbf{0}} \mathbf{( c m )}$ & $\boldsymbol{\Delta \mathbf { R } ( \mathbf { c m } )}$ \\
\hline 1 & 7.119504 & $7.2-$ & 0.08054 \\
2 & 7.20 & 7.35 & 0.15 \\
3 & 7.35 & 7.50 & 0.15 \\
4 & 7.50 & 8.00 & 0.50 \\
5 & 8.00 & 8.50 & 0.50 \\
6 & 8.50 & 9.50 & 1.00 \\
7 & 9.50 & 10.50 & 1.00 \\
8 & 10.50 & 11.50 & 1.00 \\
9 & 11.50 & 12.00 & 0.50 \\
10 & 12.00 & 12.40 & 0.40 \\
11 & 12.40 & 12.532386 & 0.132386 \\
\hline
\end{tabular}

${ }^{a} \mathrm{R}_{\mathrm{i}}$ and $\mathrm{R}_{\mathrm{o}}$ are inner and outer radii; $\Delta \mathrm{R}=\mathrm{R}_{\mathrm{o}}-\mathrm{R}_{\mathrm{i}}$. 
Table 26. Radii of the outer fuel element fuel regions in the simplified model

\begin{tabular}{cccc}
\hline Region & $\mathbf{R}_{\mathbf{i}}(\mathbf{c m})^{\boldsymbol{a}}$ & $\mathbf{R}_{\mathbf{0}} \mathbf{( c m )}$ & $\boldsymbol{\Delta} \mathbf{R} \mathbf{( c m )}$ \\
\hline 1 & 15.115859 & 15.30 & 0.184141 \\
2 & 15.30 & 15.50 & 0.20 \\
3 & 15.50 & 16.00 & 0.50 \\
4 & 16.00 & 16.50 & 0.50 \\
5 & 16.50 & 17.50 & 1.00 \\
6 & 17.50 & 18.50 & 1.00 \\
7 & 18.50 & 19.50 & 1.00 \\
8 & 19.50 & 20.00 & 0.50 \\
9 & 20.00 & 20.50 & 0.50 \\
10 & 20.50 & 20.75 & 0.25 \\
11 & 20.75 & 20.870728 & 0.120728 \\
\hline
\end{tabular}

${ }^{a} \mathrm{R}_{\mathrm{i}}$ and $\mathrm{R}_{\mathrm{o}}$ are inner and outer radii; $\Delta \mathrm{R}=\mathrm{R}_{\mathrm{o}}-\mathrm{R}_{\mathrm{i}}$.

Table 27. Axial mesh for fuel regions in the HFIR model

\begin{tabular}{cccc}
\hline Region & Upper $^{a} \mathbf{Z}(\mathbf{c m})$ & Lower $\mathbf{Z}(\mathbf{c m})$ & $\boldsymbol{\Delta Z} \mathbf{( c m})$ \\
\hline 1 & 25.40 & 24.90 & 0.50 \\
2 & 24.90 & 24.40 & 0.50 \\
3 & 24.40 & 23.40 & 1.00 \\
4 & 23.40 & 22.40 & 1.00 \\
5 & 22.40 & 21.00 & 1.40 \\
6 & 21.00 & 16.00 & 5.00 \\
7 & 16.00 & 11.00 & 5.00 \\
8 & 11.00 & 6.00 & 5.00 \\
9 & 6.00 & 1.00 & 5.00 \\
10 & 1.00 & -1.00 & 2.00 \\
11 & -1.00 & -6.00 & 5.00 \\
12 & -6.00 & -11.00 & 5.00 \\
13 & -11.00 & -16.00 & 5.00 \\
14 & -16.00 & -21.00 & 5.00 \\
15 & -21.00 & -22.40 & 1.40 \\
16 & -22.40 & -23.40 & 1.00 \\
17 & -23.40 & -24.40 & 1.00 \\
18 & -24.40 & -24.90 & 0.50 \\
19 & -24.90 & -25.40 & 0.50 \\
\hline${ }^{a}$ Location is with respect to the core midplane (at axial location $\left.0.0 \mathrm{~cm}\right)$.
\end{tabular}

\subsubsection{Material Data for Homogenized Fuel Plates}

Material composition data for the homogenized fuel regions in the simplified model were updated for consistency with updated material specifications for water, fuel meat, filler, and cladding, discussed in Section 5. The number of radial and axial regions used in each of the two fuel elements is 11 and 19, respectively. The volume for fuel meat, filler, and cladding in each of the homogenized zones was estimated based on the intersections of the delimiting radii of these zones with the surfaces defining the fuel meat, filler, and clad within the involute fuel plates.

The IFE and OFE each have 209 spatial meshes for a total of 418. One material is defined for each spatial mesh; the spatial mesh and the material mesh are identical in this case. Materials within the same 
radial zone have the same composition at BOC because the fuel meat profile is uniform axially for a given radius. The compositions for each of the radial zones in the IFE and OFE are presented in Tables 28 and 29. 
Table 28. Isotopic composition for homogenized inner fuel element plate radial regions

\begin{tabular}{|c|c|c|c|c|c|c|c|c|c|c|c|}
\hline $\begin{array}{c}\text { Nuclide } \\
\text { identifier }\end{array}$ & $\begin{array}{l}\text { Region } 1 \\
\text { (at/b-cm) }\end{array}$ & $\begin{array}{l}\text { Region } 2 \\
\text { (at/b-cm) }\end{array}$ & $\begin{array}{l}\text { Region } 3 \\
\text { (at/b-cm) }\end{array}$ & $\begin{array}{l}\text { Region } 4 \\
\text { (at/b-cm) }\end{array}$ & $\begin{array}{l}\text { Region } 5 \\
\text { (at/b-cm) }\end{array}$ & $\begin{array}{l}\text { Region } 6 \\
(\mathbf{a t} / \mathbf{b}-\mathrm{cm}) \\
\end{array}$ & $\begin{array}{l}\text { Region } 7 \\
\text { (at/b-cm) }\end{array}$ & $\begin{array}{l}\text { Region } 8 \\
(\text { at/b-cm) } \\
\end{array}$ & $\begin{array}{l}\text { Region } 9 \\
(\mathbf{a t} / \mathbf{b}-\mathrm{cm}) \\
\end{array}$ & $\begin{array}{l}\text { Region } 10 \\
\text { (at/b-cm) }\end{array}$ & $\begin{array}{l}\text { Region } 11 \\
\text { (at/b-cm) }\end{array}$ \\
\hline 1001 & 3.29272E-02 & 3.29272E-02 & $3.29272 \mathrm{E}-02$ & 3.29272E-02 & $3.29272 \mathrm{E}-02$ & 3.29272E-02 & 3.29272E-02 & 3.29272E-02 & 3.29272E-02 & 3.29272E-02 & $3.29272 \mathrm{E}-02$ \\
\hline 3006 & 7.05366E-09 & 6.81668E-09 & $6.50461 \mathrm{E}-09$ & 5.82627E-09 & 4.80732E-09 & 3.39603E-09 & 2.07977E-09 & 2.00099E-09 & 2.72543E-09 & 3.44540E-09 & 3.94264E-09 \\
\hline 3007 & $8.58800 \mathrm{E}-08$ & 8.29947E-08 & 7.91952E-08 & 7.09362E-08 & 5.85303E-08 & 4.13475E-08 & $2.53216 \mathrm{E}-08$ & 2.43625E-08 & 3.31828E-08 & 4.19485E-08 & 4.80025E-08 \\
\hline 5010 & 2.07095E-05 & 2.00137E-05 & $1.90974 \mathrm{E}-05$ & $1.71058 \mathrm{E}-05$ & $1.41142 \mathrm{E}-05$ & $9.97070 \mathrm{E}-06$ & 6.10617E-06 & 5.87486E-06 & 8.00183E-06 & $1.01156 \mathrm{E}-05$ & $1.15755 \mathrm{E}-05$ \\
\hline 5011 & 8.29767E-05 & 8.01889E-05 & 7.65179E-05 & $6.85381 \mathrm{E}-05$ & $5.65516 \mathrm{E}-05$ & 3.99497E-05 & 2.44656E-05 & $2.35388 \mathrm{E}-05$ & 3.20610E-05 & 4.05304E-05 & 4.63797E-05 \\
\hline 6012 & $2.58864 \mathrm{E}-05$ & $2.50167 \mathrm{E}-05$ & $2.38714 \mathrm{E}-05$ & 2.13819E-05 & $1.76425 \mathrm{E}-05$ & $1.24632 \mathrm{E}-05$ & 7.63258E-06 & 7.34346E-06 & $1.00021 \mathrm{E}-05$ & $1.26443 \mathrm{E}-05$ & $1.44692 \mathrm{E}-05$ \\
\hline 8016 & $1.70266 \mathrm{E}-02$ & $1.70619 \mathrm{E}-02$ & $1.71085 \mathrm{E}-02$ & $1.72097 \mathrm{E}-02$ & $1.73617 \mathrm{E}-02$ & $1.75722 \mathrm{E}-02$ & $1.77685 \mathrm{E}-02$ & 1.77803E-02 & $1.76722 \mathrm{E}-02$ & $1.75648 \mathrm{E}-02$ & $1.74906 \mathrm{E}-02$ \\
\hline 12024 & $1.03705 \mathrm{E}-04$ & $1.03705 \mathrm{E}-04$ & $1.03705 \mathrm{E}-04$ & $1.03705 \mathrm{E}-04$ & $1.03705 \mathrm{E}-04$ & $1.03705 \mathrm{E}-04$ & $1.03705 \mathrm{E}-04$ & $1.03705 \mathrm{E}-04$ & $1.03705 \mathrm{E}-04$ & $1.03705 \mathrm{E}-04$ & $1.03705 \mathrm{E}-04$ \\
\hline 12025 & $1.31289 \mathrm{E}-05$ & $1.31289 \mathrm{E}-05$ & $1.31289 \mathrm{E}-05$ & $1.31289 \mathrm{E}-05$ & $1.31289 \mathrm{E}-05$ & $1.31289 \mathrm{E}-05$ & $1.31289 \mathrm{E}-05$ & $1.31289 \mathrm{E}-05$ & $1.31289 \mathrm{E}-05$ & $1.31289 \mathrm{E}-05$ & $1.31289 \mathrm{E}-05$ \\
\hline 12026 & $1.44550 \mathrm{E}-05$ & $1.44550 \mathrm{E}-05$ & $1.44550 \mathrm{E}-05$ & $1.44550 \mathrm{E}-05$ & $1.44550 \mathrm{E}-05$ & $1.44550 \mathrm{E}-05$ & $1.44550 \mathrm{E}-05$ & $1.44550 \mathrm{E}-05$ & $1.44550 \mathrm{E}-05$ & $1.44550 \mathrm{E}-05$ & $1.44550 \mathrm{E}-05$ \\
\hline 13027 & 2.88583E-02 & 2.88025E-02 & $2.87290 \mathrm{E}-02$ & $2.85691 \mathrm{E}-02$ & 2.83291E-02 & 2.79965E-02 & $2.76864 \mathrm{E}-02$ & $2.76678 \mathrm{E}-02$ & 2.78385E-02 & 2.80082E-02 & 2.81253E-02 \\
\hline 14028 & 6.74013E-05 & $6.72491 \mathrm{E}-05$ & $6.70485 \mathrm{E}-05$ & 6.66126E-05 & $6.59578 \mathrm{E}-05$ & $6.50509 \mathrm{E}-05$ & $6.42050 \mathrm{E}-05$ & $6.41544 \mathrm{E}-05$ & $6.46200 \mathrm{E}-05$ & 6.50826E-05 & $6.54021 \mathrm{E}-05$ \\
\hline 14029 & 3.42404E-06 & 3.41630E-06 & 3.40612E-06 & 3.38397E-06 & 3.35071E-06 & 3.30464E-06 & 3.26167E-06 & 3.25909E-06 & 3.28274E-06 & 3.30625E-06 & 3.32248E-06 \\
\hline 14030 & 2.25979E-06 & $2.25469 \mathrm{E}-06$ & 2.24796E-06 & 2.23335E-06 & $2.21140 \mathrm{E}-06$ & 2.18099E-06 & 2.15263E-06 & 2.15093E-06 & 2.16654E-06 & 2.18205E-06 & 2.19277E-06 \\
\hline 22046 & $4.12481 \mathrm{E}-07$ & $4.12481 \mathrm{E}-07$ & $4.12481 \mathrm{E}-07$ & $4.12481 \mathrm{E}-07$ & $4.12481 \mathrm{E}-07$ & 4.12481E-07 & $4.12481 \mathrm{E}-07$ & 4.12481E-07 & $4.12481 \mathrm{E}-07$ & $4.12481 \mathrm{E}-07$ & 4.12481E-07 \\
\hline 22047 & 3.71983E-07 & 3.71983E-07 & 3.71983E-07 & 3.71983E-07 & 3.71983E-07 & 3.71983E-07 & 3.71983E-07 & 3.71983E-07 & 3.71983E-07 & 3.71983E-07 & 3.71983E-07 \\
\hline 22048 & 3.68583E-06 & 3.68583E-06 & 3.68583E-06 & 3.68583E-06 & 3.68583E-06 & 3.68583E-06 & 3.68583E-06 & 3.68583E-06 & 3.68583E-06 & 3.68583E-06 & 3.68583E-06 \\
\hline 22049 & $2.70488 \mathrm{E}-07$ & $2.70488 \mathrm{E}-07$ & $2.70488 \mathrm{E}-07$ & $2.70488 \mathrm{E}-07$ & $2.70488 \mathrm{E}-07$ & $2.70488 \mathrm{E}-07$ & $2.70488 \mathrm{E}-07$ & $2.70488 \mathrm{E}-07$ & 2.70488E-07 & 2.70488E-07 & $2.70488 \mathrm{E}-07$ \\
\hline 22050 & $2.58988 \mathrm{E}-07$ & $2.58988 \mathrm{E}-07$ & $2.58988 \mathrm{E}-07$ & $2.58988 \mathrm{E}-07$ & $2.58988 \mathrm{E}-07$ & $2.58988 \mathrm{E}-07$ & $2.58988 \mathrm{E}-07$ & $2.58988 \mathrm{E}-07$ & $2.58988 \mathrm{E}-07$ & $2.58988 \mathrm{E}-07$ & $2.58988 \mathrm{E}-07$ \\
\hline 24050 & $5.19971 \mathrm{E}-07$ & 5.19971E-07 & $5.19971 \mathrm{E}-07$ & 5.19971E-07 & $5.19971 \mathrm{E}-07$ & 5.19971E-07 & $5.19971 \mathrm{E}-07$ & 5.19971E-07 & $5.19971 \mathrm{E}-07$ & 5.19971E-07 & 5.19971E-07 \\
\hline 24052 & $1.00271 \mathrm{E}-05$ & $1.00271 \mathrm{E}-05$ & $1.00271 \mathrm{E}-05$ & $1.00271 \mathrm{E}-05$ & $1.00271 \mathrm{E}-05$ & $1.00271 \mathrm{E}-05$ & $1.00271 \mathrm{E}-05$ & $1.00271 \mathrm{E}-05$ & $1.00271 \mathrm{E}-05$ & $1.00271 \mathrm{E}-05$ & $1.00271 \mathrm{E}-05$ \\
\hline 24053 & $1.13699 \mathrm{E}-06$ & $1.13699 \mathrm{E}-06$ & $1.13699 \mathrm{E}-06$ & $1.13699 \mathrm{E}-06$ & $1.13699 \mathrm{E}-06$ & $1.13699 \mathrm{E}-06$ & $1.13699 \mathrm{E}-06$ & $1.13699 \mathrm{E}-06$ & $1.13699 \mathrm{E}-06$ & $1.13699 \mathrm{E}-06$ & $1.13699 \mathrm{E}-06$ \\
\hline 24054 & $2.83022 \mathrm{E}-07$ & 2.83022E-07 & $2.83022 \mathrm{E}-07$ & $2.83022 \mathrm{E}-07$ & $2.83022 \mathrm{E}-07$ & 2.83022E-07 & $2.83022 \mathrm{E}-07$ & $2.83022 \mathrm{E}-07$ & 2.83022E-07 & $2.83022 \mathrm{E}-07$ & 2.83022E-07 \\
\hline 25055 & 4.35626E-06 & 4.35626E-06 & 4.35626E-06 & 4.35626E-06 & 4.35626E-06 & 4.35626E-06 & 4.35626E-06 & 4.35626E-06 & 4.35626E-06 & 4.35626E-06 & 4.35626E-06 \\
\hline 26054 & $1.62635 \mathrm{E}-06$ & $1.61098 \mathrm{E}-06$ & $1.59075 \mathrm{E}-06$ & $1.54676 \mathrm{E}-06$ & $1.48068 \mathrm{E}-06$ & 1.38917E-06 & $1.30381 \mathrm{E}-06$ & $1.29870 \mathrm{E}-06$ & $1.34568 \mathrm{E}-06$ & $1.39237 \mathrm{E}-06$ & $1.42461 \mathrm{E}-06$ \\
\hline 26056 & $2.55302 \mathrm{E}-05$ & $2.52890 \mathrm{E}-05$ & 2.49713E-05 & $2.42808 \mathrm{E}-05$ & 2.32436E-05 & 2.18069E-05 & $2.04670 \mathrm{E}-05$ & $2.03868 \mathrm{E}-05$ & 2.11243E-05 & 2.18572E-05 & 2.23633E-05 \\
\hline 26057 & 5.89605E-07 & $5.84034 \mathrm{E}-07$ & 5.76697E-07 & $5.60750 \mathrm{E}-07$ & 5.36795E-07 & 5.03617E-07 & 4.72673E-07 & 4.70821E-07 & 4.87852E-07 & 5.04778E-07 & 5.16467E-07 \\
\hline 26058 & 7.84656E-08 & 7.77241E-08 & 7.67478E-08 & 7.46255E-08 & 7.14376E-08 & $6.70222 \mathrm{E}-08$ & $6.29041 \mathrm{E}-08$ & 6.26576E-08 & $6.49241 \mathrm{E}-08$ & 6.71766E-08 & 6.87323E-08 \\
\hline 29063 & $1.41949 \mathrm{E}-05$ & $1.41847 \mathrm{E}-05$ & $1.41712 \mathrm{E}-05$ & $1.41418 \mathrm{E}-05$ & $1.40977 \mathrm{E}-05$ & $1.40366 \mathrm{E}-05$ & $1.39796 \mathrm{E}-05$ & $1.39762 \mathrm{E}-05$ & $1.40076 \mathrm{E}-05$ & $1.40387 \mathrm{E}-05$ & $1.40602 \mathrm{E}-05$ \\
\hline 29065 & $6.33280 \mathrm{E}-06$ & 6.32823E-06 & $6.32220 \mathrm{E}-06$ & $6.30910 \mathrm{E}-06$ & $6.28942 \mathrm{E}-06$ & 6.26217E-06 & 6.23675E-06 & $6.23522 \mathrm{E}-06$ & $6.24921 \mathrm{E}-06$ & $6.26312 \mathrm{E}-06$ & $6.27272 \mathrm{E}-06$ \\
\hline 48106 & $1.43458 \mathrm{E}-10$ & $1.38639 \mathrm{E}-10$ & $1.32292 \mathrm{E}-10$ & $1.18496 \mathrm{E}-10$ & $9.77721 \mathrm{E}-11$ & 6.90691E-11 & $4.22986 \mathrm{E}-11$ & 4.06963E-11 & 5.54303E-11 & 7.00730E-11 & 8.01859E-11 \\
\hline 48108 & $1.02142 \mathrm{E}-10$ & $9.87108 \mathrm{E}-11$ & $9.41918 \mathrm{E}-11$ & $8.43688 \mathrm{E}-11$ & 6.96137E-11 & 4.91772E-11 & 3.01166E-11 & 2.89758E-11 & 3.94664E-11 & 4.98920E-11 & $5.70924 \mathrm{E}-11$ \\
\hline 48110 & $1.43344 \mathrm{E}-09$ & $1.38528 \mathrm{E}-09$ & $1.32186 \mathrm{E}-09$ & $1.18401 \mathrm{E}-09$ & $9.76939 \mathrm{E}-10$ & $6.90138 \mathrm{E}-10$ & $4.22648 \mathrm{E}-10$ & 4.06638E-10 & $5.53860 \mathrm{E}-10$ & 7.00170E-10 & $8.01218 \mathrm{E}-10$ \\
\hline 48111 & 1.46902E-09 & 1.41966E-09 & $1.35467 \mathrm{E}-09$ & $1.21339 \mathrm{E}-09$ & $1.00119 \mathrm{E}-09$ & 7.07267E-10 & $4.33138 \mathrm{E}-10$ & 4.16731E-10 & $5.67606 \mathrm{E}-10$ & 7.17548E-10 & $8.21104 \mathrm{E}-10$ \\
\hline
\end{tabular}


Table 28. (continued)

\begin{tabular}{|c|c|c|c|c|c|c|c|c|c|c|c|}
\hline $\begin{array}{c}\text { Nuclide } \\
\text { identifier }\end{array}$ & $\begin{array}{l}\text { Region } 1 \\
\text { (at/b-cm) }\end{array}$ & $\begin{array}{l}\text { Region } 2 \\
\text { (at/b-cm) }\end{array}$ & $\begin{array}{l}\text { Region } 3 \\
\text { (at/b-cm) }\end{array}$ & $\begin{array}{l}\text { Region } 4 \\
\text { (at/b-cm) }\end{array}$ & $\begin{array}{l}\text { Region } 5 \\
\text { (at/b-cm) }\end{array}$ & $\begin{array}{l}\text { Region } 6 \\
\text { (at/b-cm) }\end{array}$ & $\begin{array}{l}\text { Region } 7 \\
\text { (at/b-cm) }\end{array}$ & $\begin{array}{l}\text { Region } 8 \\
\text { (at/b-cm) }\end{array}$ & $\begin{array}{l}\text { Region } 9 \\
\text { (at/b-cm) }\end{array}$ & $\begin{array}{l}\text { Region } 10 \\
\text { (at/b-cm) }\end{array}$ & $\begin{array}{c}\text { Region } 11 \\
\text { (at/b-cm) }\end{array}$ \\
\hline 48112 & $2.76932 \mathrm{E}-09$ & $2.67628 \mathrm{E}-09$ & 2.55376E-09 & $2.28744 \mathrm{E}-09$ & 1.88739E-09 & 1.33331E-09 & $8.16533 \mathrm{E}-10$ & $7.85602 \mathrm{E}-10$ & 1.07003E-09 & 1.35269E-09 & $1.54791 \mathrm{E}-09$ \\
\hline 48113 & 1.40245E-09 & 1.35533E-09 & $1.29329 \mathrm{E}-09$ & $1.15841 \mathrm{E}-09$ & $9.55820 \mathrm{E}-10$ & 6.75219E-10 & 4.13511E-10 & 3.97847E-10 & $5.41887 \mathrm{E}-10$ & $6.85034 \mathrm{E}-10$ & $7.83898 \mathrm{E}-10$ \\
\hline 48114 & 3.29725E-09 & 3.18647E-09 & 3.04060E-09 & 2.72350E-09 & 2.24719E-09 & $1.58748 \mathrm{E}-09$ & $9.72192 \mathrm{E}-10$ & $9.35365 \mathrm{E}-10$ & $1.27401 \mathrm{E}-09$ & 1.61056E-09 & $1.84299 \mathrm{E}-09$ \\
\hline 48116 & 8.59603E-10 & 8.30723E-10 & 7.92693E-10 & $7.10025 \mathrm{E}-10$ & $5.85850 \mathrm{E}-10$ & 4.13862E-10 & $2.53453 \mathrm{E}-10$ & $2.43852 \mathrm{E}-10$ & 3.32138E-10 & 4.19877E-10 & $4.80474 \mathrm{E}-10$ \\
\hline 92234 & $2.15670 \mathrm{E}-06$ & $2.29390 \mathrm{E}-06$ & $2.47456 \mathrm{E}-06$ & 2.86727E-06 & 3.45717E-06 & 4.27420E-06 & 5.03622E-06 & 5.08183E-06 & 4.66243E-06 & 4.24562E-06 & 3.95776E-06 \\
\hline 92235 & $1.95227 \mathrm{E}-04$ & 2.07646E-04 & $2.24000 \mathrm{E}-04$ & $2.59549 \mathrm{E}-04$ & 3.12947E-04 & 3.86905E-04 & 4.55884E-04 & 4.60013E-04 & $4.22048 \mathrm{E}-04$ & 3.84319E-04 & 3.58261E-04 \\
\hline 92236 & 7.77595E-07 & $8.27060 \mathrm{E}-07$ & 8.92199E-07 & $1.03379 \mathrm{E}-06$ & $1.24648 \mathrm{E}-06$ & $1.54105 \mathrm{E}-06$ & $1.81580 \mathrm{E}-06$ & $1.83224 \mathrm{E}-06$ & 1.68103E-06 & $1.53075 \mathrm{E}-06$ & $1.42696 \mathrm{E}-06$ \\
\hline 92238 & 1.11727E-05 & $1.18834 \mathrm{E}-05$ & $1.28194 \mathrm{E}-05$ & $1.48538 \mathrm{E}-05$ & $1.79097 \mathrm{E}-05$ & 2.21423E-05 & $2.60899 \mathrm{E}-05$ & 2.63262E-05 & $2.41535 \mathrm{E}-05$ & 2.19943E-05 & $2.05030 \mathrm{E}-05$ \\
\hline Total & 7.94252E-02 & 7.94132E-02 & 7.93974E-02 & 7.93632E-02 & 7.93117E-02 & 7.92404E-02 & 7.91740E-02 & 7.91700E-02 & 7.92066E-02 & 7.92429E-02 & $7.92680 \mathrm{E}-02$ \\
\hline
\end{tabular}

Table 29. Isotopic composition for homogenized outer fuel element plate radial regions

\begin{tabular}{|c|c|c|c|c|c|c|c|c|c|c|c|}
\hline $\begin{array}{c}\text { Nuclide } \\
\text { identifier }\end{array}$ & $\begin{array}{l}\text { Region } 1 \\
\text { (at/b-cm) }\end{array}$ & $\begin{array}{l}\text { Region } 2 \\
\text { (at/b-cm) }\end{array}$ & $\begin{array}{l}\text { Region } 3 \\
\text { (at/b-cm) }\end{array}$ & $\begin{array}{l}\text { Region } 4 \\
(\text { at/b-cm) }\end{array}$ & $\begin{array}{l}\text { Region } 5 \\
\text { (at/b-cm) }\end{array}$ & $\begin{array}{l}\text { Region } 6 \\
\text { (at/b-cm) }\end{array}$ & $\begin{array}{l}\text { Region } 7 \\
\text { (at/b-cm) }\end{array}$ & $\begin{array}{l}\text { Region } 8 \\
(\text { at/b-cm) }\end{array}$ & $\begin{array}{l}\text { Region } 9 \\
\text { (at/b-cm) }\end{array}$ & $\begin{array}{l}\text { Region } 10 \\
\text { (at/b-cm) }\end{array}$ & $\begin{array}{c}\text { Region } 11 \\
\text { (at/b-cm) }\end{array}$ \\
\hline 1001 & 3.29272E-02 & 3.29272E-02 & 3.29272E-02 & $3.29272 \mathrm{E}-02$ & 3.29272E-02 & $3.29272 \mathrm{E}-02$ & 3.29272E-02 & $3.29272 \mathrm{E}-02$ & 3.29272E-02 & 3.29272E-02 & 3.29272E-02 \\
\hline 3006 & 4.94141E-09 & 4.38342E-09 & 3.40410E-09 & 2.15519E-09 & $1.15960 \mathrm{E}-09$ & $1.58108 \mathrm{E}-09$ & 3.35140E-09 & 5.00065E-09 & 6.09518E-09 & 6.85489E-09 & 7.19698E-09 \\
\hline 3007 & 6.01628E-08 & 5.33692E-08 & 4.14457E-08 & $2.62400 \mathrm{E}-08$ & $1.41184 \mathrm{E}-08$ & $1.92501 \mathrm{E}-08$ & $4.08041 \mathrm{E}-08$ & $6.08841 \mathrm{E}-08$ & 7.42102E-08 & 8.34598E-08 & $8.76248 \mathrm{E}-08$ \\
\hline 5010 & 7.93168E-08 & $7.03602 \mathrm{E}-08$ & 5.46407E-08 & $3.45940 \mathrm{E}-08$ & $1.86132 \mathrm{E}-08$ & $2.53787 \mathrm{E}-08$ & 5.37948E-08 & 8.02677E-08 & 9.78364E-08 & $1.10031 \mathrm{E}-07$ & $1.15522 \mathrm{E}-07$ \\
\hline 5011 & 3.17799E-07 & 2.81913E-07 & 2.18929E-07 & $1.38608 \mathrm{E}-07$ & 7.45777E-08 & $1.01685 \mathrm{E}-07$ & $2.15540 \mathrm{E}-07$ & 3.21609E-07 & 3.92002E-07 & $4.40861 \mathrm{E}-07$ & 4.62862E-07 \\
\hline 8016 & $1.76610 \mathrm{E}-02$ & $1.77739 \mathrm{E}-02$ & 1.79719E-02 & $1.82245 \mathrm{E}-02$ & $1.84259 \mathrm{E}-02$ & $1.83406 \mathrm{E}-02$ & $1.79826 \mathrm{E}-02$ & $1.76490 \mathrm{E}-02$ & $1.74277 \mathrm{E}-02$ & $1.72740 \mathrm{E}-02$ & $1.72048 \mathrm{E}-02$ \\
\hline 12024 & $1.04002 \mathrm{E}-04$ & $1.04002 \mathrm{E}-04$ & $1.04002 \mathrm{E}-04$ & $1.04002 \mathrm{E}-04$ & $1.04002 \mathrm{E}-04$ & $1.04002 \mathrm{E}-04$ & $1.04002 \mathrm{E}-04$ & $1.04002 \mathrm{E}-04$ & $1.04002 \mathrm{E}-04$ & $1.04002 \mathrm{E}-04$ & $1.04002 \mathrm{E}-04$ \\
\hline 12025 & $1.31665 \mathrm{E}-05$ & $1.31665 \mathrm{E}-05$ & $1.31665 \mathrm{E}-05$ & $1.31665 \mathrm{E}-05$ & 1.31665E-05 & $1.31665 \mathrm{E}-05$ & 1.31665E-05 & $1.31665 \mathrm{E}-05$ & 1.31665E-05 & $1.31665 \mathrm{E}-05$ & $1.31665 \mathrm{E}-05$ \\
\hline 12026 & 1.44963E-05 & 1.44963E-05 & 1.44963E-05 & 1.44963E-05 & 1.44963E-05 & 1.44963E-05 & 1.44963E-05 & 1.44963E-05 & 1.44963E-05 & 1.44963E-05 & 1.44963E-05 \\
\hline 13027 & 2.79976E-02 & 2.78223E-02 & $2.75144 \mathrm{E}-02$ & 2.71217E-02 & $2.68086 \mathrm{E}-02$ & 2.69412E-02 & $2.74978 \mathrm{E}-02$ & 2.80163E-02 & 2.83605E-02 & 2.85994E-02 & 2.87069E-02 \\
\hline 14028 & 6.62237E-05 & $6.58652 \mathrm{E}-05$ & 6.52358E-05 & 6.44333E-05 & 6.37935E-05 & 6.40643E-05 & $6.52020 \mathrm{E}-05$ & 6.62618E-05 & 6.69652E-05 & $6.74534 \mathrm{E}-05$ & 6.76732E-05 \\
\hline 14029 & 3.36422E-06 & $3.34600 \mathrm{E}-06$ & 3.31403E-06 & 3.27326E-06 & 3.24076E-06 & 3.25452E-06 & 3.31231E-06 & 3.36615E-06 & 3.40188E-06 & $3.42668 \mathrm{E}-06$ & 3.43785E-06 \\
\hline 14030 & 2.22031E-06 & $2.20829 \mathrm{E}-06$ & 2.18719E-06 & 2.16028E-06 & 2.13883E-06 & 2.14791E-06 & 2.18605E-06 & 2.22159E-06 & 2.24517E-06 & $2.26154 \mathrm{E}-06$ & $2.26891 \mathrm{E}-06$ \\
\hline 22046 & $4.13661 \mathrm{E}-07$ & $4.13661 \mathrm{E}-07$ & $4.13661 \mathrm{E}-07$ & 4.13661E-07 & $4.13661 \mathrm{E}-07$ & 4.13661E-07 & $4.13661 \mathrm{E}-07$ & 4.13661E-07 & $4.13661 \mathrm{E}-07$ & $4.13661 \mathrm{E}-07$ & $4.13661 \mathrm{E}-07$ \\
\hline 22047 & 3.73047E-07 & 3.73047E-07 & 3.73047E-07 & 3.73047E-07 & 3.73047E-07 & 3.73047E-07 & 3.73047E-07 & 3.73047E-07 & 3.73047E-07 & 3.73047E-07 & 3.73047E-07 \\
\hline 22048 & 3.69637E-06 & 3.69637E-06 & 3.69637E-06 & 3.69637E-06 & 3.69637E-06 & 3.69637E-06 & 3.69637E-06 & 3.69637E-06 & 3.69637E-06 & 3.69637E-06 & 3.69637E-06 \\
\hline 22049 & $2.71261 \mathrm{E}-07$ & $2.71261 \mathrm{E}-07$ & $2.71261 \mathrm{E}-07$ & $2.71261 \mathrm{E}-07$ & $2.71261 \mathrm{E}-07$ & $2.71261 \mathrm{E}-07$ & $2.71261 \mathrm{E}-07$ & $2.71261 \mathrm{E}-07$ & $2.71261 \mathrm{E}-07$ & $2.71261 \mathrm{E}-07$ & $2.71261 \mathrm{E}-07$ \\
\hline 22050 & 2.59729E-07 & $2.59729 \mathrm{E}-07$ & 2.59729E-07 & $2.59729 \mathrm{E}-07$ & $2.59729 \mathrm{E}-07$ & $2.59729 \mathrm{E}-07$ & $2.59729 \mathrm{E}-07$ & $2.59729 \mathrm{E}-07$ & $2.59729 \mathrm{E}-07$ & $2.59729 \mathrm{E}-07$ & $2.59729 \mathrm{E}-07$ \\
\hline 24050 & 5.21457E-07 & $5.21457 \mathrm{E}-07$ & 5.21457E-07 & 5.21457E-07 & 5.21457E-07 & 5.21457E-07 & 5.21457E-07 & 5.21457E-07 & 5.21457E-07 & 5.21457E-07 & 5.21457E-07 \\
\hline
\end{tabular}


Table 29. (continued)

\begin{tabular}{|c|c|c|c|c|c|c|c|c|c|c|c|}
\hline $\begin{array}{c}\text { Nuclide } \\
\text { identifier }\end{array}$ & $\begin{array}{l}\text { Region } 1 \\
\text { (at/b-cm) }\end{array}$ & $\begin{array}{l}\text { Region } 2 \\
\text { (at/b-cm) }\end{array}$ & $\begin{array}{l}\text { Region } 3 \\
\text { (at/b-cm) }\end{array}$ & $\begin{array}{l}\text { Region } 4 \\
\text { (at/b-cm) }\end{array}$ & $\begin{array}{l}\text { Region } 5 \\
\text { (at/b-cm) }\end{array}$ & $\begin{array}{l}\text { Region } 6 \\
\text { (at/b-cm) }\end{array}$ & $\begin{array}{l}\text { Region } 7 \\
\text { (at/b-cm) }\end{array}$ & $\begin{array}{l}\text { Region } 8 \\
\text { (at/b-cm) }\end{array}$ & $\begin{array}{l}\text { Region } 9 \\
\text { (at/b-cm) }\end{array}$ & $\begin{array}{l}\text { Region } 10 \\
\text { (at/b-cm) }\end{array}$ & $\begin{array}{l}\text { Region } 11 \\
\text { (at/b-cm) }\end{array}$ \\
\hline 24052 & $1.00558 \mathrm{E}-05$ & $1.00558 \mathrm{E}-05$ & $1.00558 \mathrm{E}-05$ & $1.00558 \mathrm{E}-05$ & $1.00558 \mathrm{E}-05$ & $1.00558 \mathrm{E}-05$ & $1.00558 \mathrm{E}-05$ & $1.00558 \mathrm{E}-05$ & $1.00558 \mathrm{E}-05$ & $1.00558 \mathrm{E}-05$ & $1.00558 \mathrm{E}-05$ \\
\hline 24053 & $1.14025 \mathrm{E}-06$ & $1.14025 \mathrm{E}-06$ & $1.14025 \mathrm{E}-06$ & $1.14025 \mathrm{E}-06$ & $1.14025 \mathrm{E}-06$ & $1.14025 \mathrm{E}-06$ & $1.14025 \mathrm{E}-06$ & $1.14025 \mathrm{E}-06$ & $1.14025 \mathrm{E}-06$ & $1.14025 \mathrm{E}-06$ & $1.14025 \mathrm{E}-06$ \\
\hline 24054 & $2.83831 \mathrm{E}-07$ & $2.83831 \mathrm{E}-07$ & $2.83831 \mathrm{E}-07$ & 2.83831E-07 & $2.83831 \mathrm{E}-07$ & $2.83831 \mathrm{E}-07$ & $2.83831 \mathrm{E}-07$ & 2.83831E-07 & $2.83831 \mathrm{E}-07$ & $2.83831 \mathrm{E}-07$ & $2.83831 \mathrm{E}-07$ \\
\hline 25055 & $4.36871 \mathrm{E}-06$ & 4.36871E-06 & $4.36871 \mathrm{E}-06$ & $4.36871 \mathrm{E}-06$ & $4.36871 \mathrm{E}-06$ & $4.36871 \mathrm{E}-06$ & $4.36871 \mathrm{E}-06$ & 4.36871E-06 & $4.36871 \mathrm{E}-06$ & 4.36871E-06 & $4.36871 \mathrm{E}-06$ \\
\hline 26054 & $1.49272 \mathrm{E}-06$ & $1.45654 \mathrm{E}-06$ & $1.39303 \mathrm{E}-06$ & $1.31204 \mathrm{E}-06$ & $1.24748 \mathrm{E}-06$ & $1.27481 \mathrm{E}-06$ & $1.38961 \mathrm{E}-06$ & $1.49656 \mathrm{E}-06$ & $1.56754 \mathrm{E}-06$ & $1.61680 \mathrm{E}-06$ & $1.63899 \mathrm{E}-06$ \\
\hline 26056 & 2.34325E-05 & 2.28645E-05 & 2.18676E-05 & 2.05963E-05 & $1.95828 \mathrm{E}-05$ & 2.00119E-05 & $2.18140 \mathrm{E}-05$ & 2.34928E-05 & $2.46070 \mathrm{E}-05$ & $2.53804 \mathrm{E}-05$ & $2.57286 \mathrm{E}-05$ \\
\hline 26057 & $5.41159 \mathrm{E}-07$ & $5.28041 \mathrm{E}-07$ & 5.05018E-07 & 4.75658E-07 & $4.52252 \mathrm{E}-07$ & $4.62161 \mathrm{E}-07$ & $5.03780 \mathrm{E}-07$ & 5.42552E-07 & 5.68283E-07 & 5.86143E-07 & 5.94186E-07 \\
\hline 26058 & 7.20184E-08 & 7.02726E-08 & $6.72087 \mathrm{E}-08$ & 6.33013E-08 & 6.01865E-08 & $6.15051 \mathrm{E}-08$ & $6.70438 \mathrm{E}-08$ & 7.22037E-08 & 7.56281E-08 & 7.80049E-08 & 7.90752E-08 \\
\hline 29063 & $1.41432 \mathrm{E}-05$ & $1.41190 \mathrm{E}-05$ & $1.40766 \mathrm{E}-05$ & $1.40226 \mathrm{E}-05$ & $1.39795 \mathrm{E}-05$ & 1.39977E-05 & $1.40744 \mathrm{E}-05$ & $1.41458 \mathrm{E}-05$ & $1.41931 \mathrm{E}-05$ & $1.42260 \mathrm{E}-05$ & $1.42408 \mathrm{E}-05$ \\
\hline 29065 & 6.30973E-06 & 6.29895E-06 & $6.28004 \mathrm{E}-06$ & $6.25592 \mathrm{E}-06$ & $6.23669 \mathrm{E}-06$ & 6.24483E-06 & $6.27902 \mathrm{E}-06$ & 6.31087E-06 & 6.33201E-06 & $6.34668 \mathrm{E}-06$ & $6.35329 \mathrm{E}-06$ \\
\hline 48106 & $1.00499 \mathrm{E}-10$ & 8.91507E-11 & 6.92331E-11 & 4.38327E-11 & $2.35841 \mathrm{E}-11$ & 3.21563E-11 & 6.81613E-11 & $1.01704 \mathrm{E}-10$ & $1.23965 \mathrm{E}-10$ & $1.39416 \mathrm{E}-10$ & $1.46373 \mathrm{E}-10$ \\
\hline 48108 & 7.15554E-11 & 6.34753E-11 & $4.92940 \mathrm{E}-11$ & $3.12089 \mathrm{E}-11$ & $1.67919 \mathrm{E}-11$ & 2.28953E-11 & 4.85309E-11 & 7.24133E-11 & 8.82628E-11 & $9.92640 \mathrm{E}-11$ & $1.04218 \mathrm{E}-10$ \\
\hline 48110 & $1.00419 \mathrm{E}-09$ & 8.90793E-10 & 6.91777E-10 & 4.37976E-10 & $2.35652 \mathrm{E}-10$ & 3.21306E-10 & $6.81068 \mathrm{E}-10$ & 1.01623E-09 & $1.23865 \mathrm{E}-09$ & $1.39304 \mathrm{E}-09$ & $1.46256 \mathrm{E}-09$ \\
\hline 48111 & $1.02911 \mathrm{E}-09$ & $9.12903 \mathrm{E}-10$ & 7.08947E-10 & $4.48847 \mathrm{E}-10$ & $2.41501 \mathrm{E}-10$ & $3.29281 \mathrm{E}-10$ & $6.97972 \mathrm{E}-10$ & 1.04145E-09 & $1.26940 \mathrm{E}-09$ & $1.42762 \mathrm{E}-09$ & $1.49886 \mathrm{E}-09$ \\
\hline 48112 & $1.94004 \mathrm{E}-09$ & 1.72096E-09 & $1.33648 \mathrm{E}-09$ & 8.46146E-10 & $4.55267 \mathrm{E}-10$ & 6.20746E-10 & 1.31579E-09 & $1.96329 \mathrm{E}-09$ & $2.39301 \mathrm{E}-09$ & 2.69128E-09 & 2.82559E-09 \\
\hline 48113 & $9.82480 \mathrm{E}-10$ & 8.71537E-10 & $6.76823 \mathrm{E}-10$ & $4.28508 \mathrm{E}-10$ & $2.30558 \mathrm{E}-10$ & $3.14360 \mathrm{E}-10$ & $6.66345 \mathrm{E}-10$ & $9.94259 \mathrm{E}-10$ & $1.21188 \mathrm{E}-09$ & $1.36293 \mathrm{E}-09$ & $1.43094 \mathrm{E}-09$ \\
\hline 48114 & 2.30987E-09 & $2.04904 \mathrm{E}-09$ & $1.59125 \mathrm{E}-09$ & 1.00745E-09 & 5.42057E-10 & 7.39081E-10 & $1.56662 \mathrm{E}-09$ & 2.33757E-09 & $2.84920 \mathrm{E}-09$ & 3.20433E-09 & $3.36424 \mathrm{E}-09$ \\
\hline 48116 & $6.02191 \mathrm{E}-10$ & 5.34191E-10 & 4.14845E-10 & $2.62645 \mathrm{E}-10$ & $1.41316 \mathrm{E}-10$ & $1.92681 \mathrm{E}-10$ & 4.08423E-10 & $6.09411 \mathrm{E}-10$ & $7.42796 \mathrm{E}-10$ & $8.35379 \mathrm{E}-10$ & $8.77068 \mathrm{E}-10$ \\
\hline 92234 & 4.61327E-06 & 5.05078E-06 & 5.81855E-06 & 6.79767E-06 & $7.57820 \mathrm{E}-06$ & 7.24776E-06 & 5.85987E-06 & 4.56689E-06 & 3.70880E-06 & $3.11320 \mathrm{E}-06$ & $2.84501 \mathrm{E}-06$ \\
\hline 92235 & $4.17598 \mathrm{E}-04$ & 4.57203E-04 & $5.26702 \mathrm{E}-04$ & 6.15333E-04 & 6.85987E-04 & 6.56076E-04 & $5.30442 \mathrm{E}-04$ & $4.13400 \mathrm{E}-04$ & 3.35725E-04 & $2.81811 \mathrm{E}-04$ & $2.57534 \mathrm{E}-04$ \\
\hline 92236 & $1.66331 \mathrm{E}-06$ & $1.82105 \mathrm{E}-06$ & 2.09787E-06 & $2.45089 \mathrm{E}-06$ & $2.73231 \mathrm{E}-06$ & 2.61317E-06 & $2.11276 \mathrm{E}-06$ & $1.64658 \mathrm{E}-06$ & $1.33720 \mathrm{E}-06$ & $1.12246 \mathrm{E}-06$ & $1.02576 \mathrm{E}-06$ \\
\hline 92238 & $2.38988 \mathrm{E}-05$ & 2.61654E-05 & $3.01428 \mathrm{E}-05$ & 3.52150E-05 & 3.92585E-05 & 3.75467E-05 & $3.03568 \mathrm{E}-05$ & 2.36586E-05 & $1.92133 \mathrm{E}-05$ & $1.61278 \mathrm{E}-05$ & $1.47385 \mathrm{E}-05$ \\
\hline total & 7.93049E-02 & 7.92838E-02 & 7.92465E-02 & 7.91990E-02 & 7.91612E-02 & 7.91772E-02 & 7.92445E-02 & 7.93073E-02 & 7.93489E-02 & 7.93778E-02 & 7.93908E-02 \\
\hline
\end{tabular}




\subsubsection{Material Data for Unfueled Regions of Fuel Plates}

Materials for the upper and lower unfueled regions of the IFE and OFE fuel plates were modeled [3] as a mixture of $50 \mathrm{vol} \%$ water and $50 \mathrm{vol} \% \mathrm{Al}-6061$. The same type of mixture was also used for the material in the inner and outer unfueled regions of the IFE and the OFE. The mixtures used for the upper unfueled regions in the IFE and OFE are identified as $\mathrm{m} 70$ and $\mathrm{m} 72$, respectively. The mixtures used for the lower unfueled regions in the IFE and OFE are identified as m71 and m73, respectively. The mixture used for the inner and outer unfueled regions is identified as m200.

Material composition data for $\mathrm{m} 70, \mathrm{~m} 71, \mathrm{~m} 72, \mathrm{~m} 73$, and $\mathrm{m} 200$ were updated for consistency with the Al-6061 specifications listed in Table 15 and the water density data listed in Tables 6 and 7. The updated data for these materials are given in Table 30. Note that the water densities for the upper, lower, and incore zones are different (see Table 6).

Table 30. Isotopic composition data for fuel element unfueled regions

\begin{tabular}{rccc}
\hline \multicolumn{1}{c}{$\begin{array}{c}\text { Nuclide } \\
\text { identifier }\end{array}$} & $\begin{array}{c}\text { Atom density } \\
\text { for m70 and m72 } \\
\text { (at/b-cm) }\end{array}$ & $\begin{array}{c}\text { Atom density } \\
\text { for m71 and m73 } \\
\text { (at/b-cm) }\end{array}$ & $\begin{array}{c}\text { Atom density } \\
\text { for m200 } \\
\text { (at/b-cm) }\end{array}$ \\
\hline 1001 & $3.30917 \mathrm{E}-02$ & $3.27430 \mathrm{E}-02$ & $3.29272 \mathrm{E}-02$ \\
8016 & $1.65458 \mathrm{E}-02$ & $1.63715 \mathrm{E}-02$ & $1.64636 \mathrm{E}-02$ \\
12024 & $2.64217 \mathrm{E}-04$ & $2.64217 \mathrm{E}-04$ & $2.64217 \mathrm{E}-04$ \\
12025 & $3.34494 \mathrm{E}-05$ & $3.34494 \mathrm{E}-05$ & $3.34494 \mathrm{E}-05$ \\
12026 & $3.68278 \mathrm{E}-05$ & $3.68278 \mathrm{E}-05$ & $3.68278 \mathrm{E}-05$ \\
13027 & $2.93193 \mathrm{E}-02$ & $2.93193 \mathrm{E}-02$ & $2.93193 \mathrm{E}-02$ \\
14028 & $1.60174 \mathrm{E}-04$ & $1.60174 \mathrm{E}-04$ & $1.60174 \mathrm{E}-04$ \\
14029 & $8.13698 \mathrm{E}-06$ & $8.13698 \mathrm{E}-06$ & $8.13698 \mathrm{E}-06$ \\
14030 & $5.37024 \mathrm{E}-06$ & $5.37024 \mathrm{E}-06$ & $5.37024 \mathrm{E}-06$ \\
22046 & $1.05091 \mathrm{E}-06$ & $1.05091 \mathrm{E}-06$ & $1.05091 \mathrm{E}-06$ \\
22047 & $9.47731 \mathrm{E}-07$ & $9.47731 \mathrm{E}-07$ & $9.47731 \mathrm{E}-07$ \\
22048 & $9.39069 \mathrm{E}-06$ & $9.39069 \mathrm{E}-06$ & $9.39069 \mathrm{E}-06$ \\
22049 & $6.89143 \mathrm{E}-07$ & $6.89143 \mathrm{E}-07$ & $6.89143 \mathrm{E}-07$ \\
22050 & $6.59845 \mathrm{E}-07$ & $6.59845 \mathrm{E}-07$ & $6.59845 \mathrm{E}-07$ \\
24050 & $1.32476 \mathrm{E}-06$ & $1.32476 \mathrm{E}-06$ & $1.32476 \mathrm{E}-06$ \\
24052 & $2.55467 \mathrm{E}-05$ & $2.55467 \mathrm{E}-05$ & $2.55467 \mathrm{E}-05$ \\
24053 & $2.89679 \mathrm{E}-06$ & $2.89679 \mathrm{E}-06$ & $2.89679 \mathrm{E}-06$ \\
24054 & $7.21073 \mathrm{E}-07$ & $7.21073 \mathrm{E}-07$ & $7.21073 \mathrm{E}-07$ \\
25055 & $1.10987 \mathrm{E}-05$ & $1.10987 \mathrm{E}-05$ & $1.10987 \mathrm{E}-05$ \\
26054 & $2.97819 \mathrm{E}-06$ & $2.97819 \mathrm{E}-06$ & $2.97819 \mathrm{E}-06$ \\
26056 & $4.67512 \mathrm{E}-05$ & $4.67512 \mathrm{E}-05$ & $4.67512 \mathrm{E}-05$ \\
26057 & $1.07969 \mathrm{E}-06$ & $1.07969 \mathrm{E}-06$ & $1.07969 \mathrm{E}-06$ \\
26058 & $1.43687 \mathrm{E}-07$ & $1.43687 \mathrm{E}-07$ & $1.43687 \mathrm{E}-07$ \\
29063 & $3.53874 \mathrm{E}-05$ & $3.53874 \mathrm{E}-05$ & $3.53874 \mathrm{E}-05$ \\
29065 & $1.57874 \mathrm{E}-05$ & $1.57874 \mathrm{E}-05$ & $1.57874 \mathrm{E}-05$ \\
& $7.96214 \mathrm{E}-02$ & $7.90984 \mathrm{E}-02$ & $7.93747 \mathrm{E}-02$ \\
\hline & & & \\
& & & \\
& & \\
& & \\
& &
\end{tabular}




\subsection{EXPLICIT MCNP MODEL}

In the explicit model, the involute fuel plates within the fuel elements are explicitly modeled, using a set of hexahedra to approximately define the fuel meat, filler, and cladding of the fuel plates and the water between them. This model, as illustrated in Fig. 19, accounts for the variation of the ${ }^{235} \mathrm{U}$ content in the radial direction of the fuel plate by explicitly approximating the radial fuel contour shape.

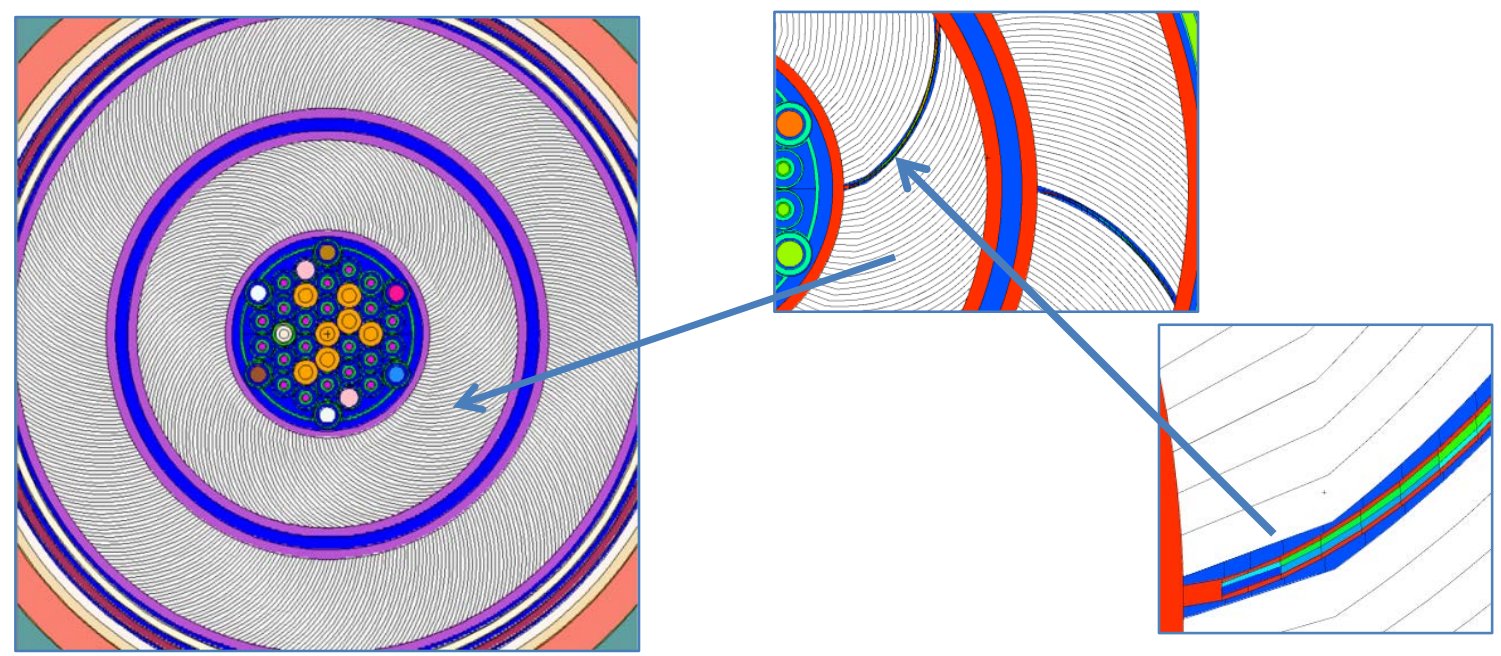

Fig. 19. Explicit modeling of the fuel elements.

\subsubsection{Approximated Fuel Plate Geometry}

The shape of the fuel meat, filler, cladding, and water are approximated with a combination of MCNP-defined surfaces as MCNP lacks an explicit involute surface description. This is essentially a 2D problem of defining a mesh of lines and/or curves that approximate the curvature of the involute and interfaces between the cladding, fuel, and filler materials. The simplest mesh uses straight-line segments to trace out the mesh, resulting in a set of hexahedra describing the involute fuel plate (see Fig. 20).

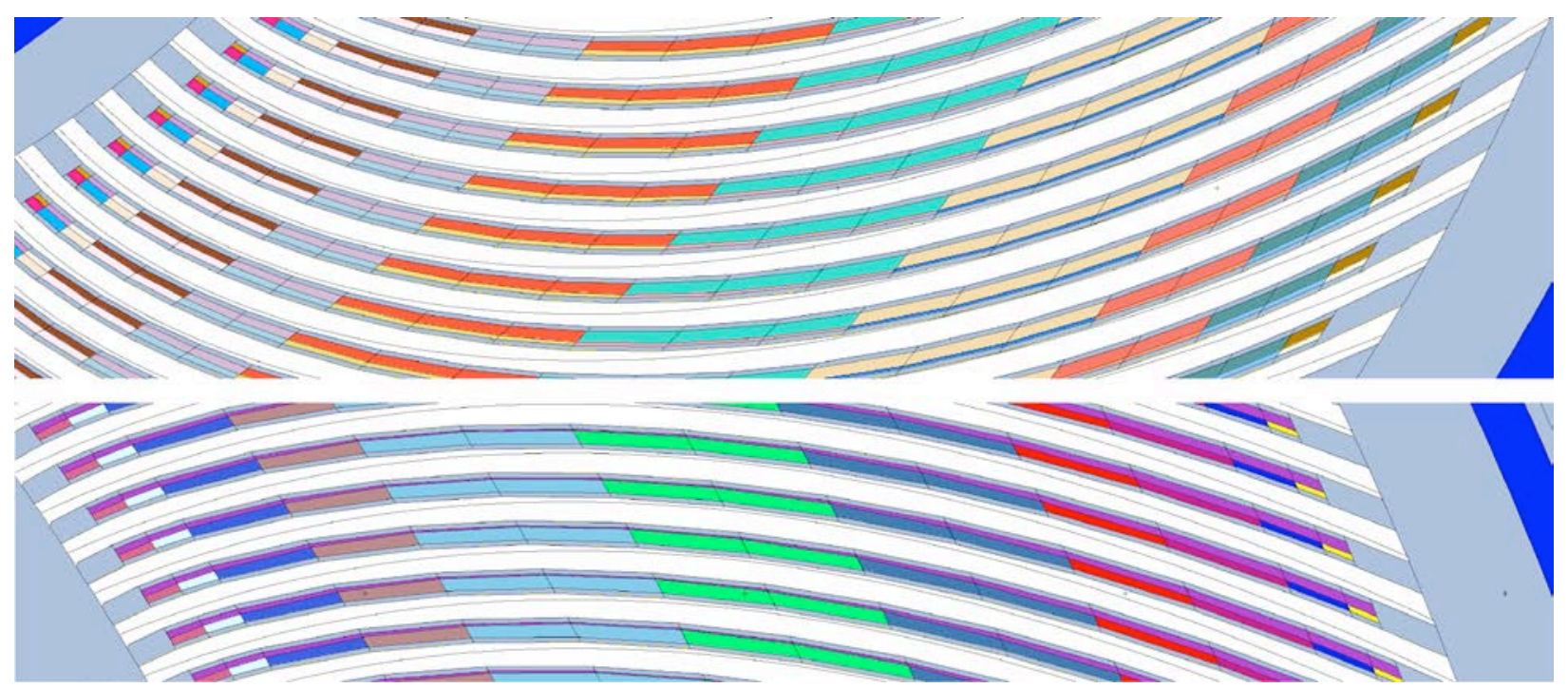

Fig. 20. Approximation of the involute-shaped inner fuel element (top) and outer fuel element (bottom) via sets of hexahedra. 
The approach of approximating involute shapes with series of hexahedra was first proposed by Argonne National Laboratory (ANL) [52]. An initial explicit model proposed for the HFIR fuel plates divided the fuel in the involute plates into 22 equally sized radial segments, or cells [52].

Based on the ANL approach, a Python script was developed to automatically generate an explicit HFIR model for any desired number, size, and location of hexahedra in the approximation. This script generates a mesh such that the vertices of each hexahedron fall along the exact curvature of the involute or interfaces between materials. In the MCNP input, a single fuel plate of the IFE and OFE is defined, duplicated, and rotated to match the total number of fuel plates in each fuel element. An arbitrary polyhedron surface in MCNP is used to define each hexahedron.

In the current explicit model, 21- and 14-hexahedra approximations of the fuel plates are used in the IFE and OFE, respectively. The radii corresponding to the surfaces bounding these hexahedra are listed in Tables 31 and 32. Fewer hexahedra are needed to model the OFE because the radius of its curvature is larger than that of the IFE [53]. Hexahedra at the radial edges of the fuel elements are smaller than those in the middle (see Tables 31 and 32). This representation minimizes the physical differences between the approximated and actual involutes and defines sufficient fuel meshes toward the edges of the fuel elements where high flux gradients exist.

Table 31. Radii of the inner fuel element fuel regions in the explicit model

\begin{tabular}{cccc}
\hline Region & $\mathbf{R}_{\mathbf{i}}(\mathbf{c m})^{\boldsymbol{a}}$ & $\mathbf{R}_{\mathbf{0}} \mathbf{( c m )}$ & $\Delta \mathbf{R}(\mathbf{c m})$ \\
\hline 1 & 7.119504 & 7.20 & 0.080496 \\
2 & 7.20 & 7.35 & 0.15 \\
3 & 7.35 & 7.50 & 0.15 \\
4 & 7.50 & 7.75 & 0.25 \\
5 & 7.75 & 8.00 & 0.25 \\
6 & 8.00 & 8.25 & 0.25 \\
7 & 8.25 & 8.50 & 0.25 \\
8 & 8.50 & 8.85 & 0.35 \\
9 & 8.85 & 9.20 & 0.35 \\
10 & 9.20 & 9.50 & 0.30 \\
11 & 9.50 & 9.85 & 0.35 \\
12 & 9.85 & 10.20 & 0.35 \\
13 & 10.20 & 10.50 & 0.30 \\
14 & 10.50 & 10.85 & 0.35 \\
15 & 10.85 & 11.20 & 0.35 \\
16 & 11.20 & 11.50 & 0.30 \\
17 & 11.50 & 11.75 & 0.25 \\
18 & 11.75 & 12.00 & 0.25 \\
19 & 12.00 & 12.20 & 0.20 \\
20 & 12.20 & 12.40 & 0.20 \\
21 & 12.40 & 12.532386 & 0.132386 \\
\hline
\end{tabular}

${ }^{a} \mathrm{R}_{\mathrm{i}}$ and $\mathrm{R}_{\mathrm{o}}$ are inner and outer radii; $\Delta \mathrm{R}=\mathrm{R}_{\mathrm{o}}-\mathrm{R}_{\mathrm{i}}$. 
Table 32. Radii of the outer fuel element fuel regions in the explicit model

\begin{tabular}{cccc}
\hline Region & $\mathbf{R}_{\mathbf{i}}(\mathbf{c m})^{\boldsymbol{a}}$ & $\mathbf{R}_{\mathbf{0}} \mathbf{( c m )}$ & $\boldsymbol{\Delta} \mathbf{R} \mathbf{( c m )}$ \\
\hline 1 & 15.115859 & 15.30 & 0.184141 \\
2 & 15.30 & 15.50 & 0.20 \\
3 & 15.50 & 16.00 & 0.50 \\
4 & 16.00 & 16.50 & 0.50 \\
5 & 16.50 & 17.00 & 0.50 \\
6 & 17.00 & 17.50 & 0.50 \\
7 & 17.50 & 18.00 & 0.50 \\
8 & 18.00 & 18.50 & 0.50 \\
9 & 18.50 & 19.00 & 0.50 \\
10 & 19.00 & 19.50 & 0.50 \\
11 & 19.50 & 20.00 & 0.50 \\
12 & 20.00 & 20.50 & 0.50 \\
13 & 20.50 & 20.75 & 0.25 \\
14 & 20.75 & 20.870728 & 0.120728 \\
\hline
\end{tabular}

${ }^{a} \mathrm{R}_{\mathrm{i}}$ and $\mathrm{R}_{\mathrm{o}}$ are inner and outer radii; $\Delta \mathrm{R}=\mathrm{R}_{\mathrm{o}}-\mathrm{R}_{\mathrm{i}}$.

\subsubsection{Material Data for Approximated Fuel Plates}

Because the explicit model defines each region of the fuel plates, no materials are homogenized in the fuel regions. But the hexahedron approximation of the involute fuel plates slightly distorts the water-toplate volume ratio in the fuel element regions and the total volume of the fuel meat, filler, and cladding regions. In the IFE and OFE regions and along the full height of the fuel plates $(60.96 \mathrm{~cm})$, the total volume occupied by the fuel plates should be equal to the total volume occupied by the water between the fuel plates (plate thickness and water channel thickness are equal). For the neutronically important materials (the fuel meat, filler with burnable absorbers, and water), this distortion is accounted for via a density adjustment that preserves the total mass of important isotopes. The density of the fuel material is changed from its actual value (see Table 11 ) to conserve the total mass of ${ }^{235} \mathrm{U}$ in a fuel plate, which is $15.25 \mathrm{~g}$ in an IFE plate and $18.52 \mathrm{~g}$ in an OFE plate according to the material certification reports for the fuel elements loaded in Cycle 400. The density of the filler material in the IFE is changed to conserve the total mass of ${ }^{10} \mathrm{~B}$ to $2.709 \mathrm{~g}$. These density adjustments are small (they typically range from $0.5-1.4 \%$ ), and the isotopic composition of the materials is not changed with respect to the content shown in Table 11 for the fuel and Table 14 for the filler. Application of these coefficients would slightly change the values of the number density data provided in Tables 11 and 14.

The density adjustment coefficients used for the IFE and OFE materials for the explicit model approximation used in this report are shown in Table 33. The adjustment to correct the water-to-plate volume ratio to $1: 1$ is very small (it is typically less than $0.05 \%$ ). For the explicit model used in this report, the correction factors used for the density of the in-core water in the IFE and the OFE are listed in Table 33. 
Table 33. Density correction for inner fuel element and outer fuel element materials in the explicit model

\begin{tabular}{cllc}
\hline No. & \multicolumn{1}{c}{ Material } & \multicolumn{1}{c}{ Conserved quantity } & Correction factor \\
\hline 1 & IFE fuel meat & ${ }^{235} \mathrm{U}$ mass per plate $=15.25 \mathrm{~g}$ & 1.011917401 \\
2 & IFE filler & ${ }^{10} \mathrm{~B}$ total mass in IFE $=2.709 \mathrm{~g}$ & 1.013842491 \\
3 & OFE fuel meat & ${ }^{235} \mathrm{U}$ mass per plate $=18.52 \mathrm{~g}$ & 1.010900476 \\
4 & IFE in-core water & plate-to-water volume ratio $=1: 1$ & 1.000006342 \\
5 & OFE in-core water & plate-to-water volume ratio $=1: 1$ & 0.999815890 \\
\hline
\end{tabular}





\section{DESCRIPTION OF DEPLETION MODELS}

In addition to the MCNP model of the configuration to be simulated, the input data for VESTA include information about the depletion mixtures (i.e., materials for which composition varies during simulation due to depletion and decay) and irradiation history. The number of depletion mixtures depends on the approximation used to model the fuel element regions. As discussed in this section, this number is different for the simplified fuel model and the explicit fuel model.

Irrespective of the fuel modeling approximation, there are 20 depletion mixtures used for the CE regions. As discussed in Sections 5.1.2 and 5.2.4 and Appendix A, there are five depletion mixtures for the gray (Ta-Al) region and five for the black $\left(\mathrm{Eu}_{2} \mathrm{O}_{3}-\mathrm{Al}\right)$ region of each of the two CEs.

The depletion simulation for which results are shown in this report used 25 depletion steps, with 24 steps of 1 day each and 1 step of 16 h. However, scoping studies with finer depletion steps were performed to assess the effect of the number of steps and their size on the simulation results, especially for irradiation times close to BOC. It was found that the 25 depletion steps were appropriate for the calculation of the data of interest at BOC, mid-cycle, and end-of-cycle (EOC).

Actual irradiation history data and CE locations during the cycle (as available from HFIR operator records) were used in the model. The location of the two HFIR CEs can be changed in the VESTA model for each of the depletion steps considered. The CE location as a function of irradiation time that was shown in Section 5.2.4 was used in the depletion model. The CEs were close to the core midplane at BOC and were fully withdrawn at EOC (see Fig. 9 in Section 5.1.2).The power used for the depletion simulation is $56.5 \mathrm{MW}$ for the first irradiation day and $85 \mathrm{MW}$ for the rest of the cycle time. A power of $56.5 \mathrm{MW}$ is used for the first day because during reactor start-up the power is increased in increments of $20 \%$ or less and power hold points are often encountered for neutron activation analysis experiments and/or for instrument calibration. The accumulated burnup for Cycle 400 in the first day was $56.5 \mathrm{MWd}$.

The MCNP transport step within the VESTA simulation uses 300 active cycles, 50 inactive cycles, and 100,000 particles per cycle. As discussed in [53], this eigenvalue source definition is adequate to ensure the source convergence (all source convergence tests related to eigenvalue are passed).

\subsection{DEPLETION WITH SIMPLIFIED FUEL MODEL}

In the simplified model, there are a total of 209 spatial fuel meshes each in the IFE and OFE (11 radial by 19 axial) for a total of 418. A unique depletion mixture is used for each spatial fuel mesh in the model; therefore, 418 fuel depletion mixtures are present in the VESTA model. In this model, the same identifier is used for the fuel mesh and the material present in that mesh. The fuel meshes and the materials filling those meshes are identified (numbered) as 2ZZRR for the IFE and 3ZZRR for the OFE, where ZZ specifies the axial mesh number and RR the radial mesh number; for example, material 20911 stands for the spatial fuel mesh and corresponding material number within the axial mesh 9 and radial mesh 11 of the IFE. The numbering of the axial mesh starts at the top of the fuel element active regionaxial mesh 1 is at the top of the active fuel, and axial mesh 25 is at the bottom of the active fuel.

\subsection{DEPLETION WITH EXPLICIT FUEL MODEL}

In the current explicit model, 11 radial depletion mixtures are distributed into the 21- and 14-hexahedra approximations used for the fuel plates in the IFE and OFE, respectively. There are 19 axial meshes and depletion mixtures for each radial depletion mesh. Therefore, the total number of fuel depletion mixtures in the model is 418, with 209 in each of the two fuel elements. The radial and axial boundaries defining the explicit model's depletion mesh are identical to those used for the simplified model. 



\section{PERFORMANCE AND SAFETY METRICS}

The calculation of relevant performance and safety parameters for Cycle 400 at the BOC and EOC states is discussed in this section. These parameters are not directly provided in VESTA output files, and their calculation requires extensive post-processing and model changes, as summarized here. The VESTA output includes the following: isotopic composition in at/b-cm units as a function of burnup step for each depleted material, microscopic cross sections for the nuclides in each depleted material as a function of the burnup step, and MCNP input and output files that correspond to each burnup step used in the depletion simulation.

\subsection{PERFORMANCE METRICS}

\subsubsection{Eigenvalue}

The eigenvalue, $\mathrm{k}_{\mathrm{eff}}$, corresponding to the end of each depletion step can be extracted from the MCNP output files produced by VESTA. The calculated value of $\mathrm{k}_{\mathrm{eff}}$ for the simplified model is 0.99865 $(\sigma=0.00015)$ at BOC and $1.00111(\sigma=0.00015)$ at EOC. The calculated value of $\mathrm{k}_{\text {eff }}$ for the explicit model is $0.99430(\sigma=0.00016)$ at BOC and $0.99842(\sigma=0.00014)$ at EOC. The variation of $k_{\text {eff }}$ with the irradiation time for both simplified and explicit models is illustrated in Fig. 21.

The simplified model $k_{\text {eff }}$ varies during the cycle within $\pm 250 \mathrm{pcm}\left(1 \mathrm{pcm}=10^{-5}\right)$ of 1.000 . There is a clear bias between the $\mathrm{k}_{\text {eff }}$ trajectories obtained with the two models, simplified and explicit, though the relative trend as a function of irradiation time is similar. The $\mathrm{k}_{\mathrm{eff}}$ difference between the two models varies between 300 and 400 pcm, with the largest difference occurring at BOC.

For a given model, the sharp variation of $\mathrm{k}_{\mathrm{eff}}$ at shorter irradiation times is mainly caused by the modeling of ${ }^{135}$ Xe buildup and the uncertainty in the power variation during the first day of irradiation, as discussed in this section. The $\mathrm{k}_{\text {eff }}$ values at longer irradiation times are closer to the critical value. This type of variation is likely due to the modeling of the CEs; the CE positions vary during the cycle and are fully withdrawn at EOC, and their worth varies during the cycle.

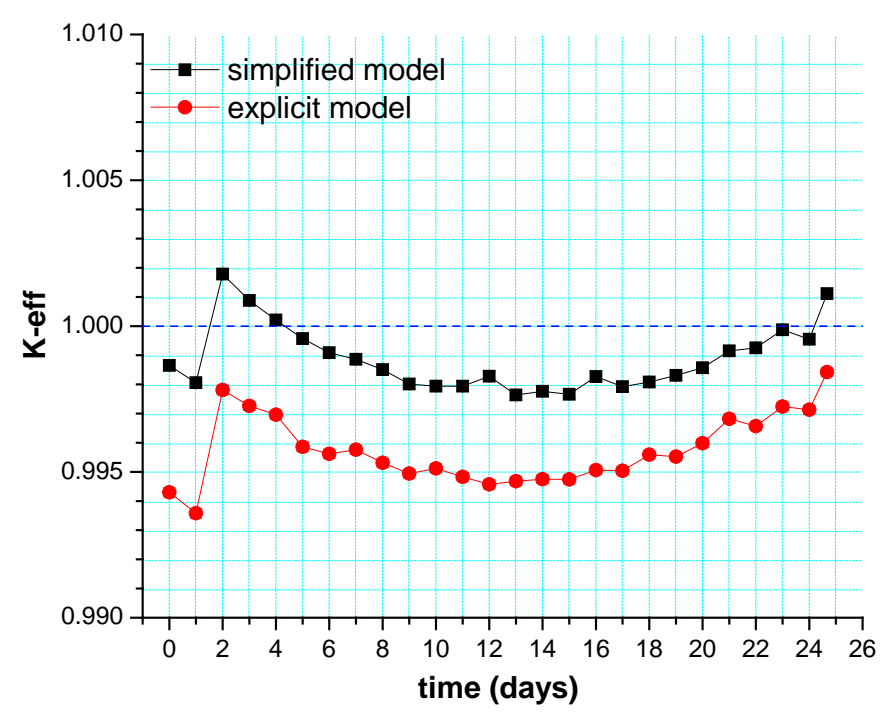

Fig. 21. Variation of $\mathbf{k}_{\text {eff }}$ with irradiation time. 
The effect of the size of the depletion step on eigenvalue is illustrated in Fig. 22 for the simplified model. This figure compares $k_{\text {eff }}$ data obtained for two cases: (1) 25 depletion steps, with the CE positions as discussed in Section 5.1.2, and (2) 55 depletion steps, with the step size being refined especially between days 2 and 4 of the irradiation, when ${ }^{135} \mathrm{Xe}$ is expected to reach its maximum content. In both cases, the CE positions correspond to the operator data recorded for the corresponding times. The depletion step refinement does not change the general trend of the $\mathrm{k}_{\mathrm{eff}}$ variation with the irradiation time. The largest variation between the two considered cases is observed for the first few irradiation days and can be correlated to the change in the as-predicted ${ }^{135} \mathrm{Xe}$ content in each of the cases (see Fig. 23, which shows the variation of the mass of ${ }^{135} \mathrm{Xe}$ in the core over time). The maximum content for ${ }^{135} \mathrm{Xe}$ is predicted to be reached at 2.75 days of irradiation in the case that uses 55 depletion steps and at 3 days of irradiation for the case that uses 25 depletion steps.

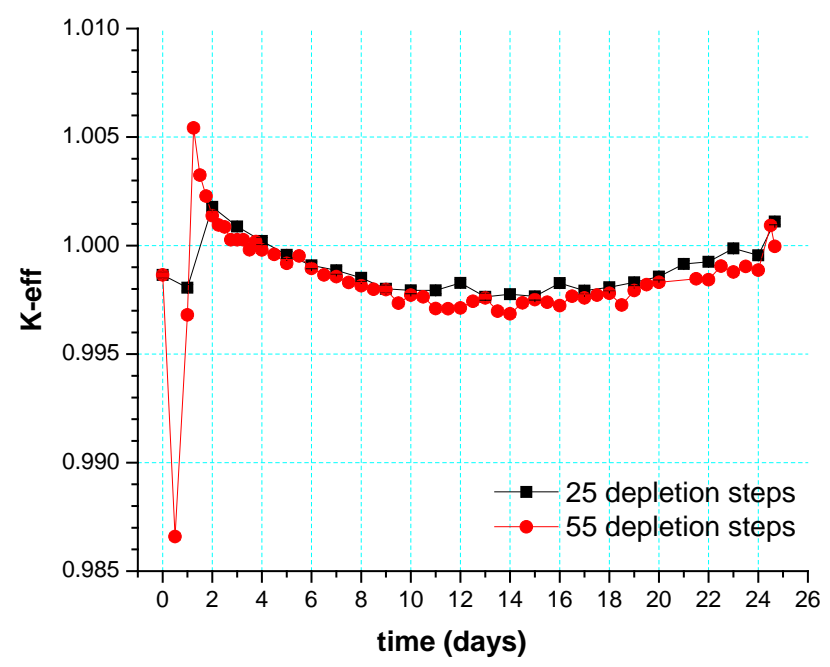

Fig. 22. Effect of depletion step size on $\mathbf{k}_{\text {eff }}$ variation during reactor cycle.

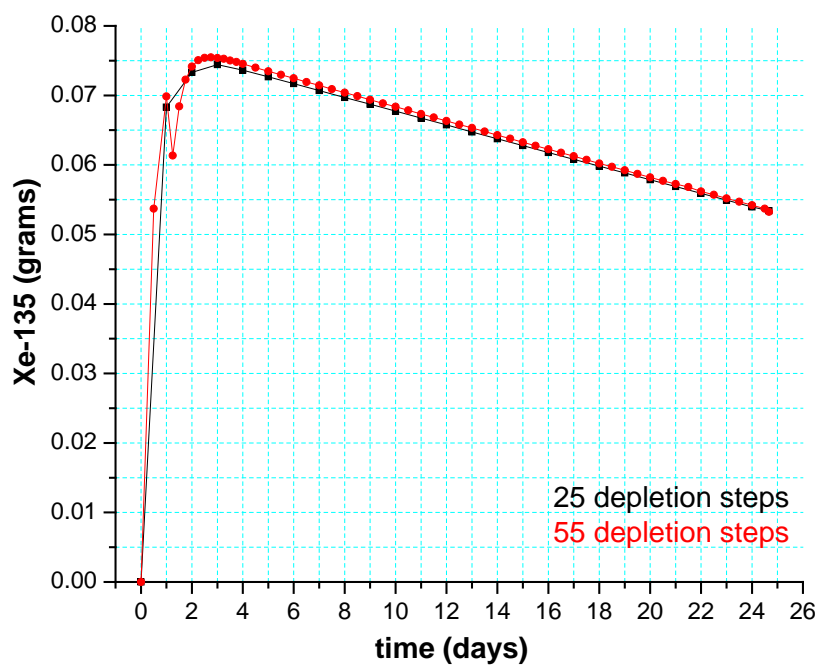

Fig. 23. Variation of ${ }^{135} \mathrm{Xe}$ content during reactor cycle. 
Note that the power used for the depletion simulation for the first day of the cycle is $56.6 \mathrm{MW}$, whereas for the rest of the cycle it is $85 \mathrm{MW}$. The sudden decrease in $\mathrm{k}_{\text {eff }}$ and ${ }^{135} \mathrm{Xe}$ between 24 and 30 hours of irradiation, as shown in Figs. 22 and 23 for the case using 55 depletion steps, is caused by the effect that the sudden increase in power (i.e., step jump by $28.5 \mathrm{MW}$ ) has on the ${ }^{135} \mathrm{I}$ and ${ }^{135} \mathrm{Xe}$ concentrations. This effect is not captured in the case using 25 depletion steps because the step sizes following the power increase differ for the two cases. As noted in Section 7, there is uncertainty in the actual value of the power for the first irradiation day, during reactor start-up.

The variation of the ${ }^{10} \mathrm{~B}$ content in the IFE filler as a function of the irradiation time is illustrated in Fig. 24 for both the explicit and simplified models. This figure shows how the ${ }^{10} \mathrm{~B}$ content varies in time relative to its content at BOC. Given the large effect on reactivity of this strong neutron absorber nuclide, the comparison of its depletion during the cycle, predicted with each of the two models, may indicate whether it is a potential factor in the $\mathrm{k}_{\mathrm{eff}}$ difference seen for the two models. At BOC there are $2.709 \mathrm{~g}$ of ${ }^{10} \mathrm{~B}$ in the IFE filler. At EOC almost all of ${ }^{10} \mathrm{~B}$ is consumed; its content decreases to 0.069 of its initial value for the simplified model and to 0.073 of its initial value for the explicit model. As seen in Fig. 24, the trajectories for the relative ${ }^{10} \mathrm{~B}$ content are similar for the two models.

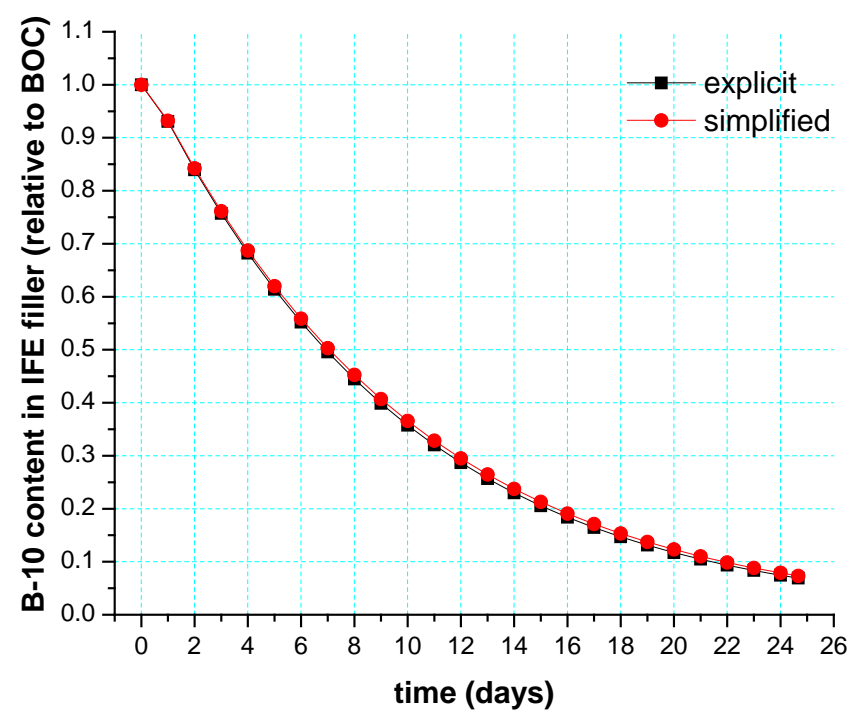

Fig. 24. Variation of ${ }^{10} \mathrm{~B}$ content during reactor cycle.

\subsubsection{Neutron Flux}

The neutron flux level is one of the key parameters for characterizing core performance, and in particular its capability to meet the experimental needs of the reactor's users. Three-group flux data were estimated based on MCNP flux tallies. The energy structure used for the three-group data is as follows: thermal $<0.625 \mathrm{eV}$; epithermal, $0.625 \mathrm{eV}-100 \mathrm{keV}$; and fast, $100 \mathrm{keV}-20 \mathrm{MeV}$. The neutron flux tallies provided by MCNP are normalized to the source (i.e., one fission neutron). The flux values, in neutrons $/ \mathrm{cm}^{2} \mathrm{~s}$, were obtained by multiplying the flux tally values given by MCNP by the total source. The total source $S$ was approximated as

$$
S=\frac{v P}{k_{e f f} Q e}
$$


where $v$ is the average number of neutrons per fission, $P$ is the reactor power in $\mathrm{MW}, Q$ is the average energy per fission in MeVmegaelectron volts, $k_{\text {eff }}$ is the eigenvalue, and $e$ is a unit conversion factor $\left(1.6 \times 10^{-19} \mathrm{MJ} / \mathrm{MeV}\right)$. An approximate value of $200 \mathrm{MeV} /$ fission is used for $Q, P$ is $85 \mathrm{MW}$, and the $v$ and $k_{\text {eff }}$ values are taken from the MCNP output.

\subsubsection{Three-group flux at relevant locations}

Three-group flux data at BOC and EOC are presented in Tables 34 and 35 for the following locations: central target in flux trap, reflector at $27.5 \mathrm{~cm}$ radius, cold source edge at $35 \mathrm{~cm}$ radius, fuel element region (average thermal flux over the IFE and OFE), and targets in the RB (maximum flux value). The relative standard deviation for the tallied flux is less than $1 \%$ in all cases.

Table 34. Flux data at beginning-of-cycle

\begin{tabular}{llccc}
\hline \multicolumn{1}{c}{ Location } & $\begin{array}{c}\text { Fuel } \\
\text { model }\end{array}$ & $\begin{array}{c}\text { Thermal flux } \\
\left(\mathbf{n} / \mathbf{c m}^{2} \mathbf{s}\right)\end{array}$ & $\begin{array}{c}\text { Epithermal flux } \\
\left(\mathbf{n} / \mathbf{c m}^{2} \mathbf{s}\right)\end{array}$ & $\begin{array}{c}\text { Fast flux } \\
\left(\mathbf{n} / \mathbf{c m}^{2} \mathbf{s}\right)\end{array}$ \\
\hline $\begin{array}{l}\text { Central target }^{a} \\
(\mathrm{r}=0.0 \mathrm{~cm})\end{array}$ & simplified & $2.15 \times 10^{15}$ & $1.34 \times 10^{15}$ & $1.15 \times 10^{15}$ \\
Reflector $^{b}$ & explicit & $2.15 \times 10^{15}$ & $1.36 \times 10^{15}$ & $1.17 \times 10^{15}$ \\
$(\mathrm{r}=27.5 \mathrm{~cm})$ & simplified & $8.51 \times 10^{14}$ & $7.16 \times 10^{14}$ & $4.35 \times 10^{14}$ \\
Cold source edge $^{b}$ & explicit & $8.56 \times 10^{14}$ & $7.20 \times 10^{14}$ & $4.38 \times 10^{14}$ \\
$(\mathrm{r}=35.0 \mathrm{~cm})$ & simplified & $6.49 \times 10^{14}$ & $2.29 \times 10^{14}$ & $9.01 \times 10^{13}$ \\
Removable beryllium reflector $^{c}$ & explicit & $6.53 \times 10^{14}$ & $2.30 \times 10^{14}$ & $9.07 \times 10^{13}$ \\
(maximum flux) $^{\text {Fuel region (inner fuel element }+}$ & simplified & $1.01 \times 10^{15}$ & $8.11 \times 10^{14}$ & $5.02 \times 10^{14}$ \\
$\begin{array}{l}\text { outer fuel element) } \\
\text { (average flux) }\end{array}$ & explicit & $1.02 \times 10^{15}$ & $8.16 \times 10^{14}$ & $4.95 \times 10^{14}$ \\
\hline
\end{tabular}

${ }^{a}$ Regular flux tallies in cylindrical region with $1 \mathrm{~cm}$ height located at the core center in the flux trap target.

${ }^{b}$ Ring detector tallies.

${ }^{c}$ Maximum flux values in targets located in the removable beryllium reflector.

Table 35. Flux data at end-of-cycle

\begin{tabular}{llccc}
\hline \multicolumn{1}{c}{ Location } & $\begin{array}{c}\text { Fuel } \\
\text { model }\end{array}$ & $\begin{array}{c}\text { Thermal flux } \\
\left(\mathbf{n} / \mathbf{c m}^{2} \mathbf{s}\right)\end{array}$ & $\begin{array}{c}\text { Epithermal flux } \\
\left(\mathbf{n} / \mathbf{c m}^{2} \mathbf{s}\right)\end{array}$ & $\begin{array}{c}\text { Fast flux } \\
\left(\mathbf{n} / \mathbf{c m}^{2} \mathbf{s}\right)\end{array}$ \\
\hline $\begin{array}{l}\text { Central target }^{a} \\
(\mathrm{r}=0.0 \mathrm{~cm})\end{array}$ & $\begin{array}{l}\text { simplified } \\
\text { explicit }\end{array}$ & $2.14 \times 10^{15}$ & $1.19 \times 10^{15}$ & $9.84 \times 10^{14}$ \\
Reflector $^{b}$ & $2.15 \times 10^{15}$ & $1.17 \times 10^{15}$ & $9.90 \times 10^{14}$ \\
$(\mathrm{r}=27.5 \mathrm{~cm})$ & $\begin{array}{l}\text { simplified } \\
\text { explicit }\end{array}$ & $1.21 \times 10^{14}$ & $7.27 \times 10^{14}$ & $4.27 \times 10^{14}$ \\
Cold source edge $^{b}$ & $1.21 \times 10^{14}$ & $7.28 \times 10^{14}$ & $4.29 \times 10^{14}$ \\
$(\mathrm{r}=35.0 \mathrm{~cm})$ & simplified & $8.17 \times 10^{14}$ & $2.32 \times 10^{14}$ & $9.06 \times 10^{13}$ \\
Removable beryllium reflector $^{c}$ & explicit & $8.18 \times 10^{14}$ & $2.33 \times 10^{14}$ & $9.10 \times 10^{13}$ \\
(maximum flux) $_{\text {Fuel region (inner fuel element }+}$ & simplified & $1.43 \times 10^{15}$ & $8.21 \times 10^{14}$ & $4.91 \times 10^{14}$ \\
$\begin{array}{l}\text { outer fuel element) } \\
\text { (average flux) }\end{array}$ & explicit & $1.44 \times 10^{15}$ & $8.41 \times 10^{14}$ & $4.90 \times 10^{14}$ \\
\hline & simplified & $4.36 \times 10^{14}$ & $9.91 \times 10^{14}$ & $1.30 \times 10^{15}$ \\
\hline
\end{tabular}

\footnotetext{
${ }^{a}$ Regular flux tallies in cylindrical region with $1 \mathrm{~cm}$ height located at the core center in the flux trap target.

${ }^{b}$ Ring detector tallies.

${ }^{c}$ Maximum flux values in targets located in the removable beryllium reflector.
} 


\subsubsection{Spatial variation of neutron flux}

Mesh tallies in MCNP were used to extract the flux within HFIR distributed across specific directions, areas, or volumes. The three-group flux distributions discussed here were obtained from three mesh tallies: (1) flux within 2,000 radial meshes at the core horizontal midplane $(-1 \mathrm{~cm} \leq \mathrm{z} \leq 1 \mathrm{~cm})$ and integrated over all azimuthal directions; (2) flux over a $200 \times 200 \mathrm{R}-\mathrm{Z}$ (radial $\times$ axial) mesh and integrated over all azimuthal directions, and (3) flux over a $300 \times 300 \mathrm{X}-\mathrm{Y}$ mesh at the core horizontal midplane. These types of fluxes were generated for both the simplified and explicit models. As expected, they do not show any significant differences between the simplified and explicit models, so only the plots for the explicit models are included here. To enable a consistent comparison with similar plots in [1], some of them obtained from HFIR critical core experiments in the 1970s, the neutron flux distributions in this section are expressed per unit power using units of neutrons $/ \mathrm{cm}^{2} \mathrm{~s}$ MW.

Only flux distributions corresponding to BOC are shown in this section. The same type of plots, for EOC, are presented in Appendix B. The radial flux distribution within HFIR, from the reactor vertical centerline to the outer edge of the permanent beryllium reflector, is presented in Fig. 25, which also illustrates the relative location within the reactor of the two fuel elements, control region, and reflector. The R-Z flux distributions for the thermal, epithermal, and fast flux are presented in Fig. 26-28. The X-Y flux distributions at reactor horizontal midplane for the thermal, epithermal, and fast flux are shown in Figs. 29-31. The relative magnitude of the fluxes in each main region of the reactor and the impact on flux of various targets are clearly seen in these figures. For example, the effect on flux of the experiment in location RB-7A is clearly seen in Figs. 28-29. This experiment had a europium liner; therefore, it has a significant effect on thermal flux due to the strong absorption properties of the europium isotopes.

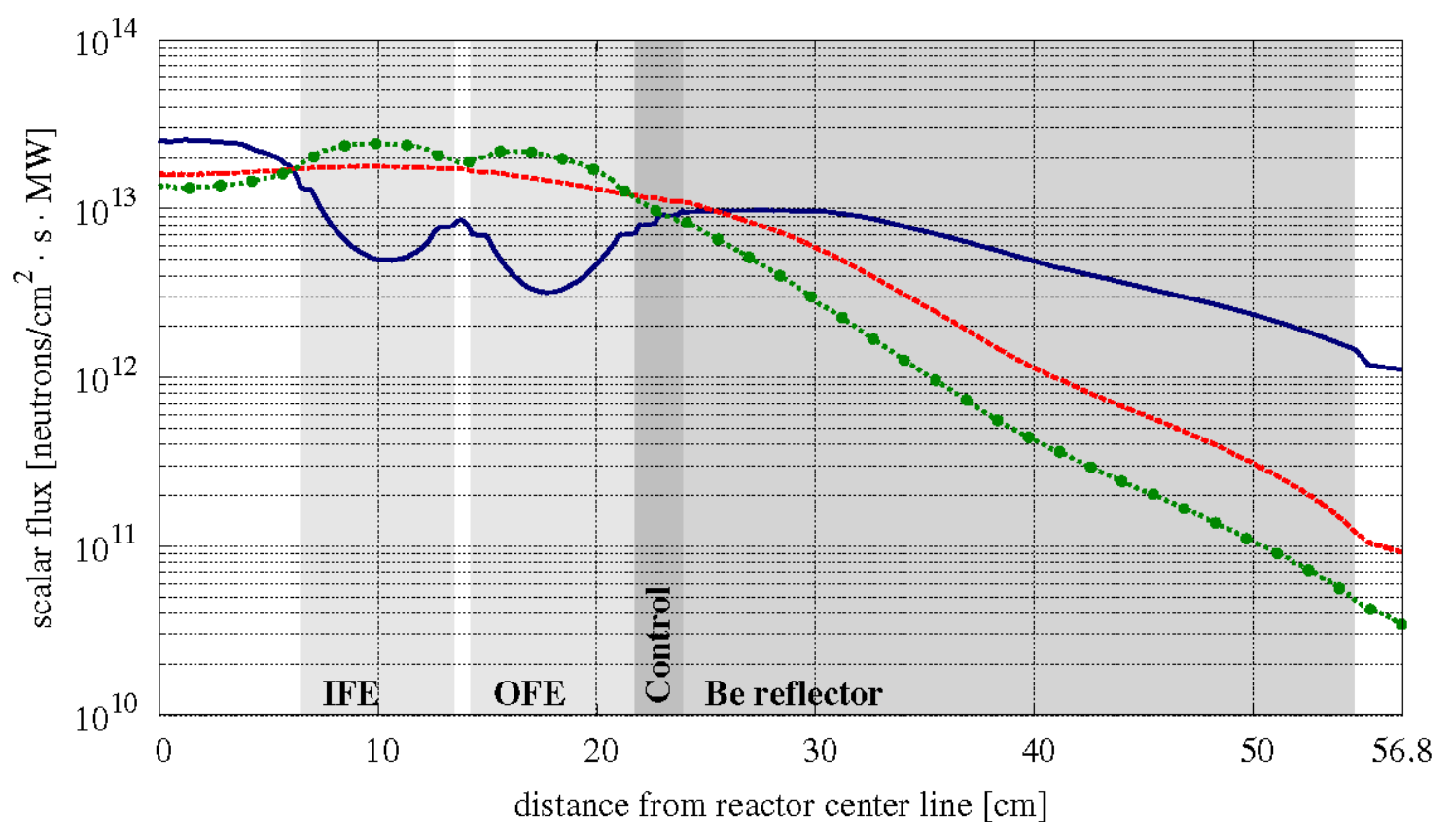

thermal $\longrightarrow \quad$ epithermal -------- $\quad$ fast $\cdots \cdots \cdot \cdots \cdot \cdots$

Fig. 25. Radial flux distribution within HFIR at beginning-of-cycle. (IFE = inner fuel element, OFE = outer fuel element.) 


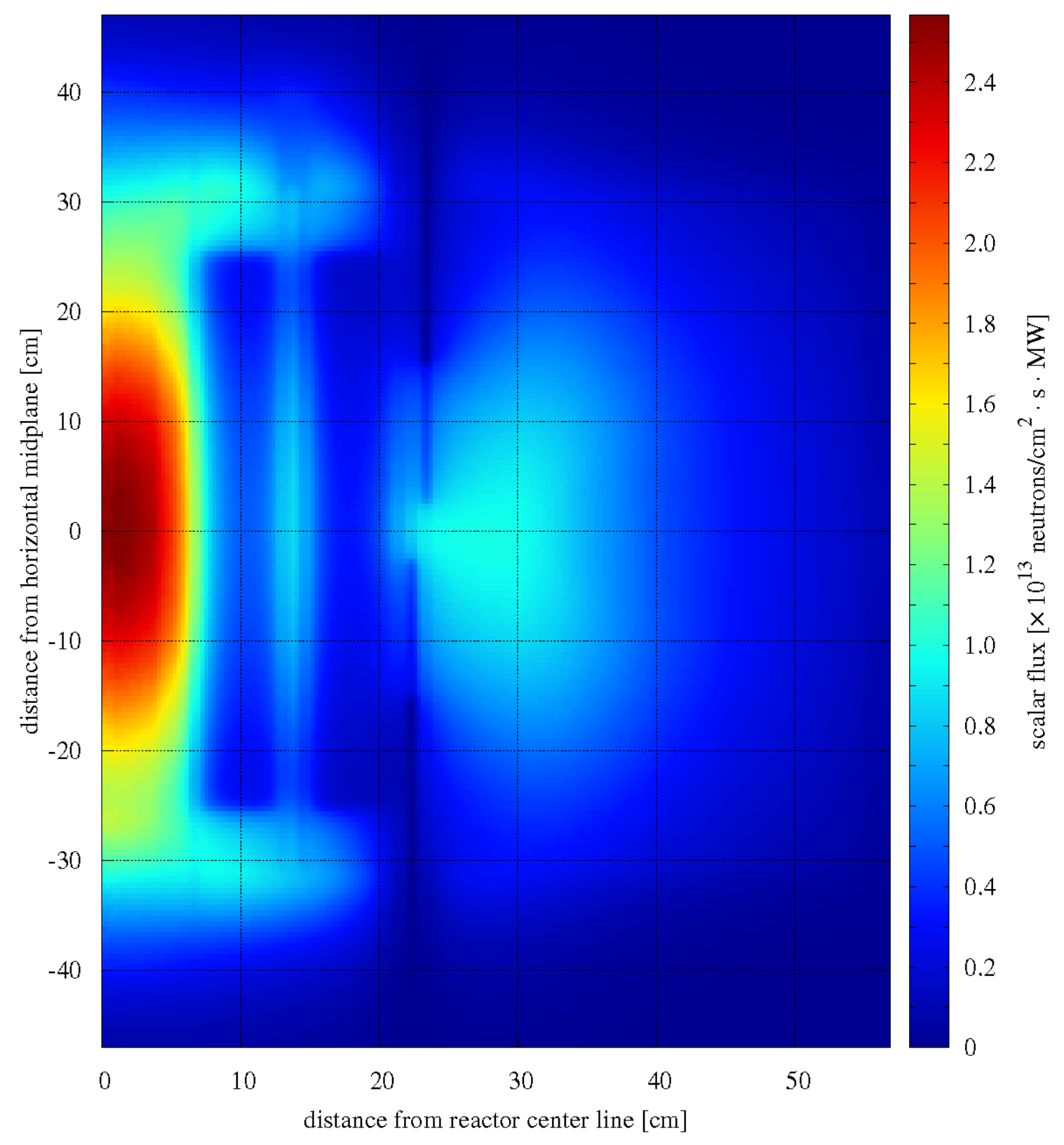

Fig. 26. R-Z thermal flux distribution within HFIR at beginning-of-cycle. 


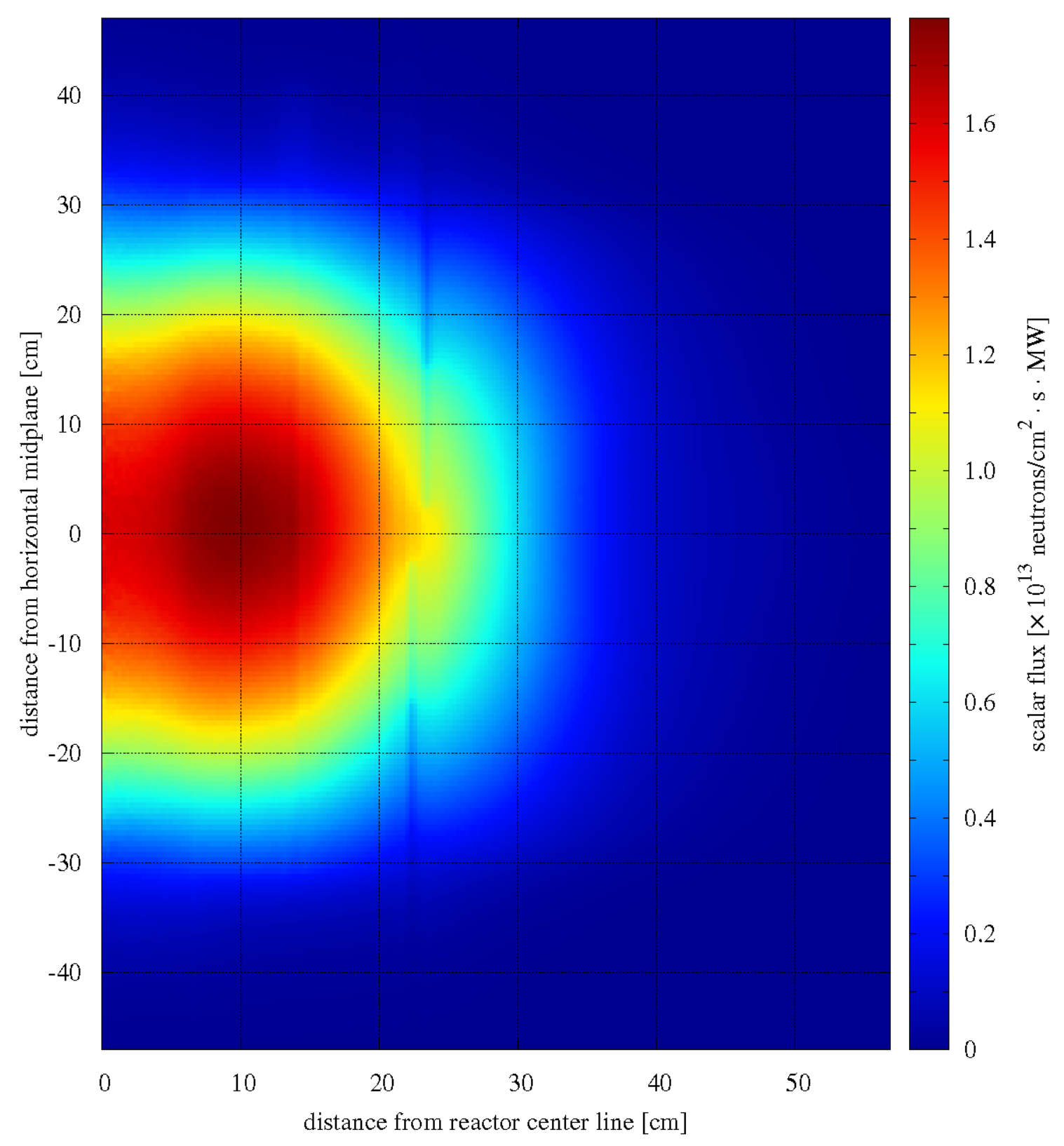

Fig. 27. R-Z epithermal flux distribution within HFIR at beginning-of-cycle. 


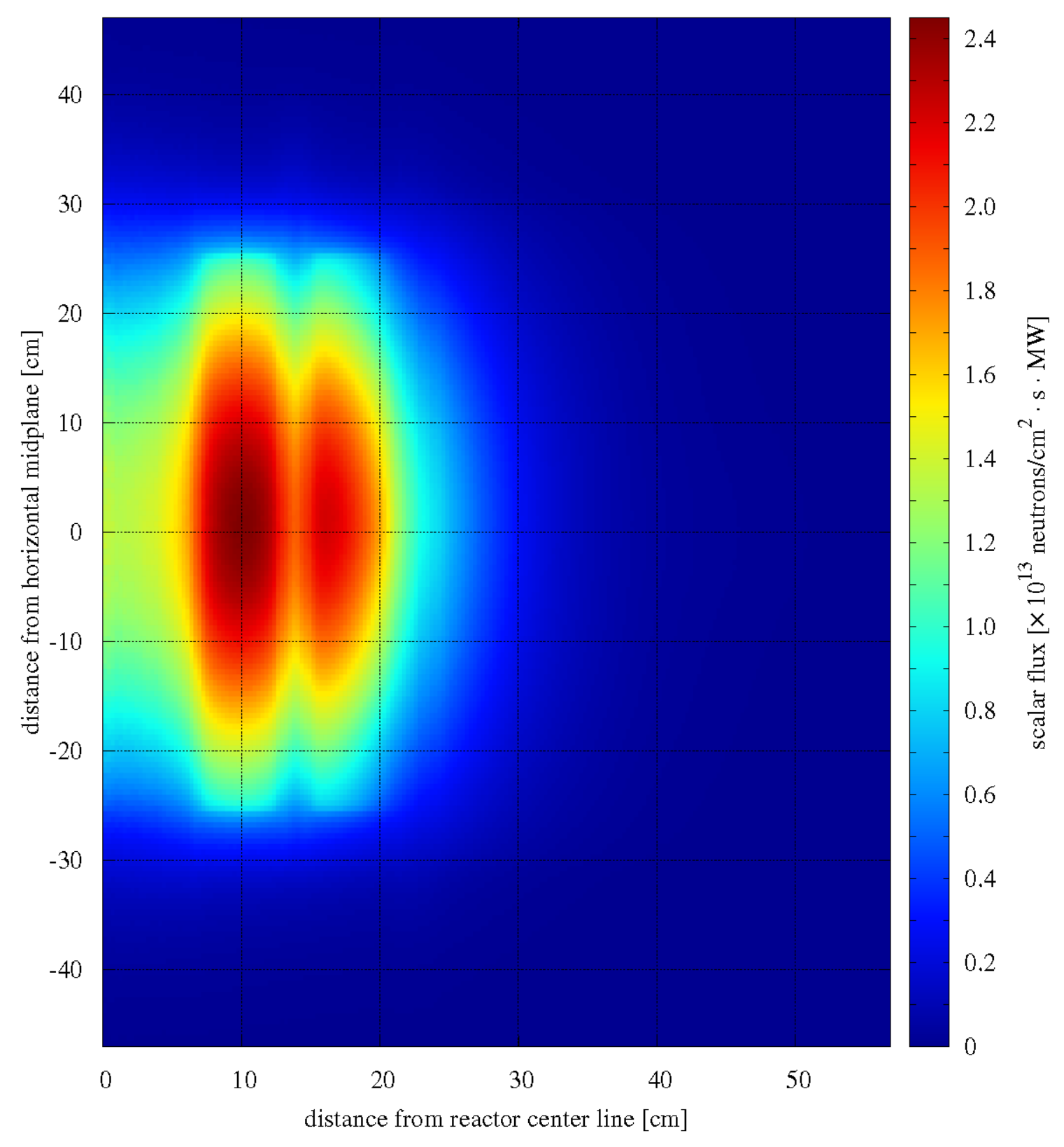

Fig. 28. R-Z fast flux distribution within HFIR at beginning-of-cycle. 


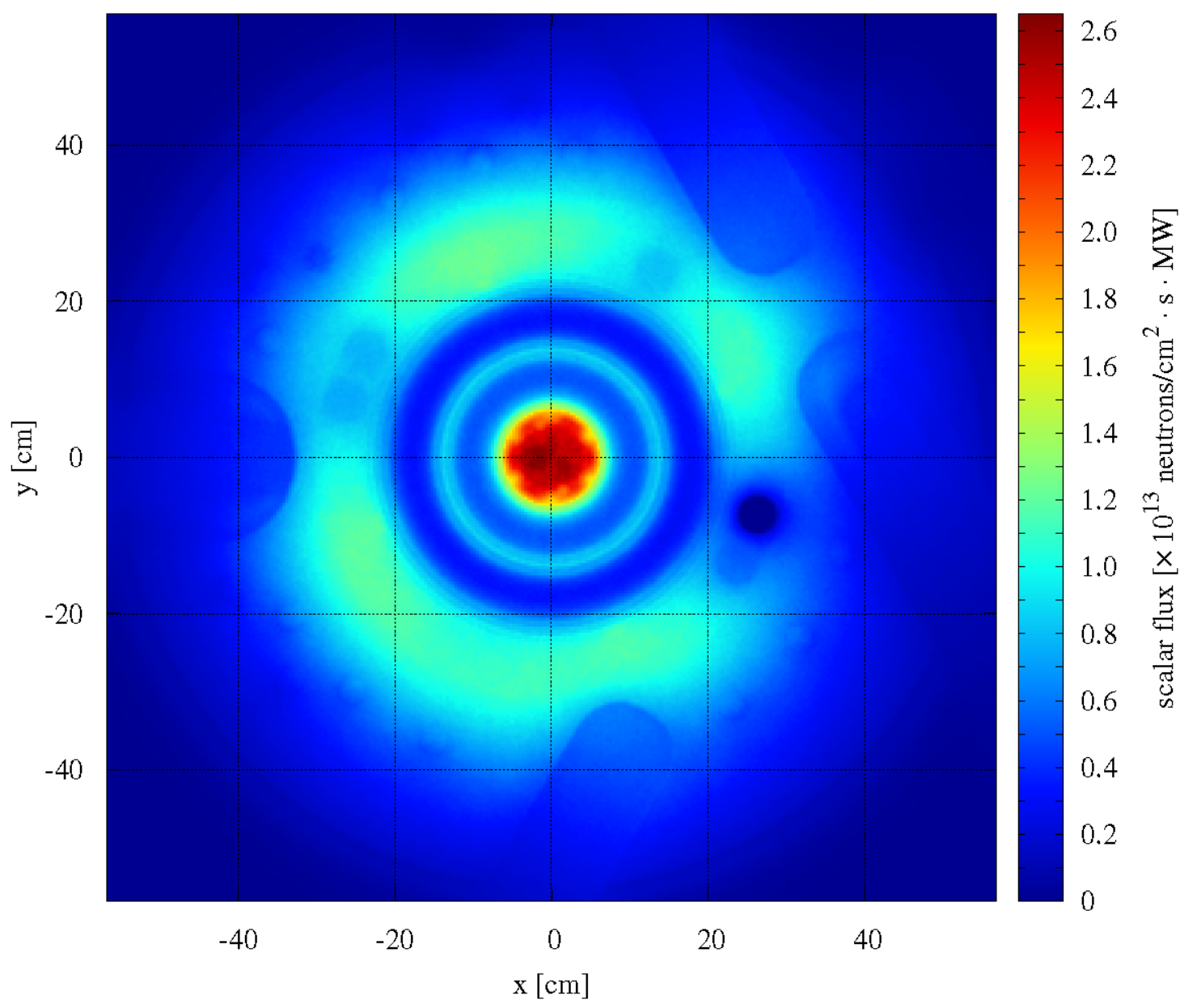

Fig. 29. X-Y thermal flux distribution at the horizontal midplane within HFIR at beginning-of-cycle. 


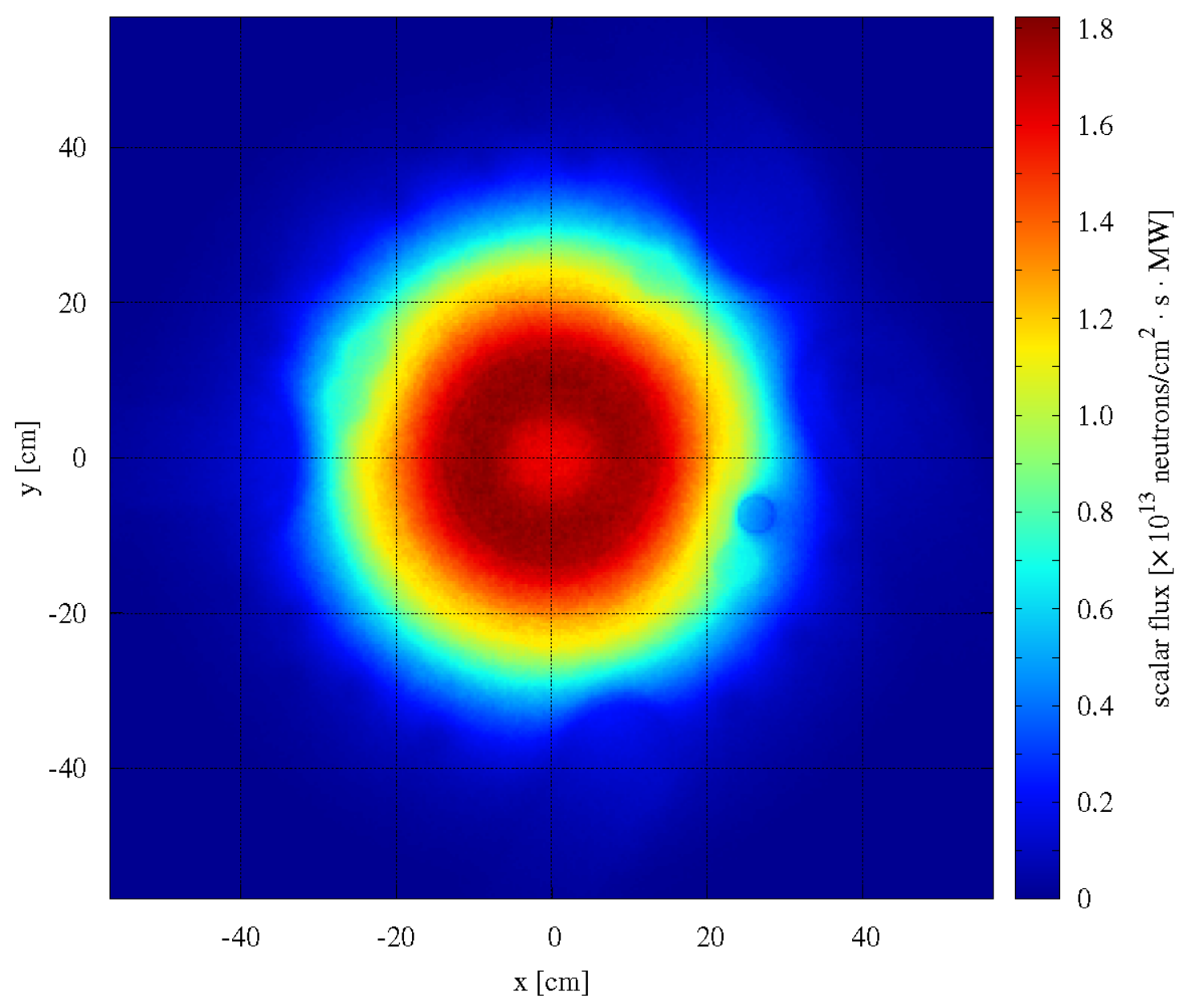

Fig. 30. X-Y epithermal flux distribution at the horizontal midplane within the HFIR at beginning-of-cycle. 


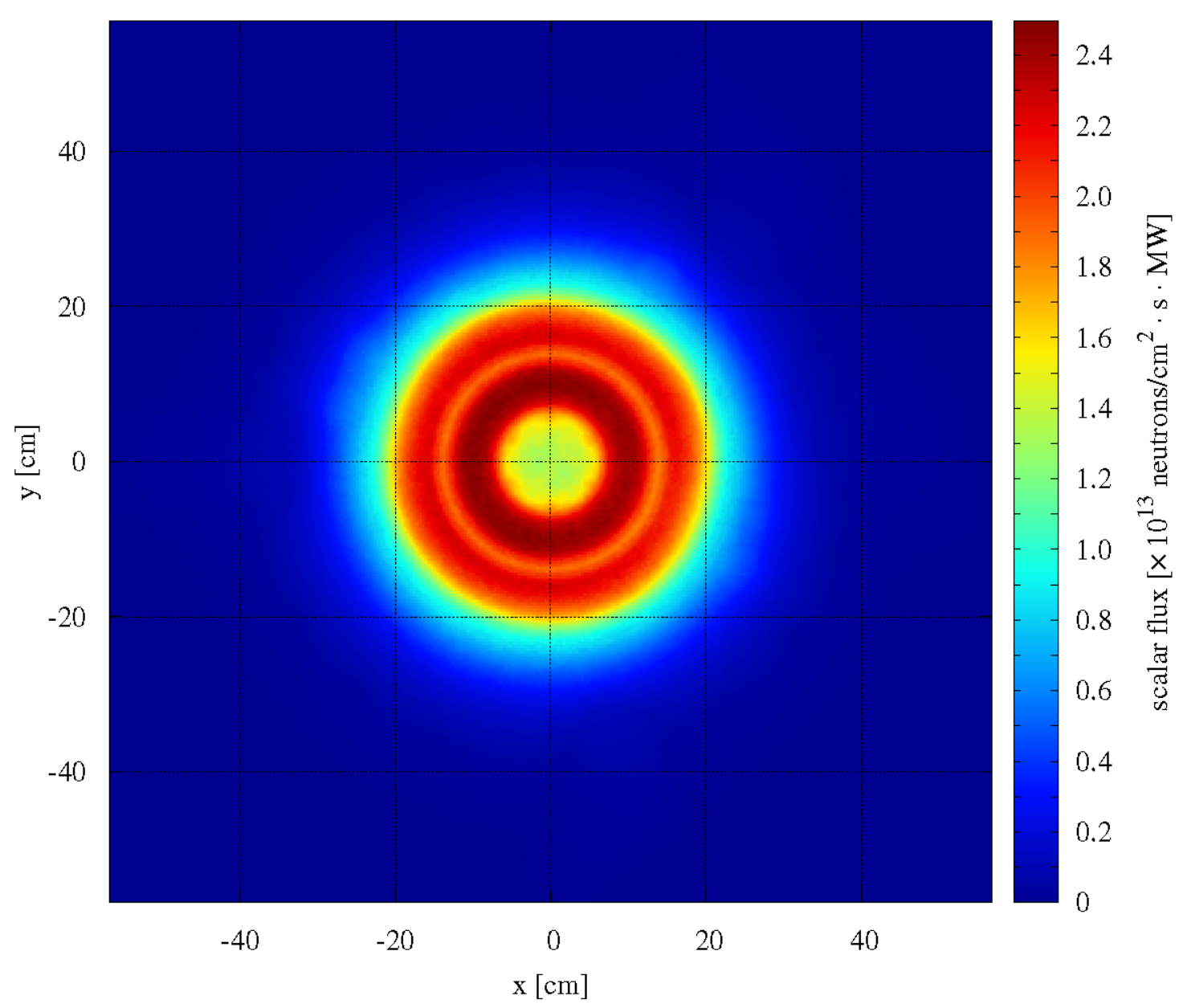
cycle.

Fig. 31. X-Y fast flux distribution at the horizontal midplane within HFIR at beginning-of-

\subsubsection{Fission Density Distribution}

The relative fission density data were calculated for BOC, EOC, and mid-cycle (day 13). The relative fission density $f_{i}^{d}$ in a spatial mesh $i$ located in the fuel region was calculated as

$$
f_{i}^{d}=\frac{\int_{i} d^{3} r \int_{E} d E \Sigma_{f}(r, E) \Phi(r, E)}{\sum_{i=1}^{N} \int_{i} d^{3} r \int_{E} d E \Sigma_{f}(r, E) \Phi(r, E)}
$$

where $r$ and $E$ are the spatial and energy variables, respectively, and $\Sigma_{f}$ and $\Phi$ are the macroscopic fission cross section and neutron scalar flux, respectively. The calculated data obtained with the simplified model at BOC and EOC are given in Tables 36 and 37. The corresponding data obtained with the explicit model are shown in Tables 38 and 39 and illustrated in Figs. 32 and 33. The data corresponding to day 13 in the cycle are shown in Appendix C. 
Table 36. Relative fission density at beginning-of-cycle (simplified model)

\begin{tabular}{|c|c|c|c|c|c|c|c|c|c|c|c|c|c|c|c|c|c|c|c|c|c|c|}
\hline \multirow{2}{*}{$\begin{array}{c}\text { Axial } \\
\text { region }\end{array}$} & \multicolumn{11}{|c|}{ IFE } & \multicolumn{11}{|c|}{ OFE } \\
\hline & $\mathbf{r}=\mathbf{1}^{a}$ & $r=2$ & $r=3$ & $r=4$ & $r=5$ & $r=6$ & $\mathrm{r}=7$ & $r=8$ & $\mathbf{r}=9$ & $r=10$ & $r=11$ & $r=1$ & $r=2$ & $r=3$ & $r=4$ & $r=5$ & $r=6$ & $r=7$ & $r=8$ & $r=9$ & $r=10$ & $r=11$ \\
\hline 1 & 1.074 & 1.073 & 1.086 & 1.126 & 1.186 & 1.269 & 1.339 & 1.320 & 1.268 & 1.250 & 1.260 & 1.263 & 1.258 & 1.271 & 1.272 & 1.211 & 1.032 & 0.792 & 0.601 & 0.478 & 0.395 & 0.362 \\
\hline 2 & 989 & 0.972 & 0.960 & 0.961 & 0.969 & 001 & 1.032 & .029 & 1.023 & 1.053 & 1.106 & 1.112 & 1.070 & 1.032 & 0.985 & 0.905 & 0.770 & 0.614 & 0.490 & 0.408 & 0.349 & 0.328 \\
\hline 3 & 0.929 & 0.910 & 0.888 & 0.871 & 0.851 & 0.847 & 0.855 & 0.864 & 0.889 & 0.938 & 1.001 & 1.006 & 0.959 & 0.904 & 0.843 & 0.753 & 0.636 & 0.519 & 0.426 & 0.365 & 0.322 & 0.304 \\
\hline 4 & 0.910 & 0.890 & 0.867 & 0.838 & 0.803 & 0.784 & 0.783 & 0.797 & 0.833 & 0.887 & 0.949 & 0.953 & 0.909 & 0.853 & 0.790 & 0.702 & 0.594 & 0.489 & 0.407 & 0.353 & 0.313 & 0.297 \\
\hline 5 & 0.930 & 0.907 & 0.886 & 0.856 & 0.817 & 0.794 & 0.792 & 0.807 & 0.840 & 0.891 & 0.945 & 0.951 & 0.911 & 0.865 & 0.807 & 0.722 & 0.612 & 0.505 & 0.423 & 0.366 & 0.324 & 0.307 \\
\hline 6 & 1.054 & 1.030 & 1.010 & 0.980 & 0.943 & 0.922 & 0.924 & 0.937 & 0.967 & 1.014 & 1.073 & 1.080 & 1.043 & 1.001 & 0.945 & 0.859 & 0.739 & 0.617 & 0.521 & 0.455 & 0.407 & 0.387 \\
\hline 7 & 1.288 & 1.261 & 1.236 & 1.201 & 1.158 & 1.136 & 1.141 & 1.158 & 1.191 & 1.246 & 1.316 & 1.331 & 1.291 & 1.242 & 1.182 & 1.089 & 0.963 & 0.845 & 0.756 & 0.696 & 0.652 & 0.637 \\
\hline 8 & 1.458 & 1.426 & 1.399 & 1.361 & 1.316 & 1.295 & 1.306 & 1.325 & 1.365 & 1.429 & 1.508 & 1.531 & 1.484 & 1.434 & 1.369 & 1.271 & 1.139 & 1.025 & 0.944 & 0.892 & 0.853 & 0.841 \\
\hline 9 & 1.536 & 1.505 & 1.477 & 1.439 & 1.393 & 1.376 & 1.389 & 1.415 & 1.458 & 1.527 & 1.613 & 1.640 & 1.590 & 1.538 & 1.471 & 1.374 & 1.250 & 1.152 & 1.088 & 1.050 & 1.022 & 1.018 \\
\hline 10 & 1.550 & 1.518 & 1.489 & 1.454 & 1.408 & 1.392 & 1.406 & 1.428 & 1.472 & 1.542 & 1.627 & 1.655 & 1.607 & 1.555 & 1.486 & 1.391 & 1.273 & 1.191 & 1.142 & 1.123 & 1.108 & 1.113 \\
\hline 11 & 1.519 & 1.488 & 1.462 & 1.424 & 1.377 & 1.359 & 1.372 & 1.393 & 1.433 & 1.502 & 1.586 & 1.607 & 1.559 & 1.506 & 1.440 & 1.340 & 1.208 & 1.096 & 1.014 & 0.961 & 0.919 & 0.907 \\
\hline 12 & 1.416 & 1.386 & 1.357 & 1.319 & 1.273 & 1.252 & 1.259 & 1.275 & 1.311 & 1.372 & 1.448 & 1.466 & 1.421 & 1.369 & 1.302 & 1.201 & 1.062 & 0.928 & 0.823 & 0.751 & 0.695 & 0.672 \\
\hline 13 & 1.220 & 1.193 & 1.170 & 1.139 & 1.098 & 1.078 & 1.080 & 1.092 & 1.122 & 1.172 & 1.237 & 1.248 & 1.208 & 1.162 & 1.100 & 1.007 & 0.873 & 0.738 & 0.633 & 0.562 & 0.507 & 0.484 \\
\hline 14 & 0.998 & 0.974 & 0.953 & 0.923 & 0.884 & 0.862 & 0.861 & 0.869 & 0.893 & 0.939 & 0.993 & 0.996 & 0.960 & 0.917 & 0.860 & 0.773 & 0.647 & 0.513 & 0.403 & 0.328 & 0.271 & 0.246 \\
\hline 15 & 0.877 & 0.853 & 0.834 & 0.802 & 0.762 & 0.738 & 0.732 & 0.743 & 0.773 & 0.817 & 0.869 & $\mid 0.871$ & 0.833 & 0.787 & 0.726 & 0.643 & 0.529 & 0.413 & 0.321 & 0.256 & 0.210 & 0.191 \\
\hline 16 & 0.857 & 0.834 & 0.816 & 0.788 & 0.753 & 0.730 & 0.724 & 0.733 & 0.762 & 0.813 & 0.868 & 0.865 & 0.823 & 0.775 & 0.711 & 0.624 & 0.509 & 0.397 & 0.307 & 0.247 & 0.202 & 0.182 \\
\hline 17 & 0.874 & 0.853 & 0.835 & 0.815 & 0.792 & 0.785 & 0.788 & 0.793 & 0.814 & 0.863 & 0.922 & 0.919 & 0.871 & 0.816 & 0.756 & 0.667 & 0.546 & 0.420 & 0.322 & 0.255 & 0.207 & 0.187 \\
\hline 18 & 0.924 & 0.911 & 0.898 & 0.901 & 0.909 & 0.931 & 0.950 & 0.950 & 0.946 & 0.970 & 1.023 & 1.017 & 0.970 & 0.931 & 0.883 & 0.799 & 0.657 & 0.496 & 0.369 & 0.285 & 0.229 & 0.203 \\
\hline 19 & 1.008 & 1.009 & 1.020 & 1.052 & 1.106 & 1.182 & 1.240 & 1.225 & 1.176 & 1.156 & 1.167 & 1.157 & 1.147 & 1.152 & 1.141 & 1.068 & 0.876 & 0.637 & 0.453 & 0.338 & 0.263 & 0.228 \\
\hline
\end{tabular}

$a_{\mathrm{r}}=\mathrm{n}$ denotes the radial region number; $\mathrm{n}$ varies from 1 to 11 for the inner fuel element (IFE) and outer fuel element (OFE). 
Table 37. Relative fission density at end-of-cycle (simplified model)

\begin{tabular}{|c|c|c|c|c|c|c|c|c|c|c|c|c|c|c|c|c|c|c|c|c|c|c|}
\hline \multirow{2}{*}{$\begin{array}{c}\text { Axial } \\
\text { region }\end{array}$} & \multicolumn{11}{|c|}{ IFE } & \multicolumn{11}{|c|}{ OFE } \\
\hline & $\mathbf{r}=\mathbf{1}^{a}$ & $r=2$ & $r=3$ & $r=4$ & $r=5$ & $r=6$ & $\mathrm{r}=7$ & $r=8$ & $\mathrm{r}=9$ & $r=10$ & $r=11$ & $r=1$ & $r=2$ & $r=3$ & $r=4$ & $r=5$ & $r=6$ & $\mathrm{r}=7$ & $\mathrm{r}=\mathbf{8}$ & $r=9$ & $r=10$ & $r=11$ \\
\hline 1 & 0.600 & 0.634 & 0.684 & 0.778 & 0.892 & 1.020 & 1.114 & 1.099 & 1.035 & 0.977 & 0.935 & 0.995 & 1.035 & 1.106 & 1.174 & 1.191 & 1.103 & 0.948 & 0.814 & 0.724 & 0.660 & 0.635 \\
\hline 2 & 0.600 & 0.633 & 0.676 & 0.757 & 0.849 & 0.930 & 0.976 & 0.964 & 0.928 & 0.902 & 0.883 & 0.920 & 0.942 & 0.965 & 0.972 & 0.947 & 0.875 & 0.788 & 0.718 & 0.671 & 0.634 & 0.623 \\
\hline 3 & 0.593 & 0.625 & 0.664 & 0.734 & 0.800 & 0.846 & 0.862 & 0.855 & 0.846 & 0.839 & 0.833 & 0.858 & 0.860 & 0.865 & 0.845 & 0.800 & 0.739 & 0.698 & 0.671 & 0.653 & 0.638 & 0.634 \\
\hline 4 & 594 & 0.623 & 0.658 & 0.721 & 0.777 & 0.805 & 0.802 & 0.795 & 0.799 & 0.800 & 0.799 & 0.822 & 0.822 & 0.817 & 0.794 & 0.744 & 0.691 & 0.675 & 0.671 & 0.669 & 0.662 & 0.663 \\
\hline 5 & 0.596 & 0.629 & 0.665 & 0.729 & 0.785 & 0.810 & 0.805 & 0.799 & 0.800 & 0.800 & 0.795 & 0.818 & 0.821 & 0.820 & 0.803 & 0.757 & 0.713 & 0.705 & 0.709 & 0.711 & 0.705 & 0.705 \\
\hline 6 & 0.613 & 0.652 & 0.697 & 0.778 & 0.858 & 0.905 & 0.911 & 0.900 & 0.888 & 0.873 & 0.860 & 0.888 & 0.902 & 0.915 & 0.909 & 0.875 & 0.834 & 0.828 & 0.829 & 0.822 & 0.804 & 0.798 \\
\hline 7 & 0.627 & 0.676 & 0.735 & 0.847 & 0.970 & 1.064 & 1.091 & 1.070 & 1.037 & 1.000 & 0.969 & 1.008 & 1.039 & 1.074 & 1.088 & 1.060 & 1.015 & 0.999 & 0.976 & 0.940 & 0.890 & 0.862 \\
\hline 8 & 0.619 & 0.674 & 0.743 & 0.874 & 1.033 & 1.166 & 1.215 & 1.191 & 1.138 & 1.081 & 1.030 & 1.082 & 1.126 & 1.182 & 1.213 & 1.190 & 1.140 & 1.110 & 1.053 & 0.973 & 0.883 & 0.832 \\
\hline 9 & 0.609 & 0.667 & 0.739 & 0.881 & 1.055 & 1.211 & 1.277 & 1.250 & 1.190 & 1.122 & 1.062 & 1.119 & 1.173 & 1.239 & 1.279 & 1.261 & 1.210 & 1.169 & 1.086 & 0.979 & 0.865 & 0.802 \\
\hline 10 & 0.607 & 0.664 & 0.737 & 0.883 & 1.062 & 1.221 & 1.290 & 1.263 & 1.199 & 1.127 & 1.067 & 1.126 & 1.183 & 1.252 & 1.293 & 1.276 & 1.227 & 1.182 & 1.093 & 0.980 & 0.863 & 0.797 \\
\hline 11 & 0.611 & 0.667 & 0.741 & 0.883 & 1.060 & 1.215 & 1.281 & 1.253 & 1.192 & 1.122 & 1.064 & 1.123 & 1.176 & 1.242 & 1.281 & 1.264 & 1.212 & 1.171 & 1.087 & 0.981 & 0.867 & 0.803 \\
\hline 12 & 0.625 & 0.680 & 0.748 & 0.882 & 1.039 & 1.171 & 1.220 & 1.194 & 1.145 & 1.089 & 1.039 & 1.091 & 1.135 & 1.189 & 1.219 & 1.194 & 1.145 & 1.114 & 1.057 & 0.977 & 0.889 & 0.838 \\
\hline 13 & 0.636 & 0.685 & 0.745 & 0.857 & 0.979 & 1.071 & 1.097 & 1.077 & 1.045 & 1.008 & 0.977 & 1.018 & 1.048 & 1.083 & 1.096 & 1.067 & 1.021 & 1.006 & 0.988 & 0.955 & 0.910 & 0.887 \\
\hline 14 & 0.627 & 0.666 & 0.712 & 0.793 & 0.870 & 0.916 & 0.921 & 0.907 & 0.898 & 0.884 & 0.873 & 0.900 & 0.912 & 0.924 & 0.918 & 0.882 & 0.839 & 0.837 & 0.842 & 0.841 & 0.831 & 0.828 \\
\hline 15 & 0.610 & 0.643 & 0.681 & 0.743 & 0.797 & 0.823 & 0.817 & 0.809 & 0.812 & 0.813 & 0.814 & 0.831 & 0.831 & 0.831 & 0.810 & 0.763 & 0.716 & 0.713 & 0.723 & 0.731 & 0.734 & 0.739 \\
\hline 16 & 0.603 & 0.634 & 0.672 & 0.733 & 0.790 & 0.816 & 0.814 & 0.808 & 0.813 & 0.817 & 0.818 & 0.836 & 0.836 & 0.830 & 0.804 & 0.750 & 0.695 & 0.680 & 0.683 & 0.688 & 0.690 & 0.697 \\
\hline 17 & 0.607 & 0.639 & 0.678 & 0.748 & 0.818 & 0.864 & 0.878 & 0.869 & 0.863 & 0.858 & 0.853 & 0.879 & 0.880 & 0.879 & 0.857 & 0.805 & 0.741 & 0.702 & 0.678 & 0.668 & 0.659 & 0.659 \\
\hline 18 & 0.613 & 0.647 & 0.693 & 0.773 & 0.865 & 0.950 & 1.000 & 0.986 & 0.956 & 0.927 & 0.906 & 0.945 & 0.962 & 0.985 & 0.992 & 0.958 & 0.876 & 0.789 & 0.720 & 0.678 & 0.647 & 0.640 \\
\hline 19 & 0.615 & 0.656 & 0.704 & 0.796 & 0.912 & 1.047 & 1.139 & 1.129 & 1.063 & 1.003 & 0.964 & 1.025 & 1.068 & 1.137 & 1.200 & 1.210 & 1.110 & 0.949 & 0.815 & 0.728 & 0.664 & 0.640 \\
\hline
\end{tabular}

$a_{\mathrm{r}}=\mathrm{n}$ denotes the radial region number; $\mathrm{n}$ varies from 1 to 11 for the inner fuel element (IFE) and outer fuel element (OFE). 
Table 38. Relative fission density at beginning-of-cycle (explicit model)

\begin{tabular}{|c|c|c|c|c|c|c|c|c|c|c|c|c|c|c|c|c|c|c|c|c|c|c|}
\hline \multirow{2}{*}{$\begin{array}{c}\text { Axial } \\
\text { region }\end{array}$} & \multicolumn{11}{|c|}{ IFE } & \multicolumn{11}{|c|}{ OFE } \\
\hline & $\mathbf{r}=\mathbf{1}^{a}$ & $r=2$ & $r=3$ & $r=4$ & $r=5$ & $r=6$ & $\mathrm{r}=7$ & $r=8$ & $\mathrm{r}=9$ & $r=10$ & $\mathrm{r}=11$ & $r=1$ & $r=2$ & $r=3$ & $r=4$ & $r=5$ & $r=6$ & $r=7$ & $r=8$ & $r=9$ & $r=10$ & $\mathrm{r}=11$ \\
\hline 1 & 1.058 & 1.059 & 1.080 & 1.114 & 1.184 & 1.273 & 1.344 & 1.317 & 1.265 & 1.237 & 1.244 & \begin{tabular}{|l}
1.241 \\
\end{tabular} & 1.242 & 1.255 & 1.263 & 1.209 & 1.032 & 0.792 & 0.605 & 0.480 & 0.395 & 0.361 \\
\hline 2 & 0.975 & 0.964 & 0.952 & 0.962 & 0.978 & 1.010 & 1.040 & 1.034 & 1.028 & 1.050 & 1.099 & 1.100 & 1.064 & 1.031 & 0.990 & 0.913 & 0.775 & 0.619 & 0.496 & 0.411 & 0.353 & 0.327 \\
\hline 3 & 0.918 & 0.897 & 0.886 & 0.868 & 0.855 & 0.853 & 0.863 & 0.870 & 0.889 & 0.937 & 0.992 & 1.002 & 0.960 & 0.906 & 0.845 & 0.760 & 0.643 & 0.527 & 0.433 & 0.370 & 0.326 & 0.306 \\
\hline 4 & 0.900 & 0.874 & 0.858 & 0.835 & 0.808 & 0.790 & 0.788 & 0.801 & 0.833 & 0.880 & 0.940 & 0.942 & 0.906 & 0.858 & 0.796 & 0.709 & 0.598 & 0.494 & 0.413 & 0.355 & 0.316 & 0.298 \\
\hline 5 & 0.917 & 0.890 & 0.874 & 0.851 & 0.822 & 0.799 & 0.796 & 0.810 & 0.838 & 0.881 & 0.937 & 0.944 & 0.912 & 0.868 & 0.811 & 0.728 & 0.615 & 0.510 & 0.427 & 0.367 & 0.324 & 0.307 \\
\hline 6 & 1.038 & 1.014 & 0.997 & 0.971 & 0.943 & 0.924 & 0.927 & 0.939 & 0.965 & 1.008 & 1.061 & 1.071 & 1.041 & 1.001 & 0.948 & 0.862 & 0.741 & 0.621 & 0.524 & 0.456 & 0.406 & 0.384 \\
\hline 7 & 1.271 & 1.241 & 1.224 & 1.192 & 1.157 & 1.137 & 1.144 & 1.157 & 1.186 & 1.236 & 1.299 & 1.316 & 1.283 & 1.242 & 1.185 & 1.092 & 0.965 & 0.847 & 0.759 & 0.696 & 0.649 & 0.631 \\
\hline 8 & 1.436 & 1.404 & 1.383 & 1.351 & 1.315 & 1.295 & 1.305 & 1.325 & 1.359 & 1.416 & 1.490 & 1.512 & 1.476 & 1.430 & 1.370 & 1.271 & 1.141 & 1.029 & 0.948 & 0.890 & 0.846 & 0.830 \\
\hline 9 & 1.506 & 1.476 & 1.454 & 1.423 & 1.389 & 1.375 & 1.389 & 1.411 & 1.453 & 1.511 & 1.589 & 1.621 & 1.583 & 1.536 & 1.473 & 1.376 & 1.253 & 1.156 & 1.093 & 1.047 & 1.015 & 1.006 \\
\hline 10 & 1.525 & 1.489 & 1.467 & 1.439 & 1.406 & 1.388 & 1.403 & 1.424 & 1.462 & 1.529 & 1.608 & 1.635 & 1.598 & 1.552 & 1.491 & 1.395 & 1.277 & 1.193 & 1.148 & 1.119 & 1.100 & 1.100 \\
\hline 11 & 1.493 & 1.464 & 1.442 & 1.410 & 1.374 & 1.357 & 1.370 & 1.390 & 1.427 & 1.487 & 1.563 & 1.594 & 1.555 & 1.509 & 1.444 & 1.343 & 1.210 & 1.099 & 1.018 & 0.959 & 0.912 & 0.898 \\
\hline 12 & 1.394 & 1.363 & 1.342 & 1.310 & 1.272 & 1.253 & 1.261 & 1.275 & 1.307 & 1.359 & 1.429 & 1.450 & 1.412 & 1.367 & 1.307 & 1.205 & 1.065 & 0.931 & 0.826 & 0.750 & 0.690 & 0.665 \\
\hline 13 & 1.203 & 1.173 & 1.157 & 1.129 & 1.097 & 1.078 & 1.082 & 1.093 & 1.119 & 1.164 & 1.224 & 1.234 & 1.201 & 1.160 & 1.103 & 1.009 & 0.875 & 0.742 & 0.637 & 0.560 & 0.503 & 0.478 \\
\hline 14 & 0.981 & 0.960 & 0.943 & 0.917 & 0.888 & 0.866 & 0.865 & 0.871 & 0.894 & 0.932 & 0.984 & 0.985 & 0.956 & 0.917 & 0.863 & 0.777 & 0.650 & 0.516 & 0.407 & 0.329 & 0.271 & 0.245 \\
\hline 15 & 0.865 & 0.842 & 0.826 & 0.803 & 0.770 & 0.744 & 0.738 & 0.746 & 0.774 & 0.814 & 0.865 & 0.864 & 0.833 & 0.790 & 0.733 & 0.646 & 0.532 & 0.416 & 0.324 & 0.259 & 0.212 & 0.191 \\
\hline 16 & 0.848 & 0.828 & 0.810 & 0.784 & 0.754 & 0.735 & 0.728 & 0.739 & 0.763 & 0.810 & 0.869 & 0.866 & 0.826 & 0.778 & 0.715 & 0.632 & 0.516 & 0.401 & 0.312 & 0.249 & 0.203 & 0.183 \\
\hline 17 & 0.869 & 0.847 & 0.833 & 0.815 & 0.800 & 0.794 & 0.797 & 0.802 & 0.820 & 0.864 & 0.916 & 0.912 & 0.873 & 0.823 & 0.758 & 0.670 & 0.552 & 0.427 & 0.327 & 0.259 & 0.210 & 0.188 \\
\hline 18 & 0.914 & 0.900 & 0.894 & 0.896 & 0.910 & 0.937 & 0.964 & 0.957 & 0.949 & 0.973 & 1.017 & 1.002 & 0.971 & 0.935 & 0.888 & 0.801 & 0.661 & 0.501 & 0.375 & 0.289 & 0.229 & 0.204 \\
\hline 19 & 0.998 & 0.992 & 1.007 & 1.042 & 1.101 & 1.181 & 1.245 & 1.224 & 1.172 & 1.143 & 1.154 & 1.133 & 1.132 & 1.138 & 1.134 & 1.066 & 0.880 & 0.640 & 0.457 & 0.341 & 0.262 & 0.229 \\
\hline
\end{tabular}

$a_{\mathrm{r}}=\mathrm{n}$ denotes the radial region number; $\mathrm{n}$ varies from 1 to 11 for the inner fuel element (IFE) and outer fuel element (OFE). 
Table 39. Relative fission density at end-of-cycle (explicit model)

\begin{tabular}{|c|c|c|c|c|c|c|c|c|c|c|c|c|c|c|c|c|c|c|c|c|c|c|}
\hline \multirow{2}{*}{$\begin{array}{c}\text { Axial } \\
\text { region }\end{array}$} & \multicolumn{11}{|c|}{ IFE } & \multicolumn{11}{|c|}{ OFE } \\
\hline & $\mathbf{r}=\mathbf{1}^{a}$ & $r=2$ & $r=3$ & $r=4$ & $r=5$ & $r=6$ & $\mathrm{r}=7$ & $r=8$ & $r=9$ & $r=10$ & $r=11$ & $r=1$ & $r=2$ & $r=3$ & $r=4$ & $r=5$ & $r=6$ & $r=7$ & $\mathrm{r}=\mathbf{8}$ & $r=9$ & $r=10$ & $r=11$ \\
\hline 1 & 0.597 & 0.637 & 0.681 & 0.771 & 0.892 & 1.021 & 1.113 & 1.097 & 1.032 & 0.972 & 0.923 & 0.986 & 1.029 & 1.100 & 1.172 & 1.189 & 1.103 & 0.946 & 0.813 & 0.721 & 0.656 & 0.629 \\
\hline 2 & 0.596 & 0.630 & 0.672 & 0.751 & 0.846 & 0.932 & 0.979 & 0.967 & 0.932 & 0.898 & 0.880 & 0.914 & 0.935 & 0.960 & 0.978 & 0.952 & 0.880 & 0.793 & 0.723 & 0.670 & 0.632 & 0.620 \\
\hline 3 & 0.594 & 0.623 & 0.660 & 0.731 & 0.801 & 0.854 & 0.868 & 0.861 & 0.849 & 0.838 & 0.834 & 0.852 & 0.858 & 0.865 & 0.853 & 0.805 & 0.744 & 0.702 & 0.676 & 0.653 & 0.635 & 0.631 \\
\hline 4 & 0.589 & 0.622 & 0.658 & 0.721 & 0.776 & 0.809 & 0.809 & 0.802 & 0.800 & 0.801 & 0.798 & 0.817 & 0.822 & 0.819 & 0.797 & 0.747 & 0.696 & 0.678 & 0.675 & 0.667 & 0.659 & 0.659 \\
\hline 5 & 0.593 & 0.623 & 0.661 & 0.727 & 0.785 & 0.815 & 0.811 & 0.802 & 0.801 & 0.799 & 0.793 & 0.813 & 0.820 & 0.820 & 0.802 & 0.760 & 0.714 & 0.707 & 0.712 & 0.709 & 0.700 & 0.700 \\
\hline 6 & 0.614 & 0.652 & 0.696 & 0.777 & 0.858 & 0.907 & 0.915 & 0.900 & 0.887 & 0.871 & 0.858 & 0.881 & 0.898 & 0.914 & 0.911 & 0.877 & 0.836 & 0.830 & 0.830 & 0.818 & 0.798 & 0.790 \\
\hline 7 & 0.628 & 0.676 & 0.735 & 0.845 & 0.969 & 1.061 & 1.090 & 1.068 & 1.033 & 0.994 & 0.964 & 1.000 & 1.033 & 1.070 & 1.085 & 1.059 & 1.016 & 0.999 & 0.976 & 0.934 & 0.883 & 0.855 \\
\hline 8 & 0.619 & 0.675 & 0.742 & 0.873 & 1.031 & 1.161 & 1.214 & 1.187 & 1.134 & 1.075 & 1.027 & 1.080 & 1.126 & 1.181 & 1.212 & 1.191 & 1.143 & 1.110 & 1.051 & 0.967 & 0.880 & 0.829 \\
\hline 9 & 0.613 & 0.670 & 0.740 & 0.880 & 1.053 & 1.208 & 1.273 & 1.243 & 1.181 & 1.113 & 1.057 & 1.116 & 1.171 & 1.239 & 1.279 & 1.262 & 1.211 & 1.166 & 1.084 & 0.975 & 0.864 & 0.802 \\
\hline 10 & 0.612 & 0.669 & 0.740 & 0.882 & 1.060 & 1.220 & 1.289 & 1.261 & 1.197 & 1.124 & 1.066 & 1.124 & 1.181 & 1.252 & 1.294 & 1.279 & 1.229 & 1.179 & 1.093 & 0.977 & 0.861 & 0.798 \\
\hline 11 & 0.614 & 0.672 & 0.741 & 0.884 & 1.058 & 1.213 & 1.280 & 1.251 & 1.186 & 1.115 & 1.059 & 1.121 & 1.174 & 1.239 & 1.281 & 1.263 & 1.213 & 1.169 & 1.087 & 0.978 & 0.866 & 0.804 \\
\hline 12 & 0.627 & 0.683 & 0.750 & 0.882 & 1.039 & 1.171 & 1.221 & 1.192 & 1.141 & 1.083 & 1.035 & 1.088 & 1.132 & 1.188 & 1.218 & 1.197 & 1.148 & 1.117 & 1.059 & 0.975 & 0.886 & 0.836 \\
\hline 13 & 0.640 & 0.689 & 0.747 & 0.858 & 0.980 & 1.070 & 1.097 & 1.076 & 1.042 & 1.004 & 0.974 & 1.013 & 1.045 & 1.082 & 1.097 & 1.069 & 1.024 & 1.009 & 0.989 & 0.952 & 0.906 & 0.882 \\
\hline 14 & 0.625 & 0.666 & 0.711 & 0.791 & 0.872 & 0.919 & 0.925 & 0.909 & 0.895 & 0.882 & 0.870 & 0.896 & 0.910 & 0.926 & 0.922 & 0.887 & 0.844 & 0.840 & 0.845 & 0.840 & 0.826 & 0.821 \\
\hline 15 & 0.606 & 0.641 & 0.677 & 0.743 & 0.799 & 0.827 & 0.821 & 0.812 & 0.812 & 0.812 & 0.809 & 0.827 & 0.833 & 0.837 & 0.817 & 0.771 & 0.722 & 0.717 & 0.728 & 0.731 & 0.730 & 0.733 \\
\hline 16 & 0.604 & 0.636 & 0.676 & 0.737 & 0.796 & 0.824 & 0.822 & 0.814 & 0.814 & 0.815 & 0.819 & 0.836 & 0.836 & 0.836 & 0.811 & 0.756 & 0.701 & 0.686 & 0.688 & 0.688 & 0.687 & 0.691 \\
\hline 17 & 0.611 & 0.643 & 0.680 & 0.749 & 0.822 & 0.871 & 0.886 & 0.876 & 0.868 & 0.861 & 0.854 & 0.876 & 0.880 & 0.883 & 0.867 & 0.813 & 0.750 & 0.708 & 0.685 & 0.666 & 0.655 & 0.653 \\
\hline 18 & 0.612 & 0.646 & 0.692 & 0.776 & 0.867 & 0.957 & 1.005 & 0.989 & 0.957 & 0.925 & 0.909 & 0.945 & 0.960 & 0.984 & 0.998 & 0.967 & 0.886 & 0.796 & 0.726 & 0.680 & 0.644 & 0.635 \\
\hline 19 & 0.617 & 0.654 & 0.700 & 0.798 & 0.919 & 1.051 & 1.145 & 1.127 & 1.064 & 1.004 & 0.964 & 1.021 & 1.066 & 1.136 & 1.202 & 1.214 & 1.116 & 0.953 & 0.815 & 0.725 & 0.657 & 0.631 \\
\hline
\end{tabular}

$a_{\mathrm{r}}=\mathrm{n}$ denotes the radial region number; $\mathrm{n}$ varies from 1 to 11 for the inner fuel element (IFE) and outer fuel element (OFE). 

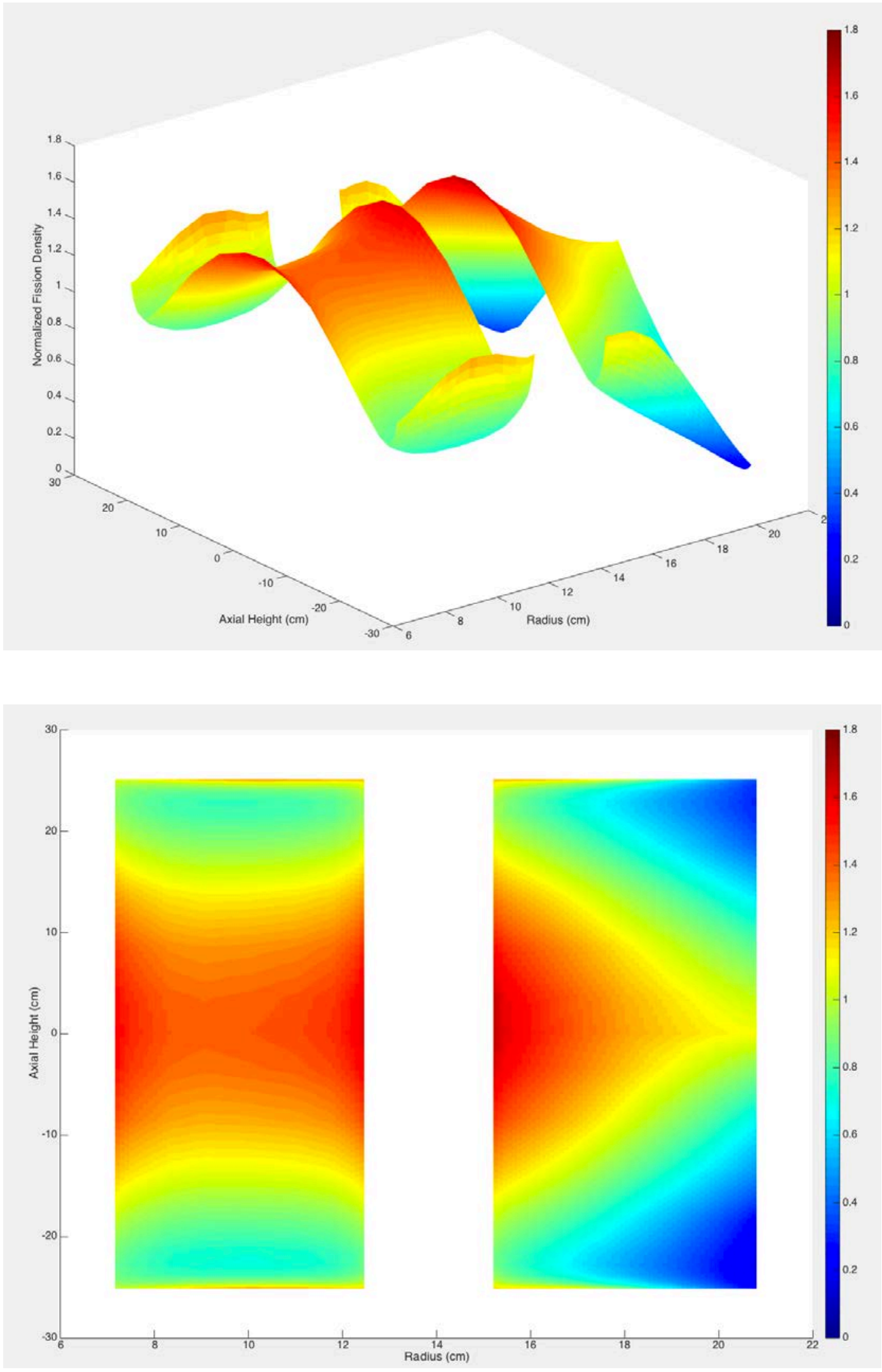

Fig. 32. Relative fission density distribution at beginning-of-cycle. 

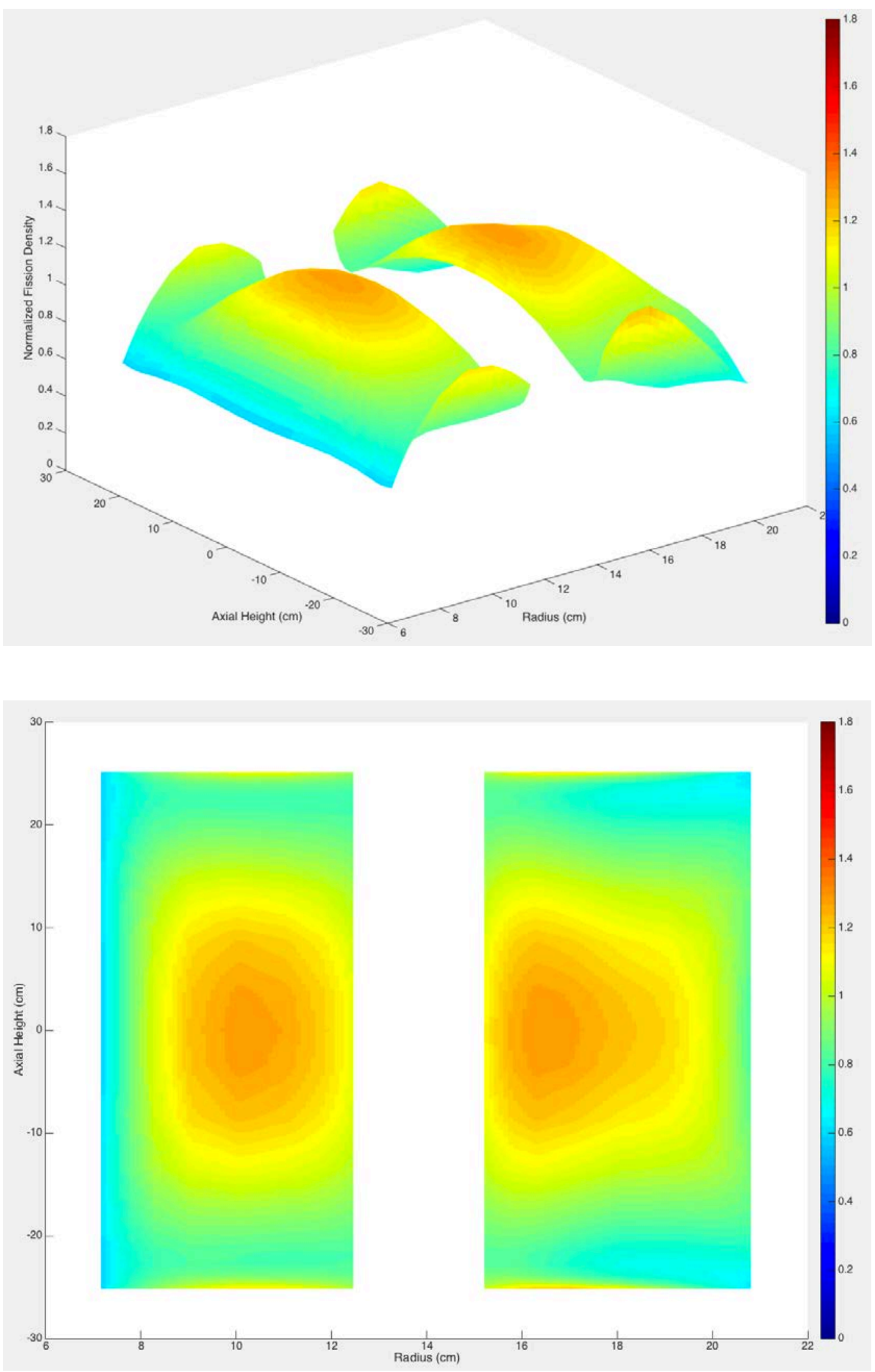

Fig. 33. Relative fission density distribution at end of cycle. 
The relative fission density distributions calculated with the simplified and explicit models are similar for each reactor state considered and agree within two standard deviations for all considered spatial meshes. The maximum percentage difference in the relative fission density values between the simplified and explicit models is $2.0 \%$ at BOC; for $\sim 75 \%$ of the spatial fuel meshes, the percentage difference is less than $1 \%$, with the differences larger than $1 \%$ occurring mostly in meshes with very small volumes. At EOC, very few (less than $1 \%$ of the total) fuel meshes show a difference larger than $1 \%$ between the relative fission densities calculated with the simplified and explicit models; the maximum difference is $1.4 \%$.

The relative fission density peak is located at the core horizontal midplane in both the IFE and OFE, at BOC and EOC. However, the radial location within the fuel element differs. At BOC, the maximum value in the IFE occurs at its outer radial edge, and the maximum in the OFE is observed at its inner radial edge; the maxima in both the IFE and OFE are 1.6. At EOC, these maxima decrease to $~ 1.3$ and their locations move closer to the radial center of the fuel element compared to BOC. Figs. 32 and 33 clearly illustrate the change of the power profiles (flattening) from BOC to EOC due to burnup.

\subsubsection{Differential Control Element Worth}

The differential control element worth $\mathrm{DW}_{i}$ at state $i$ corresponding to a position $p_{i}$ of the control element was calculated for each of the two control elements as:

$$
D W_{i}=\frac{1}{\beta_{e f f} / 100} \times \frac{\left|k_{i}-k_{i, p}\right|}{k_{i} k_{i, p}\left|p_{i}-\left(p_{i}+\Delta p\right)\right|}
$$

where $k_{i}$ is the effective multiplication constant corresponding to state $i ; p_{i}$ is the control element location in state $i ; k_{i, p}$ is the effective multiplication constant corresponding to a perturbed state; $p_{i}+\Delta p$ is the perturbed location for one control element in the perturbed state; $\Delta p$ is the perturbation of the location on one control element location, used as $1 \mathrm{~cm}\left(0.3937 \mathrm{in}\right.$.) for the data shown here; and $\beta_{\text {eff }}$ is the effective delayed neutron fraction. In the initial state $i$, the location of both control elements is symmetric with respect to the core horizontal midplane. In the perturbed state, the position of only one control element is perturbed.

The calculated differential control element worth data expressed in cents/in. are illustrated in Fig. 34 for the ICE and Fig. 35 for the OCE as a function of the control element position. These data were calculated separately for the simplified and explicit HFIR models. The material compositions used in these models correspond to BOC-400. The value used for the effective delayed neutron fraction is 0.0076 [31]. Figures 34-35 also include measurement data from the HFIRCE-3 critical experiments [1], which were digitized from Fig. 4.3-9 in the HFIR SAR [31].

The worth data calculated with the simplified and explicit models are consistent; all the data points agree within three standard deviations. There is also good agreement between the calculated and the measured data. The total calculated maximum differential worth occurs at a withdrawal position of 18.8 in. for both the simplified and explicit models. The value of this total maximum is 279 cents/in. ( $\sigma=11$ cents/in.) for the simplified model and 292 cents/in. ( $\sigma=8$ cents/in.) for the explicit model. Both of these calculated maxima agree within three standard deviations with the value of 310 cents/in. that is the maximum differential worth used for predicting startup CE positions for the current HFIR core when the estimated critical CE position is between 17.5 and $18.0 \mathrm{in}$. withdrawn. The 310 cents/in. value is based on extrapolations from measurements performed with CEs that had fresh material compositions and borated moderator for reactivity balance; whereas, the total worth values calculated in this report were obtained for CEs with a predicted material composition corresponding to an exposure history as applicable to the CEs present in the core at BOC-400. 


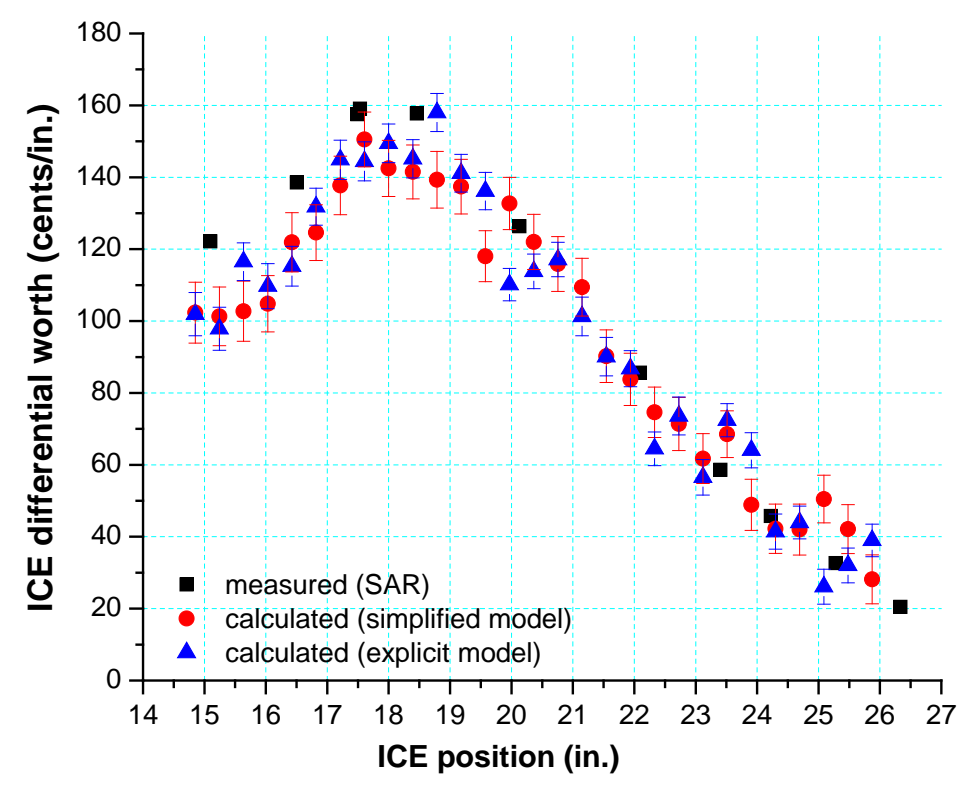

Fig. 34. ICE differential worth.

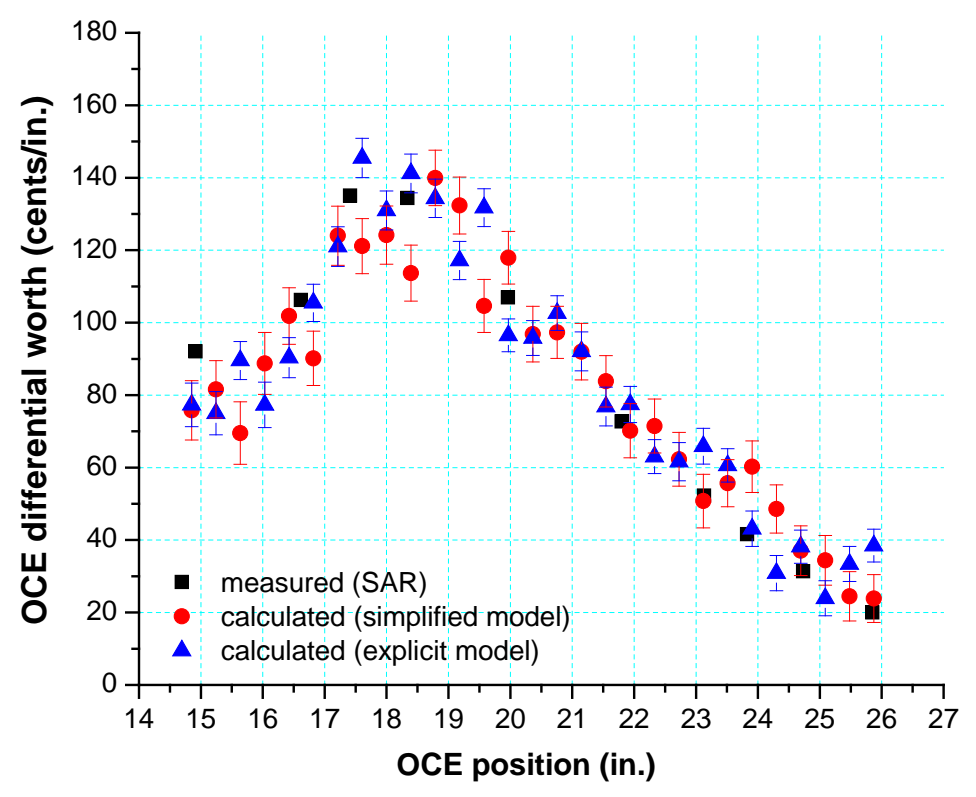

Fig. 35. OCE differential worth. 


\subsection{SAFETY AND SAFEGUARDS METRICS}

\subsubsection{Isotopic Composition of Irradiated Fuel}

The isotopic compositions of the irradiated fuel are relevant for reactor safety, safeguards, and waste management.

\subsubsection{Major actinides inventory at end-of-cycle}

The inventory for isotopes of the major actinides uranium and plutonium at EOC is listed in Table 40, as obtained with the simplified and explicit models. The EOC isotopic content for the shown nuclides is consistent between the two models; the difference between the total mass of ${ }^{235} \mathrm{U}$ in the core calculated with the simplified and explicit models is only $2 \mathrm{~g}$.

Table 40. Major actinides inventory at end-of-cycle

\begin{tabular}{lrrrrrrrrrr}
\hline & \multicolumn{3}{c}{ Mass in IFE $^{\boldsymbol{a}}$ (g) } & \multicolumn{3}{c}{ Mass in OFE (g) } & \multicolumn{3}{c}{ Mass in IFE+OFE (g) } \\
\cline { 2 - 11 } Isotope & $\begin{array}{c}\text { explicit } \\
\text { model }\end{array}$ & $\begin{array}{c}\text { simplified } \\
\text { model }\end{array}$ & diff $^{b}$ & $\begin{array}{c}\text { explicit } \\
\text { model }\end{array}$ & $\begin{array}{c}\text { simplified } \\
\text { model }\end{array}$ & diff $^{b}$ & $\begin{array}{c}\text { explicit } \\
\text { model }\end{array}$ & $\begin{array}{c}\text { simplified } \\
\text { model }\end{array}$ & diff $^{b}$ \\
\hline${ }^{234} \mathrm{U}$ & 24.47 & 24.50 & 0.03 & 67.16 & 67.22 & 0.06 & 91.63 & 91.72 & 0.09 \\
${ }^{235} \mathrm{U}$ & $1,654.82$ & $1,656.32$ & 1.50 & $5,190.76$ & $5,191.17$ & 0.41 & $6,845.58$ & $6,847.49$ & 1.91 \\
${ }^{236} \mathrm{U}$ & 173.30 & 172.70 & -0.60 & 324.21 & 323.00 & -1.21 & 497.51 & 495.70 & -1.80 \\
${ }^{238} \mathrm{U}$ & 144.95 & 145.07 & 0.13 & 382.92 & 383.25 & 0.33 & 527.86 & 528.32 & 0.46 \\
${ }^{238} \mathrm{Pu}$ & 0.11 & 0.11 & 0.00 & 0.14 & 0.14 & 0.00 & 0.25 & 0.25 & -0.01 \\
${ }^{239} \mathrm{Pu}$ & 3.32 & 3.25 & -0.06 & 8.02 & 7.83 & -0.20 & 11.34 & 11.08 & -0.26 \\
${ }^{240} \mathrm{Pu}$ & 0.52 & 0.51 & -0.01 & 0.88 & 0.86 & -0.03 & 1.40 & 1.37 & -0.04 \\
${ }^{241} \mathrm{Pu}$ & 0.24 & 0.24 & -0.01 & 0.35 & 0.34 & -0.01 & 0.60 & 0.58 & -0.02 \\
${ }^{242} \mathrm{Pu}$ & 0.03 & 0.02 & 0.00 & 0.02 & 0.02 & 0.00 & 0.05 & 0.05 & 0.00 \\
\hline
\end{tabular}

${ }^{a} \mathrm{IFE}=$ inner fuel element, OFE $=$ outer fuel element.

${ }^{b}$ Calculated as difference between mass predicted by the explicit model and mass predicted by the simplified model.

\subsubsection{2 ${ }^{235} \mathrm{U}$ depletion}

The mass of uranium isotopes in each of the two fuel elements and in the core at BOC and EOC, as well as the amount of isotope depleted or produced during the cycle, are shown in Table 41. In the case of ${ }^{236} \mathrm{U}$, the data represent the buildup of this isotope during the cycle. Approximately $36.5 \%$ and $24.05 \%$ of the initial ${ }^{235} \mathrm{U}$ in the IFE and the OFE, respectively, is depleted during irradiation. The variation of the ${ }^{235} \mathrm{U}$ total mass during irradiation, relative to its mass at BOC, is illustrated in Fig. 36 for the IFE and OFE.

The distribution of ${ }^{235} \mathrm{U}$ depletion at EOC, in percent, is illustrated in Fig. 37 as a function of radial and axial location in the core for the explicit model. The spatial distribution of ${ }^{235} \mathrm{U}$ depletion that was obtained with the simplified model is consistent with that obtained with the explicit model. The maximum depletion in the IFE is $72 \%$ and occurs in fuel located in the innermost radial layer of the IFE at the core horizontal midplane. The maximum depletion in the OFE is 55\% and occurs in the fuel located in the outermost radial layer of the OFE at the core horizontal midplane. 
Table 41. Depletion of uranium isotopes ${ }^{a}$

\begin{tabular}{|c|c|c|c|c|c|c|c|c|c|}
\hline \multirow[b]{2}{*}{ Isotope } & \multicolumn{3}{|c|}{ Inner fuel element (IFE) } & \multicolumn{3}{|c|}{ Outer fuel element (OFE) } & \multicolumn{3}{|c|}{ IFE + OFE } \\
\hline & $\begin{array}{l}\text { BOC } \\
\text { (g) }\end{array}$ & $\begin{array}{c}\text { EOC } \\
\text { (g) }\end{array}$ & $\begin{array}{c}\text { Depletion }^{b} \\
(\%)\end{array}$ & $\begin{array}{l}\text { BOC } \\
\text { (g) }\end{array}$ & $\begin{array}{c}\text { EOC } \\
\text { (g) }\end{array}$ & $\begin{array}{c}\text { Depletion }^{b} \\
(\%)\end{array}$ & $\begin{array}{c}\text { BOC } \\
\text { (g) }\end{array}$ & $\begin{array}{c}\text { EOC } \\
\text { (g) }\end{array}$ & $\begin{array}{c}\text { Depletion }^{b} \\
(\%)\end{array}$ \\
\hline${ }^{234} \mathrm{U}$ & 28.69 & 24.50 & 14.6 & 75.17 & 67.22 & 10.6 & 103.86 & 91.72 & 11.7 \\
\hline${ }^{235} \mathrm{U}$ & 2607.76 & 1656.32 & 36.5 & 6833.89 & 5191.17 & 24.0 & 9441.65 & 6847.49 & 27.5 \\
\hline${ }^{236} \mathrm{U}$ & 10.43 & 172.70 & 1555.7 & 27.34 & 323.00 & 1081.6 & 37.77 & 495.70 & 1212.5 \\
\hline${ }^{238} \mathrm{U}$ & 151.15 & 145.07 & 4.0 & 396.10 & 383.25 & 3.2 & 547.25 & 528.32 & 3.5 \\
\hline
\end{tabular}

${ }^{a}$ Shown for the explicit model. Data are similar for the simplified model.

${ }^{b}$ Calculated as relative difference in percent between the end-of-cycle (EOC) and beginning-of-cycle (BOC) mass. For ${ }^{236} \mathrm{U}$, the data represent the buildup.

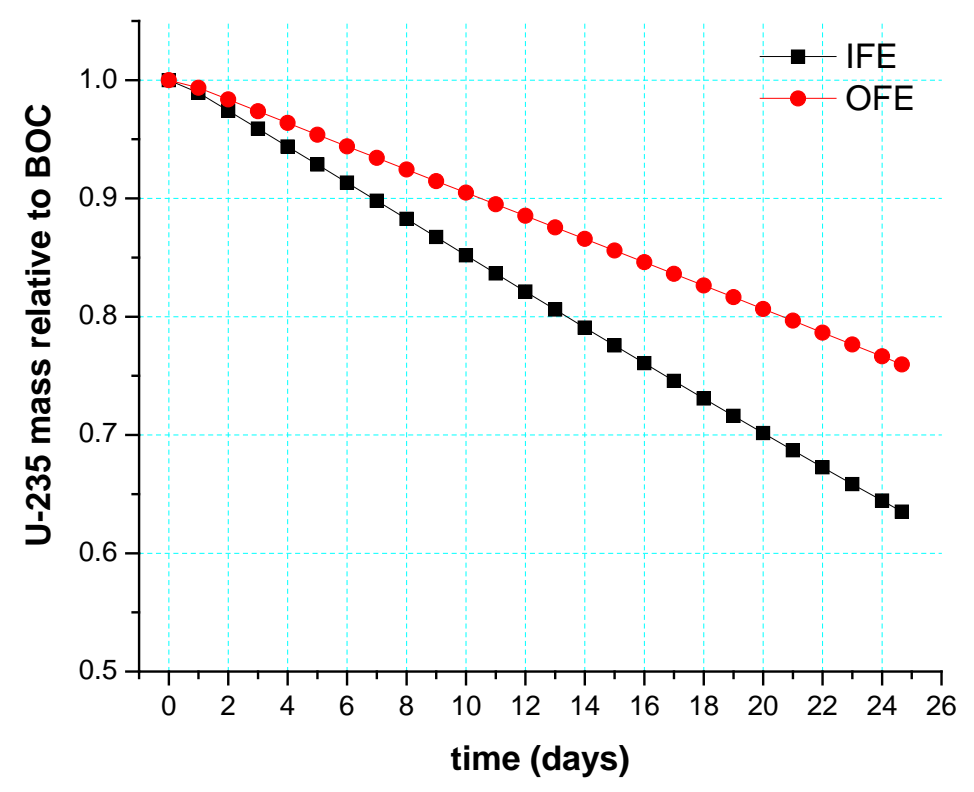

Fig. 36. Variation with irradiation time of ${ }^{235} \mathrm{U}$ total mass. (BOC = beginning-of-cycle, IFE = inner fuel element, OFE = outer fuel element.) 

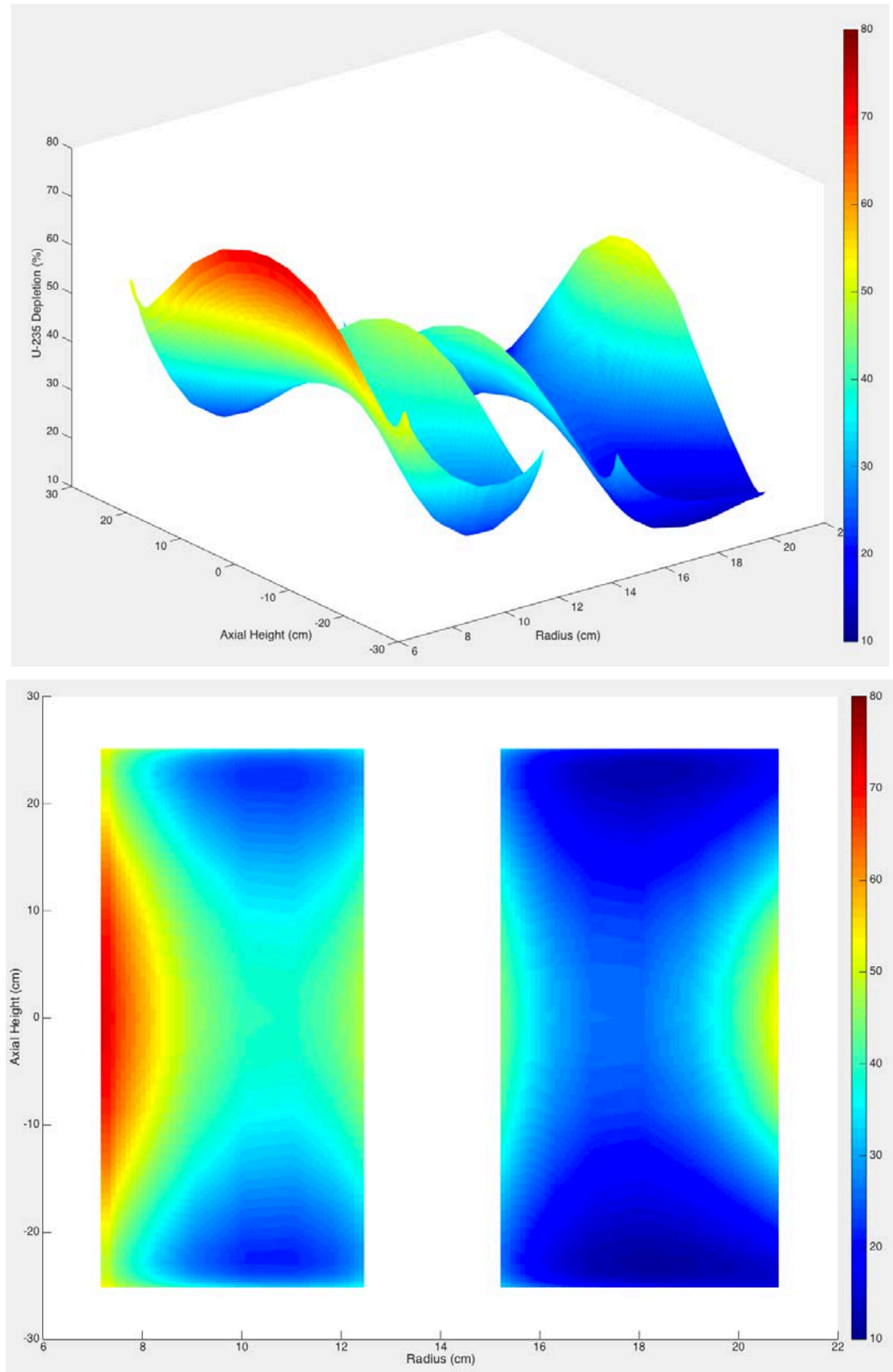

Fig. 37. Distribution of ${ }^{235} \mathrm{U}$ depletion at end-of-cycle. 


\subsubsection{Decay Heat in Irradiated Fuel}

The residual decay heat in irradiated fuel was calculated using the depleted fuel compositions provided in the VESTA output files. Isotopic composition data for more than a thousand isotopes present in the fuel at shutdown were fed into the ORIGEN code [54] in SCALE [18] for source term characterization. The total mass of used fuel from the core (as a sum of the IFE and OFE compositions) was considered as one source. The calculated total decay heat for values of the cooling time from reactor shutdown (i.e., $0 \mathrm{~s}$ ) to 100 years is presented in Table 42. This table also shows the contribution to the total decay heat of fission products, which are the major contributor to the total decay heat over all cooling times considered here. The actinide contribution to decay heat is much smaller than that of the fission products.

The total decay heat data calculated with the simplified model are similar to those calculated with the explicit model. The variation of the total decay heat as a function of cooling time is illustrated in Fig. 38. At 1 year's cooling time, the total decay heat decreases by 3 orders of magnitude from the shutdown value of $\sim 5 \mathrm{MW}$; at 10 years' cooling it decreases further to $\sim 70 \mathrm{~W}$, and becomes less than $10 \mathrm{~W}$ after 100 years of decay.

The total decay heat at very short cooling times (less than $10 \mathrm{~s}$ ) calculated for the present report is significantly different, 20 to $60 \%$ smaller, than corresponding values reported previously [9, 54] for these decay times. For longer cooling times, the decay heat values are consistent with those reported previously.

The cause of this difference was identified as being the use of different fission yield data and nuclear decay data with the depletion solver in VESTA. As noted in Section 4.2 of this report, the fission yield data and the nuclear decay data used with ORIGEN 2.2 in VESTA for this report are based on ENDF/B-VII.1 evaluations. The previous VESTA analyses [5, 10, 55] used the fission yield data and decay data library as released with the ORIGEN 2.2 package and included in library files "pwru50" and “decay.lib," respectively. These two latter libraries are based on older ENSDF and ENDF/B-IV evaluations, which were the state of the art at the time, a few decades ago, when ORIGEN 2.2 was released.

Investigations into the effect of nuclear data used with VESTA on decay heat calculations were prompted by findings reported in [10], which showed that decay heat calculated for a HFIR LEU core at shutdown using the fuel isotopic composition obtained with VESTA is 46\% larger than the decay heat calculated using the ANSI/ANS standard [57]. The decay heat from shutdown to about 1 day of decay is required for follow-on thermal-hydraulic calculations, and its estimated values for decay times shortly after the reactor is scrammed ( $<15 \mathrm{~s}$ ) can have a significant impact on the corresponding results.

It was found that both fission yield data and decay data have a major effect on the calculated total decay heat at shutdown. The effect is significant for the short-lived fission products that are important contributors to total decay heat at very short decay times after shutdown. Following these investigations, it was decided to use the most recent releases of the fission yield and decay data based on ENDF/B-VII.1 with the depletion solver in VESTA. Note that VESTA allows user-provided fission yield data and decay data files in ENDF format. However, the extent of the use of such data that come from more recent data evaluations (ENDF/B-VII.0, ENDF/B-VII.1) with ORIGEN 2.2 is limited to the data-handling capabilities (e.g, number of actinides with fission yields, treatment of nuclear chains, treatment of background and metastable states, isomeric ratios) implemented in the ORIGEN 2.2 code itself. 
Table 42. Decay heat in irradiated HFIR fuel

\begin{tabular}{|c|c|c|c|c|}
\hline \multirow{2}{*}{ Decay time } & \multicolumn{2}{|c|}{$\begin{array}{l}\text { Total decay heat } \\
\text { (W) }\end{array}$} & \multicolumn{2}{|c|}{$\begin{array}{l}\text { Fission products decay heat } \\
\text { (W) }\end{array}$} \\
\hline & $\begin{array}{c}\text { Explicit } \\
\text { model }\end{array}$ & $\begin{array}{l}\text { Simplified } \\
\text { model }\end{array}$ & $\begin{array}{c}\text { Explicit } \\
\text { model }\end{array}$ & $\begin{array}{l}\text { Simplified } \\
\text { model }\end{array}$ \\
\hline $0 \mathrm{~s}$ & $4.91 \times 10^{6}$ & $4.91 \times 10^{6}$ & $4.90 \times 10^{6}$ & $4.90 \times 10^{6}$ \\
\hline $10 \mathrm{~s}$ & $3.56 \times 10^{6}$ & $3.56 \times 10^{6}$ & $3.55 \times 10^{6}$ & $3.55 \times 10^{6}$ \\
\hline $10^{2} \mathrm{~s}$ & $2.32 \times 10^{6}$ & $2.32 \times 10^{6}$ & $2.32 \times 10^{6}$ & $2.32 \times 10^{6}$ \\
\hline $10^{3} \mathrm{~s}$ & $1.37 \times 10^{6}$ & $1.37 \times 10^{6}$ & $1.37 \times 10^{6}$ & $1.37 \times 10^{6}$ \\
\hline $10^{4} \mathrm{~s}$ & $6.01 \times 10^{5}$ & $6.01 \times 10^{5}$ & $5.99 \times 10^{5}$ & $5.99 \times 10^{5}$ \\
\hline 1 day & $2.38 \times 10^{5}$ & $2.38 \times 10^{5}$ & $2.36 \times 10^{5}$ & $2.36 \times 10^{5}$ \\
\hline 1 year & $1.25 \times 10^{3}$ & $1.25 \times 10^{3}$ & $1.25 \times 10^{3}$ & $1.25 \times 10^{3}$ \\
\hline 3 year & $2.17 \times 10^{2}$ & $2.17 \times 10^{2}$ & $2.17 \times 10^{2}$ & $2.17 \times 10^{2}$ \\
\hline 10 year & $6.06 \times 10^{1}$ & $6.06 \times 10^{1}$ & $6.04 \times 10^{1}$ & $6.04 \times 10^{1}$ \\
\hline 30 year & $3.65 \times 10^{1}$ & $3.65 \times 10^{1}$ & $3.63 \times 10^{1}$ & $3.63 \times 10^{1}$ \\
\hline 100 year & $7.10 \times 10^{0}$ & $7.10 \times 10^{0}$ & $6.90 \times 10^{0}$ & $6.90 \times 10^{0}$ \\
\hline
\end{tabular}

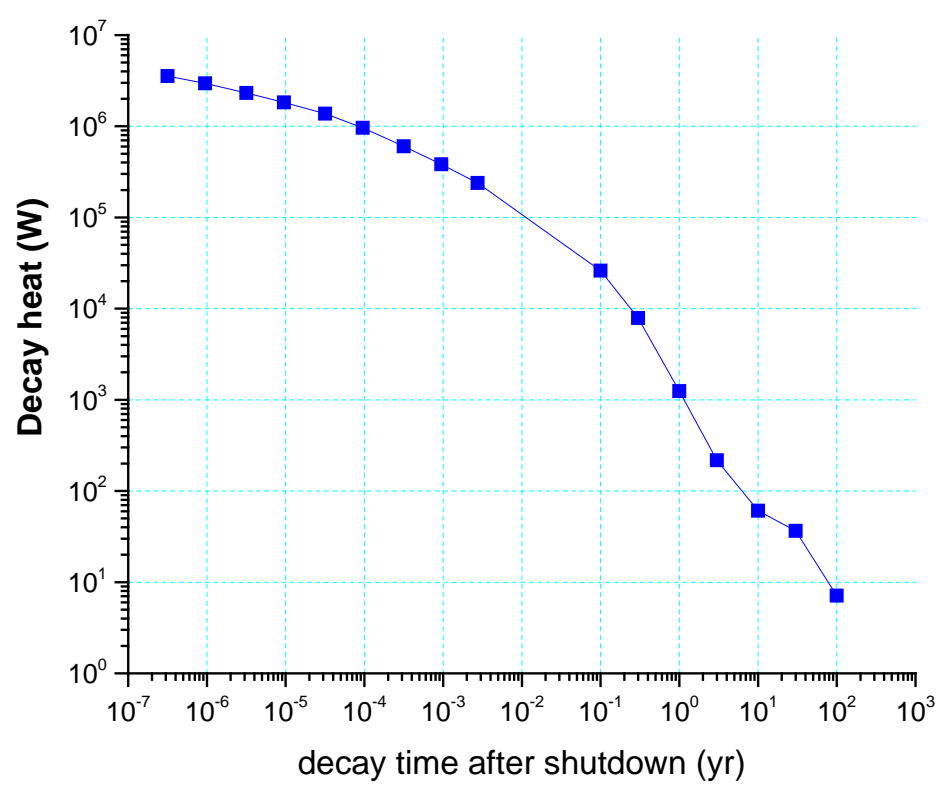

Fig. 38. Variation of total decay heat with cooling time. 


\subsubsection{Effective Delayed Neutron Fraction and Neutron Lifetime}

The effective delayed neutron fraction ( $\left.\beta_{\text {eff }}\right)$ was calculated using two approaches [57]: the k-ratio method and the direct calculation of point kinetics parameters in MCNP5-1.6. The k-ratio method [56] determines $\beta_{\text {eff }}$ as the ratio of the effective delayed neutron production rate and the effective (prompt and delayed) neutron production rate by fission using the following approximation:

$$
\beta_{\text {eff }}=\frac{\left\langle v_{d} \chi_{d}\right\rangle}{\langle v \chi\rangle} \approx 1-\frac{\left\langle v_{p} \chi_{p}\right\rangle}{\langle v \chi\rangle} \approx 1-\frac{k_{p}}{k},
$$

where indices $p$ and $d$ stand for prompt and delayed, respectively; $\chi$ is the neutron spectrum; $v$ is the average number of neutrons per fission; and the brackets stand for integration over the phase space. The values $k_{p}$ and $k$ for the effective multiplication constant can be estimated from two MCNP kcode criticality calculations: (1) a calculation including only prompt neutrons and (2) a calculation with both prompt and delayed neutrons (default MCNP mode) included in the simulation.

The $\beta_{\text {eff }}$ values at BOC and EOC for both simplified and explicit models are presented in Table 43. The $\beta_{\text {eff }}$ value accepted in the current safety basis for HFIR [31] is 0.0076 for both BOC and EOC. The values calculated for a given core state with the k-ratio method for the two models (simplified and explicit) agree within 2 standard deviations. The $\beta_{\text {eff }}$ values calculated for a given core state and a given model with the two methods (k-ratio and direct MCNP) agree within 1 standard deviation of each other.

The prompt neutron lifetime for BOC and EOC was calculated using the point kinetics capability in MCNP5-1.6. Table 44 shows a comparison of the calculated data and measured data from pulsed-neutron experiments performed at HFIR in the 1960s for HFIR Critical Experiment 2 (HFIRCE-2) [1]. Measurement uncertainties are not available for the reported measurement data. The calculated neutron lifetime values differ from the as-reported measurement data by less than $10 \%$ at BOC and less than $13 \%$ at EOC. There is reasonable agreement between the calculated and experimentally obtained results; there is not complete consistency between the conditions for the experimental configuration and the computational model.

Table 43. Effective delayed neutron fraction

\begin{tabular}{llcccc}
\hline \multirow{2}{*}{ Core state } & \multirow{2}{*}{ Method } & \multicolumn{2}{c}{ Explicit model } & \multicolumn{2}{c}{ Simplified model } \\
\cline { 3 - 6 } & & $\boldsymbol{\beta}_{\text {eff }}$ & $\boldsymbol{\sigma}$ & $\boldsymbol{\beta}_{\text {eff }}$ & $\boldsymbol{\sigma}$ \\
\hline \multirow{2}{*}{ BOC } & k-ratio & 0.00755 & 0.00010 & 0.00759 & 0.00010 \\
& point kinetics in MCNP5-1.6 & 0.00742 & 0.00010 & 0.00776 & 0.00015 \\
\multirow{2}{*}{ EOC } & k-ratio & 0.00737 & 0.00011 & 0.00751 & 0.00009 \\
& point kinetics in MCNP5-1.6 & 0.00740 & 0.00009 & 0.00743 & 0.00014 \\
\hline
\end{tabular}

Table 44. Prompt neutron lifetime

\begin{tabular}{|c|c|c|c|}
\hline $\begin{array}{l}\text { Core } \\
\text { state }\end{array}$ & $\begin{array}{c}\text { Calculated }^{a}(\mu \mathrm{s}) \\
\text { explicit model }^{-}\end{array}$ & $\begin{array}{l}\text { Calculated }^{a}(\mu \mathrm{s}) \\
\text { simplified model }\end{array}$ & $\operatorname{Measured}^{b}(\mu \mathrm{s})$ \\
\hline BOC & $36.32 \pm 0.11^{\mathrm{a}}$ & $35.51 \pm 0.15^{\mathrm{a}}$ & 33 \\
\hline EOC & $65.58 \pm 0.17^{\mathrm{a}}$ & $64.24 \pm 0.25^{\mathrm{a}}$ & 74 \\
\hline
\end{tabular}

${ }^{a}$ Value and standard deviation $(1 \sigma)$ calculated by MCNP.

${ }^{b}$ Reported in [1]. 


\subsubsection{Reactivity Coefficients}

\subsubsection{Flux trap void}

The effect on reactivity of the flux trap void was assessed by calculating the variation of $\mathrm{k}_{\mathrm{eff}}$ with the reduction of water density in the flux trap region at BOC. This type of calculated data can be compared to measurement data for the first preconstruction critical experiment at HFIR that used a prototypic fuel element (HFIRCE-2) [1]. The measurement data are available for two cases: one case with no target in the flux trap and one case with a 300 g plutonium simulated target included. The comparison between the available measurement data and the corresponding data calculated in this report is presented in Fig. 39 for the BOC state. The points shown in this figure for the measurement data were digitized from plots available in [1] and [31]. The data calculated with the simplified and explicit models at BOC are the same and therefore difficult to separately identify in Fig. 39.

The calculated $\mathrm{k}_{\text {eff }}$ variations over the whole range considered for water density reduction are smaller than the $1.5 \% \Delta \mathrm{k} / \mathrm{k}$ value that was adopted in the SAR [31] as a design basis reactivity event for protection system design and evaluation. The maximum increase in $\mathrm{k}_{\text {eff }}$ occurs at $\sim 60 \%$ reduction in water density for both simplified and explicit models at BOC and EOC.

The shapes of the $\mathrm{k}_{\text {eff }}$ variation calculated with the simplified and explicit models for a given core state (BOC or EOC) are almost identical. However as seen in Fig. 40, there is a clear difference between the behavior of the shapes at EOC compared to BOC - the EOC shape is shifted up, indicating a slightly increased effect on reactivity at EOC for water density reductions higher than $60 \%$. At a $90 \%$ void, this increase in $\mathrm{k}_{\mathrm{eff}}$ at EOC compared to BOC is $\sim 200 \mathrm{pcm}$.

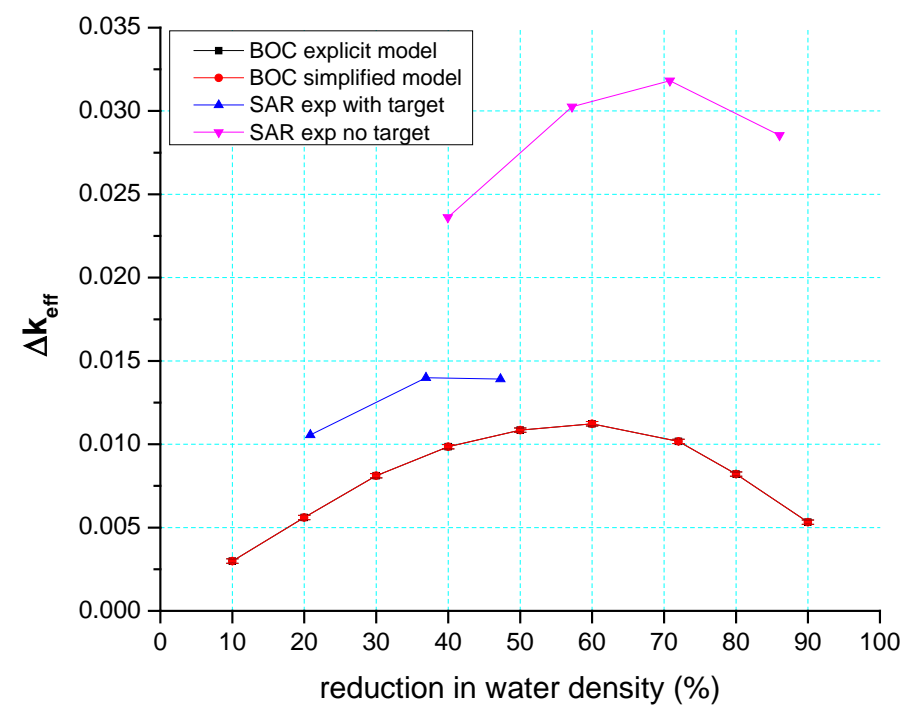

Fig. 39. Variation of $\mathbf{k}_{\mathrm{eff}}$ with reduction of water density in flux trap region at beginning-of-cycle (BOC). (SAR = safety analysis report.) 


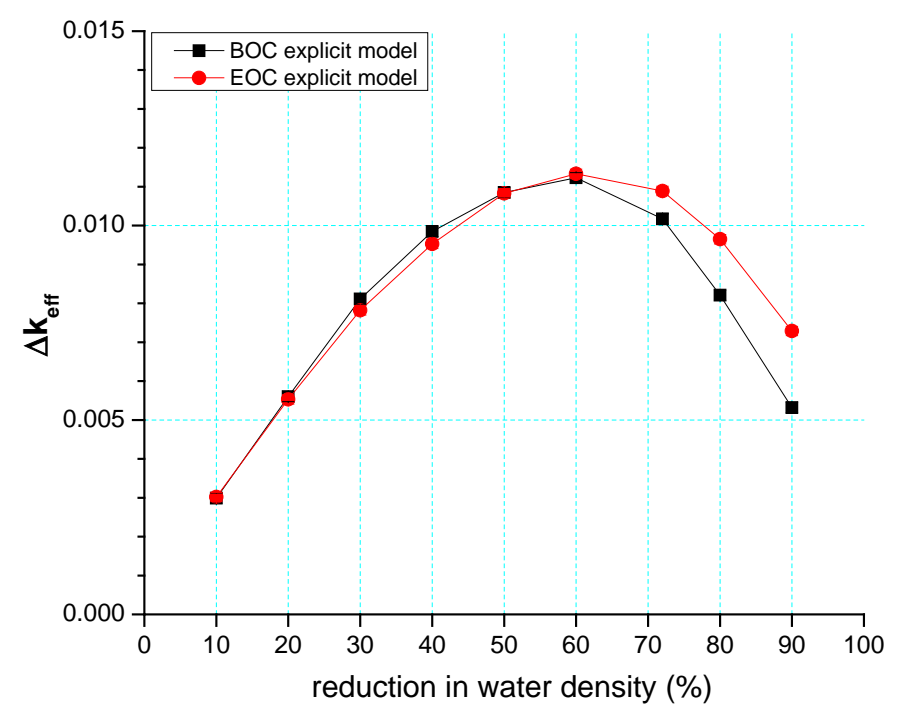

Fig. 40. Variation of $\mathbf{k}_{\mathrm{eff}}$ with reduction of water density in flux trap region at beginning-of-cycle (BOC) and end of cycle (EOC).

\subsubsection{Coolant void}

The coolant void reactivity coefficient (CVR) for the coolant in the fuel region was calculated for each of the two fuel elements to enable a direct comparison with measurement data [1] from HFIR start-up tests performed in the 1960s for HFIRCE-4. For these measurements, which were performed separately for the IFE and OFE, a few of the fuel plates in a fuel element were replaced with aluminum plates and then the latter replaced with water; the reported void coefficients were estimated by making corrections to as-measured aluminum coefficients.

The CVR is calculated in the present report as

$$
C V R=\frac{\Delta k_{e f f} / k_{e f f}}{\Delta V_{c} / V_{c}}
$$

where $V_{c}$ is the volume of the coolant in the region of interest and $\Delta$ signifies the variation in the value for eigenvalue or volume. Two values of the coolant density were considered for the CVR calculation: the nominal value and a perturbed value at $90 \%$ of the nominal coolant density.

The calculated and measured CVR data are shown in Table 45. The data calculated with the explicit model are consistent with those determined using the simplified model. The CVR at EOC slightly increases compared to its BOC value- the absolute value of the CVR at EOC decreases to approximately two-thirds of its BOC value.

There is reasonable agreement between the calculated and measured data, considering the differences between the modeled core and the actual experimental configuration and the corrections used for the reported experimental data. 
Table 45. Coolant void reactivity coefficients in $(\Delta \mathrm{k} / \mathrm{k}) /(\Delta \mathrm{V} / \mathrm{V})$

\begin{tabular}{|c|c|c|c|c|}
\hline \multirow{2}{*}{$\begin{array}{l}\text { Core } \\
\text { state }\end{array}$} & \multirow{2}{*}{$\begin{array}{l}\text { Fuel } \\
\text { region }\end{array}$} & \multicolumn{2}{|c|}{ Calculated $^{a}$ coolant void reactivity coefficient (CVR) } & \multirow{2}{*}{ Measured $^{b}$ CVR } \\
\hline & & Explicit model & Simplified model & \\
\hline \multirow[t]{3}{*}{ BOC $^{c}$} & IFE & -0.110 & -0.104 & -0.080 \\
\hline & OFE & -0.221 & -0.211 & -0.170 \\
\hline & $\mathrm{IFE}+\mathrm{OFE}$ & -0.339 & -0.325 & NA \\
\hline \multirow[t]{3}{*}{ EOC } & IFE & -0.072 & -0.072 & NA \\
\hline & OFE & -0.148 & -0.148 & NA \\
\hline & $\mathrm{IFE}+\mathrm{OFE}$ & -0.226 & -0.224 & NA \\
\hline
\end{tabular}

\footnotetext{
${ }^{a}$ Absolute value of standard deviation for the calculated data is 0.001 in all cases.

${ }^{b}$ From [30].

${ }^{c} \mathrm{BOC}=$ beginning-of-cycle, IFE $=$ inner fuel element, $\mathrm{OFE}=$ outer fuel element, $\mathrm{NA}=$ not applicable, $\mathrm{EOC}=$ end-of-cycle.
}

\subsubsection{Temperature coefficients}

Temperature coefficients (TCs) were calculated as

$$
T C=\frac{k_{p}-k_{r}}{k_{p} k_{0}\left(T_{p}-T_{r}\right)}
$$

where indices $p$ and $r$ indicate a perturbed state and a reference state, respectively; $k$ is the core effective multiplication constant; and $T$ is the temperature. The temperatures considered for the reference and perturbed state are $300 \mathrm{~K}$ and $600 \mathrm{~K}$, respectively.

Three temperature coefficients were calculated, with both explicit and simplified models, for three regions: (1) fuel element region; (2) flux trap region; and (3) all regions in the model. For the perturbed cases, the cross-section data for materials in the considered regions were modified to correspond to $600 \mathrm{~K}$. No changes were made to material number densities. The TC for the fuel region, also known as the Doppler coefficient of reactivity, was calculated in the explicit model by perturbing only the temperature of the fuel meat material; in the simplified model, the change of temperature is applied to the spatially homogenized material compositions in the fuel element region. The TC for the flux trap regions was calculated by perturbing the temperature of all materials present in this region. The third type of TC, the isothermal TC, was calculated by perturbing the temperatures of all materials in the MCNP model.

The calculated TCs for the BOC and EOC states, expressed in units of $\Delta \mathrm{k} / \mathrm{k} / \mathrm{K}$, are given in Table 46 . The calculated TCs are in general consistent with the corresponding values included in the HFIR SAR [31]. The TCs calculated with the simplified and explicit models are consistent with one another, except for the fuel region TC. Part of this difference is due to the approximation used in the modeling of this region. Note that the fuel temperature feedback is smaller relative to other feedback effects. As stated in SAR [31], "Because of the small fraction of ${ }^{238} U$ in the HFIR fuel, the Doppler effect does not contribute significantly to the normal reactivity feedback effects, which are dominated by moderator density changes.”

The calculated flux trap region TC is consistent with the value reported in SAR [31], "approximately $6 \times 10^{-5} \mathrm{\Delta} / \mathrm{k} / \mathrm{F}$ at normal operating temperature"; the cited data are based on values obtained from critical experiments performed in the 1960s.

It is mentioned in SAR [31] that "the isothermal coefficient measured in the actual HFIR facility (with the target installed) was slightly positive over the temperature range of 80 to $120^{\circ} \mathrm{F}$, with the 
maximum reactivity addition being about 10 cents”; this reactivity addition would correspond to an approximate TC value of $3.4 \times 10^{-5} \Delta \mathrm{k} / \mathrm{k} / \mathrm{K}$. The calculated TC at BOC is consistent with this value.

The temperature coefficient calculated with the explicit model in the fuel region at BOC is consistent with its EOC value (within 1 standard deviation). The TC for the flux trap region is practically the same at BOC and EOC and does not vary with the model used. The isothermal TC is larger at EOC compared to BOC. The major component of this TC is clearly due to the flux trap region.

Table 46. Temperature coefficients of reactivity in $(\Delta \mathbf{k} / \mathbf{k}) / \mathrm{K}$

\begin{tabular}{|c|c|c|c|c|c|}
\hline \multirow{2}{*}{ Case } & \multirow{2}{*}{ Region } & \multicolumn{2}{|c|}{ Beginning-of-cycle } & \multicolumn{2}{|c|}{ End-of-cycle } \\
\hline & & Explicit model & Simplified model & Explicit model & Simplified model \\
\hline 1 & Fuel region & $\begin{array}{c}-2.5 \times 10^{-6} \\
\left(\sigma=4.3 \times 10^{-7}\right)\end{array}$ & $\begin{array}{c}-6.1 \times 10^{-5} \\
\left(\sigma=4.8 \times 10^{-7}\right)\end{array}$ & $\begin{array}{c}-2.2 \times 10^{-6} \\
\left(\sigma=3.8 \times 10^{-7}\right)\end{array}$ & $\begin{array}{c}-8.9 \times 10^{-5} \\
\left(\sigma=4.1 \times 10^{-7}\right)\end{array}$ \\
\hline 2 & Flux trap region & $\begin{array}{c}4.4 \times 10^{-5} \\
\left(\sigma=4.2 \times 10^{-7}\right)\end{array}$ & $\begin{array}{c}4.4 \times 10^{-5} \\
\left(\sigma=4.4 \times 10^{-7}\right)\end{array}$ & $\begin{array}{c}4.4 \times 10^{-5} \\
\left(\sigma=3.7 \times 10^{-7}\right)\end{array}$ & $\begin{array}{c}4.5 \times 10^{-5} \\
\left(\sigma=3.9 \times 10^{-7}\right)\end{array}$ \\
\hline 3 & All regions in the model & $\begin{array}{c}3.4 \times 10^{-5} \\
\left(\sigma=4.2 \times 10^{-7}\right)\end{array}$ & $\begin{array}{c}3.6 \times 10^{-5} \\
\left(\sigma=4.4 \times 10^{-7}\right)\end{array}$ & $\begin{array}{c}7.5 \times 10^{-5} \\
\left(\sigma=3.7 \times 10^{-7}\right)\end{array}$ & $\begin{array}{c}7.7 \times 10^{-5} \\
\left(\sigma=4.1 \times 10^{-7}\right)\end{array}$ \\
\hline
\end{tabular}




\section{EFFECT OF NUCLEAR DATA}

This section describes a preliminary sensitivity analysis to assess the effect of the cross-section data used in the simulations on the results obtained. One of the motivations behind this study was to attempt quantifying the effect of the assumptions used for the cross-section data on the variation of the observed bias in $\mathrm{k}_{\mathrm{eff}}$ as a function of irradiation time (see Section 8.1.1).

\subsection{CROSS-SECTION DATA USED WITH VESTA}

The simulations discussed in all previous sections of this report were performed using cross sections based on ENDF/B-VII.0 data [26] with both the MCNP neutron transport solver and the ORIGEN 2.2 depletion solver in VESTA. All cross sections are considered at $300 \mathrm{~K}$ temperature, with the water thermal scattering data, as available from the MCNP5 release, at $293.6 \mathrm{~K}$. The fission yield data and the nuclear decay data used with ORIGEN 2.2 are based on ENDF/B-VII.1 [28] evaluations (see Section 8.2.2).

The cross-section libraries released with VESTA, for use with the neutron transport solver and the depletion solver, are available at seven temperatures: $293.6 \mathrm{~K}, 300 \mathrm{~K}, 600 \mathrm{~K}, 900 \mathrm{~K}, 1200 \mathrm{~K}, 1500 \mathrm{~K}$, and $1800 \mathrm{~K}$. The libraries released with VESTA do not include thermal scattering kernel data, also referred to as $S(\alpha, \beta)$ data, for use with the MCNP transport solver. These types of data are taken from the MCNP5 package. The $S(\alpha, \beta)$ data in the MCNP5 package are available on a finer temperature grid than that for which the other libraries are available. This includes $S(\alpha, \beta)$ data at $300 \mathrm{~K}$ and $350 \mathrm{~K}$ for water and beryllium, which are important moderators for the HFIR model. The MCNP5 package also includes the MAKXSF utility program for manipulating cross-section library files, which can be used to interpolate $S(\alpha, \beta)$ data to new temperatures. Therefore, it is possible to generate $S(\alpha, \beta)$ data at various temperatures by interpolating between the available data sets.

The temperatures throughout HFIR at the nominal core condition are in the range of approximately 320-436 K [1]. For example, the region-average coolant temperature varies between approximately $324 \mathrm{~K}$ in the flux trap region and $332 \mathrm{~K}$ in the fuel element region [47]. The nominal maximum temperatures at the fuel plate centerline and plate-water interface in the fuel element region are $436 \mathrm{~K}$ and $405 \mathrm{~K}$, respectively [1]. Of the available VESTA cross-section libraries, the set at $300 \mathrm{~K}$ is the closest to the range of temperatures in HFIR at the nominal condition. Detailed information on the approach used to generate the cross sections released with VESTA is not available. This makes it difficult for an independent user to generate cross sections at custom temperatures for use with VESTA.

Assessment of the importance of the cross-section temperatures for HFIR depletion simulations would require generating data at custom temperatures for all materials in the reactor model. As mentioned, this is impossible at this time because of limited information on the cross-section generator used for VESTA, which is not publicly available. However, sensitivity studies could be performed to quantify the effect on depletion of only the $S(\alpha, \beta)$ data at custom temperatures. In addition, the MAKXSF utility could be used to generate cross sections at custom temperatures for MCNP only (not for ORIGEN 2.2 in VESTA) for use with the MCNP HFIR models at BOC; it would be adequate to use MAKXSF for interpolating only between the libraries released with the MCNP package, not those released with VESTA.

\subsection{EFFECT OF WATER $S(\alpha, \beta)$ DATA ON EIGENVALUE}

New $S(\alpha, \beta)$ data were generated for water at $325 \mathrm{~K}$ and $332 \mathrm{~K}$ temperatures by interpolating with MAKXSF using $S(\alpha, \beta)$ libraries (lwtr files) at $293.6 \mathrm{~K}$ and $350 \mathrm{~K}$ that are available with the MCNP5 release. These lwtr data were used in VESTA depletion simulations with the simplified and explicit models. The lwtr data set at $332 \mathrm{~K}$ was applied to water in the fuel element region. The lwtr data set at $325 \mathrm{~K}$ was applied to water present everywhere else in the model, except for the reactor pool water and 
the water in the fuel element region. The lwtr data used for the pool water correspond to $293.6 \mathrm{~K}$. All other cross sections in the model were at a temperature of $300 \mathrm{~K}$. The $S(\alpha, \beta)$ data for beryllium and graphite were not updated because, according to a recent notification on the MCNP forum list by the MCNP developers, a deficiency was identified in MAKXSF and its use is not recommended at this time for selected types of $S(\alpha, \beta)$ data; however, its use with $S(\alpha, \beta)$ data for water is not affected by this deficiency.

The effect of the water $S(\alpha, \beta)$ data on $\mathrm{k}_{\text {eff }}$ is illustrated in Fig. 41 for the simplified model and in Fig. 42 for the explicit model. For each of the two models, the $\mathrm{k}_{\mathrm{eff}}$ trajectories are shifted up. The magnitude of the increase in the $\mathrm{k}_{\mathrm{eff}}$ values varies during each day in the cycle and is in the range of 154$339 \mathrm{pcm}$ for the simplified model and $137-247 \mathrm{pcm}$ for the explicit model; the statistical uncertainties $(1 \sigma)$ associated with these eigenvalue differences are in the range of 22-25 pcm.

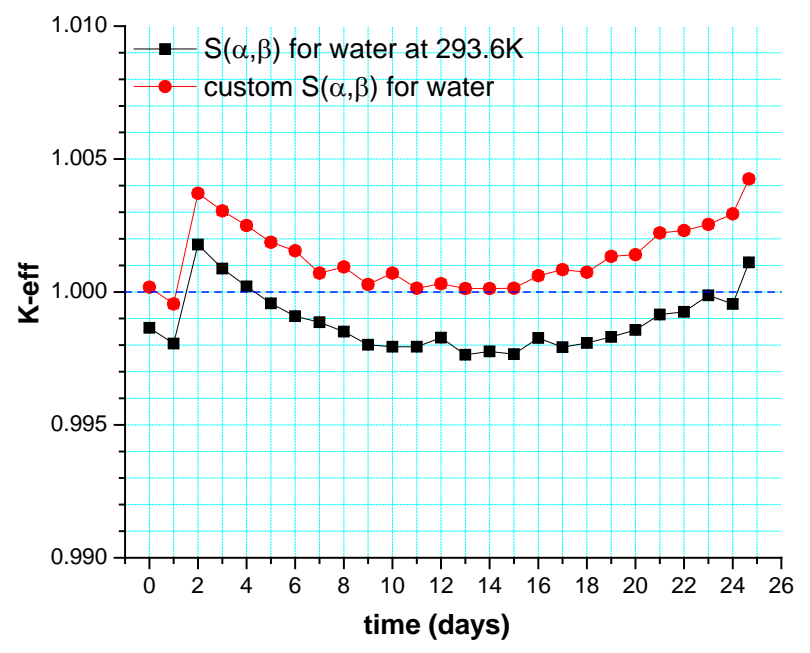

Fig. 41. Effect on $k_{\text {eff }}$ of $S(\alpha, \beta)$ data for water (simplified HFIR model).

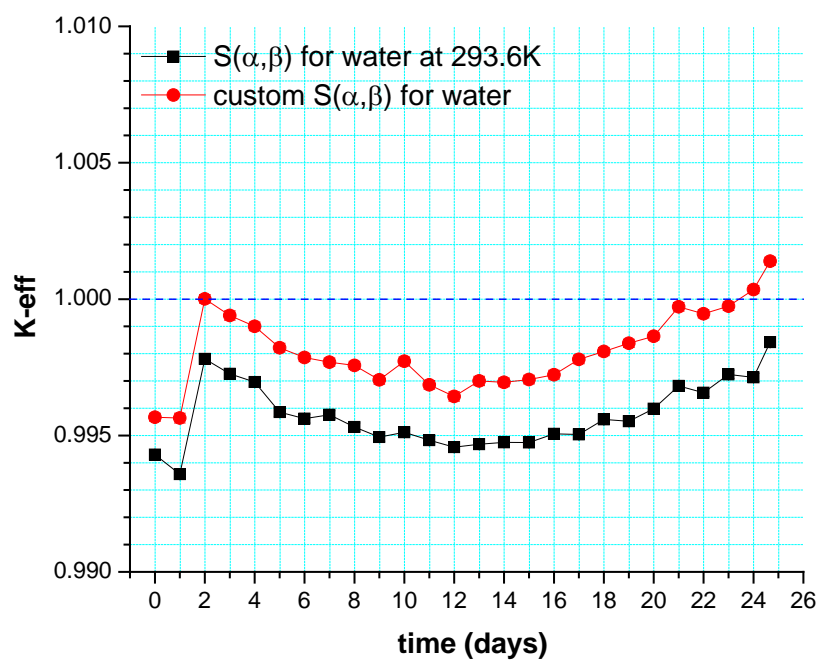

Fig. 42. Effect on $k_{\text {eff }}$ of $S(\alpha, \beta)$ data for water (explicit HFIR model). 
The effect on eigenvalue discussed in this section is consistent with the temperature effects on reactivity presented in Section 8.2.4.3 (see TCs in Table 46). The fuel TC is negative and has a much smaller absolute value (an order of magnitude smaller) than the positive TC for the flux trap and the isothermal TC. There is also a variation with the irradiation time in the magnitude of the isothermal TC, which more than doubles in absolute value from BOC to EOC. Application of the isothermal TCs calculated for the simplified model to a temperature change throughout the reactor of $32 \mathrm{~K}$ would result in a reactivity effect of $115 \mathrm{pcm}$ at BOC and $246 \mathrm{pcm}$ at EOC. The effect of the water $S(\alpha, \beta)$ temperature on $\mathrm{k}_{\text {eff }}$ calculated in this section is also changing as a function of the irradiation time, as illustrated in Fig. 43 for data obtained with the simplified and explicit models. This effect on $\mathrm{k}_{\mathrm{eff}}$ increases quasilinearly with increasing time, from $153 \mathrm{pcm}$ at BOC to $314 \mathrm{pcm}$ at EOC for the simplified model, and from $137 \mathrm{pcm}$ at BOC to $332 \mathrm{pcm}$ at EOC for the explicit model.

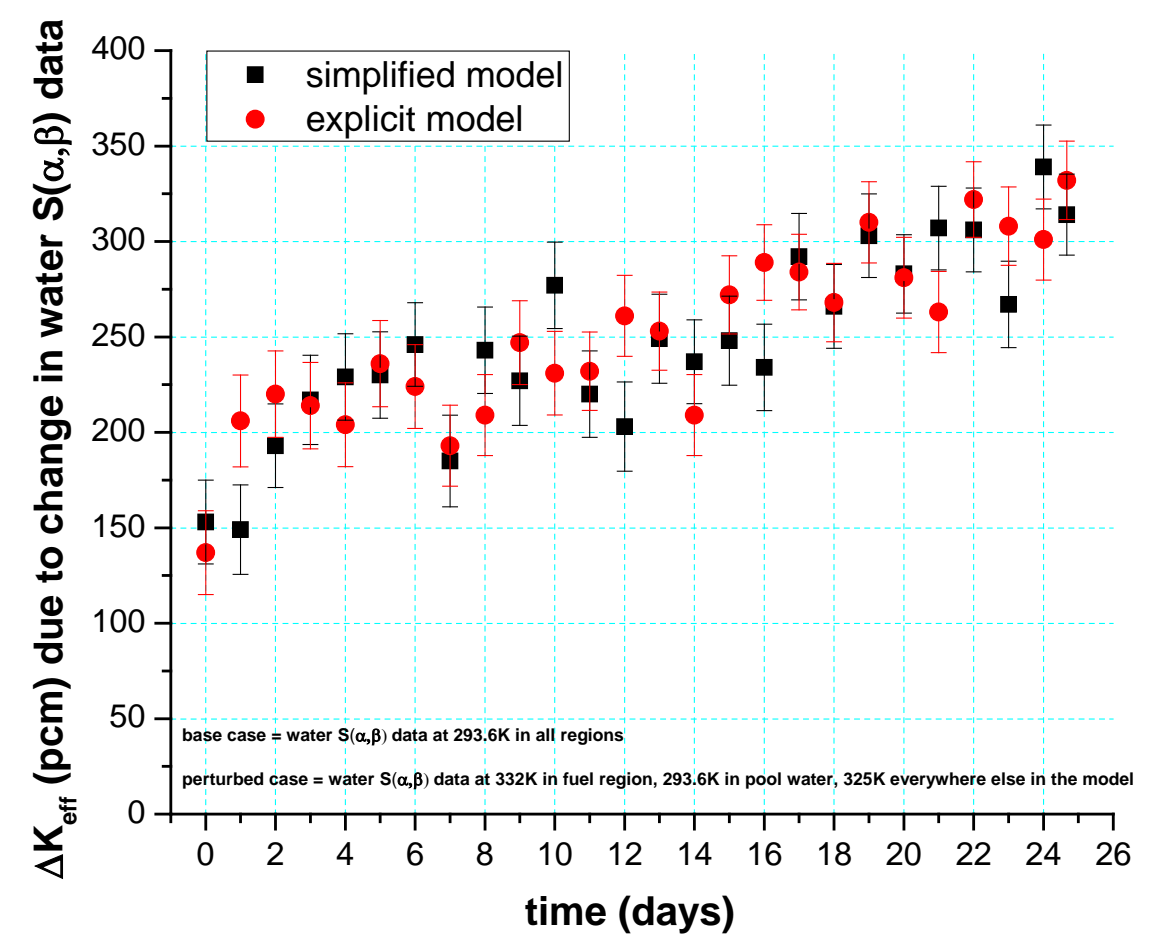

Fig. 43. Difference in $k_{\text {eff }}$ due to water $S(\alpha, \beta)$ data.

\subsection{EFFECT OF WATER $S(\alpha, \beta)$ DATA ON OTHER METRICS}

Comparisons were made for other relevant metrics to determine the effect, if any, from the change in the water $S(\alpha, \beta)$ data. There is no significant change of the BOC or EOC three-group fluxes at relevant locations; the flux values obtained with the changed water $S(\alpha, \beta)$ data agree within two standard deviation with the values shown in Section 8.1.2, in Tables 34 and 35.

There is no significant effect of the water $S(\alpha, \beta)$ data on the fission density data at BOC and EOC; for each of these two reactor states and each of the two considered models (simplified and explicit), the data agree within two standard deviations for all considered spatial meshes. For example, for the explicit model at BOC, the maximum percentage difference in the fission density is $2.4 \%$, the difference in fission density is smaller than $2 \%$ for $98 \%$ of the 418 spatial fuel meshes, and the average difference over all fuel meshes is $0.9 \%$. 
There is no significant effect of the water $S(\alpha, \beta)$ data on the major actinides inventory at EOC. For the simplified model, the ${ }^{235} \mathrm{U}$ content at EOC varies by only $0.1 \mathrm{~g}$ due to this change in the water data, as presented in Table 47. The effect for the explicit model is similar to that seen for the simplified model.

The ${ }^{235} \mathrm{U}$ depletion is essentially unaffected by the change in the water $S(\alpha, \beta)$ data. There is no change in the location (i.e., the individual fuel mesh) where the maximum depletion value occurs in the IFE and OFE. The maximum depletion in the IFE, previously calculated as $72 \%$, is calculated as $71 \%$ with the new $S(\alpha, \beta)$ data. The maximum depletion in the OFE changes from $55 \%$ to $54 \%$ due to the change in the water $S(\alpha, \beta)$ data.

Table 47. Effect of water $S(\alpha, \beta)$ data on major actinides inventory at end-of-cycle (simplified model)

\begin{tabular}{|c|c|c|c|c|c|c|c|c|c|}
\hline \multirow[b]{2}{*}{ Isotope } & \multicolumn{3}{|c|}{ Mass in $\mathrm{IFE}^{a}(\mathrm{~g})$} & \multicolumn{3}{|c|}{ Mass in OFE (g) } & \multicolumn{3}{|c|}{ Mass in IFE+OFE (g) } \\
\hline & $\begin{array}{c}S(\sigma, \beta) \text { at } \\
293.6 K\end{array}$ & $\begin{array}{l}\text { custom } \\
S(\sigma, \beta)\end{array}$ & $\operatorname{diff}^{b}$ & $\begin{array}{c}\mathrm{S}(\sigma, \beta) \text { at } \\
293.6 \mathrm{~K}\end{array}$ & $\begin{array}{l}\text { custom } \\
S(\sigma, \beta)\end{array}$ & $\operatorname{diff}^{b}$ & $\begin{array}{c}\mathrm{S}(\sigma, \beta) \text { at } \\
293.6 \mathrm{~K}\end{array}$ & $\begin{array}{l}\text { custom } \\
S(\sigma, \beta)\end{array}$ & $\operatorname{diff}^{b}$ \\
\hline${ }^{234} \mathrm{U}$ & 24.47 & 24.47 & 0.00 & 67.16 & 67.17 & -0.01 & 91.63 & 91.64 & -0.01 \\
\hline${ }^{235} \mathrm{U}$ & $1,654.82$ & $1,654.44$ & 0.38 & $5,190.76$ & $5,191.24$ & -0.48 & $6,845.58$ & $6,845.68$ & -0.10 \\
\hline${ }^{236} \mathrm{U}$ & 173.30 & 173.31 & -0.01 & 324.21 & 324.07 & 0.14 & 497.51 & 497.38 & 0.13 \\
\hline${ }^{238} \mathrm{U}$ & 144.95 & 144.95 & 0.00 & 382.92 & 382.95 & -0.03 & 527.87 & 527.90 & -0.03 \\
\hline${ }^{238} \mathrm{Pu}$ & 0.11 & 0.11 & 0.00 & 0.14 & 0.14 & 0.00 & 0.25 & 0.25 & 0.00 \\
\hline${ }^{239} \mathrm{Pu}$ & 3.32 & 3.29 & 0.03 & 8.02 & 7.96 & 0.06 & 11.34 & 11.25 & 0.09 \\
\hline${ }^{240} \mathrm{Pu}$ & 0.52 & 0.53 & -0.01 & 0.88 & 0.90 & -0.02 & 1.40 & 1.43 & -0.03 \\
\hline${ }^{241} \mathrm{Pu}$ & 0.24 & 0.25 & -0.01 & 0.35 & 0.36 & -0.01 & 0.59 & 0.61 & -0.02 \\
\hline${ }^{242} \mathrm{Pu}$ & 0.03 & 0.03 & 0.00 & 0.02 & 0.02 & 0.00 & 0.05 & 0.05 & 0.00 \\
\hline
\end{tabular}

${ }^{a} \mathrm{IFE}=$ inner fuel element, OFE = outer fuel element.

${ }^{b}$ Calculated as absolute difference between mass predicted by the simplified model in two cases: (1) water $S(\alpha, \beta)$ data at 293.6K in all regions and (2) water $S(\alpha, \beta)$ data at custom temperatures.

\subsection{COMPREHENSIVE EFFECT OF NUCLEAR DATA}

The results of the preliminary sensitivity analysis discussed in this section indicate that a comprehensive temperature treatment of cross sections for all materials in the model could decrease the potential biases and uncertainties in the depletion calculation associated to temperature effects. The results discussed here are pertinent to a single perturbation of the model, the change in the water $S(\alpha, \beta)$ data only, and therefore do not account for any correlation that would be embedded in a compound effect, if a global temperature treatment were applied. Application of a comprehensive cross-section temperature treatment by either generating libraries at custom temperatures for use with VESTA (when its library generation utility program becomes available) or by modeling the reactor using a different code that allows accounting for temperature effects, would ultimately quantify the actual overall temperature effect.

Until these modeling capabilities become available, sensitivity analyses to assess temperature effects can be conducted via MCNP simulations at steady-state core points. Temperature-dependent cross section libraries for MCNP can be generated over a temperature grid relevant for HFIR core simulations using the NJOY code [58]. This type of analysis provides the best estimates of temperature effects with the currently available tools. 


\section{CONCLUSIONS}

The present report documents the results of a concerted effort over the past few years to improve the HFIR core models for Cycle 400. This effort is part of a comprehensive study for designing a HFIR core that would use a new, LEU fuel. A HFIR core depletion model that is based on current state-of-the-art methods and nuclear data was needed to serve as a reference for the design of an LEU fuel for HFIR.

The recent enhancements in modeling and simulations for HFIR that are discussed here include (1) revision of the 2005 MCNP model for the beginning of Cycle 400 to improve the modeling data and assumptions as necessary based on appropriate primary reference sources (HFIR drawings and reports); (2) improvement of the fuel region model, including an explicit representation for the involute fuel plate geometry that is characteristic to HFIR fuel; and (3) revision of the Monte Carlo-based depletion model for HFIR, in use since 2009 but never documented in detail, with the development of a new depletion model for the HFIR core that represents the fuel plate explicitly. The discussion of the modeling data and assumptions emphasizes those data and assumptions that have been updated compared to the previous modeling efforts.

Two HFIR core models are presented for steady-state and time-dependent depletion analyses of the core: a simplified model and an explicit model, which differ only by the approach used for the modeling of the fuel elements. These two models are used to simulate the core irradiation history for Cycle 400 and to determine metrics of relevance for reactor performance and safety assessments. The depletion simulations performed for this report use nuclear data that are based on recent evaluations: ENDF/B-VII.0 for cross sections and ENDF/B-VII.1 for fission yields and decay data.

The calculated metrics include neutron flux at important locations in the core, relative fission density distributions, reactivity coefficients (coolant void, flux trap void, and temperature coefficients), point kinetics parameters (effective delayed neutron fraction and neutron lifetime), and isotopic composition and decay heat in irradiated fuel. The calculated metrics are compared with measured data from preconstruction critical experiments at HFIR, data included in the current HFIR SAR, and/or data from previous calculations. The comparison indicates reasonable agreement between calculated and measured results for those cases where experimental data are available. A relevant outcome is the resolution of a previously identified discrepancy [10] between the values of the decay heat at shutdown calculated based on a previous depletion model and that calculated with the ANSI/ANS standard.

The comparison of the results obtained with the simplified and explicit models indicates that, in general, these results are consistent for most of the analyzed performance and safety metrics. The use of the simplified model would be adequate for those analyses that are not focused on obtaining very detailed spatial information for the fuel element region or calculating data that cannot be adequately calculated with the simplified model (e.g., Doppler coefficient of reactivity) because of the approximations that are inherent to this model. A comparison of data calculated with the simplified and explicit models at BOC, EOC, and during the irradiation shows good consistency between results that are a function of fuel depletion, indicating that both models would be adequate for core depletion simulations. The relative fission density distributions are practically the same, as are the isotopic compositions of main actinides at EOC (e.g., only 2 g difference in the predicted ${ }^{235} \mathrm{U}$ core load) and the spatial distribution of the burnup (i.e., ${ }^{235} \mathrm{U}$ depletion).

A preliminary sensitivity analysis to assess the effect of the cross-section data used in the simulations is discussed. Results of this study indicate that a comprehensive temperature treatment of cross sections for all materials in the model could decrease the potential biases and uncertainties associated to temperature effects in the depletion calculation. Application of this type of treatment is recommended to be conducted when the needed capabilities become available. Until these modeling capabilities become available, sensitivity analyses to assess temperature effects can be conducted only at steady-state core points.

The results of the analyses discussed here show that the developed core models provide a robust and reliable basis for HFIR core depletion analyses, verification or update of data included in the HFIR SAR, 
and design and analysis of experiments at different locations in HFIR. Moreover, these models constitute a foundation for developing cycle-specific HFIR models or models for a HFIR LEU core. 


\section{REFERENCES}

1. R. D. Cheverton and T. M. Sims, HFIR Core Nuclear Design, ORNL-4621, Oak Ridge National Laboratory (1971).

2. X-5 Monte Carlo Team, MCNP—A General Monte Carlo N-Particle Transport Code, Version 5, LACP-03-0245, Los Alamos National Laboratory (2003).

3. N. Xoubi and R. T. Primm III, Modelling of the High Flux Isotope Reactor Cycle 400, ORNL/TM2004/251, Oak Ridge National Laboratory (2005).

4. R. T. Primm III, D. Chandler, G. Ilas, B.C. Jolly, J. H. Miller, and J. D. Sease, Design Study for a Low-Enriched Uranium Core for the High Flux Isotope Reactor, Annual Report for FY 2008, ORNL/TM-2009/87, Oak Ridge National Laboratory (2009).

5. G. Ilas and R. T. Primm III, "Methodology for simulating the irradiation of the control elements in HFIR,” ANS Transactions, vol. 103, 696-698 (2010).

6. D. Chandler, R. T. Primm, III, and G. I. Maldonado, "Power Distribution Analysis for the High Flux Isotope Reactor Critical Experiment 3,” Nuclear Science and Engineering, vol. 164 (2010).

7. D. Chandler, R. T. Primm, III, and G. I. Maldonado, "Validation of a Monte Carlo Based Depletion Methodology via High Flux Isotope Reactor HEU Post-Irradiation Examination Measurements," Nuclear Engineering and Design, vol. 240 (2010).

8. R. T. Primm III, R. J Ellis, J. C. Gehin, D. L. Moses, J. L. Binder, and N. Xoubi, Assumptions and Criteria for Performing a Feasibility Study of the Conversion of the High Flux Isotope Reactor Core to Use Low-Enriched Uranium Fuel, ORNL/TM-2005/269, Oak Ridge National Laboratory (2006).

9. G. Ilas and R. T. Primm III, Low Enriched Uranium Fuel Design with Two-Dimensional Grading for the High Flux Isotope Reactor, ORNL/TM-2010/318, Oak Ridge National Laboratory (2011).

10. D. Renfro, D. Chandler, D. Cook, G. Ilas, P. Jain, and J. Valentine, Preliminary Evaluation of Alternate Designs for HFIR Low-Enriched Uranium Fuel, ORNL/TM-2014/154, Oak Ridge National Laboratory (2014).

11. D. R Vondy, T. B. Fowler, G. W. Cunningham III, The BOLD VENTURE Computation System for Nuclear Reactor Core Analysis, Version III, ORNL-5711, Oak Ridge National Laboratory (1981).

12. R. T. Primm, III and N. M. Greene, "Generation of Lumped Fission Product Cross Sections for HighBurnup, Highly Enriched Uranium Fuel,” ANS Transactions, vol. 56, 592-594 (1988).

13. R. T. Primm III, Reactor Physics Input to the Safety Analysis Report for the High Flux Isotope Reactor, ORNL/TM-11956, Oak Ridge National Laboratory (1992).

14. W. W. Engle, Jr, and L. R. Williams, Temperature and Void Reactivity Coefficient Calculations for the High Flux Isotope Reactor Safety Analysis Report, ORNL/TM-12386, Oak Ridge National Laboratory (1994).

15. J. A. Bucholz, MCNP4B Run HF220, Research Reactor Division Records, Oak Ridge National Laboratory (1999).

16. D. L. Selby, J. A. Bucholz, S. E. Burnette, D. H. Cook, M. B. Farrar, J. C. Gehin, J. B. Hayter, W. E. Hill, A. T. Lucas, T. J. McManamy, B. F. Siefken, M. A. Woody, High Flux Isotope Reactor Cold Source Preconceptual Design Study Report, ORNL/TM-13136, Oak Ridge National Laboratory (December 1995).

17. D. E. Peplow, A Computational Model of the High Flux Isotope Reactor for the Calculation of Cold Source, Beam Tube, and Guide Hall Nuclear Parameters, ORNL/TM-2004/237, Oak Ridge National Laboratory (2004).

18. SCALE: A Modular Code System for Performing Standardized Computer Analyses for Licensing Evaluation, ORNL/TM-2005/39, Version 6.1, Vols. I-III, June 2011. (Available from Radiation Safety Information Computational Center at Oak Ridge National Laboratory as CCC-785).

19. D. Ilas, Development of a SCALE Model for High Flux Isotope Reactor Cycle 400, ORNL/TM2011/367, Oak Ridge National Laboratory (February 2012). 
20. N. Xoubi, R. T. Primm III, and G. I. Maldonado, "Neutronic Analysis of an Advanced Fuel Design Concept for the High Flux Isotope Reactor,” Nuclear Science and Engineering 162, pp. 87-97 (2009).

21. G. Ilas, R.T. Primm, III, and J.C. Gehin, "Designing a New Fuel for HFIR-Performance Parameters for LEU Core Configurations,” CD Proceedings, Advances in Nuclear Fuel Management IV, Hilton Head, SC (2009).

22. D. I. Poston, H. R. Trellue, “User's manual version 2.0 for MONTEBURNS version 1.0, Technical Report LAUR-99-4999, Los Alamos National Laboratory (1999).

23. W. Haeck, An Optimum Approach to Monte Carlo Burnup, Ph.D. thesis, Ghent University, Belgium (2007).

24. W. Haeck and B. Verboomen, “An optimum approach to Monte Carlo burnup”, Nuclear Science and Engineering 156, pp. 180-196 (2007).

25. W. Haeck, VESTA User's Manual-Version 2.0.0, IRSN Report DSU/SEC/T/2008-331 Indice A, France (2009).

26. M. B. Chadwick et al., "ENDF/B-VII.0: Next Generation Evaluated Nuclear Data Library for Nuclear Science and Technology,” Nuclear Data Sheets 107, pp.2931-3060 (2006).

27. RSICC Computer Code Collection CCC-371, ORIGEN 2.2. Available from RSICC, Oak Ridge National Laboratory (2002).

28. M. B. Chadwick et al, "ENDF/B-VII.1 Nuclear Data for Science and Technology: Cross Sections, Covariances, Fission Product Yields and Decay Data,” Nuclear Data Sheets, 112, pp.2887-2996 (2011).

29. National Institute of Standards and Technology (NIST) Atomic Weights and Isotopic Compositions at http://www.nist.gov/pml/data/comp.cfm.

30. MatWeb: Material Property Data, http://www.matweb.com.

31. HFIR Safety Analysis Report, ORNL/HFIR/SAR/2344, Rev. 13, Oak Ridge National Laboratory (2014).

32. National Institute of Standards and Technology (NIST) Thermophysical Properties of Fluid Systems at http://webbook.nist.gov/chemistry/fluid/.

33. J.E. Matos and J.L. Snelgrove, Selected Thermal Properties and Uranium Density Relations for Alloy, Aluminide, Oxide, and Silicide Fuels, Appendix I-1.1 in Research Reactor Core Conversion Guidebook, Volume 4 : Fuels, IAEA-TECDOC-643, International Atomic Energy Agency (1992). Available at http://www-pub.iaea.org/books/IAEABooks/899/Research-Reactor-Core-ConversionGuidebook-Volume-4-Fuels-Appendices-I-K.

34. HFIR-SS-601, HFIR Core Components, RRD-FE-3, Rev.4, Specifications for High Flux Isotope Reactor Fuel Elements, Research Reactors Division, ORNL/RRD/INT-37/V3, Oak Ridge National Laboratory (June 2012).

35. M. M. Martin, A. E. Richt, and W. R. Martin, Irradiation Behavior of Aluminum-Base Fuel Dispersions, ORNL-4856, Oak Ridge National Laboratory (May 1973).

36. Certificate of Compliance and Analysis, Product ATA 101 Aluminum Powder, Lot No. C077118, Toyal America, Inc. (November 24, 1997).

37. Certificate of Compliance and Analysis, Product 101 Aluminum Powder, Lot No. C026004, Toyal America, Inc. (October 5, 2000).

38. Certificate of Compliance and Analysis, Product 101 Aluminum Powder, Lot No. C070078, Toyal America, Inc. (August 18, 2000).

39. Analytical Report, Al Powder, Lot C052014, Evans Analytical Group (August 15, 2012).

40. Material Certification for Boron Carbide P. O. 037300, Norton Company (April 19, 1974).

41. "Standards Specification for Aluminum and Aluminum-Alloy Seamless Pipe and Seamless Extruded Tube”, ASTM B241/B241M-12, ASTM International.

42. "Standard Specification for Aluminum and Aluminum-Alloy Sheet and Plate", ASTM B209/B209M, ASTM International.

43. "HFIR Beryllium Specification”, HFIR-JS-32, ORNL (February 14, 1974). 
44. "HFIR Beryllium Reflector No.9 “, Quality Assurance Audit Checklist and Certification for Use OPRO-JN-5-1-76, ORNL (May 1, 1976).

45. “Specification for Beryllium Material”, RRD-MS-32, Rev. 0, ORNL Research Reactor Division (July 4, 1989).

46. "Material Certification for Lot 4974 by Brush Wellman”, ORNL Research Reactor Division Purchase Order 61XGQK09 (April 11, 1995).

47. "Summary of HFIR Design Parameters for 85MW Operation”, ORNL Research Reactors Division, ORNL/RRD/INT-55 (March 1989).

48. D. Ilas, "Impact of HFIR LEU Conversion on Beryllium Reflector Degradation Factors", ORNL/TM2013/441, Oak Ridge National laboratory (October 2013).

49. “Specification for Normal Concrete, Section 4," Section 9f, S\&B job number 1546, ORNL Research Reactor Division (February 2, 1961).

50. “Specification for High Density Concrete, Section 5," Section 2a, S\&B job number 1546, ORNL Research Reactor Division (March 30, 1961).

51. "American National Standard Nuclear Analysis and Design of Concrete Radiation Shielding for Nuclear Power Plants,” ANSI/ANS-6.4-2006 (2006).

52. A. Bergeron, Review of the Oak Ridge National Laboratory Neutronic Calculations Regarding the Conversion of the High Flux Isotope Reactor to the Use of LEU Fuel, ANL/RERTR/TM-12/49, Argonne National Laboratory (2012).

53. B. Betzler, B. Ade, D. Chandler, G. Ilas, and E. Sunny, "Optimization of Depletion Modeling and Simulation for the High Flux Isotope Reactor”, CD Proceedings, Joint International Conference on Mathematics and Computation, Supercomputing in Nuclear Applications and the Monte Carlo Method, Nashville, TN (April 2015).

54. I. C. Gauld, G. Radulescu, G. Ilas, B. D. Murphy, M. L. Williams, and D. Wiarda, "Isotopic depletion and decay methods and analysis capabilities in SCALE," Nuclear Technology, vol.174, no.2, p.169 (2011).

55. G. Ilas and R.T. Primm, III, "Performance and Safety Parameters for the High Flux Isotope Reactor," CD Proceedings, International Conference on Reactor Physics PHYSOR 2012, Knoxville, TN (2012)

56. M. M. Bretscher, "Evaluation of Reactor Kinetic Parameters without the Need for Perturbation Codes,” Proceedings of RERTR 1997, Jackson Hole, Wyoming (October 5-10, 1997).

57. “American National Standard for Decay Heat Power in Light Water Reactors,” ANSI/ANS-5.1-2005, American Nuclear Society (April 2005).

58. RSICC Computer Code Collection PSR-480, "NJOY99.0: Code System for Producing Pointwise and Multigroup Neutron and Photon Cross Sections from ENDF/B Data”. Available from RSICC, Oak Ridge National Laboratory (2000).

59. R. W. Knight and A. E. Richt, "Evaluation of Absorber Materials Performance in HFIR Control Cylinders,” Nuclear Technology 15, 384 (1972). 

APPENDIX A. MODELING OF CONTROL ELEMENT COMPOSITION 



\section{APPENDIX A. MODELING OF CONTROL ELEMENT COMPOSITION}

\section{A.1 BACKGROUND}

The modeling of the control elements (CEs) for the High Flux Isotope Reactor (HFIR) Cycle 400 model has been enhanced, as discussed in Sections 5.1.2 and 5.2.4 of the present report, to improve both the geometry model and the CE materials compositions at the beginning of Cycle 400 (BOC-400). The CEs are present in the HFIR core for a large number of reactor cycles, for periods of time as large as a thousand days of irradiation. The design lifetime of the control elements is 100,000 MWd [32], which is equivalent to about 45-50 typical cycles. Typically, an outer control element (OCE) is removed from the core for maintenance (i.e., bearing replacements) after six to eight irradiation cycles and is inserted back in the core after a period of decay time. During irradiation, the composition of the CE materials changes due to neutron interactions, leading to a change in the absorption properties (cross sections) of the materials. Previous analyses [5, 9] indicated that the isotopic composition of the absorber regions in the control plates has a significant impact on reactivity and may potentially be one of the major reasons for any bias observed in $\mathrm{k}_{\mathrm{eff}}$. Understanding the relationship between the bias in $\mathrm{k}_{\mathrm{eff}}$ and the uncertainty in the CE compositions, as well as identifying the sources for the latter uncertainties, are necessary for clarification of the expected modeling uncertainties for any HFIR core model.

A method has been developed [5, 9] to perform fast simulations of the irradiation history of the HFIR CEs to determine their material compositions at a given time. This method has been applied in this report to determine the material compositions of the CEs present in the reactor at BOC-400 using the new core model. The isotopic composition in the gray and black regions in the previous core model [3] was modeled as uniform across the region (i.e., one material used for the gray region and one material for the black region). In the revised model, each of the inner control element (ICE) and OCE absorber regions are modeled as five axially subdivided zones with different material compositions for a total of 20 different material mixtures in the gray and black regions of the CEs. The isotopic compositions, which account for the exposure (activation) history of these gray and black materials, are listed in Tables 16-19 of this report. More details about the updates of the CE model are provided in this appendix.

\section{A.2 ACTIVATION OF CONTROL ELEMENTS PRESENT IN CORE AT BOC-400}

The four OCE plates present in the core at BOC-400 had the same exposure history. They were inserted in the core at BOC-390. The ICE present in the core at BOC-400 (identified as number 12) was known to have an exposure of 28,267.89 MWd at BOC-388, with no specific information available on the actual cycle when it was first inserted in the core.

A slightly different, more detailed exposure history than previously used $[5,9]$ has been considered for the simulation of the ICE and OCE activation before Cycle 400, based on more detailed cycle data available for cycles 290 through 445. Recent information mentions Cycle 372 as the possible insertion cycle for ICE 12, indicating potential uncertainties in the exposure history for this ICE that would affect to some extent the simulated material compositions at BOC-400. The declared exposure of 28,267.89 MWd at BOC-388 for ICE would indicate Cycle 274 or 275 as the insertion cycle. Addition of Cycles 372-374 to the ICE activation history would result in the addition of $\sim 5,800 \mathrm{MWd}$ to its exposure. The conflicting information on the insertion cycle for ICE 12 has not been completely resolved. For modeling purposes, it was assumed that this ICE was inserted in the core at BOC-374.

Note that uncertainties in the estimated composition of the absorber materials can lead to significant variations in $\mathrm{k}_{\mathrm{eff}}$. For example, sensitivity studies showed that an overestimation by $20 \%$ of the ${ }^{182} \mathrm{Ta}$ content in the gray regions would lead to a decrease in $\mathrm{k}_{\text {eff }}$ of $\sim 200 \mathrm{pcm}$. The ${ }^{182} \mathrm{Ta}$ isotope $\left(T_{1 / 2}=114.74 \mathrm{~d}\right)$, though present in small quantity in the irradiated gray regions, has a very high neutron capture cross section and is a significant contributor to the total neutron absorption in these regions. Its variation is very sensitive to the operation history (irradiation and decay time), as illustrated in Fig. A.1. 


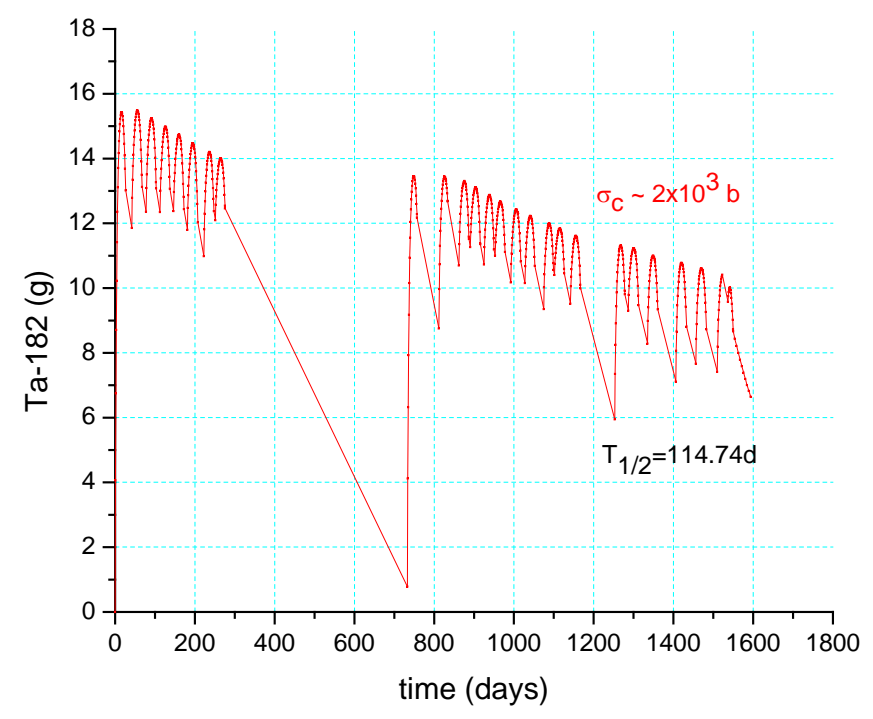

Fig. A.1. Variation of Ta-182 content during inner control element 12 irradiation history.

\section{A.3 VALIDATION OF THE NEW CONTROL ELEMENTS ACTIVATION MODEL}

Measurement data for an irradiated ICE, obtained from destructive analysis, have been reported by Knight and Richt [59], as also discussed in [9]. The measurement data correspond to an ICE exposure of 48,615 MWd. Isotopic experimental data are provided for five specimens from the black region of the ICE, selected from locations at $0.5,2,5,10$, and 20 in. with respect to the interface between the gray and the black regions. To facilitate a comparison of these data with the calculated data, region-averaged values were estimated from the reported experimental data by integrating the available curves representing the isotopic compositions as a function of distance.

A comparison of the measurement data and the results of calculations performed with the most recent modeling approach in this report is presented in Table A.1 for the europium isotopic composition in the black region. As observed, there is very good agreement between measurement and calculation.

Table A.1. Comparison calculation-measurement for inner control element validation data

\begin{tabular}{|c|r|r|r|}
\hline \multicolumn{4}{|c|}{ Europium isotopic composition (at. \%) } \\
\hline Isotope & Calculated & Measured & Difference \\
\hline Eu-151 & 38.34 & 37.98 & 0.36 \\
Eu-153 & 3.54 & 3.50 & 0.04 \\
Eu-152 & 55.21 & 54.93 & 0.29 \\
Eu-154 & 2.43 & 2.63 & -0.21 \\
Eu-155 & 0.48 & 0.95 & -0.48 \\
\hline
\end{tabular}

A measurement-calculation comparison of the spatial variation of the isotopic content of the europium isotopes is presented in Figs. A.2-A.6. For the calculated data, the spatial location shown in the plots is the center of the axial mesh (each 4.4 in. height). As observed in these plots, there is good agreement between calculated and measured isotopics. 


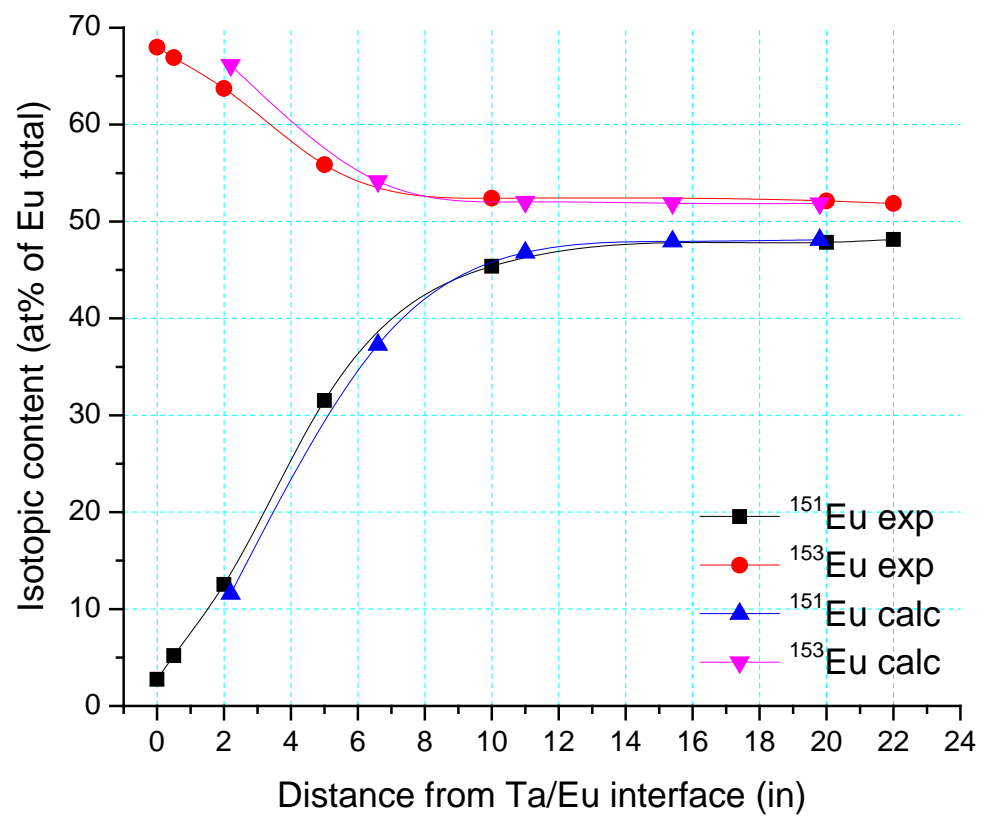

Fig. A.2. Comparison measurement-calculation for isotopic content of Eu-151 and Eu-153. (Exp = measured or experimentally derived, calc $=$ calculated.)

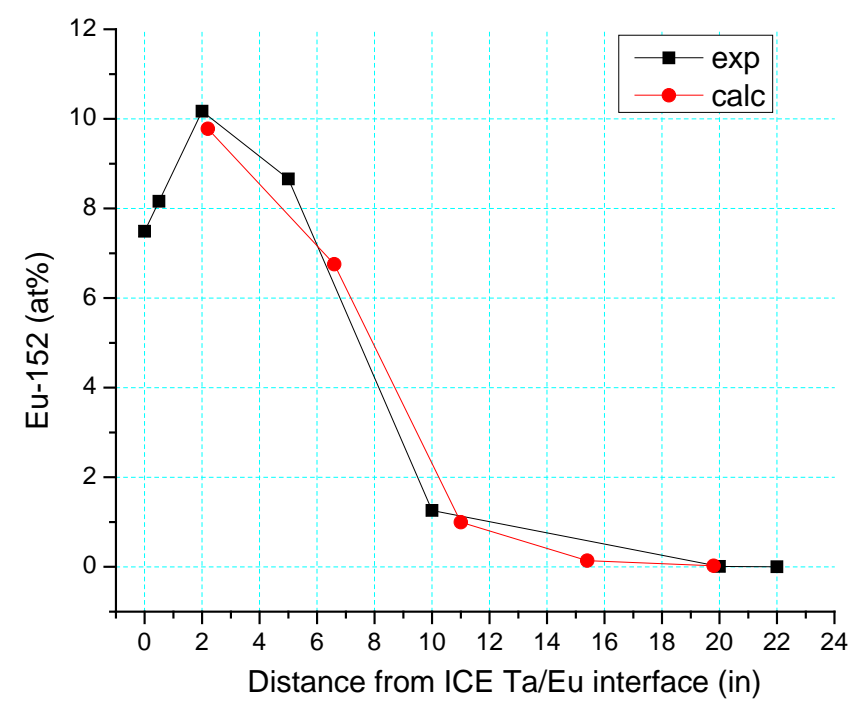

Fig. A.3. Comparison measurement-calculation for isotopic content of Eu-152. (Exp = measured or experimentally derived, calc $=$ calculated, ICE $=$ inner control element.) 


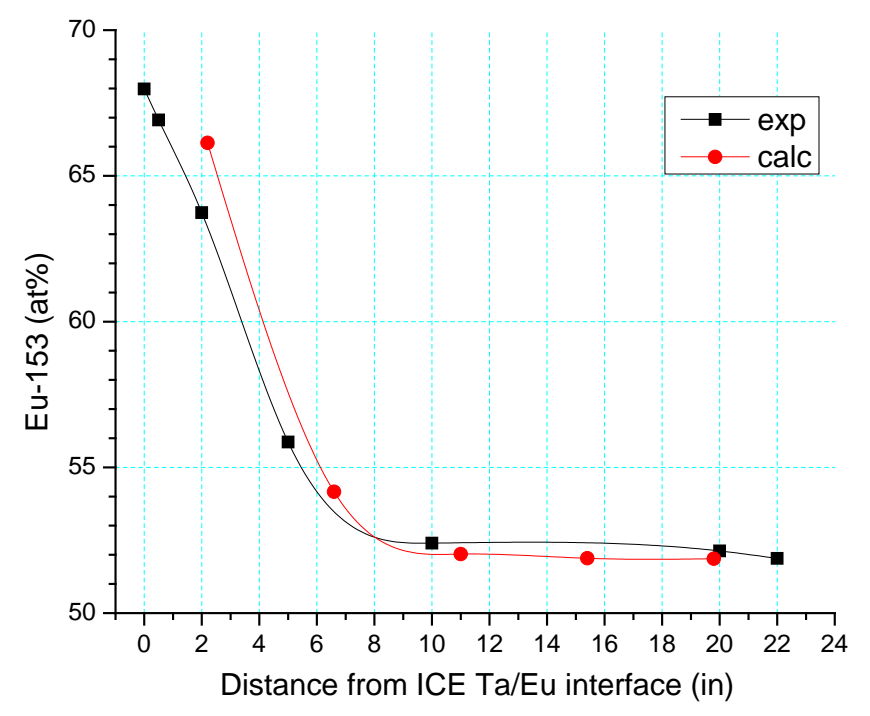

Fig. A.4. Comparison measurement-calculation for isotopic content of Eu-153. (Exp = measured or experimentally derived, calc $=$ calculated, ICE $=$ inner control element.)

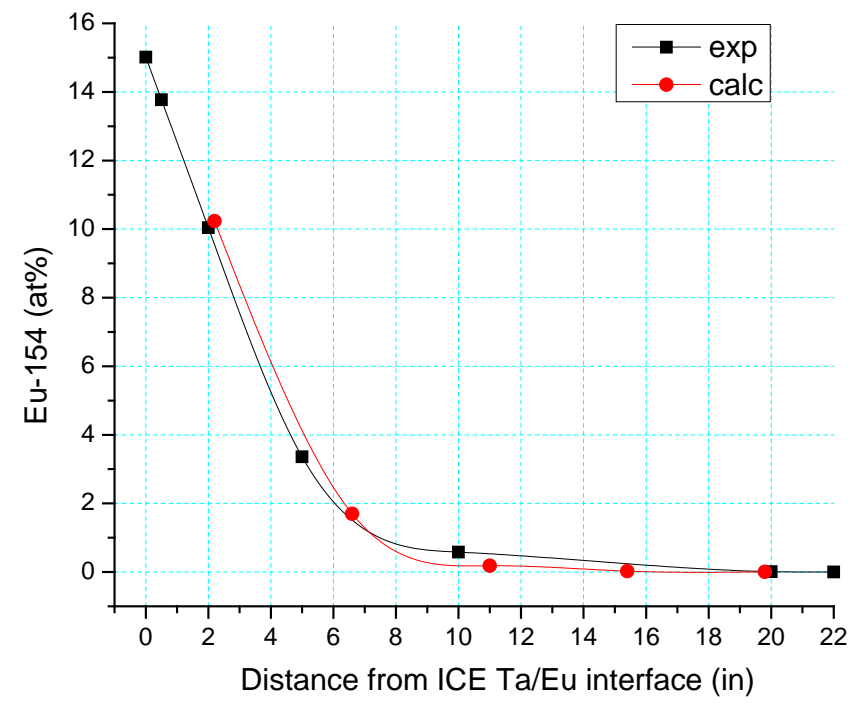

Fig. A.5. Comparison measurement-calculation for isotopic content of Eu-154. (Exp = measured or experimentally derived, calc $=$ calculated, ICE $=$ inner control element.) 


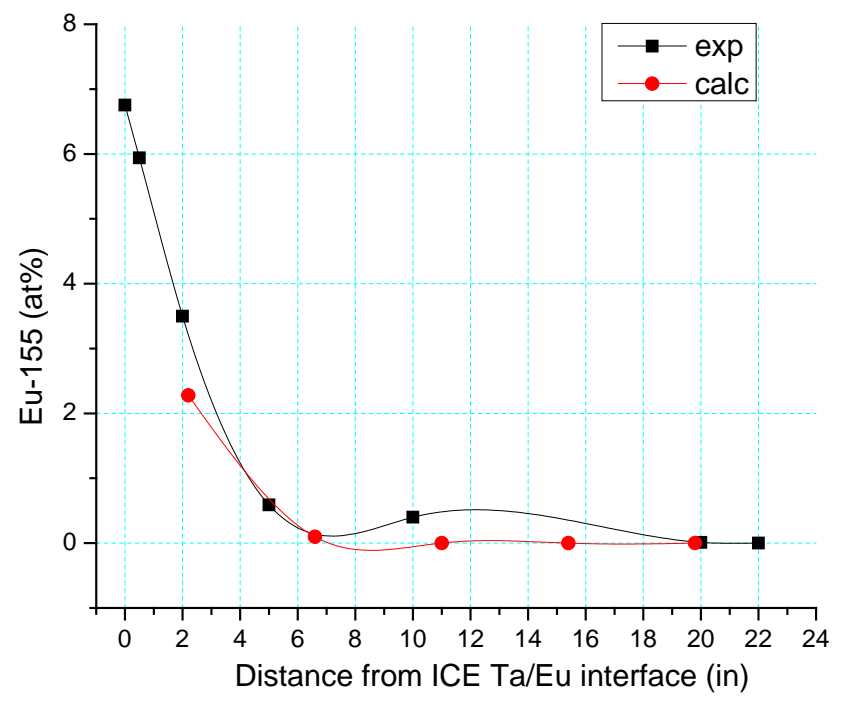

Fig. A.6. Comparison measurement-calculation for isotopic content of Eu-155. (Exp = measured or experimentally derived, calc $=$ calculated, ICE $=$ inner control element.) 



\section{APPENDIX B. FLUX DISTRIBUTIONS WITHIN THE HIGH FLUX}

ISOTOPE REACTOR AT END-OF-CYCLE 



\section{APPENDIX B. FLUX DISTRIBUTIONS WITHIN THE HIGH FLUX ISOTOPE REACTOR AT END-OF-CYCLE}

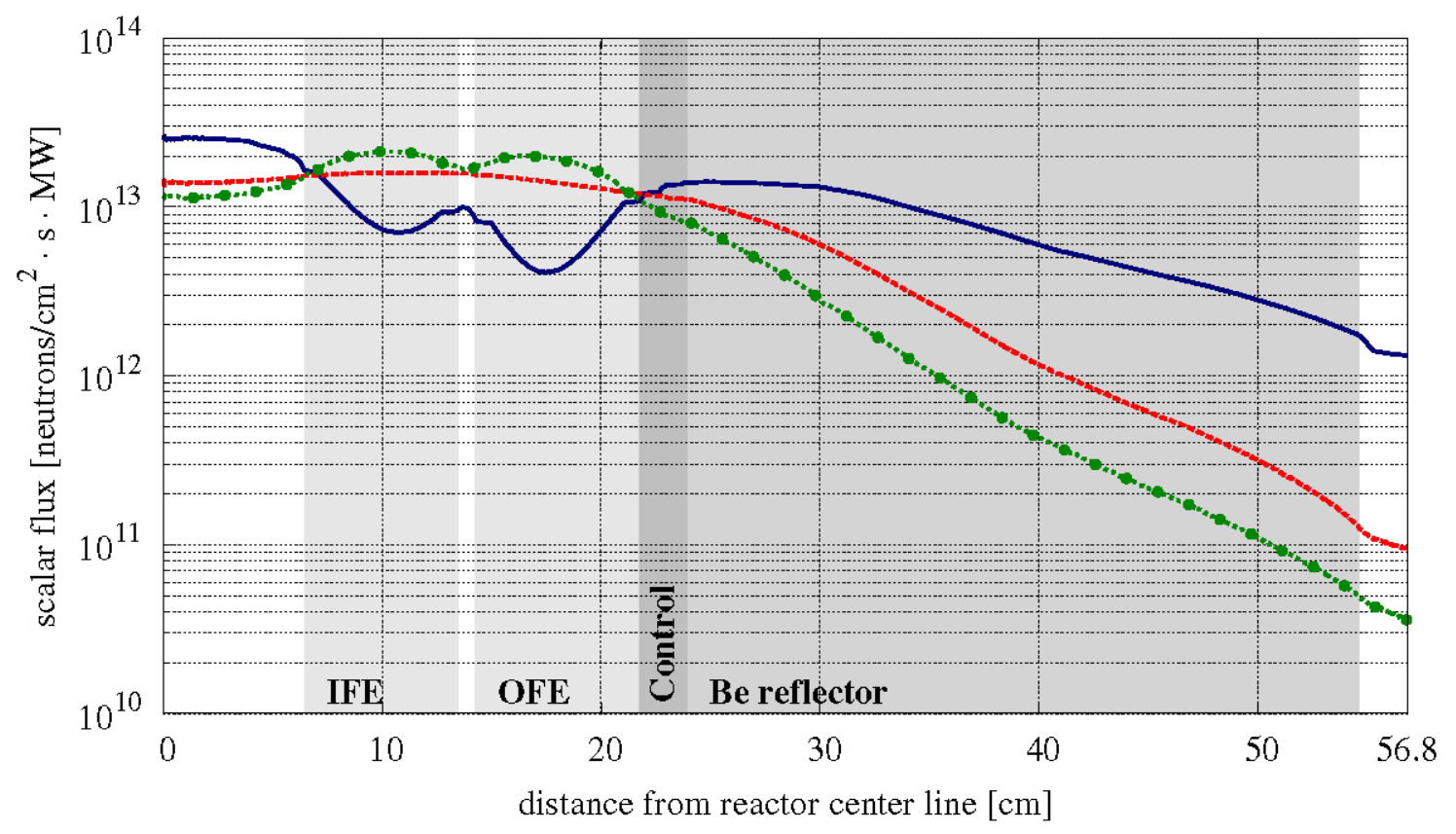

thermal $\longrightarrow \quad$ epithermal -------- fast $\cdots \cdots \cdot \cdots \cdot$

Fig. B.1. Radial flux distribution within HFIR at end-of-cycle. (IFE = inner fuel element, OFE = outer fuel element.) 


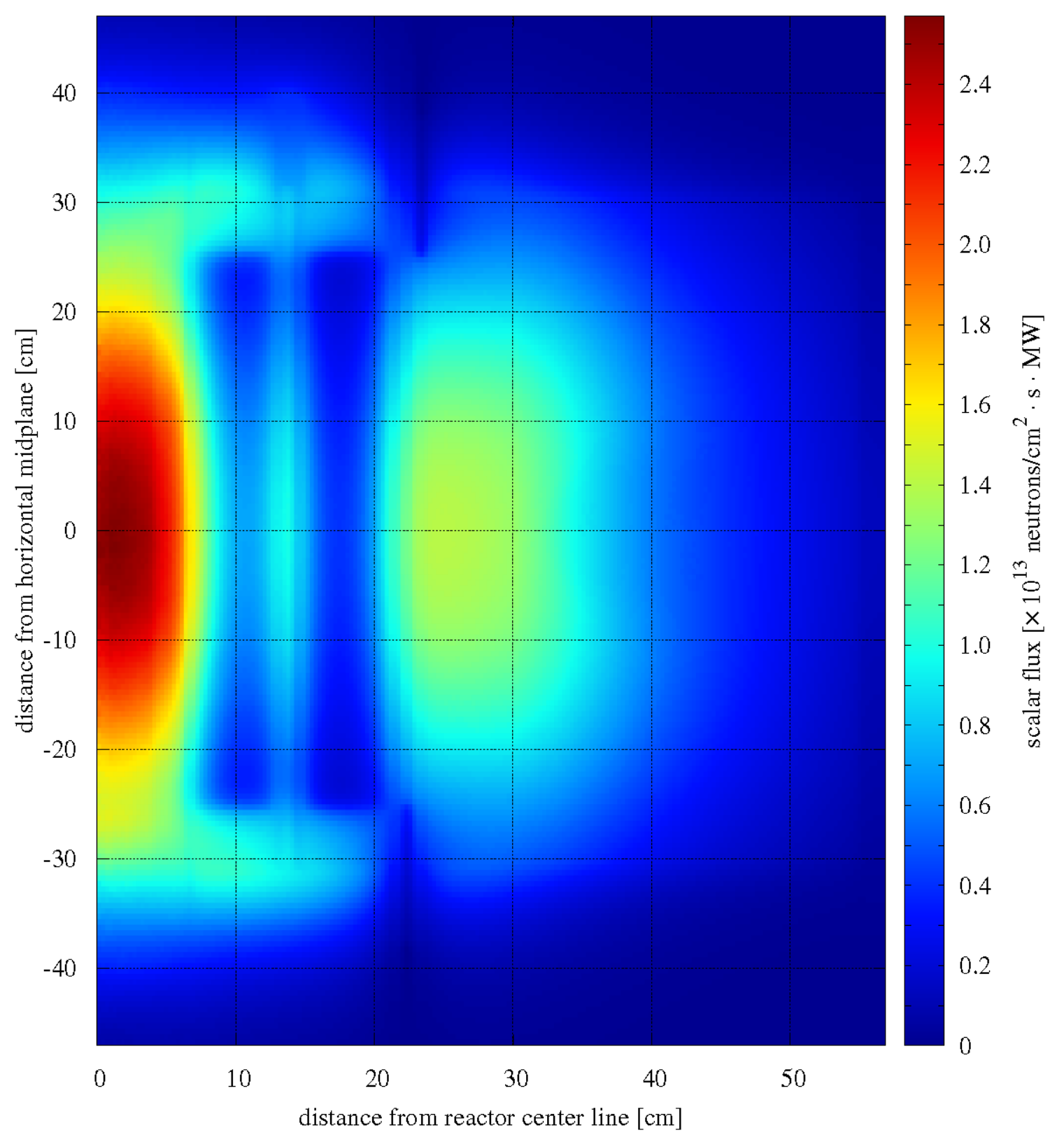

Fig. B.2. R-Z thermal flux distribution within HFIR at end-of-cycle. 


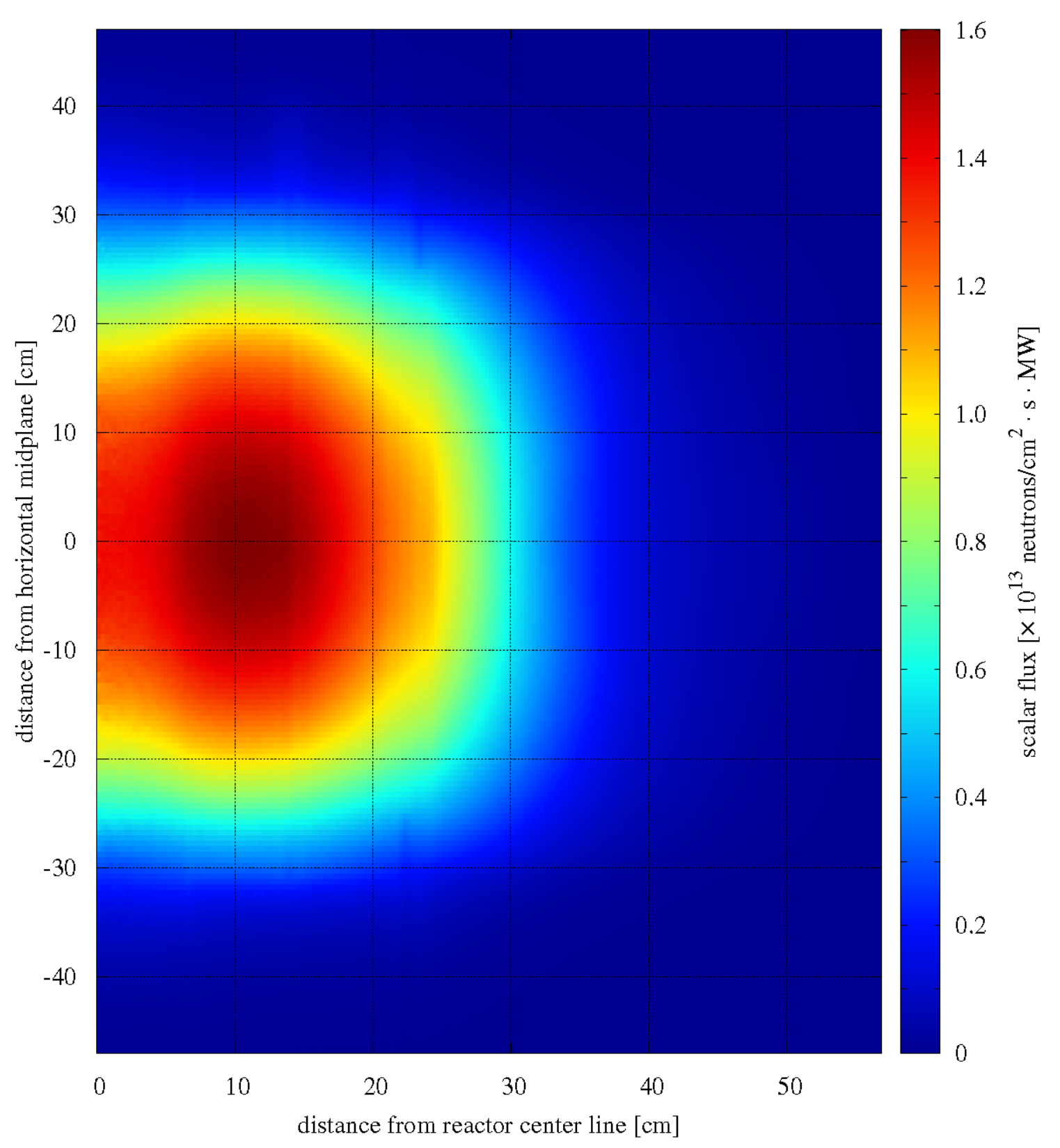

Fig. B.3. R-Z epithermal flux distribution within HFIR at end-of-cycle. 


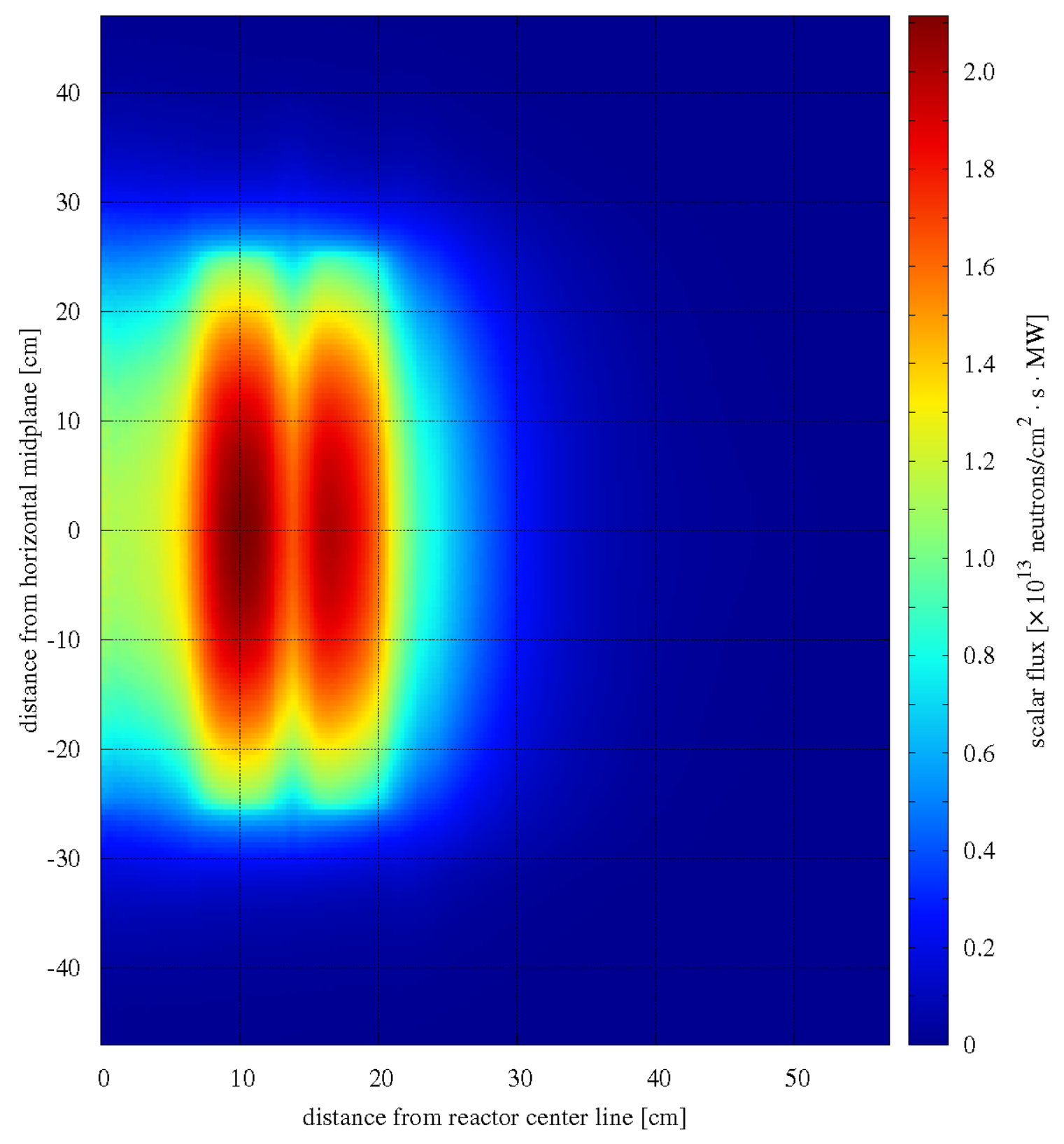

Fig. B.4. R-Z fast flux distribution within HFIR at end-of-cycle. 


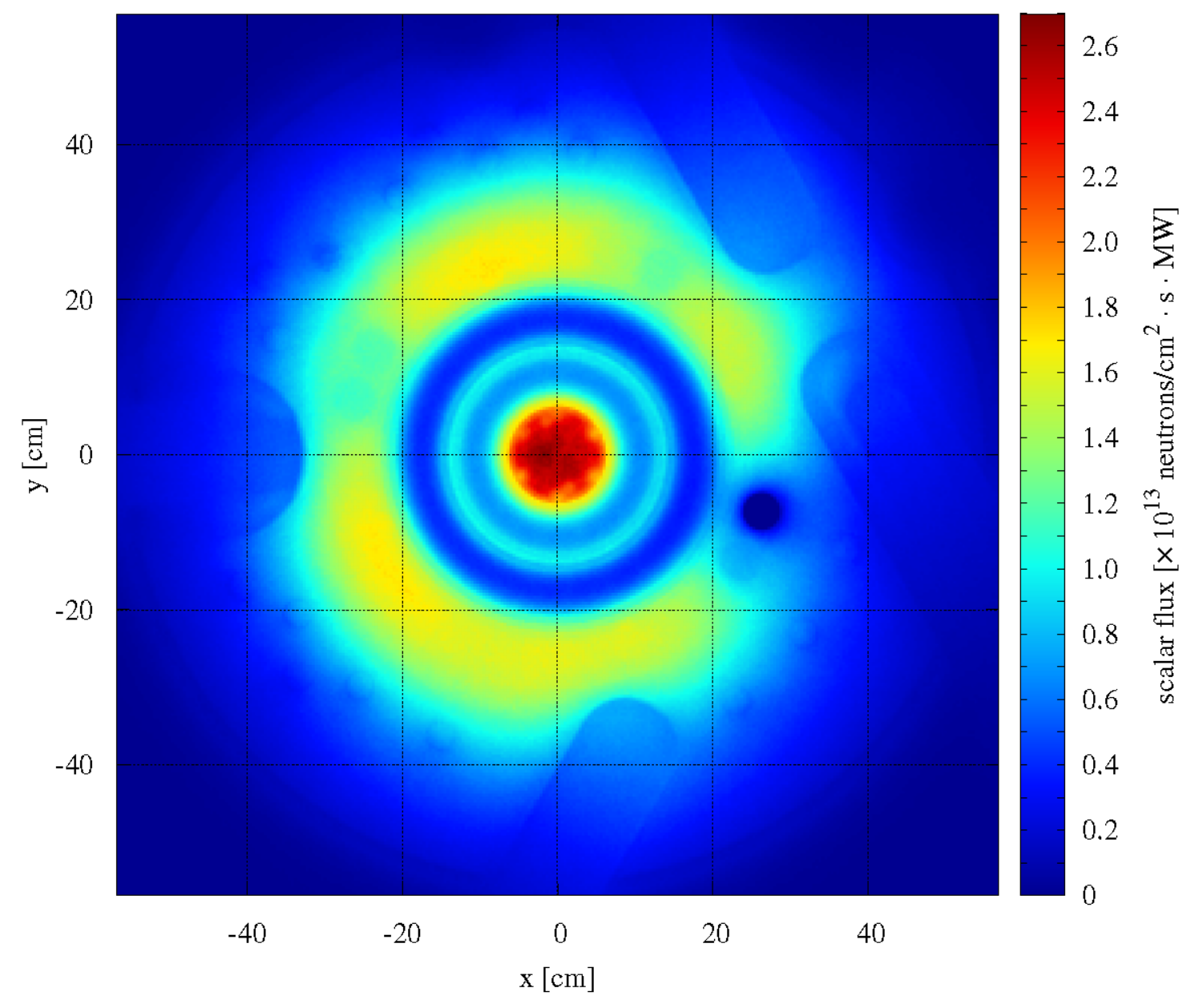

Fig. B.5. X-Y thermal flux distribution at horizontal midplane within HFIR at end-of-cycle. 


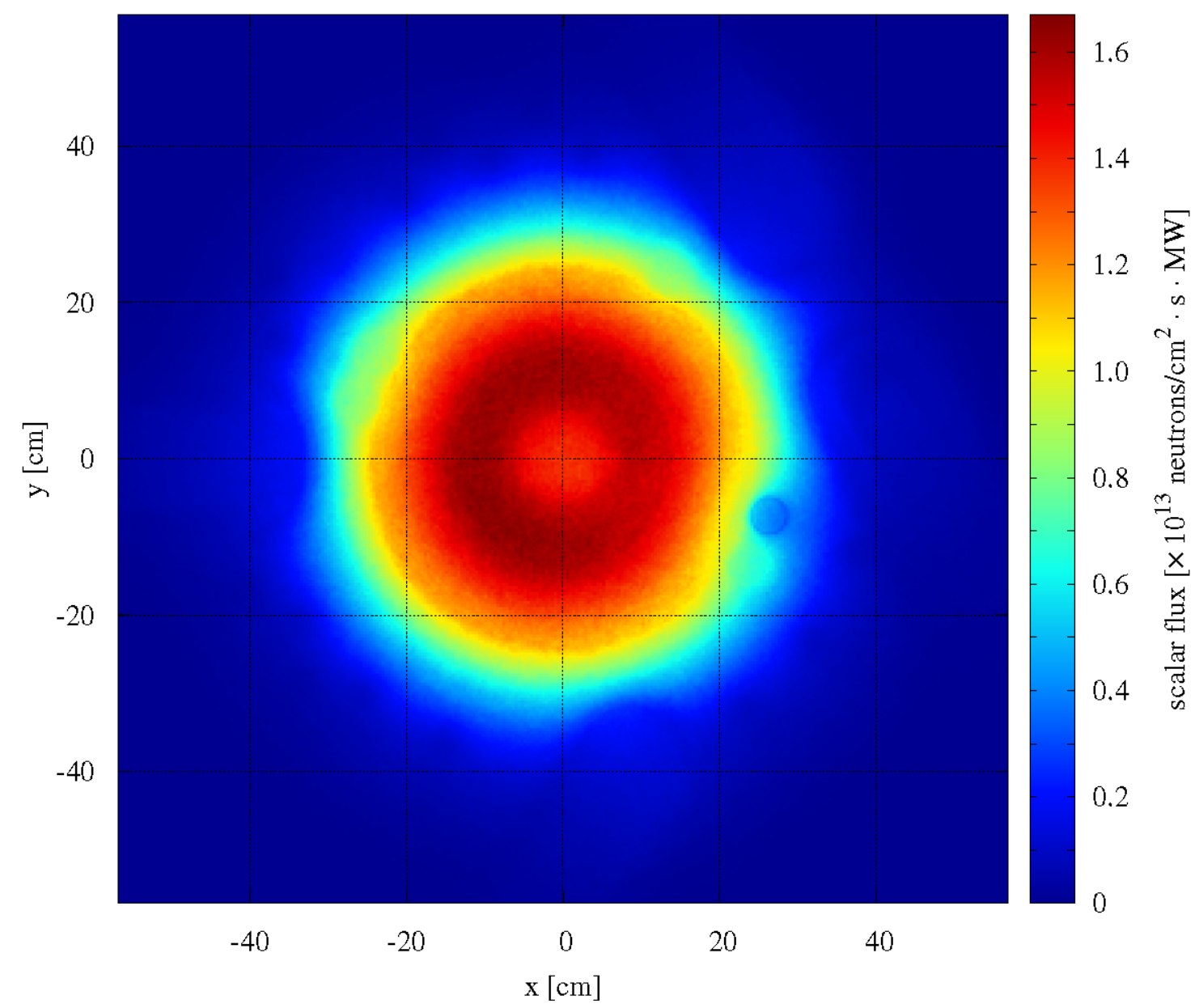

Fig. B.6. X-Y epithermal flux distribution at horizontal midplane within HFIR at end-ofcycle. 


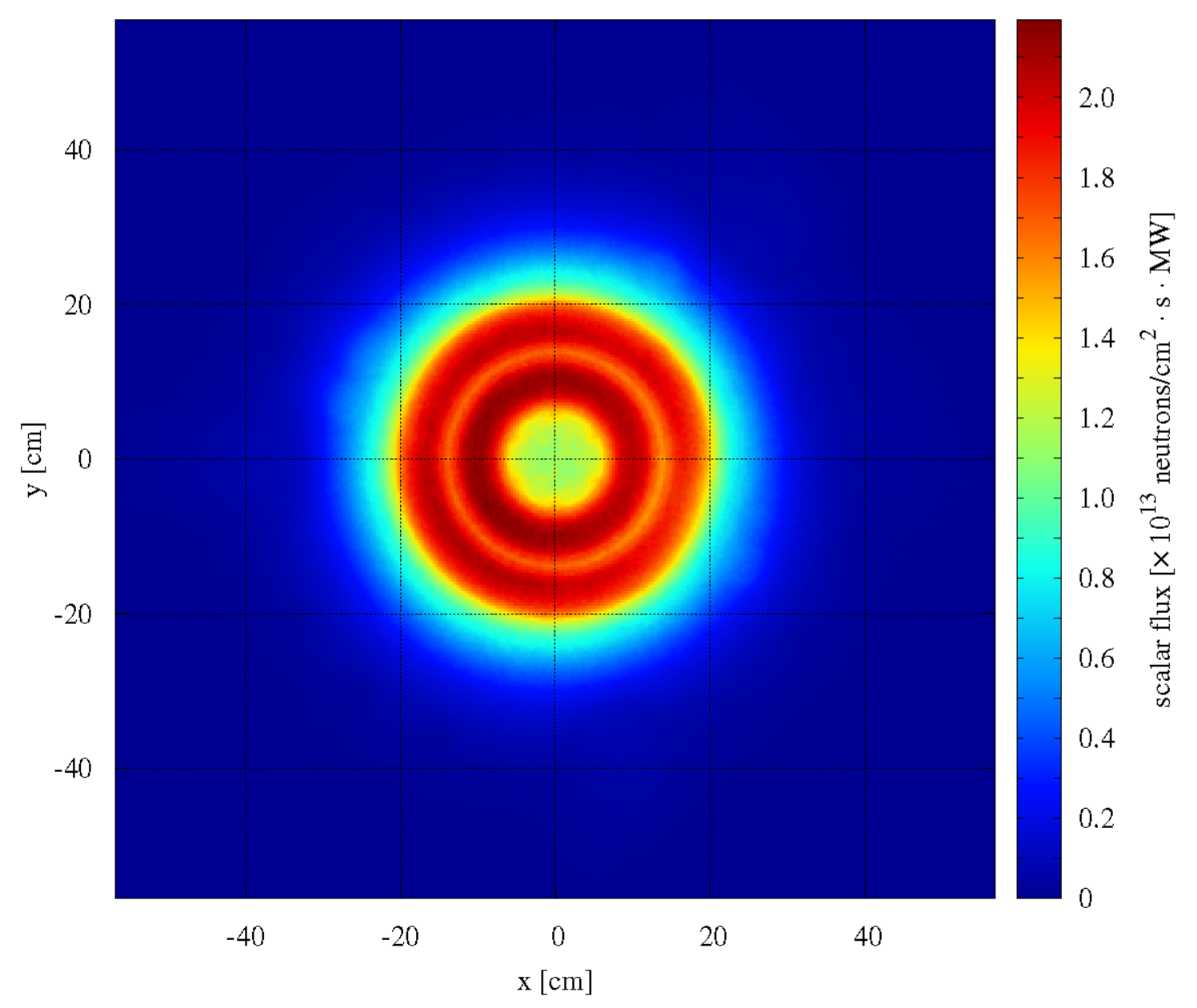

Fig. B.7. X-Y fast flux distribution at horizontal midplane within HFIR at end-of-cycle. 

APPENDIX C. FISSION DENSITY DISTRIBUTION DATA AT DAY 13 



\section{APPENDIX C. FISSION DENSITY DISTRIBUTION DATA AT DAY 13}

\section{Table C.1. Relative fission density at day 13 (simplified model)}

\begin{tabular}{|c|c|c|c|c|c|c|c|c|c|c|c|c|c|c|c|c|c|c|c|c|c|c|}
\hline \multirow{2}{*}{$\begin{array}{c}\text { Axial } \\
\text { region }\end{array}$} & \multicolumn{11}{|c|}{ IFE } & \multicolumn{11}{|c|}{ OFE } \\
\hline & $\mathbf{r}=\mathbf{1}^{a}$ & $r=2$ & $r=3$ & $r=4$ & $r=5$ & $r=6$ & $r=7$ & $r=8$ & $r=9$ & $r=10$ & $r=11$ & $r=1$ & $r=2$ & $r=3$ & $r=4$ & $r=5$ & $r=6$ & $r=7$ & $r=8$ & $r=9$ & $r=10$ & $r=11$ \\
\hline 1 & 0.799 & 0.829 & 0.868 & 0.941 & 1.028 & 1.120 & 1.181 & 1.154 & 1.097 & 1.055 & 1.037 & 1.050 & 1.061 & 1.094 & 1.121 & 1.089 & 0.942 & 0.741 & 0.579 & 0.474 & 0.404 & 0.373 \\
\hline 2 & 0.771 & 0.795 & 0.820 & 0.865 & 0.914 & 0.950 & 0.968 & 0.953 & 0.938 & 0.936 & 0.943 & 0.944 & 0.934 & 0.920 & 0.897 & 0.836 & 0.725 & 0.594 & 0.489 & 0.419 & 0.371 & 0.353 \\
\hline 3 & 0.751 & 0.767 & 0.786 & 0.812 & 0.830 & 0.833 & 0.826 & 0.816 & 0.828 & 0.848 & 0.871 & 0.870 & 0.847 & 0.818 & 0.774 & 0.704 & 0.608 & 0.516 & 0.445 & 0.395 & 0.360 & 0.346 \\
\hline 4 & 0.741 & 0.757 & 0.772 & 0.793 & 0.795 & 0.782 & 0.761 & 0.758 & 0.776 & 0.804 & 0.831 & 0.831 & 0.809 & 0.779 & 0.732 & 0.659 & 0.571 & 0.496 & 0.438 & 0.400 & 0.370 & 0.359 \\
\hline 5 & 0.757 & 0.772 & 0.787 & 0.806 & 0.808 & 0.794 & 0.771 & 0.769 & 0.784 & 0.809 & 0.835 & 0.835 & 0.817 & 0.790 & 0.748 & 0.679 & 0.593 & 0.520 & 0.465 & 0.426 & 0.398 & 0.386 \\
\hline 6 & 0.836 & 0.857 & 0.880 & 0.914 & 0.925 & 0.918 & 0.900 & 0.892 & 0.902 & 0.918 & 0.939 & 0.939 & 0.927 & 0.910 & 0.875 & 0.809 & 0.718 & 0.636 & 0.572 & 0.525 & 0.489 & 0.475 \\
\hline 7 & 0.961 & 0.995 & 1.031 & 1.091 & 1.129 & 1.135 & 1.119 & 1.106 & 1.108 & 1.116 & 1.126 & 1.136 & 1.132 & 1.124 & 1.094 & 1.028 & 0.933 & 0.855 & 0.793 & 0.745 & 0.702 & 0.685 \\
\hline 8 & 1.037 & 1.081 & 1.132 & 1.214 & 1.277 & 1.300 & 1.289 & 1.274 & 1.269 & 1.270 & 1.272 & 1.292 & 1.297 & 1.300 & 1.277 & 1.216 & 1.138 & 1.095 & 1.061 & 1.026 & 0.983 & 0.962 \\
\hline 9 & 1.073 & 1.122 & 1.179 & 1.275 & 1.352 & 1.386 & 1.382 & 1.368 & 1.362 & 1.356 & 1.353 & 1.380 & 1.389 & 1.398 & 1.383 & 1.327 & 1.255 & 1.225 & 1.194 & 1.151 & 1.094 & 1.062 \\
\hline 10 & 1.080 & 1.130 & 1.189 & 1.285 & 1.364 & 1.405 & 1.402 & 1.391 & 1.384 & 1.380 & 1.375 & 1.399 & 1.410 & 1.419 & 1.403 & 1.349 & 1.279 & 1.253 & 1.221 & 1.176 & 1.115 & 1.079 \\
\hline 11 & 1.073 & 1.121 & 1.178 & 1.272 & 1.349 & 1.383 & 1.380 & 1.366 & 1.360 & 1.355 & 1.352 & 1.378 & 1.388 & 1.394 & 1.379 & 1.323 & 1.252 & 1.224 & 1.196 & 1.154 & 1.097 & 1.067 \\
\hline 12 & 1.039 & 1.082 & 1.130 & 1.211 & 1.270 & 1.292 & 1.280 & 1.265 & 1.260 & 1.262 & 1.264 & 1.286 & 1.288 & 1.290 & 1.269 & 1.209 & 1.132 & 1.094 & 1.066 & 1.037 & 0.999 & 0.980 \\
\hline 13 & 0.954 & 0.987 & 1.024 & 1.080 & 1.115 & 1.119 & 1.103 & 1.091 & 1.096 & 1.106 & 1.116 & 1.124 & 1.119 & 1.110 & 1.078 & 1.010 & 0.913 & 0.831 & 0.766 & 0.716 & 0.673 & 0.657 \\
\hline 14 & 0.833 & 0.853 & 0.875 & 0.905 & 0.916 & 0.902 & 0.883 & 0.875 & 0.885 & 0.903 & 0.923 & 0.924 & 0.910 & 0.890 & 0.854 & 0.785 & 0.690 & 0.603 & 0.534 & 0.486 & 0.447 & 0.430 \\
\hline 15 & 0.759 & 0.769 & 0.786 & 0.805 & 0.802 & 0.782 & 0.759 & 0.755 & 0.771 & 0.795 & 0.820 & 0.819 & 0.800 & 0.771 & 0.727 & 0.656 & 0.566 & 0.485 & 0.426 & 0.384 & 0.352 & 0.338 \\
\hline 16 & 0.744 & 0.755 & 0.768 & 0.789 & 0.790 & 0.770 & 0.748 & 0.746 & 0.763 & 0.793 & 0.821 & 0.817 & 0.793 & 0.759 & 0.710 & 0.634 & 0.540 & 0.455 & 0.394 & 0.350 & 0.320 & 0.306 \\
\hline 17 & 0.750 & 0.767 & 0.782 & 0.809 & 0.822 & 0.820 & 0.813 & 0.803 & 0.813 & 0.835 & 0.862 & 0.857 & 0.835 & 0.799 & 0.750 & 0.672 & 0.567 & 0.467 & 0.387 & 0.335 & 0.296 & 0.280 \\
\hline 18 & 0.774 & 0.796 & 0.817 & 0.864 & 0.902 & 0.939 & 0.955 & 0.941 & 0.925 & 0.925 & 0.939 & 0.932 & 0.918 & 0.905 & 0.872 & 0.801 & 0.673 & 0.531 & 0.419 & 0.344 & 0.291 & 0.269 \\
\hline 19 & 0.805 & 0.834 & 0.870 & 0.938 & 1.021 & 1.110 & 1.167 & 1.145 & 1.089 & 1.052 & 1.034 & 1.037 & 1.045 & 1.074 & 1.090 & 1.043 & 0.877 & 0.660 & 0.490 & 0.384 & 0.308 & 0.275 \\
\hline
\end{tabular}

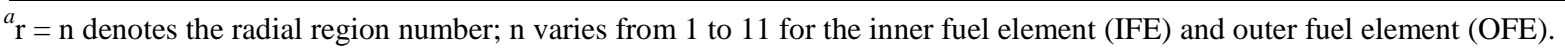




\section{Table C.2. Relative fission density at day 13 (explicit model)}

\begin{tabular}{|c|c|c|c|c|c|c|c|c|c|c|c|c|c|c|c|c|c|c|c|c|c|c|}
\hline \multirow{2}{*}{$\begin{array}{c}\text { Axial } \\
\text { region }\end{array}$} & \multicolumn{11}{|c|}{ IFE } & \multicolumn{11}{|c|}{ OFE } \\
\hline & $\mathbf{r}=\mathbf{1}^{a}$ & $r=2$ & $r=3$ & $r=4$ & $r=5$ & $r=6$ & $r=7$ & $r=8$ & $r=9$ & $r=10$ & $r=11$ & $r=1$ & $r=2$ & $r=3$ & $r=4$ & $r=5$ & $r=6$ & $r=7$ & $r=8$ & $r=9$ & $r=10$ & $r=11$ \\
\hline 1 & 0.800 & 0.826 & 0.866 & 0.941 & 1.026 & 1.119 & 1.179 & 1.152 & 1.091 & 1.049 & 1.027 & 1.036 & 1.055 & 1.092 & 1.120 & 1.086 & 0.943 & 0.743 & 0.583 & 0.475 & 0.403 & 0.373 \\
\hline 2 & 0.772 & 0.792 & 0.822 & 0.869 & 0.914 & 0.958 & 0.971 & 0.957 & 0.940 & 0.931 & 0.941 & 0.934 & 0.928 & 0.925 & 0.903 & 0.842 & 0.730 & 0.600 & 0.494 & 0.423 & 0.371 & 0.351 \\
\hline 3 & 0.748 & 0.765 & 0.785 & 0.816 & 0.837 & 0.840 & 0.836 & 0.827 & 0.834 & 0.849 & 0.871 & 0.867 & 0.846 & 0.823 & 0.781 & 0.709 & 0.611 & 0.521 & 0.450 & 0.399 & 0.362 & 0.348 \\
\hline 4 & 0.742 & 0.755 & 0.772 & 0.796 & 0.800 & 0.789 & 0.771 & 0.765 & 0.779 & 0.803 & 0.827 & 0.825 & 0.808 & 0.780 & 0.737 & 0.664 & 0.574 & 0.500 & 0.443 & 0.402 & 0.372 & 0.360 \\
\hline 5 & 0.756 & 0.770 & 0.786 & 0.808 & 0.816 & 0.800 & 0.780 & 0.775 & 0.786 & 0.805 & 0.827 & 0.830 & 0.815 & 0.793 & 0.752 & 0.684 & 0.597 & 0.524 & 0.468 & 0.428 & 0.397 & 0.384 \\
\hline 6 & 0.830 & 0.850 & 0.875 & 0.909 & 0.928 & 0.920 & 0.901 & 0.891 & 0.899 & 0.912 & 0.929 & 0.933 & 0.925 & 0.910 & 0.878 & 0.810 & 0.718 & 0.637 & 0.573 & 0.526 & 0.487 & 0.470 \\
\hline 7 & 0.958 & 0.990 & 1.028 & 1.086 & 1.130 & 1.136 & 1.119 & 1.106 & 1.104 & 1.110 & 1.118 & 1.126 & 1.126 & 1.122 & 1.094 & 1.029 & 0.935 & 0.856 & 0.794 & 0.742 & 0.698 & 0.679 \\
\hline 8 & 1.032 & 1.077 & 1.128 & 1.208 & 1.276 & 1.302 & 1.291 & 1.274 & 1.266 & 1.263 & 1.263 & 1.282 & 1.291 & 1.296 & 1.277 & 1.218 & 1.142 & 1.097 & 1.062 & 1.021 & 0.977 & 0.954 \\
\hline 9 & 1.068 & 1.116 & 1.172 & 1.267 & 1.350 & 1.388 & 1.385 & 1.366 & 1.356 & 1.348 & 1.345 & 1.369 & 1.382 & 1.396 & 1.384 & 1.329 & 1.258 & 1.226 & 1.196 & 1.146 & 1.087 & 1.055 \\
\hline 10 & 1.076 & 1.125 & 1.183 & 1.279 & 1.368 & 1.408 & 1.407 & 1.385 & 1.377 & 1.366 & 1.360 & 1.392 & 1.407 & 1.421 & 1.408 & 1.351 & 1.284 & 1.253 & 1.221 & 1.170 & 1.108 & 1.072 \\
\hline 11 & 1.069 & 1.117 & 1.174 & 1.268 & 1.350 & 1.386 & 1.382 & 1.364 & 1.353 & 1.343 & 1.340 & 1.368 & 1.383 & 1.394 & 1.380 & 1.325 & 1.257 & 1.227 & 1.196 & 1.149 & 1.092 & 1.059 \\
\hline 12 & 1.031 & 1.075 & 1.126 & 1.204 & 1.271 & 1.291 & 1.281 & 1.263 & 1.257 & 1.254 & 1.255 & 1.275 & 1.283 & 1.288 & 1.269 & 1.210 & 1.135 & 1.096 & 1.067 & 1.031 & 0.990 & 0.969 \\
\hline 13 & 0.947 & 0.981 & 1.017 & 1.075 & 1.116 & 1.123 & 1.107 & 1.092 & 1.091 & 1.096 & 1.106 & 1.114 & 1.114 & 1.108 & 1.078 & 1.011 & 0.915 & 0.833 & 0.768 & 0.716 & 0.671 & 0.650 \\
\hline 14 & 0.828 & 0.846 & 0.871 & 0.903 & 0.917 & 0.906 & 0.886 & 0.876 & 0.883 & 0.897 & 0.916 & 0.916 & 0.907 & 0.891 & 0.856 & 0.788 & 0.693 & 0.604 & 0.536 & 0.484 & 0.443 & 0.425 \\
\hline 15 & 0.752 & 0.765 & 0.780 & 0.800 & 0.803 & 0.784 & 0.762 & 0.754 & 0.768 & 0.792 & 0.816 & 0.811 & 0.796 & 0.771 & 0.729 & 0.659 & 0.568 & 0.488 & 0.427 & 0.383 & 0.349 & 0.335 \\
\hline 16 & 0.736 & 0.753 & 0.768 & 0.786 & 0.789 & 0.773 & 0.754 & 0.749 & 0.764 & 0.789 & 0.818 & 0.811 & 0.793 & 0.759 & 0.712 & 0.637 & 0.543 & 0.458 & 0.396 & 0.351 & 0.319 & 0.305 \\
\hline 17 & 0.751 & 0.764 & 0.781 & 0.808 & 0.826 & 0.827 & 0.817 & 0.809 & 0.816 & 0.832 & 0.861 & 0.849 & 0.832 & 0.803 & 0.754 & 0.678 & 0.572 & 0.471 & 0.390 & 0.337 & 0.296 & 0.278 \\
\hline 18 & 0.770 & 0.792 & 0.819 & 0.863 & 0.908 & 0.943 & 0.959 & 0.945 & 0.924 & 0.920 & 0.927 & 0.921 & 0.915 & 0.901 & 0.869 & 0.801 & 0.675 & 0.535 & 0.421 & 0.346 & 0.289 & 0.266 \\
\hline 19 & 0.795 & 0.829 & 0.861 & 0.935 & 1.021 & 1.111 & 1.170 & 1.143 & 1.080 & 1.036 & 1.017 & 1.017 & 1.030 & 1.061 & 1.082 & 1.035 & 0.874 & 0.658 & 0.490 & 0.382 & 0.306 & 0.276 \\
\hline
\end{tabular}



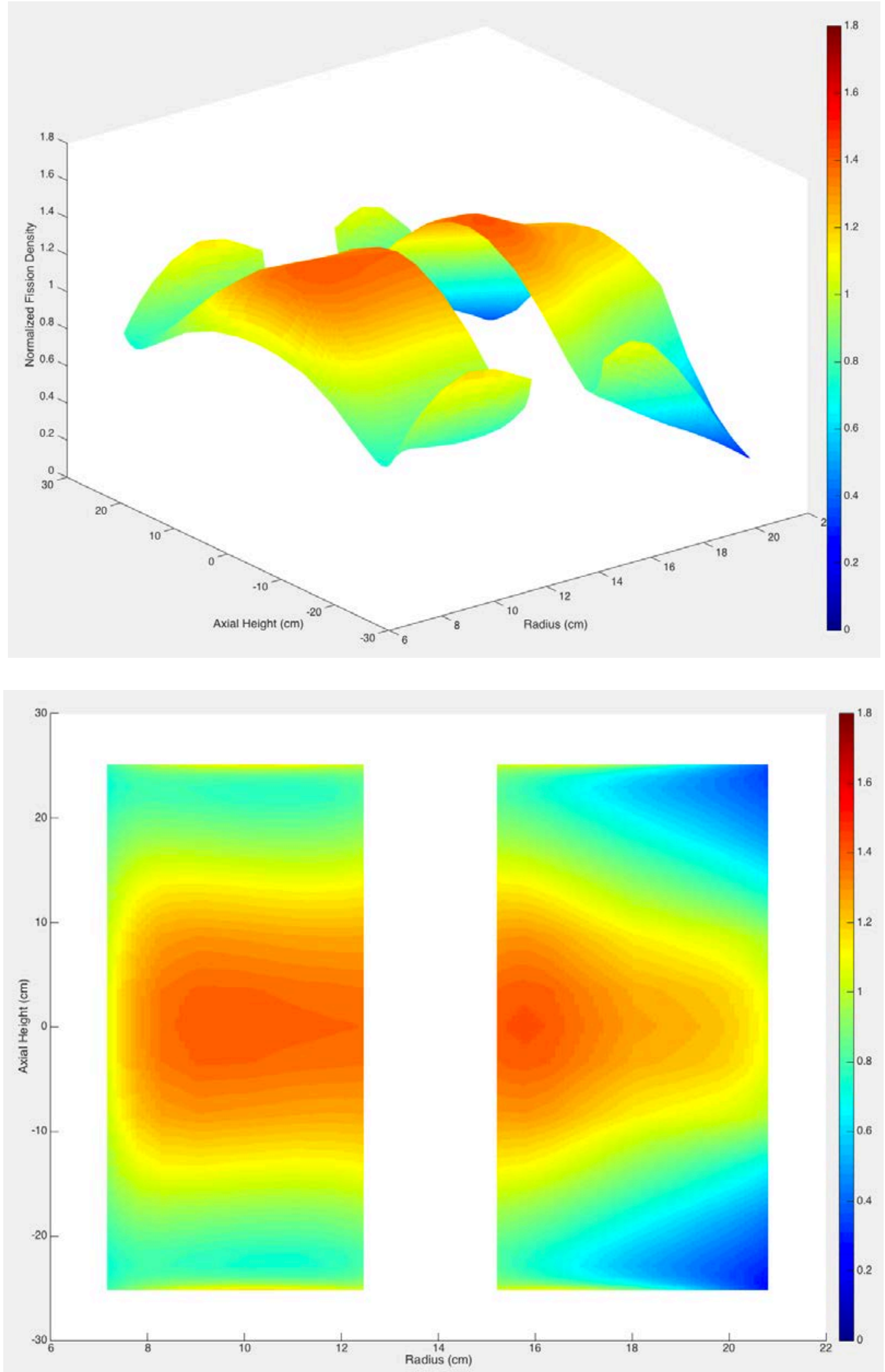

Fig. C.1. Relative fission density distribution at day 13. 
